\title{
The Australian Continent: A Geophysical Synthesis
}

B.L.N. Kennett ${ }^{1}$, R. Chopping ${ }^{2}$, and R. Blewett ${ }^{3}$

${ }^{1}$ Research School of Earth Sciences, The Australian National University

2 Deep Earth Imaging Future Science Platform, CSIRO

${ }^{3}$ Geoscience Australia 


\section{ANU \\ PRESS}

Published by ANU Press

The Australian National University

Acton ACT 2601, Australia

Email: anupress@anu.edu.au

Available to download for free at press.anu.edu.au

ISBN (print): 9781760462468

ISBN (online): 9781760462475

WorldCat (print): 1048423106

WorldCat (online): 1048423169

DOI: 10.22459/AC.08.2018

This title is published under a Creative Commons Attribution 4.0 International (CC BY 4.0).

\section{(C)}

The full licence terms are available at www.creativecommons.org/licenses/by/4.0

Cover design by ANU Press

Text and plate layout by Brian Kennett

This edition (C 2018 ANU Press and Commonwealth of Australia (Geoscience Australia)

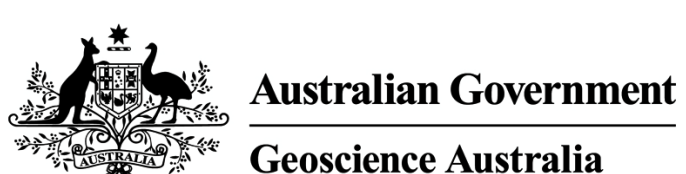

Department of Industry, Innovation and Science

Minister for Resources and Northern Australia:

Senator the Hon Matt Canavan

Secretary: Dr Heather Smith PSM

\section{Geoscience Australia}

Chief Executive Officer: Dr James Johnson

\section{This work is published with the permission of the CEO, Geoscience Australia}

Geoscience Australia has tried to make the information in this product as accurate as possible. However, it does not guarantee that the information is totally accurate or complete. Therefore, you should not solely rely on this information when making a commercial decision.

\section{eCat 122334}

\section{Citation:}

Kennett B.L.N, Chopping R. and Blewett R, 2018.

The Australian Continent: a Geophysical Synthesis.

ANU Press and Geoscience Australia, Canberra 


\section{Foreword}

This synthesis of geophysical results for Australia is designed to provide an summary of the character of the Australian continent through the extensive information available at the continental scale. We present a broad range of geophysical attributes for the continent nation. We also endeavour to examine the relationships between different fields, and their relations to known resources.

The work represents part of a continuing collaboration between the Research School of Earth Sciences at The Australian National University and Geoscience Australia, with the objective of bringing together all aspects of the structure of Australia in convenient forms. The results build on the extensive databases assembled at Geoscience Australia, particularly for potential fields, supplemented by the full range of seismological information mostly from The Australian National University. The book builds in part on the AUSREM project, sponsored by the AuScope infrastructure organisation, to develop a 3-D representation of seismological structure beneath the Australian region.

The diverse and extensive geophysical datasets available for Australia in part reflect the poor outcrop of bedrock geology for this ancient weathered continent, and the economic importance of this geology to the Australian economy through its resource potential. Geophysics provides an important way to examine the structures that lie beneath the cover.

This book is intended to make a contribution to the UNCOVER initiative, which has identified improved information on the subsurface as a prerequisite for extending exploration in Australia from regions of exposure into those with sedimentary cover. To aid in cross-comparison of results from different disciplines, an effort has been made to present all continental-scale geophysical information with a common format and map projection. It is hoped that this compilation of the many different facets of geophysical studies of the continent will make a contribution to the understanding of Australia's lithospheric architecture and its evolution. We have not attempted to impose interpretations on the datasets, rather we believe that the diverse strands of information may inspire new ways of looking at the continent.
To facilitate comparison of the many classes of geophysical information, all the continental-scale images are available at the same size, in an Electronic Image Gallery hosted at: rses.anu.edu.au/AuSREM/Continental. In this location we also provide additional overlays on the geophysical results to provide geological context.

The geophysical images depicted depend on the work of many at Geoscience Australia and its predecessors, and also at the Research School of Earth Sciences, The Australian National University. We would like to acknowledge all the contributors to the development of knowledge of the structure of the Australian continent in three (and four) dimensions.

We would like to thank the many people who have helped with provision of information and datasets, who have often gone to considerable trouble to get material into appropriate formats for subsequent use.

The work has benefited from reviews of specific components by many different individuals. We are particularly grateful to Gideon Rosenbaum who provided an exceptionally thorough review of an earlier draft.

Brian Kennett, Richard Chopping, Richard Blewett 
The Australian Continent: A Geophysical Synthesis

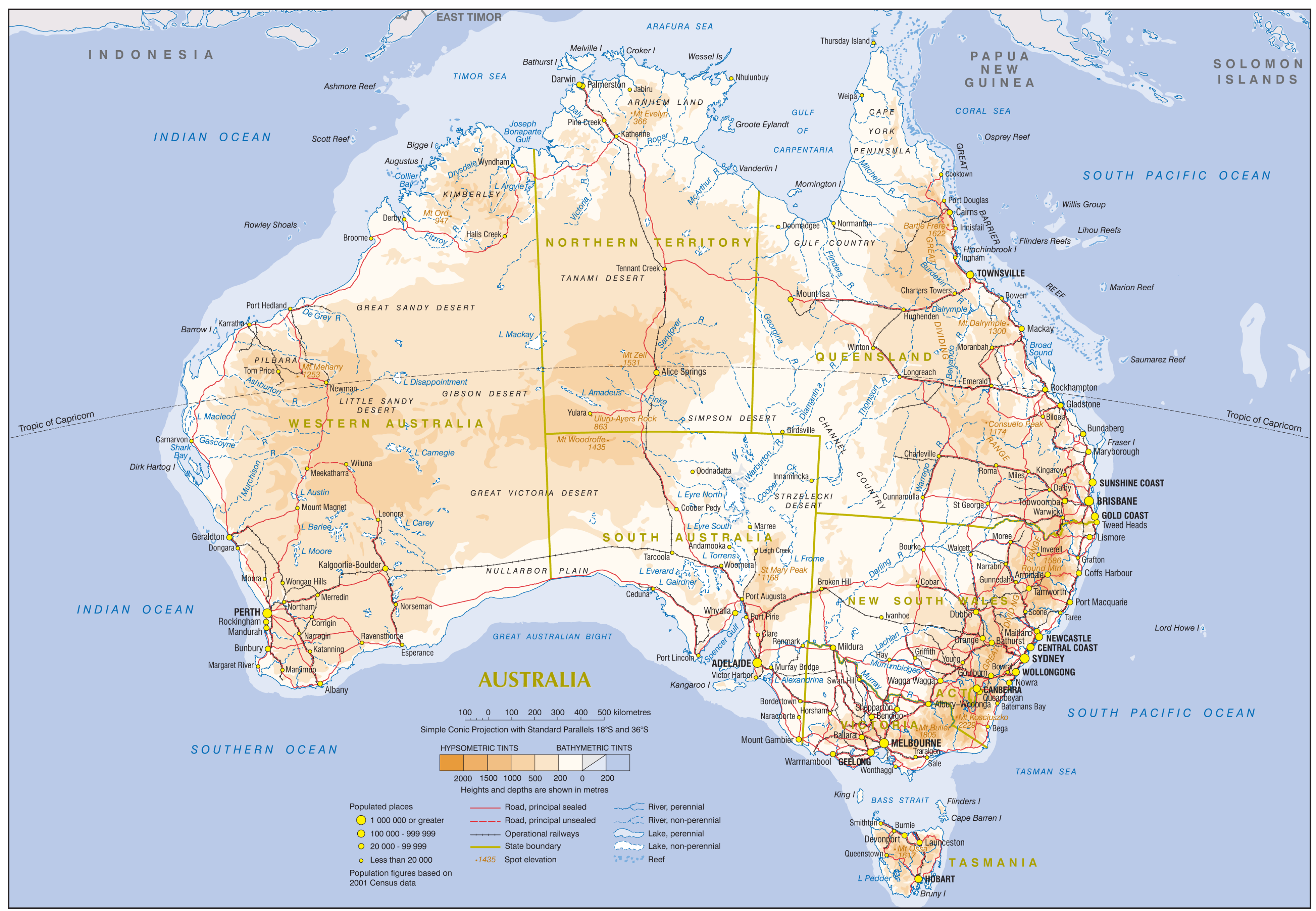

Reference map of Australia for localities and general physiography 


\section{Contents}

1 Introduction

2 Continental Setting of Australia

2.1 Physiographic Setting

2.2 Tectonic Setting

2.3 Geological Setting

2.4 Crustal Age

2.5 Sedimentary Basins

3 Radiometry

3.1 Potassium

3.2 Thorium

3.3 Uranium

3.4 The Nature of the Radiometric Signal

\section{Magnetics}

4.1 Reference Magnetic Field

4.2 Magnetic Anomalies

4.3 Character of Magnetisation

\section{Gravity}

5.1 Geoid Variations

5.2 Absolute Gravity

5.3 Gravity Variations

6 Earthquakes and Stress Field

6.1 Earthquake Activity

6.2 Earthquake Source Mechanisms

6.3 Neotectonic Features

6.4 Continental deformation

6.5 Current Stress Field
7 Seismic Structure: Crust

7.1 Crustal Structure

7.2 Moho

7.3 Crustal Attenuation

8 Seismic Structure: Mantle

8.1 Mantle Lithosphere

8.2 Uppermost Mantle

8.3 Nature of Lithospheric Structure

9 Density Structure

10 Electrical Conductivity

11 Heat Flow and Temperature

11.1 Temperature Distribution

11.2 Use of Geological and Geophysical Information

12 Relations between Fields

12.1 Gravity and Magnetics

12.2 Gravity and Topography

12.3 Depth of Magnetisation

12.4 Temperature and Compositional Variation

in the Lithospheric Mantle

13 Resources and Geophysical Fields

112

14 Weathering and Regolith

116

14.1 Weathering Intensity Index

123

14.2 Regolith Thickness

123

125

Bibliography

127

National Geophysical Datasets

131

Appendix: Spectral stabilisation 



\section{Introduction}

Since the foundation of the Bureau of Mineral Resources in 1948, and through its successors the Australian Geological Survey Organisation and Geoscience Australia, a major effort has been made to assemble continent-wide datasets across Australia. Much of the work has been put into collecting potential field data, notably for gravity and magnetic anomalies, and also a variety of airborne information, including radiometry and airborne electromagnetics. In recent years, the State and Territory Geological Surveys have collected much of the field data, and the continent-wide synthesis has been carried out by Geoscience Australia, with careful stitching together of data grids with very different resolutions.

In addition to the potential field data, a range of seismological information has been assembled for the Australian continent. A number of major seismic refraction experiments were carried out from the 1960s to the 1980s, and these provide an important control on seismic wavespeeds across the continent. There has been little such work since, except for some offshore/onshore experiments mostly in Western Australia. Reflection studies of the whole crust have grown from short experimental spreads in the 1960s to large-scale transects. By the end of 2015 , over $16,000 \mathrm{~km}$ of reflection profiles with full crustal penetration had been collected (Kennett et al., 2016). The regional earthquake belts to the north and east of Australia, as well as more distant events, have been exploited for passive seismic studies with extensive coverage of the continent using portable seismic instruments. A wide range of techniques have been employed to gain a good representation of the variations of seismic wavespeeds in the crust and mantle components of the lithosphere in the AuSREM model (Kennett and Salmon, 2012).

For the International Geological Congress held in Brisbane, Australia in 2012, a major volume, Shaping a Nation: a Geology of Australia (Blewett, 2012), was prepared. In this work and its electronic appendices can be found a wealth of information about the continent with a geological emphasis. In the current book we draw on the latest results for many different types of geophysical measurements, and aim to present a wide range of material in a common format to provide a uniform perspective and synthesis at the continental scale.
The original datasets have been assembled at different resolutions, which makes comparisons difficult. We have therefore endeavoured to present the results for the entire Australian continent in forms that provide a common basis for presentation and comparison.

For the larger datasets, such as topography and the potential fields, we have used a spectral stabilisation approach (Chopping and Kennett, 2015) to place all the different datasets on a common geographical grid with $1.2 \mathrm{~km}$ spacing. This approach is described in detail in the Appendix. Using this procedure we are able to represent diverse fields with a common basis of $4096 \times 4096$ points that is both practical for plotting, and very suitable for spectral manipulation. In consequence, we are able to construct and display a variety of useful secondary fields to aid in cross-comparisons between different geophysical properties. We are also in a position to examine the interrelations between different fields by exploiting spectral relationships.

For seismological results and other datasets acquired on a much sparser grid, we use plotting grids with a constant spacing of $0.125^{\circ}$, or $0.5^{\circ}$ where that is the resolution of the original product.

Images have been developed using a number of different classes of software, but all have been brought into the same format with a common framing. Each of the continental-scale geophysical figures uses the same geographic projection for the Australian continent:

Lambert conformal equal-area with reference latitudes of $18^{\circ} S$ and $36^{\circ} S$,

and reference meridian $135^{\circ} \mathrm{E}$

As far as possible, the different classes of geophysical images are plotted at fixed scales, so that direct comparisons can be made between different fields. In all maps a $500 \mathrm{~km}$ scale bar is included. For each class of geophysical data, a common scale large image is provided. Discussions of relations to geological features are illustrated with images using overlays of geological provinces or major crustal boundaries, which are often at a smaller scale. 
The Australian continent is unique as it is the only single nation continent. This has facilitated the collection of the suite of geophysical data across the entire continent that is presented in this work. This extensive data suite enables us to gain some perspective on the relationship between the deep and surface features of the continent.

Although the work is focused on Australia, we hope that the insights it provides into the character of a continent and how continental structures are built up over time will be of value those working beyond Australian shores.

\section{Structure of the Book}

In Chapter 2 we provide an overview of the continental setting of Australia. We start with the physiographic and plate tectonic environment, and then present the surface geology. We also summarise information on Crustal Age and the distribution of sedimentary basins.

Nearly all of the surface area of Australia has been covered using airborne radiometry. Considerable efforts have been made to bring the multifold surveys into a common framework and these results form the basis of Chapter 3, where we present ternary radiometric images and specific results for the distribution of potassium $(\mathrm{K})$, thorium $(\mathrm{Th})$ and uranium $(\mathrm{U})$.

Chapter 4 is devoted to magnetic studies based on the extensive collection of aeromagnetic data. Magnetic anomalies are presented in various ways and we also discuss the character of magnetisation and its relation to Curie depth. The other main potential field, gravity, is covered in Chapter 5, with discussion of both the absolute gravity field and the anomaly patterns (both Bouguer and free-air).

Chapter 6 introduces the earthquake distribution across Australia and the considerable neotectonic activity within what is commonly regarded as very stable continent. We also summarise the available information on the current stress field. The next two chapters are linked in theme and describe what has been learnt from seismological studies about the structure beneath Australia from crustal studies (Chapter 7) and work on the lithospheric mantle (Chapter 8).
Chapter 9 describes the 3-D density structure beneath the continent derived by inversion of gravity observations, both at the surface and from satellites.

Chapter 10 presents a continent-wide model for electrical conductivity structure derived from geomagnetic measurements. Extensive deployments are progressively covering the continent with a dense network of magnetotelluric stations in the AUSLAMP project, but this has yet to reach the stage of an improved continental-scale conductivity model. Chapter 11 presents information about the thermal state of the continent inferred from the temperature distribution in boreholes, and efforts to exploit other geological and geophysical information to counter the patchy distribution of direct sampling.

The next two chapters build on the full suite of geophysical data presented in Chapters 3-11:

In Chapter 12 we consider the relationships between the different fields, notably the relations between gravity and magnetics, and gravity and topography. we introduce a number of ancillary fields that have the merit of enhancing trends in the geographic distribution. Use is made of binary and ternary colour images to enhance the visual impact of the relations between fields. The relation between the depth to base of magnetisation and temperature is also discussed. The chapter concludes with estimates of the thermal and compositional state of the lithospheric mantle derived from the combination of gravity data and 3-D seismic models.

In Chapter 13 we look at the relationships between the distribution of known resources across the Australian continent and the nature of the various geophysical fields. The results highlight some interesting relations between composite field attributes and resource distribution that may be of value in assessing future resource potential.

Chapter 14 presents the exploitation of the radiometric map of Australia to develop a measure of the local weathering intensity across the continent. This information is then integrated with a broad range of other topographic and geophysical information to extend the limited direct information on regolith depth to a model for the full continent. 
Many of the datasets we present are available in the Geoscience Australia Common Earth Model, and can be visualised in three dimensions with the EarthSci Viewer freeware system from www.ga.gov.au.

Such visualisation can go well beyond what is readily presented on a simple page. As an example of what can be achieved, Figure 1.1 shows the surface geology of Australia draped over land and marine topography.

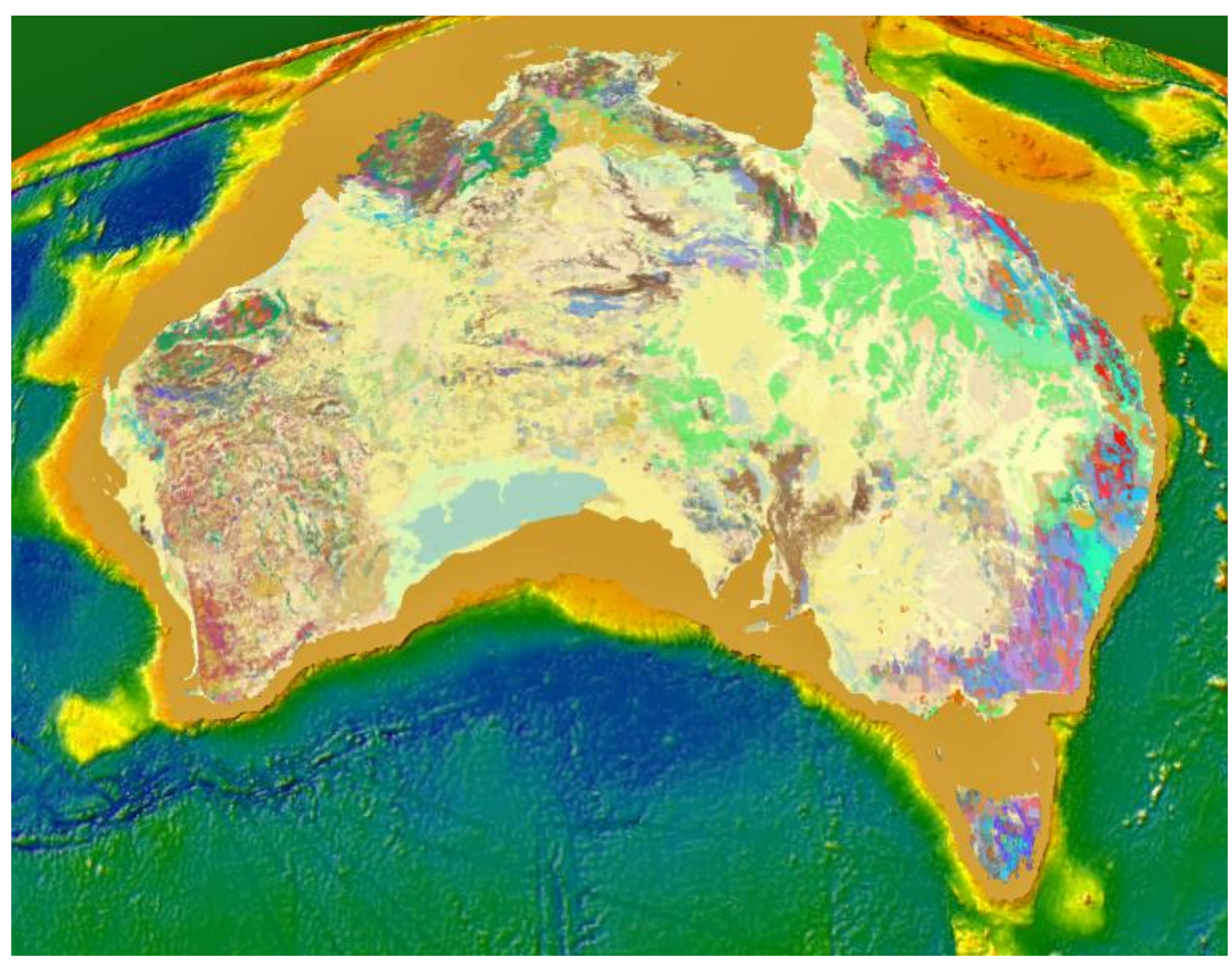

Figure 1.1: The geological structure of Australia draped over land and marine topography. Image created using the Geoscience Australia EarthSci visualisation software. 


\section{Continental Setting of Australia}

Australia, with an area of 7.69 million $\mathrm{km}^{2}$, is the Earth's largest island and smallest continent. The continental landmass, which measures about $3700 \mathrm{~km}$ from north to south and $4000 \mathrm{~km}$ from east to west, occupies a significant part of the Australian Plate, which is currently separating from the Indian Plate in a diffuse zone in the Indian Ocean. Since its separation from Antarctica at about $35 \mathrm{Ma}$, the Australian continent has been moving steadily northwards, currently at around $7 \mathrm{~cm} /$ year with respect to a hotspot frame of reference. Australia is the most rapidly moving continent on the globe, and has swept into the southern fringe of Asia with current collision active in Timor and Papua New Guinea (e.g., van Ufford and Cloos, 2005).

\subsection{Physiographic Setting}

Australia is an island continent with a landmass defined by a distinctive coastal outline, which has maintained its current shape for the last 6000 years. At the time of maximum glaciation, the Australian mainland, Tasmania and the island of New Guinea formed a single larger and differently shaped landmass that stretched from the equator to latitude $45 \circ \mathrm{S}$. With the end of the last lce Age, global temperatures increased, much of the continental ice melted and sea levels rose. This caused flooding of the land bridges between Tasmania and the Australian mainland 6000 years ago, and between Australia and New Guinea 8000 years ago. The rise in sea levels inundated about one-seventh of the larger ice age continent isolating Tasmania, the Australian mainland and New Guinea.

Much of the present topography of Australia is the result of prolonged erosion by wind and water, since there have been no major mountain building episodes in the last 200 Myr. Dating of the surface regolith indicates a weathering history stretching back over $300 \mathrm{Ma}$ in some parts of the continent (Pillans, 2008). The landscape has been strongly shaped by continent-wide glaciation; large ice caps developed in the Permian when Australia was very near the South Pole, and this glacial influence on the landscape persists to the present day. By the early Cretaceous, Australia was already so topographically flat and of low elevation that a major rise in sea level divided the continent into three landmasses as a shallow sea spread over the land.
Today, the major physiographic features of the Australian continent comprise: (1) a major Western Plateau with localised ranges incorporating most of the Precambrian cratons, (2) the Eastern Uplands with the highest elevations concentrated along the Great Divide with dominantly Phanerozoic rocks and (3) an intervening zone of Interior Lowlands. The topography of the Australian continent is subdued. The highest point on the continent, Mount Kosciuszko, is only $2228 \mathrm{~m}$ above sea level, and the lowest point is Lake Eyre at $15 \mathrm{~m}$ below sea level. The average elevation is only $330 \mathrm{~m}$, the lowest of any of the continents (Figure 2.1).

The Australian continent currently has passive margins on three sides and the fourth is the lower plate of a collision zone to the north. Thus in the recent geological past there have been no destructive convergent plate margins that are generally associated with mountain building, landscape rejuvenation and the formation of large reliable river systems. The largest rivers thus flow from the Eastern Uplands through the interior lowlands. Many of the rivers, particularly in the north are intermittent, with flow starting in the summer 'wet' season, but tapering off in the winter 'dry'. After a particularly heavy wet, sufficient water can reach and fill the Lake Eyre basin that lies below sea level.

Although the glaciation in the Permo-Carboniferous had a broad impact on continental Australia, the last ice ages had only limited impact on the physiography. The Australian continent was already at fairly low latitudes in the Pleistocene, so that glaciation was confined to small areas in southeastern Australia, with little reworking of the older landscape.

The continental slope on all margins is deeply incised, with steep-sided canyons up to $2 \mathrm{~km}$ deep, reflecting either extinct drainage systems or the drowned valleys of current river systems (such as the Perth Canyon in West Australia). On the southern part of the eastern margin, the continental shelf is rather narrow, with a shelf break closer than $20 \mathrm{~km}$ from the coast and the base of the abyssal plain sometimes reaching within $60 \mathrm{~km}$ of the coastline (Figure 2.1). The conjugate southern margins of Australia along the Great Australian Bight and the Antarctic coast, created by the opening of the Southern Ocean, show somewhat wider continental shelves. 
Figure 2.1: Topography of the Australian continent and bathymetry of the surrounding oceans. The state boundaries and state capitals are also indicated.

The broad continental shelf off Queensland, left behind after the Coral Sea opened, forms a foundation for the Earth's largest single living entity - the Great Barrier Reef - with 2900 reefs, 600 continental islands and 300 coral cays created in a mixed siliciclasticcarbonate depositional environment. The wide continental shelf between the coast of northern Australia and Indonesia, Timor and New Guinea represents the drowned remnants of the former single landmass. The extended continental shelf off Western Australia is host to most of Australia's natural gas resources, and is marked by complex embayments and salients left over from periGondwanan fragments that broke away in the Mesozoic era and now form the basement in Southeast Asia. (Huston et al., 2012).

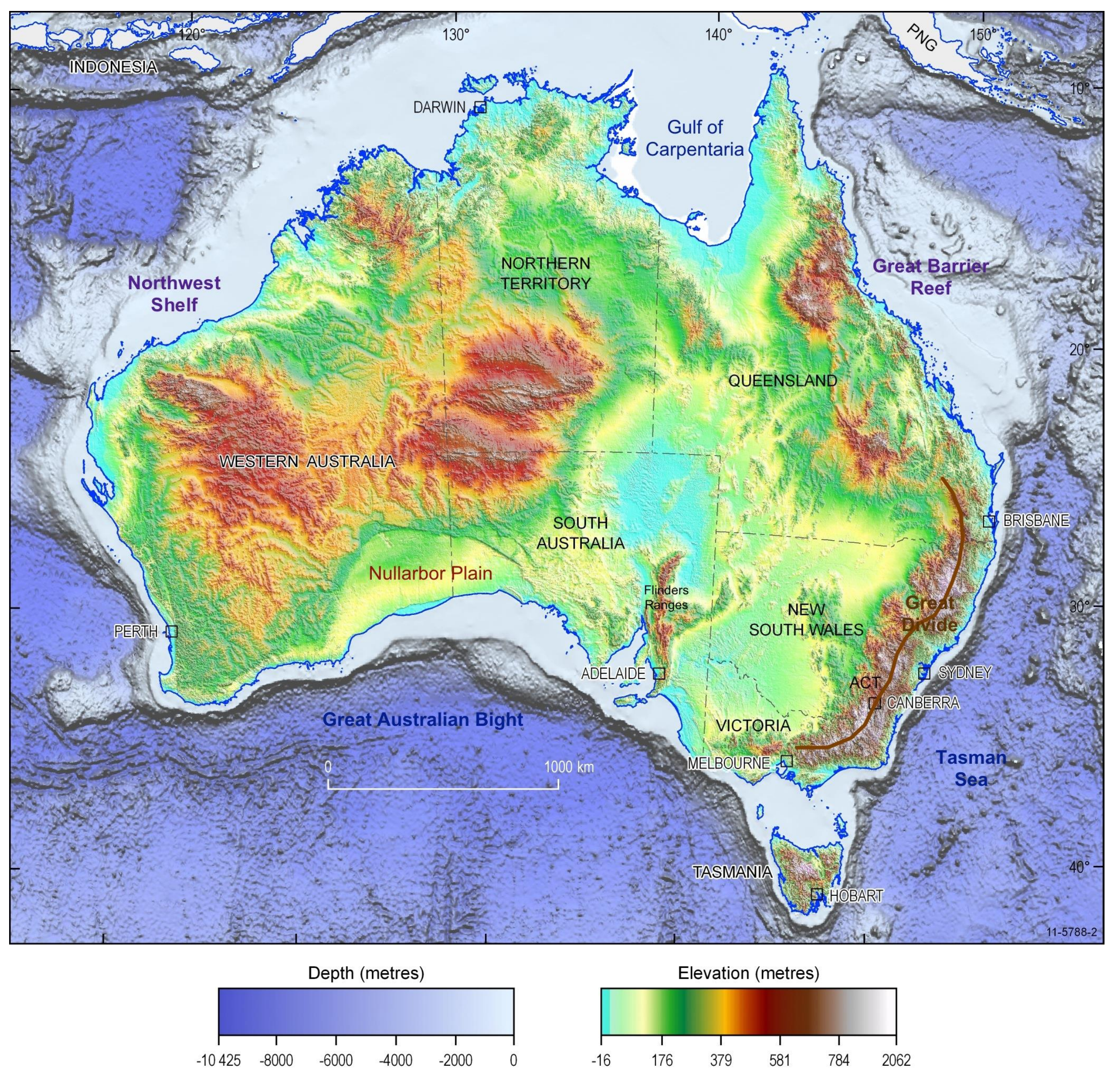




\subsection{Tectonic Setting}

The Australian Plate is undergoing a complex set of interactions with its neighbours. To the south, an active spreading centre separates the Australian Plate from the Antarctic Plate. This margin developed with the break-up of Gondwana around $99 \mathrm{Ma}$, with full separation by $35 \mathrm{Ma}$. Following a major plate reorganisation in the Pacific Ocean at around $40 \mathrm{Ma}$, Australia acquired its present north-northeast trajectory. Australia has migrated more than $3000 \mathrm{~km}$ along this path at a rate of $6-7 \mathrm{~cm} / \mathrm{yr}$ over the past $45 \mathrm{Myr}$, which makes it the fastest moving continent since the Eocene (Tregoning, 2003).

Following break-up, Australia's initial drift was to the northwest. Ridge subduction in the northwest Pacific at around 52 Ma resulted in the termination of spreading in the Tasman Sea, and a change in the Australian Plate vector to its present-day northerly orientation. Sea floor spreading in the Southern Ocean accelerated at around $45 \mathrm{Ma}$, but it was not until $35 \mathrm{Ma}$ that full separation of Australia and Antarctica occurred. Australia, as a separate continent, was released from the remnants of Gondwana and commenced a northward passage to meet Asia.

The eastern boundary of the Australian Plate with the Pacific Plate is marked by the Tonga-Kermadec Trench, north of New Zealand, where the Pacific Plate is being subducted, giving rise to many of the Earth's deep earthquakes. In New Zealand itself, there is oblique subduction along the east coast of the North Island, with collision through the South Island moderated by the Alpine Fault. Beneath the Fiordland region of the South Island, the Australian Plate is subducting at the Puysegur Trench. This short subduction zone links to a largely strike-slip boundary that passes Macquarie Island and links to the boundaries of the Antarctic Plate (DeMets et al., 2010).

The Australian Plate is subducting beneath the Pacific Plate along its northeastern margin at the New Hebrides and Solomon Trenches. The northern boundary of the Australian Plate is complex. Continental Australia is colliding with the Pacific Plate through New Guinea. But to the west, the interaction is with the Eurasian Plate with collision in the Banda Arc region and subduction of the Australian Plate beneath Indonesia at the Java and Sumatra trenches (Figure 2.2).
Subduction in the Banda Arc region may well already have come to a halt with the arrival of thick buoyant Australian lithosphere that cannot readily descend to depth. The western boundary of the plate is a diffuse zone called the Capricorn Plate, which lies between the Australian Plate and the Indian Plate further to the northwest (DeMets et al., 2010).

The boundary forces acting upon the Australian Plate vary from tension in the south and southwest to compression in the east and north. The present stress state is largely controlled by compression originating from the three main collisional boundaries located in New Zealand, Indonesia and New Guinea, and the Himalaya (transmitted through the Indian and Capricorn plates). South of latitude $30^{\circ} \mathrm{S}$, the stress trajectories in the Australian continent are oriented east-west to northwest-southeast. North of $30^{\circ} S$, the stress trajectories are closer to the present day plate motion, with an orientation between eastnortheast-west-southwest and northeast-southwest (see, e.g., Hillis and Müller, 2003).

The complex pattern of stress in the continent is expressed in a relative high level of seismicity for what would normally be regarded as a 'stable' intraplate continental region. The distribution of the larger events, which have reached nearly Mw 7 in recent years, is not uniformly distributed across Australia. Earthquakes are clustered into regions towards the edges of major structural blocks. The rate of occurrence of earthquakes is normally low, but is punctuated by periods of enhanced seismic activity associated with one or more large earthquakes. Since 1901, 18 earthquakes with magnitude Mw>6 have been recorded in Australia. The recurrence times for larger earthquakes, such as the 1988 Tennant Creek sequence with three Mw 6+ events in 12 hours, is more than 10,000 years, so that the brief snapshot of seismicity available will certainly be incomplete. Many neotectonic features have been recognised through careful mapping across the continent (Clark et al., 2011). In the Flinders Ranges in South Australia, there are clear indications of active faults thrusting Precambrian basement over Quaternary gravels (Quigley et al., 2010). The active intraplate deformation in Australia is likely to be guided by structures generated by past tectonic activity and thermal weakening of the lithosphere. 


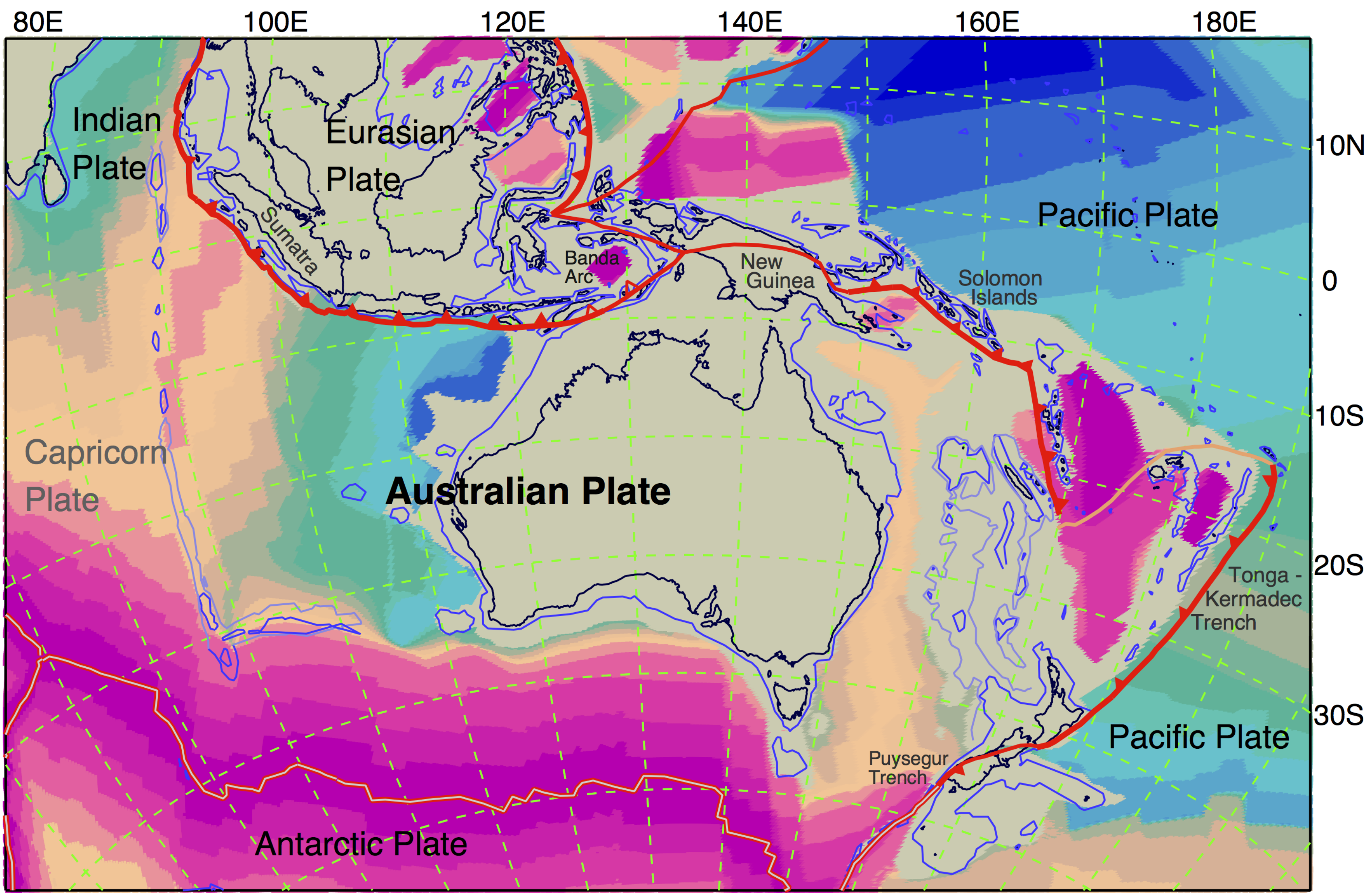

Figure 2.2: Tectonic setting of Australia, with major seabed features and plate boundaries, superimposed on the age of the sea floor (Müller et al., 2008). The mid-ocean ridges are indicated with a double line and the sense of subduction is indicated 


\subsection{Geological Setting}

Rocks exposed at the surface in Australia span much of the Earth's geological history (Figure 2.3). The Archean regions include rocks older than $3700 \mathrm{Ma}$ in Western Australia and $3100 \mathrm{Ma}$ in the Gawler Craton of South Australia. The oldest zircon crystals yet found on the Earth, dating back to $4400 \mathrm{Ma}$, occur in Proterozoic conglomerates within the Yilgarn Craton of Western Australia. In contrast, recent volcanic activity in both northeast and southeast Australia has left distinct volcanic edifices, with the latest eruptions in the southeast at about 4600 BCE.

Around 80 per cent of Australia is covered by extensive Mesozoic and younger sedimentary rocks and regolith (beige areas in Figure 2.4). These cover rocks indicate the general tectonic stability of much of the continent from Mesozoic times to the Present.

The underlying Australian continental crust was accreted in three major supercontinent cycles, each building about one-third of the continental area from the Archean cratons in the west to the Phanerozoic provinces in the east (Huston et al., 2012). Disparate Archean crustal elements were assembled into three major cratonic zones in the Proterozoic.

The West Australian, the North Australian and the South Australian elements were formed by $\sim 1830 \mathrm{Ma}$, and these cratonic elements were joined to the Rodinian supercontinent by 1300-1100 Ma. The configuration of these Archean materials is indicated in Figure 2.3, which shows a simplified map of solid geological provinces, along with the surrounding and linking Proterozoic belts.

Since the Proterozoic, there has been a set of deformation cycles in central Australia culminating in the Alice Springs Orogeny around $400 \mathrm{Ma}$. These events occurred away from plate boundaries and involved extension as well as compression, although their precise history remains difficult to unravel from the geologic record. Much evidence of deformation is left in the central Australian crust, which features significant Moho topography and an associated gravity signal.
The fold belt structures of the Phanerozoic Tasman Element comprise the eastern third of Australia, which was accreted onto the eastern margin of the Precambrian cratons in a number of stages (see, e.g., Collins and Vernon, 1992; Rosenbaum, 2018). The Delamarian Orogen at around $500 \mathrm{Ma}$ formed part of a much larger belt of accretion along the eastern margin of Gondwana. This was followed by at least two further periods of accretion that added the Lachlan Orogen and the New England Orogen to the Australia-Antarctic land mass.

The break-up of Gondwana, through a series of rifting events from about $180 \mathrm{Ma}$, resulted in the formation of the passive margins around Australia, with the formation of the Coral and Tasman seas in the east, the Southern Ocean in the south and the Indian Ocean in the west (Huston et al., 2012). These rift events created the accommodation space for the late Paleozoic and Mesozoic sedimentary basins that host most of Australia's hydrocarbon resources.

There has been significant subsequent volcanism; in the Mesozoic, Australia was the continental margin of the subducting Pacific Plate and subsequently a set of chains of hotspot-related volcanism have developed through eastern Australia. The eastern margin of Australia has been influenced by sea floor spreading in the Tasman Sea from $\sim 80 \mathrm{Ma}$ and also by back-arc spreading in the Coral Sea.

The eastern seaboard, including Tasmania, is a patchwork of Paleozoic metamorphic, sedimentary and igneous rocks. These rocks are revealed, as highlands, due to the rift-flank uplift generated by opening of the Tasman and Coral seas which finished around $80 \mathrm{Ma}$.

The Flinders Ranges, a Y-shaped region of uplifted Neoproterozoic sedimentary rocks in South Australia, attest to the influence of regional compression across the Australian Plate. Across northern Australia, large areas of mostly Proterozoic metasedimentary rocks occur in the Kimberley, Pine Creek, Macarthur and Mt Isa areas. These basins were filled with vast sandsheets during a time when the Earth's land surface was devoid of the stabilising influence of life, and became the containers for major base metal and uranium mineral systems. 
Figure 2.3: Simplified geological provinces of Australia.

Key to marked features:

AF - Albany-Fraser Orogen

AFB - Adelaide Fold Belt

Am - Amadeus Basin

$\mathrm{Ar}$ - Arunta Province

Bo - Bowen Basin

$\mathrm{Ca}$ - Canning Basin

$\mathrm{Cp}$ - Capricorn Orogen

$\mathrm{Cu}$ - Curnamona Craton

De - Delamarian Orogen

$\mathrm{Er}$ - Eromanga Basin

Eu - Eucla Basin

$\mathrm{Ga}$ - Gawler Craton

Ge - Georgetown Inlier

Ha - Hamersley Basin

$\mathrm{HC}$ - Halls Creek Belt

$\mathrm{Ki}$ - Kimberley Block

La - Lachlan Orogen

Mc - MacArthur Basin

$\mathrm{Ml}$ - Mt Isa Province

$\mathrm{Mu}$ - Musgrave Province

$\mathrm{NE}$ - New England Orogen

Of - Officer Basin

$\mathrm{Pc}$ - Pine Creek Inlier

$\mathrm{Pi}$ - Pilbara Craton

$\mathrm{Pj}$ - Pinjarra Orogen

T - Tennant Creek Inlier

$\mathrm{Tp}$ - Thomson Orogen

Yi - Yilgarn Craton

Archean basement

Archean sediments

Proterozoic basement

Proterozoic sediments

Paleozoic

Mesozoic \& Cenozoic

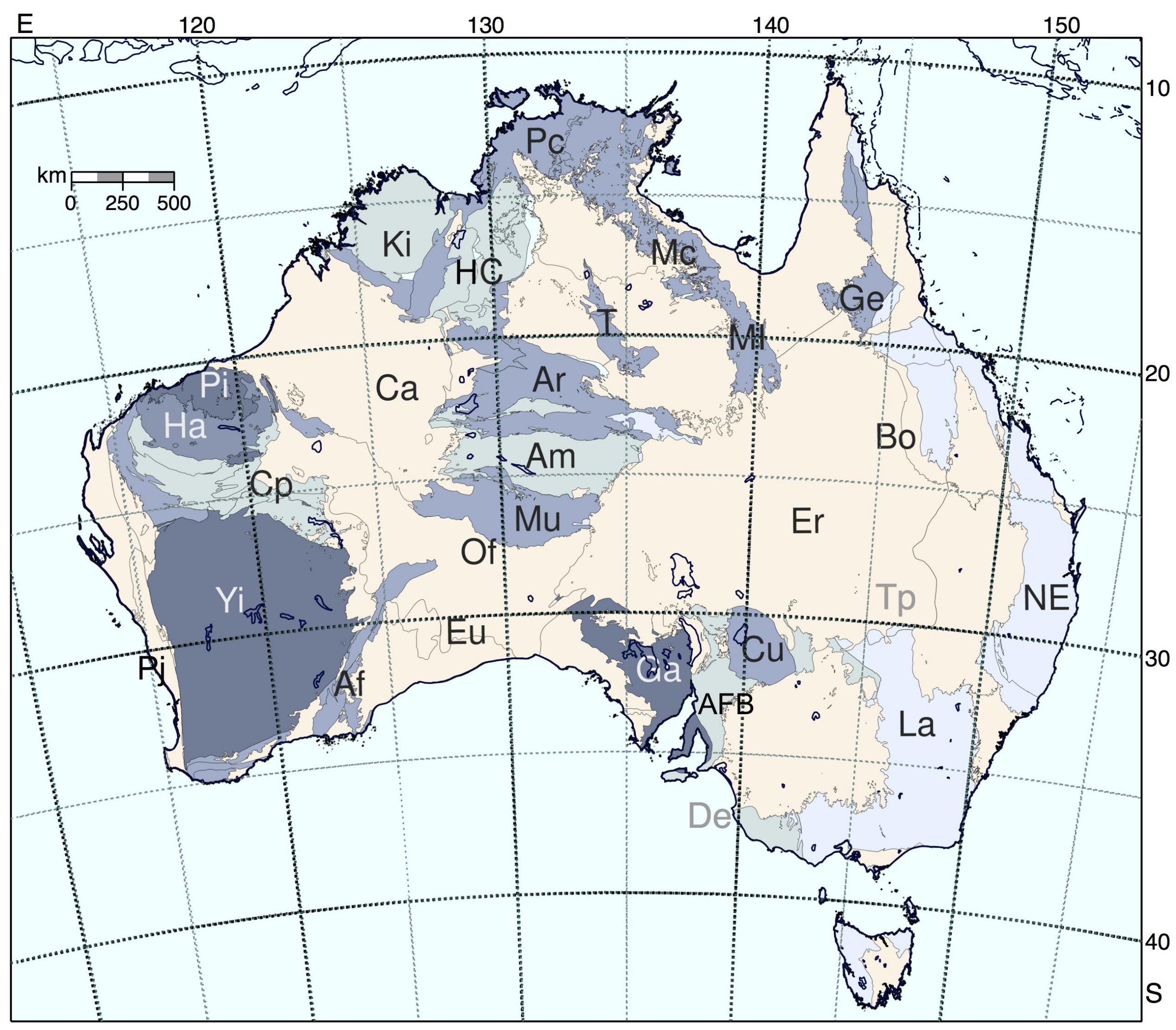




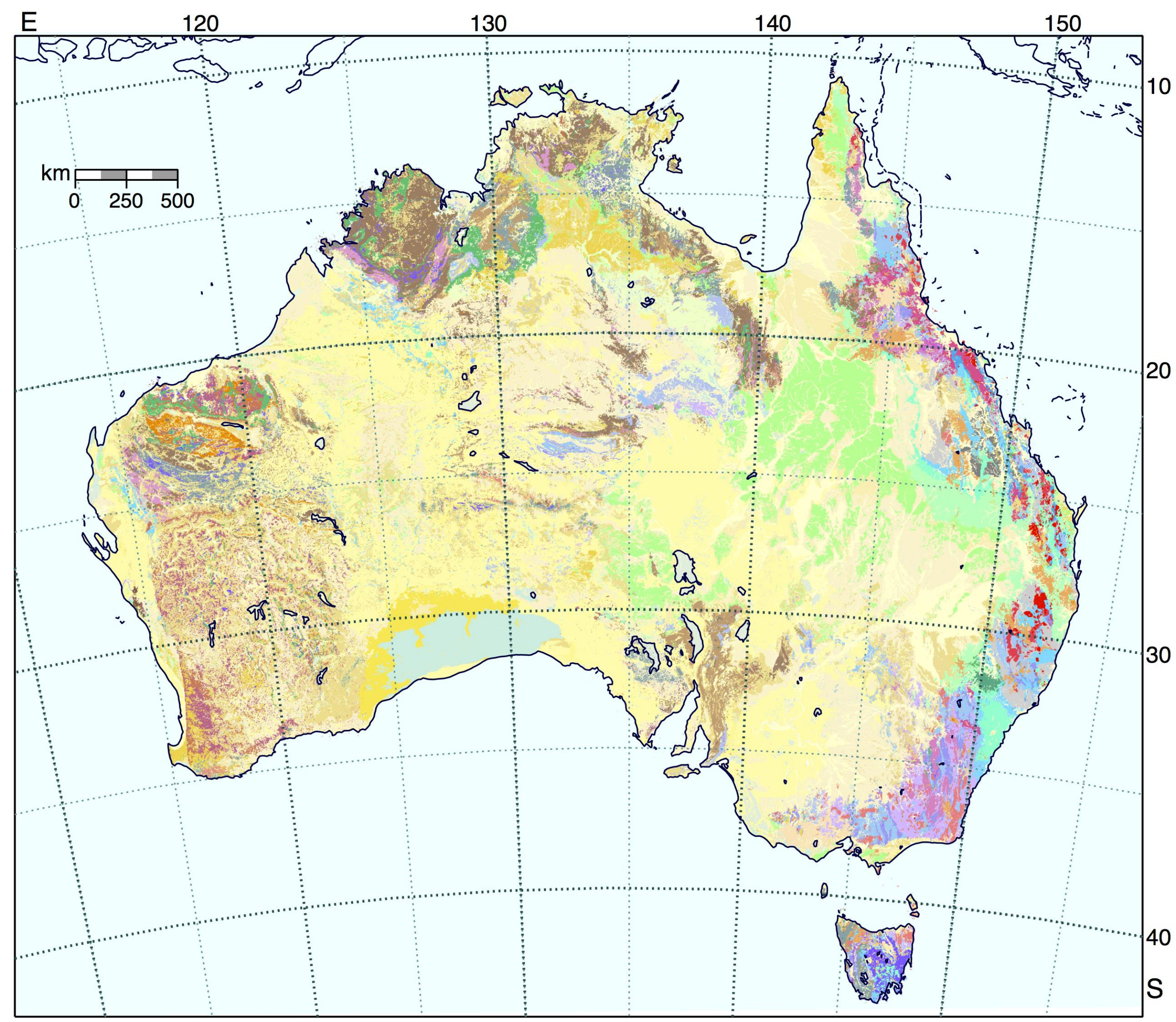

Figure 2.4: Surface geology of Australia. 
Quaternary

Q Quaternary sediments, undivided

Qa Channel and flood plain alluvium; gravel, sand, silt, clay

Calcrete

NOZOIC UNITS (mainly unconsolidated deposits)

ab Volcanic rocks, predominantly matc

orc Colluvium andor residual deposits; boulder, gravel, sand

Cenozoic

arlb Black soil plains

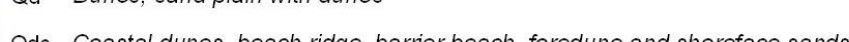

Osg Glacial sediments morain

Estuarine, tidal delta deposits; coastal mud flats

ai Carbonate sediments

Czu Cenozoic sediments, undivided

Czk Calcrete

Cza Alluvial deposits; typically incised by current drainage

Czb Volcanic rocks, predominantly matic

Czc Consolidated siliclastic rocks

SEDIMENTARY ROCKS AND LOW-GRADE METAMORPHIC ROCKS

mudstone, siltstone, sandstone, conglomerate $(s)$,
limestone $(1)$, coal measures $(0)$, volcanogenic sediments (i), mixed sediments and volcanic rocks (w), chemical sediments (c)
rol

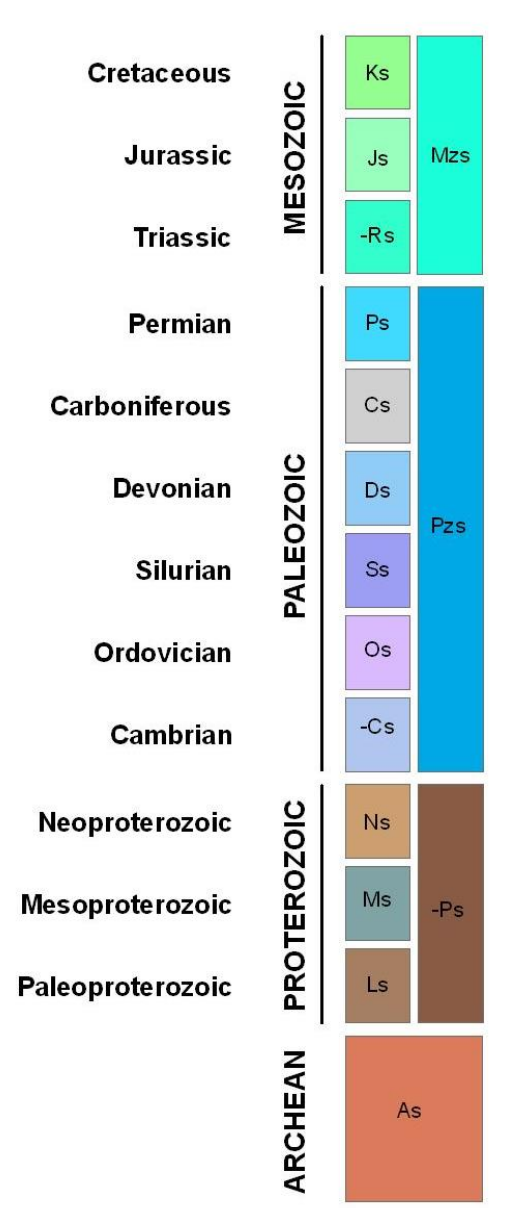

asm Anthropogenic deposits; mining waste, salt pans

at Lake and swamp deposits; mud, silt, evaporites, limestone, minor sand

$\square$ Cze Esturine and delta deposits

CZf Felsic to intermediate volcanic rocks

Czg Felsic intrusive rocks

Czi Carbonate sediments

\begin{tabular}{|c|c|c|c|c|c|c|}
\hline \multicolumn{7}{|c|}{ IGNEOUS ROCKS } \\
\hline \multicolumn{4}{|c|}{ Volcanic rocks } & \multicolumn{3}{|c|}{ Intrusive rocks } \\
\hline Felsic & Intermediate & $\begin{array}{l}\text { Mafic to } \\
\text { ultramafic }\end{array}$ & $\begin{array}{l}\text { Felsic to } \\
\text { mafic }\end{array}$ & Felsic & Mafic & Mafic to ultramafic \\
\hline $\begin{array}{l}(f), \\
\text { metamorphosed (r) }\end{array}$ & (a) & $\begin{array}{l}\text { metamorophosed (t), } \\
\text { mixed intrusives (i) }\end{array}$ & (v) & $\begin{array}{l}(\mathrm{g}), \\
\text { quartz vein (q) }\end{array}$ & $\begin{array}{l}(d), \\
\text { metamorphosed (t) }\end{array}$ & $\begin{array}{l}\quad(u), \\
\text { metamorophosed (e), } \\
\text { alkaline ultrabasic (k) }\end{array}$ \\
\hline
\end{tabular}

\begin{tabular}{ccc} 
METAMORPHIC ROCKS \\
\hline $\begin{array}{c}\text { Low-medium grade } \\
\text { metacarbonate }(m), \\
\text { siliciclastic }(y), \\
\text { hornfels }(h)\end{array}$ & $\begin{array}{c}\text { High-grade } \\
\text { metamorphics }(n), \\
\text { complexes }(x)\end{array}$ & $\begin{array}{c}\text { Fault/shear } \\
\text { rocks }\end{array}$ \\
& (z)
\end{tabular}
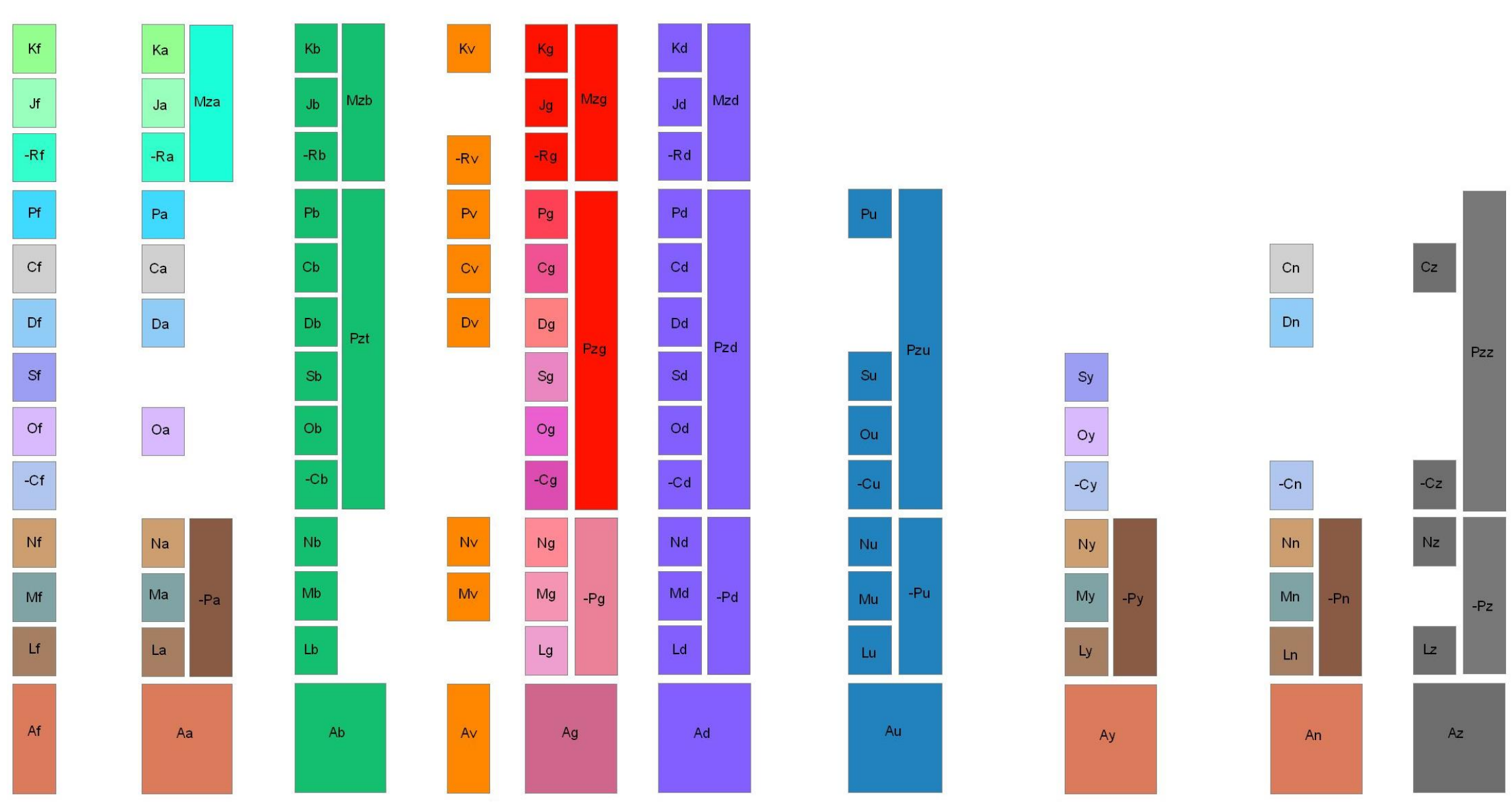

Czt Lake and swamp deposits

Czu Uttramafici intrusive rocks

Czz silcrete

Figure 2.5: Legend for surface geology maps. 


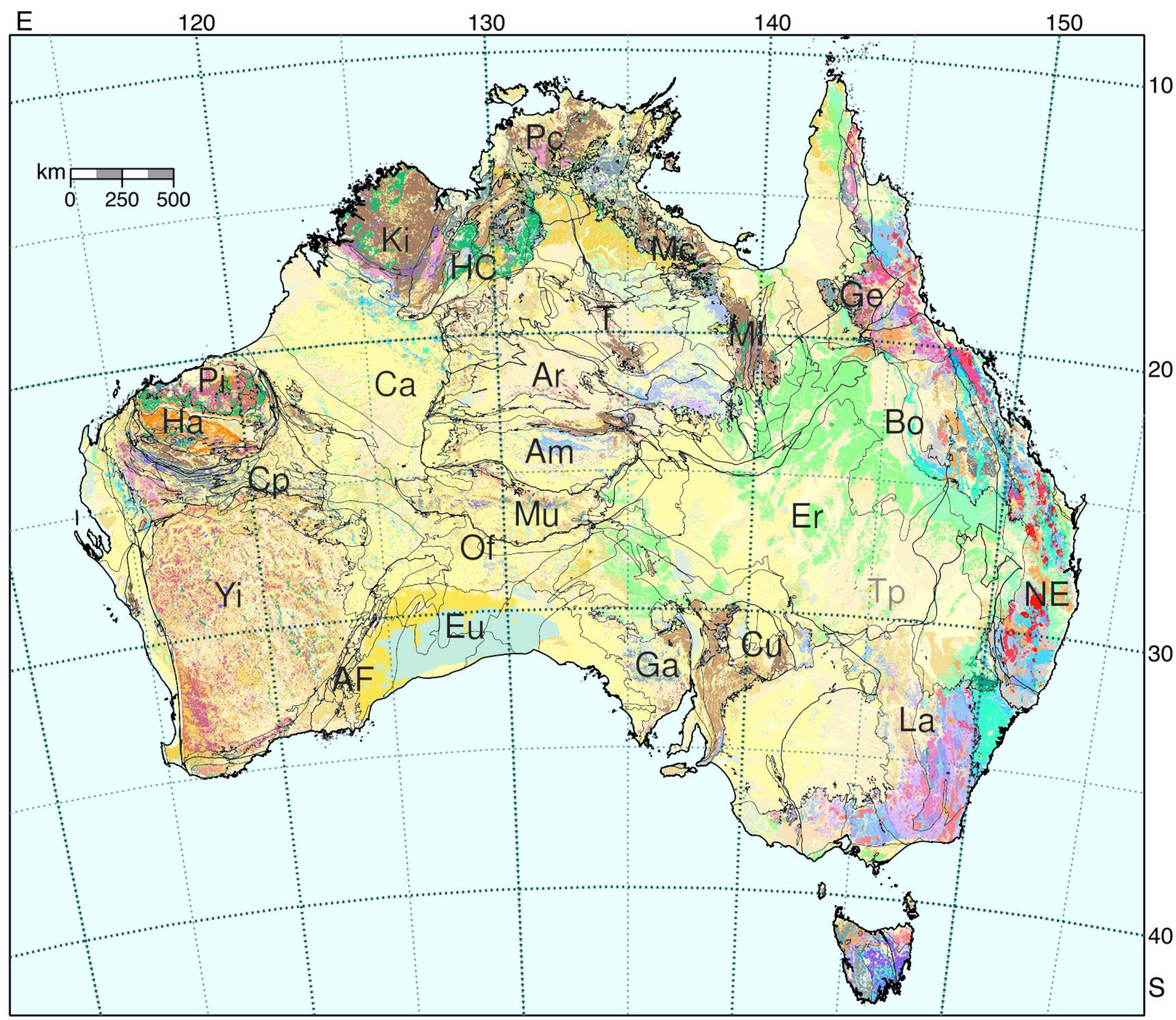

Figure 2.6: Surface geology of Australia with main geological provinces marked (following Figure 2.3).

These simplified geological province boundaries provide a useful summary of the main features of the solid geology, as can be seen from Figure 2.6.

In subsequent sections, these province outlines are used in combination with the major crustal boundaries dataset, illustrated in Figure 2.7, as an overlay on many of the geophysical images.

The two sets of boundaries provide a convenient reference frame for comparison of geophysical datasets. They also help to provide a tie between the distribution of geophysical properties and the different classes of geological environments. 
Figure 2.7: Major crustal boundaries from Korsch and Doublier (2016) superimposed on the surface geology of Australia.

Korsch and Doublier (2016) have developed a dataset of major crustal boundaries, based on the occurrence of crustal-scale breaks in the extensive continental coverage of seismic reflection profiles. Such features are often inferred to be relict sutures between different crustal blocks and hence mark changes in crustal properties. The boundaries have been extended away from the seismic profiles with the aid of geological information (e.g., outcrop mapping, drill hole sampling, geochronology, isotopes) and geophysical imagery (e.g., gravity, aeromagnetic, magnetotelluric)

The dataset is built from rather heterogeneous materials and so the various boundary lines have different levels of confidence. In particular, in regions covered by thick sedimentary successions, the locations of some crustal boundaries are not at all well constrained. It is likely that some significant boundaries may be missed under cover in the Northern Territory, where little deep seismic reflection work has been undertaken.

Nevertheless, this crustal boundary dataset provides a useful reference frame for comparison of geophysical datasets.

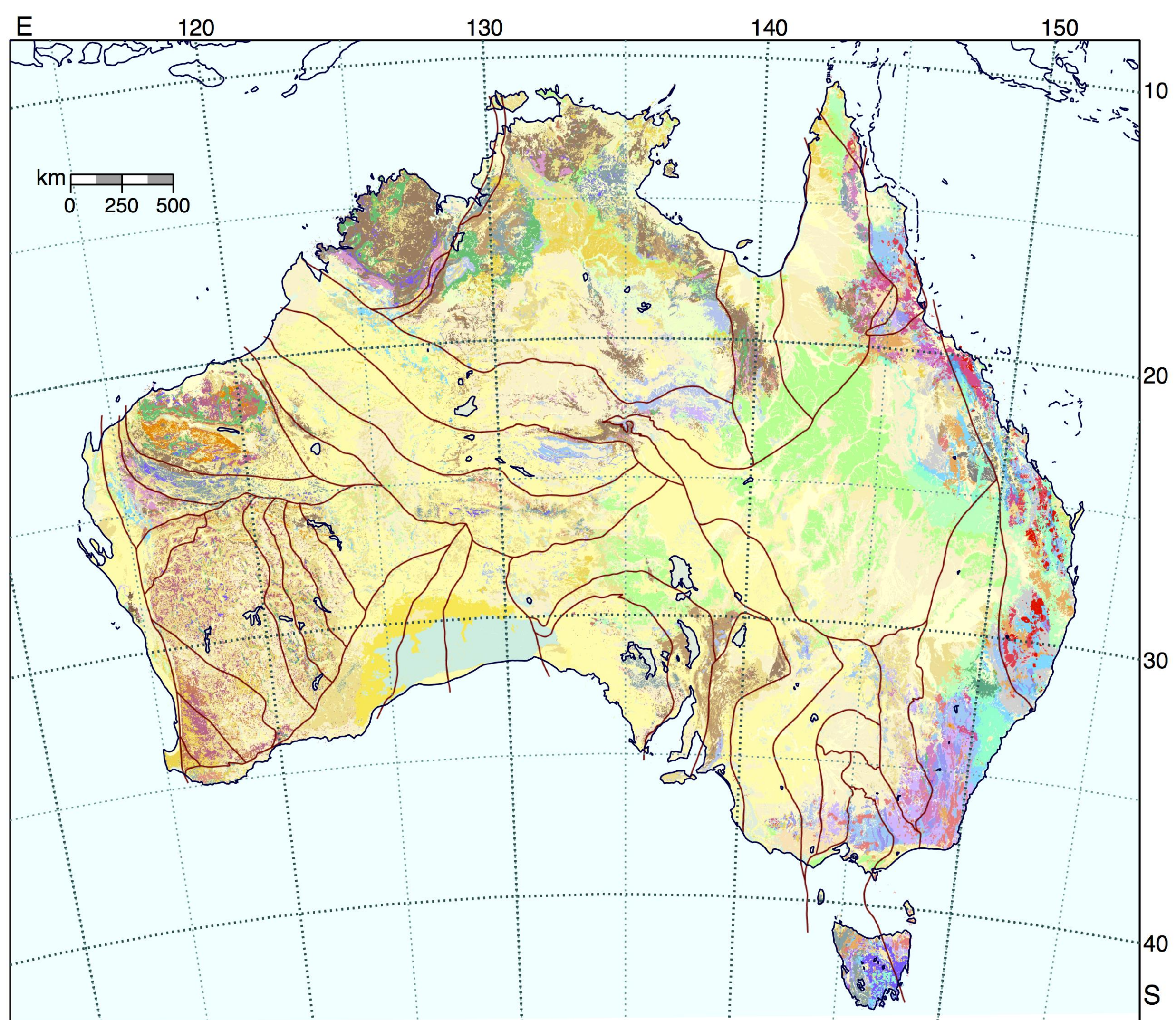




\subsection{Crustal Age}

The accessible rocks at the Earth's surface provide one facet of the nature of the continent, but the middle and lower crust remain hidden. Fortunately studies of isotopic tracers such as samarium-neodymium $(\mathrm{Sm}-\mathrm{Nd})$ provide a way to exploit felsic igneous rocks across the continent to map the development of the crust over time (Champion, 2013).

This work has established a database of $\mathrm{Sm}-\mathrm{Nd}$ isotopic data, and associated metadata, for $>2650$ samples of Australian rocks. Results have been compiled for a range of lithologies, including felsic and mafic igneous rocks, sedimentary rocks, as well as some mineral data. For felsic samples there was a good agreement with estimated or known magmatic age.

The Sm-Nd data were standardised and used to calculate epsilon $\mathrm{Nd}(\varepsilon \mathrm{Nd})$ and two-stage depleted mantle model ages (T2DM). The map in Figure 2.8 has been constructed from around 1500 data points, with the exclusion of samples from S- type magmatism to avoid sediment contamination.

The estimated model ages range from $\sim 4.0 \mathrm{Ga}$ in the Yilgarn and Pilbara cratons of the West Australian Element to ca. $0.3 \mathrm{Ga}$ in the New England Orogen of the Tasman Element in eastern Australia. Even though the granites may have somewhat variable properties with respect to retention of $\mathrm{Nd}$ signals, the model ages generally correlate well with the known geology of Australia and the major crustal elements.

There is a broad eastward trend in decreasing model ages across the Australian continent, mirroring the surface exposures. Younger domains through Central Australia separate the cratonic zones in West Australia and the Northern and Southern Australian cratons. Archean model ages are most common in the Archean Pilbara and Yilgarn cratons of West Australia, but also occur in both the North and South Australian cratons. The majority of Australian model ages are Proterozoic in age. The youngest model ages are restricted to the Tasman Belt in the east, chiefly within the New England Orogen.

Within all the major elements of structure across the Australian continent there are indications of internal isotopic zonation, including regions with relatively sharp changes over narrow bands or distinct, but diffuse, gradients.

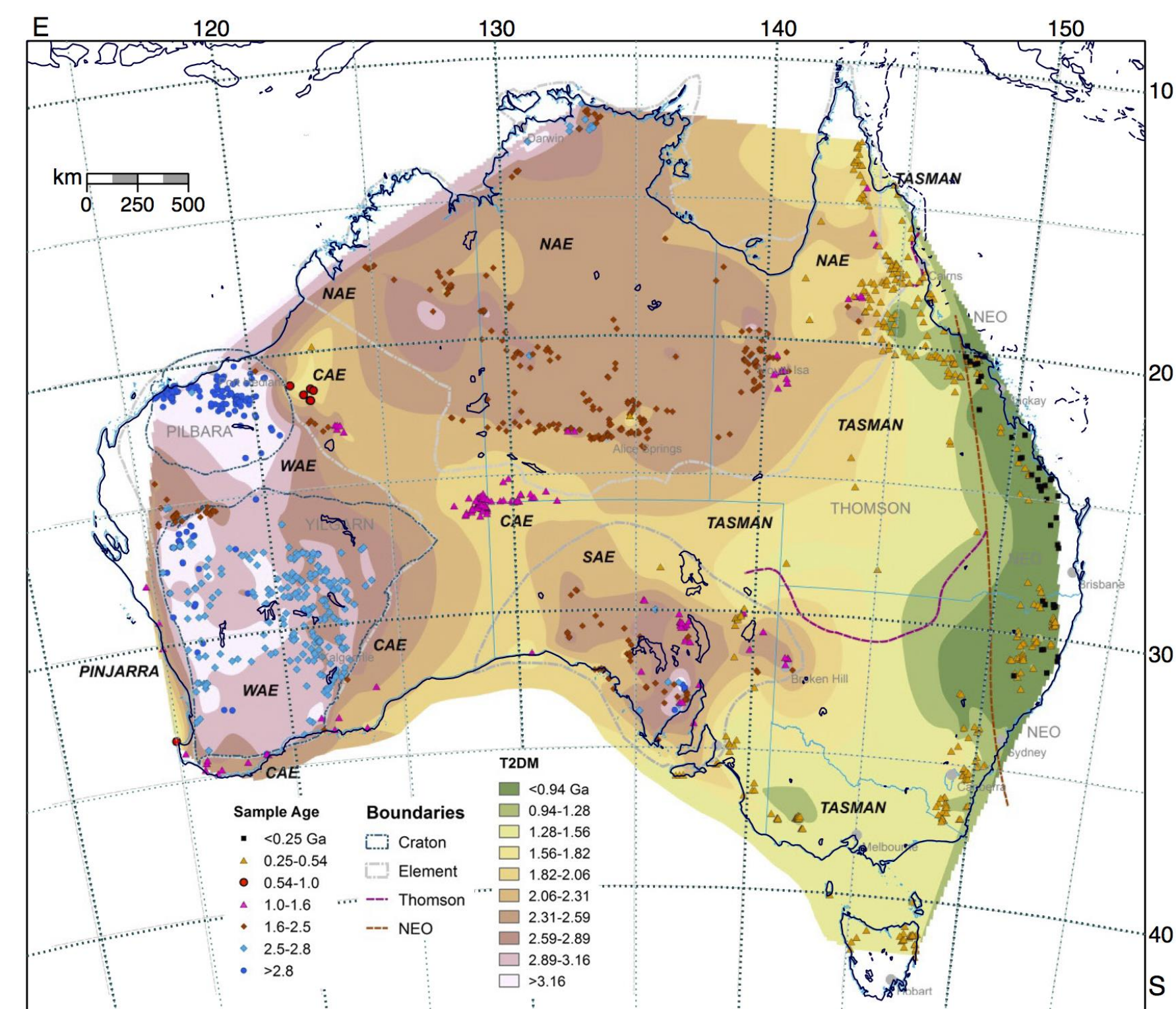

Figure 2.8: Distribution of crustal ages across Australia from Sm-Nd analysis of felsic igneous rocks (Champion, 2013).

Many of the breaks and gradients in the distribution of model ages across the continent correspond to known crustal boundaries or changes in geology, which indicates that Sm-Nd whole rock signatures can be used to identify crustal changes. For example, the strong increase in younger isotopic signatures in the southern half of the Northern Territory suggests processes associated with an accretionary margin, similar to the patterns observed in the Tasman orogens. 


\subsection{Sedimentary Basins}

Figure 2.9 displays the combined thickness of Neoproterozoic and Phanerozoic basins across Australia, building on input from reflection seismology, gravity and magnetic surveys. Older Proterozoic sediments are included in the righthand panel of Figure 2.9, many of these are metasediments so that the distinction from basement is not always obvious.

Although a significant part of Australia is covered in sediments, the sequences on the continent are generally less than $7 \mathrm{~km}$ thick (Figure 2.9). Deeper basins $(>15 \mathrm{~km})$ occur offshore particularly in northwestern Australia. These deep sedimentary basins host most of Australia's oil and gas.
The onshore basins are also important, with major coal deposits in eastern Australia, mostly from the Permian, and gas accumulations in the Cooper Basin in southern Queensland. The majority of these basins are associated with gentle downwarps due to thermal sagging rather than localised rifting, and many in the western part of the continent lie on relatively thick lithosphere.

A narrow band of deep sediments occurs in the Fitzroy Trough at the northern end of the Canning Basin, abutting the Precambrian Kimberley Block. This appears to be an area with periodic tectonic reactivation, and still displays moderate seismicity.
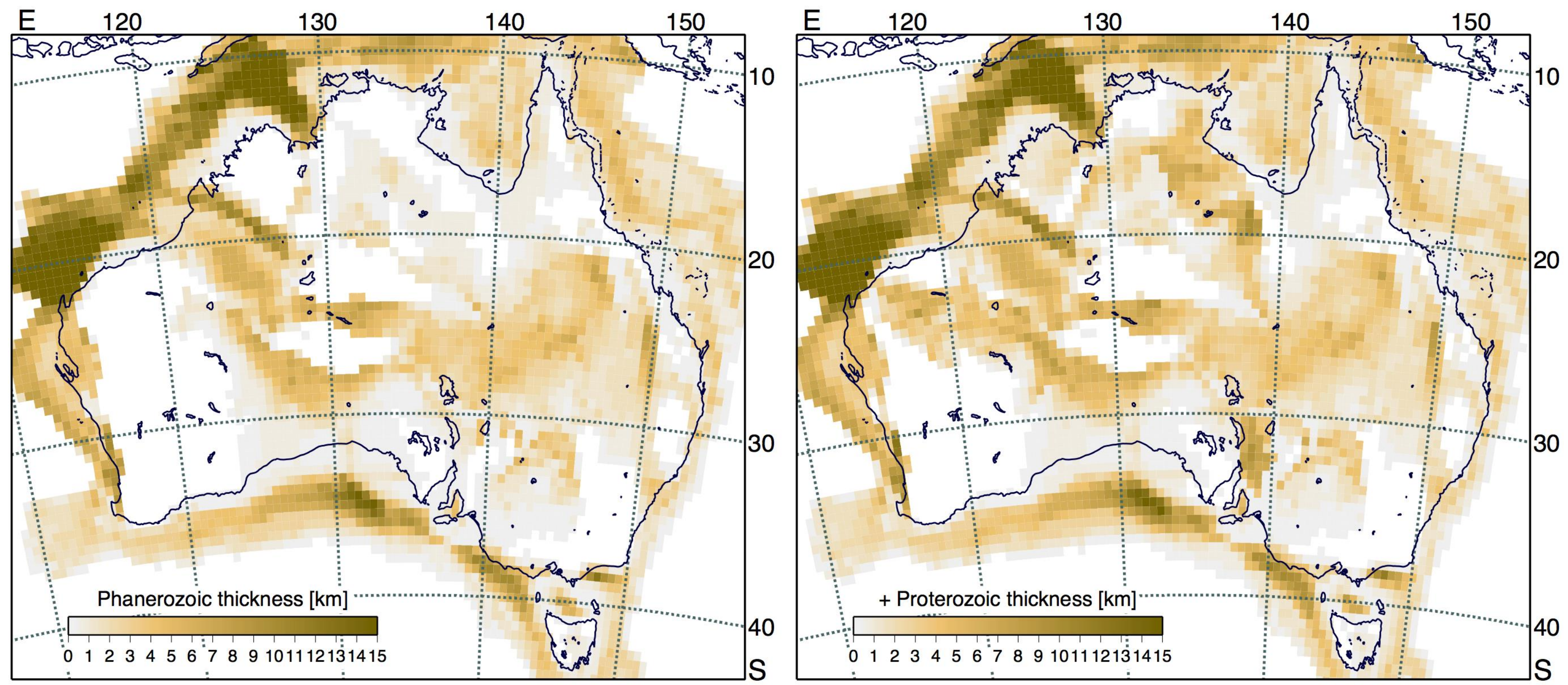

Figure 2.9: The distribution of sedimentary basin thickness across the continent based on the OZSeebase study (Frogtech, 2005). 


\section{Radiometry}

A major effort has been made to assemble a continent-scale study combining the results of many different airborne radiometric surveys (Figure 3.1).

The radiometric surveys measure the gamma-ray spectrum at a modest altitude (around $100 \mathrm{~m}$ ) arising from the decay of the major radioactive elements potassium $(\mathrm{K})$, uranium $(\mathrm{U})$ and thorium (Th) in the top metre or so of the ground. The energy distribution of the gamma rays is specific to the decay chain for the particular elements, and hence the relative contributions can be measured and extrapolated back to the concentrations of the radioactive elements at the Earth's surface.

Corrections need to be made for the background radiation, the height of the aircraft above the ground and the response and sensitivity of the detector. Further processing is required when many different surveys are combined as in Figure 3.1, to ensure that a common scale for element abundance is used across the entire image (Minty et al., 2009), and that background effects are treated in a consistent manner.

Figure 3.1 employs the normal mode of display of radiometric results using a three-colour image. The potassium concentration is placed on the red channel, thorium on the green channel and uranium on the blue channel. The relative concentrations of the elements determine the local colour.

This ternary image can be regarded as a chemical map of the near-surface distribution of the elements and is strongly correlated with the surface geology and the rate of erosion or deposition in the landscape. Areas low in all three radioactive elements appear as dark hues (ultramafics, quartzites and sandstones) and areas high in all three radioactive elements appear as white hues (felsic volcanics and granites).

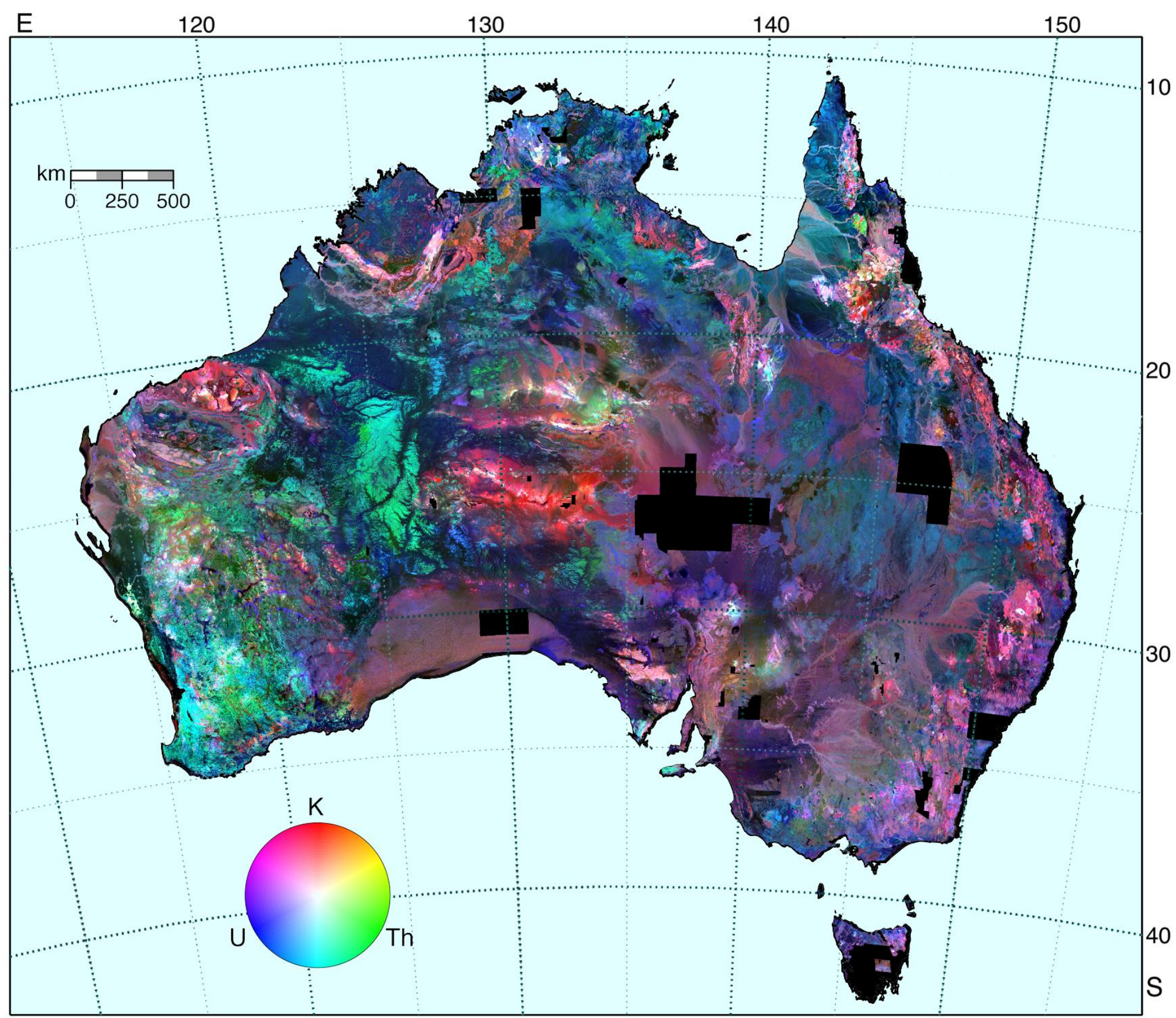

Figure 3.1: Gamma-ray spectrometric map for the continent of Australia created by combining results from many individual airborne surveys with careful cross-calibration. The map shows the distribution of potassium ( $\mathrm{K}$ - red), thorium (Th - green) and Uranium $(U$ - blue) in the top $30 \mathrm{~cm}$ of the surface. Dark coloured regions are low in total counts of the radioelements - these are commonly areas covered in quartz-rich sands. White regions have relatively high concentrations of the radioelements and are commonly associated with areas of active erosion, especially of felsic (granitic) rocks. The black areas are data acquisition gaps. 
Weathering, erosional and depositional processes play a large part in forming the radiometric response (Wilford, 2012)-see Chapter 14. Many of the green and green-blue areas, representing high thorium but low potassium, are highly weathered surfaces rich in iron.

Localised high concentrations of the radioactive elements are clearly visible in the granites of the Pilbara Craton and the eastern Yilgarn Craton, in central Australia and in the New England region of northern New South Wales.

Many geological features and boundaries are well delineated in the continental-scale image, e.g. the Mesozoic shoreline behind the Nullabor Plain, with a clear distinction from the thorium-rich Yilgarn Craton. The actively eroding fold belts surrounding the Kimberley region are prominent against the more sombre tones of the Kimberley itself. There is also a clear image of the remote Canning Basin in Western Australia, much of it forming the Great Sandy Desert between the Kimberley and the Pilbara regions. The mineral provinces around Mt Isa and Broken Hill have a distinctive signature. Other concentrations occur in the Flinders Ranges, which is also noted as a zone with enhanced geothermal heat flux, most likely associated with a high concentration of these heat-producing elements in the crust. The granites of the Tasman Element along the eastern margin are bright red and white colours and shades, consistent with their high concentrations in radioelements (Figure 3.1)

Although the ternary image provides a useful overall summary of the element distribution, there is considerable useful information in the individual element maps as can be seen in Figure 3.2, where the contributions are shown without any reference markers. In later figures, the same element maps are presented with the addition of either the geological provinces or the major crustal boundaries from Korsch and Doublier (2016).
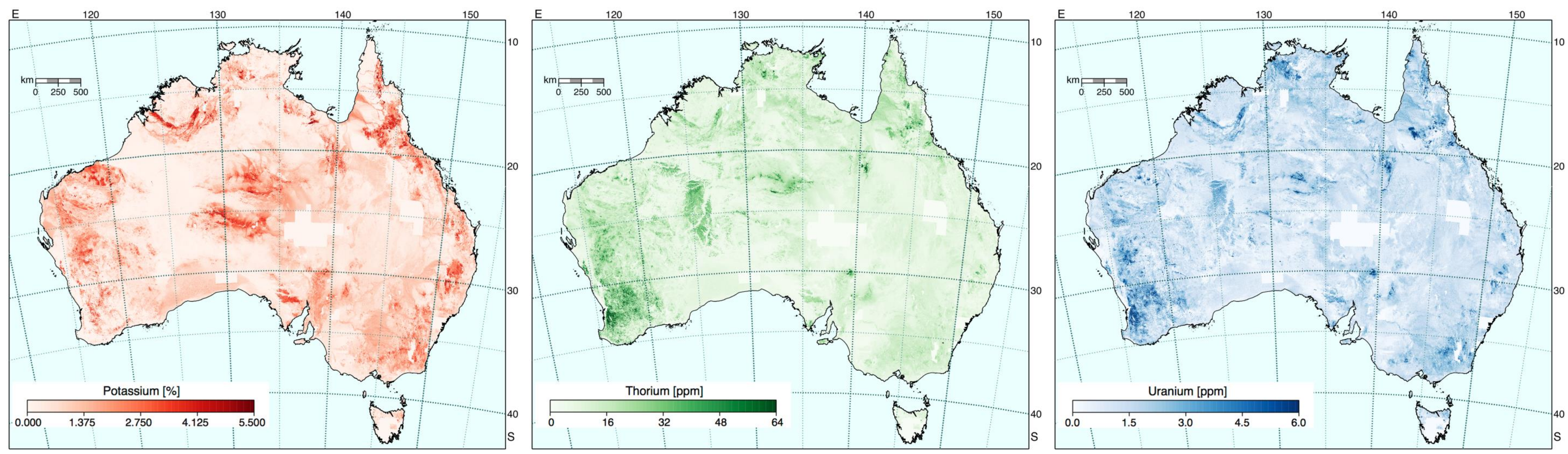

Figure 3.2: Estimated concentrations from radiometric surveys for individual elements: red—potassium (K), green—thorium (Th), blue—uranium (U). 


\subsection{Potassium}

The strong dull red of much of the southern and eastern parts of Australia in Figure 3.1 reflects the dominance of potassium over uranium and thorium, even though concentrations are low. There are distinct patches of potassium in the near surface in the granites of the Pilbara Craton, the fold belts around the Kimberley Block and the Georgetown Inlier.

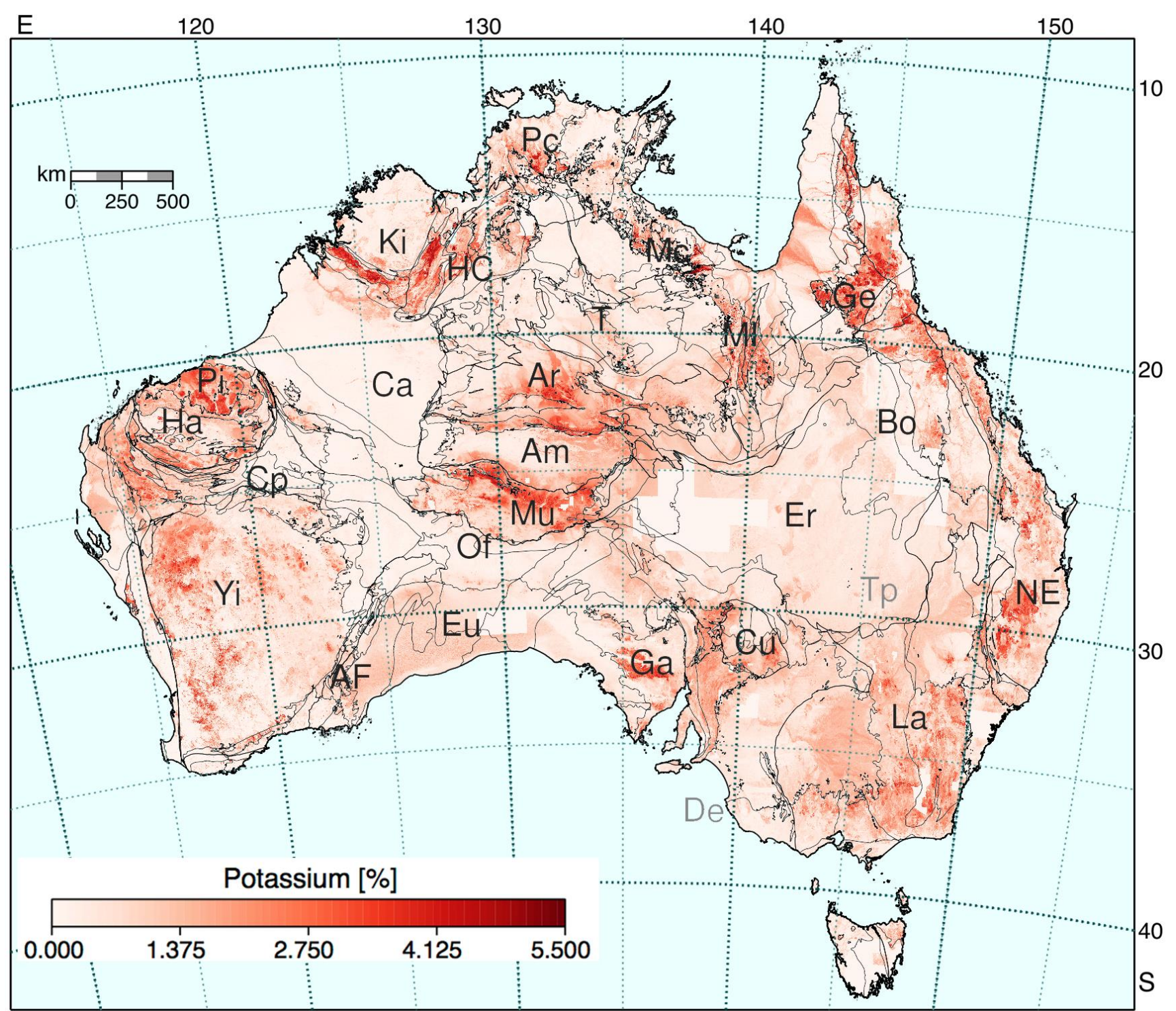

Figure 3.3: (a) Potassium concentration with geological provinces.
The Arunta and Musgrave provinces and the Gawler Range volcanics are also very prominent. Lesser concentrations are seen in the Mt Isa Province and the Adelaide rift. There is patchy surface potassium in the Yilgarn Craton, and the Lachlan and New England orogens, largely associated with granites.

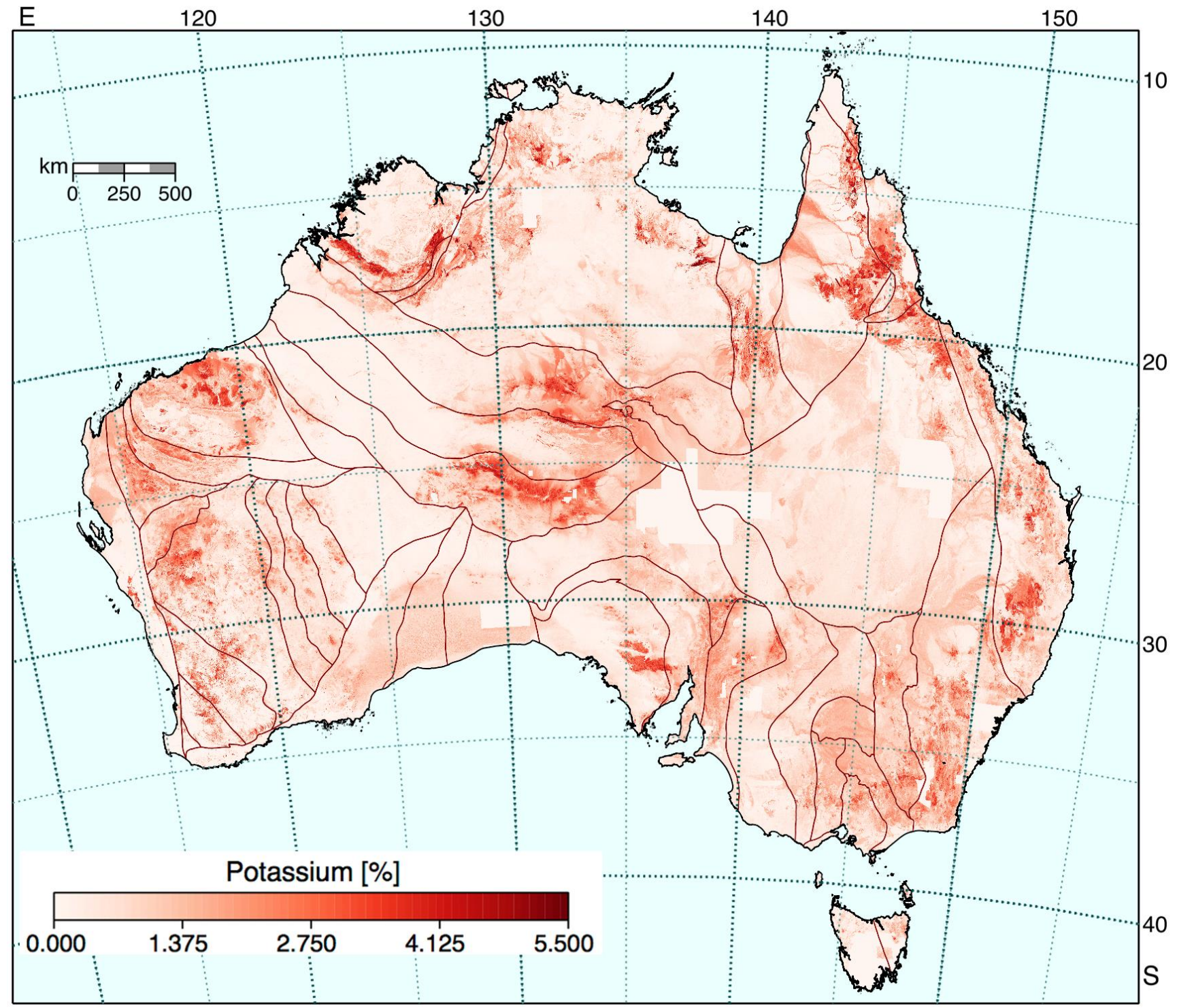

(b) With major crustal boundaries from Korsch and Doublier (2016). 


\subsection{Thorium}

There is a broad distribution of near-surface thorium across Australia, with particularly noticeable concentration in both the west and the east of the Yilgarn Craton. Other prominent features are enhanced concentration in the Arunta Province and the Georgetown Inlier.

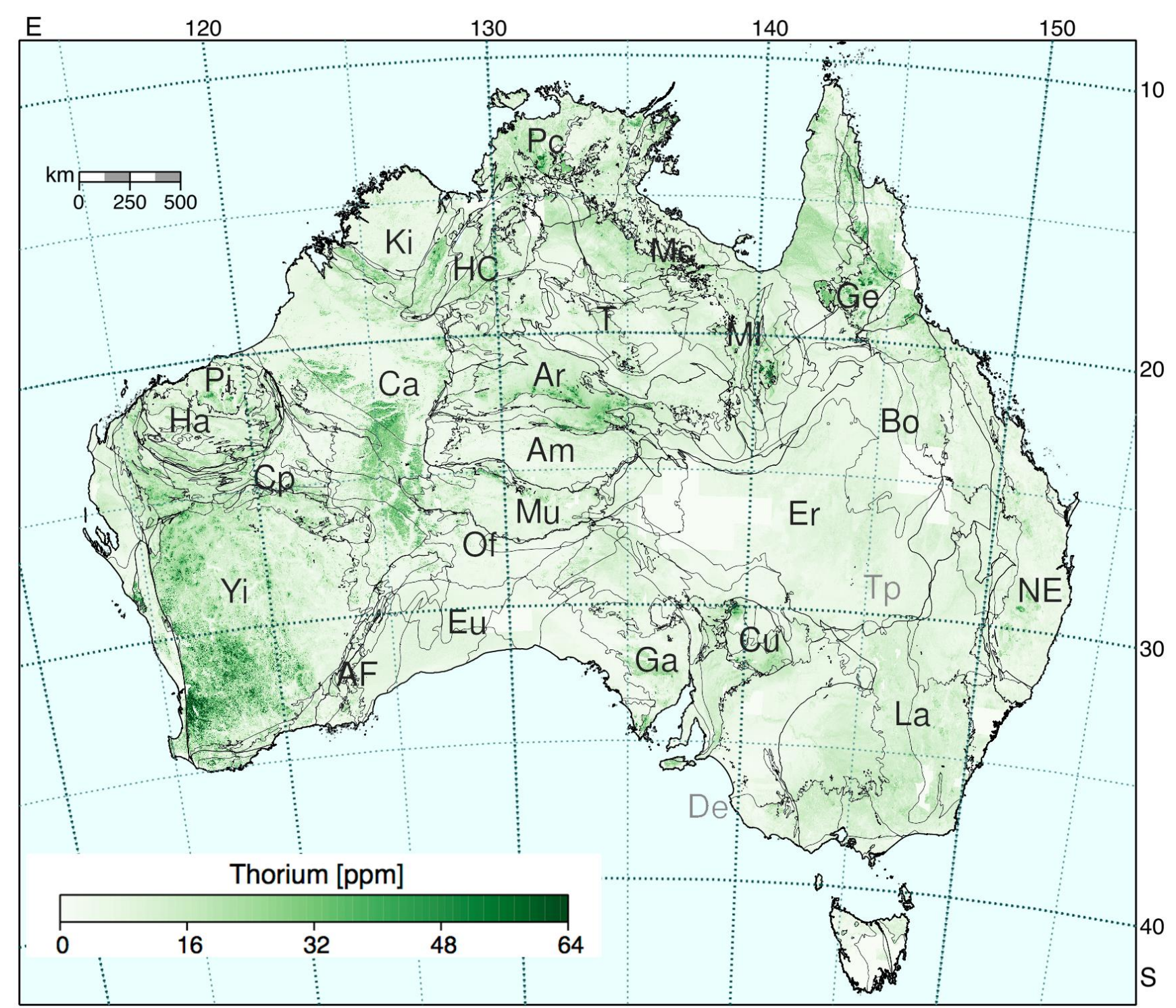

Figure 3.4: (a) Thorium concentration with geological provinces.
Very localised patches of enhanced concentration are seen around the Kimberley Block and in the Pine Creek region, in Mt Isa and at the edge of the Curnamona Craton. The behaviour in the Phanerozoic terranes is rather bland, even in areas with major granite outcrop.

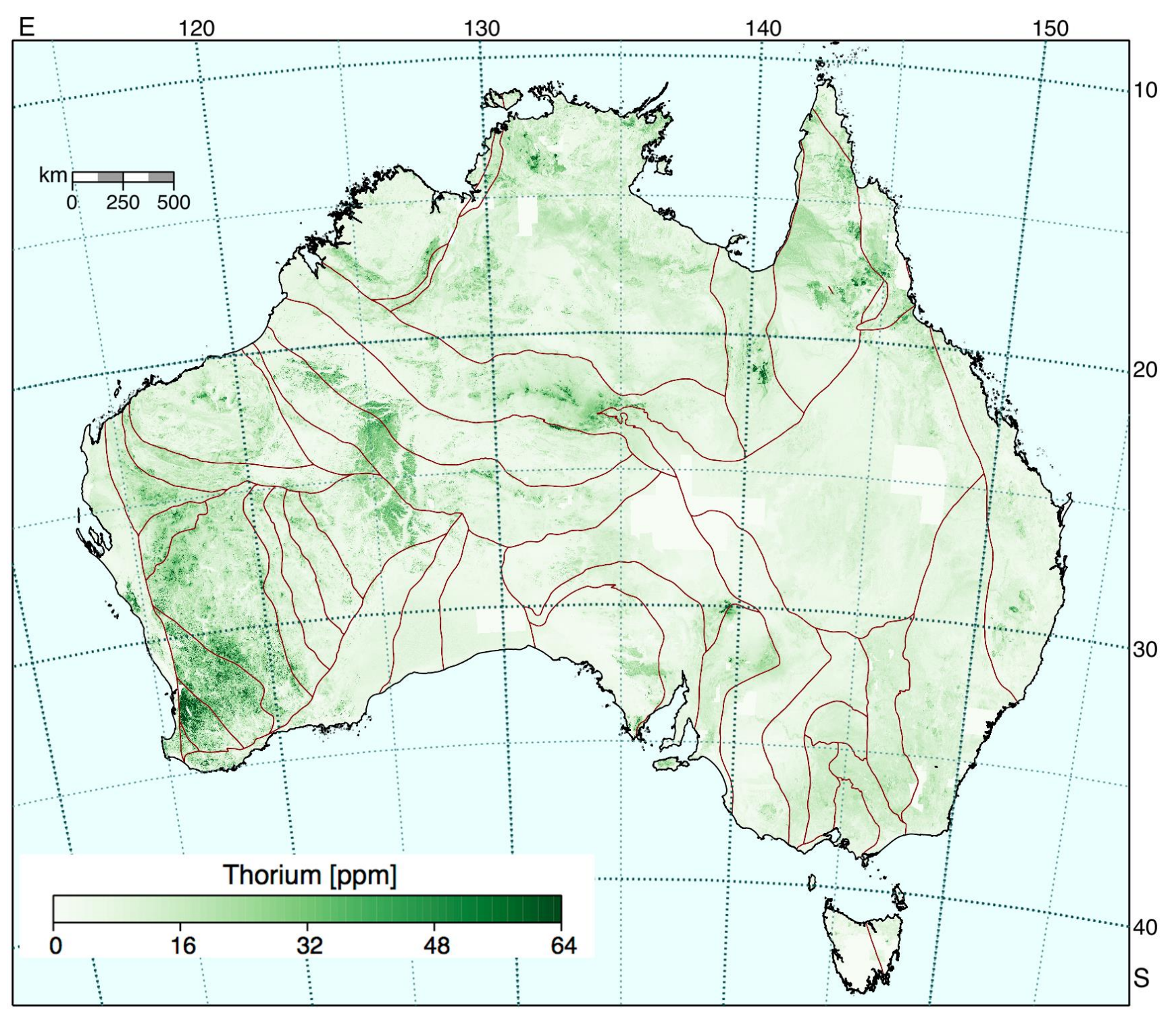

(b) With major crustal boundaries from Korsch and Doublier (2016). 


\subsection{Uranium}

Australia has a rich uranium endowment with approximately one-third of the known world reserves, but these rich deposits are highly localised and are too small to be evident at the continental scale. There is a broad correlation between the surface patterns of thorium and uranium concentrations, which is not surprising since they form part of the same radioactive decay chains.

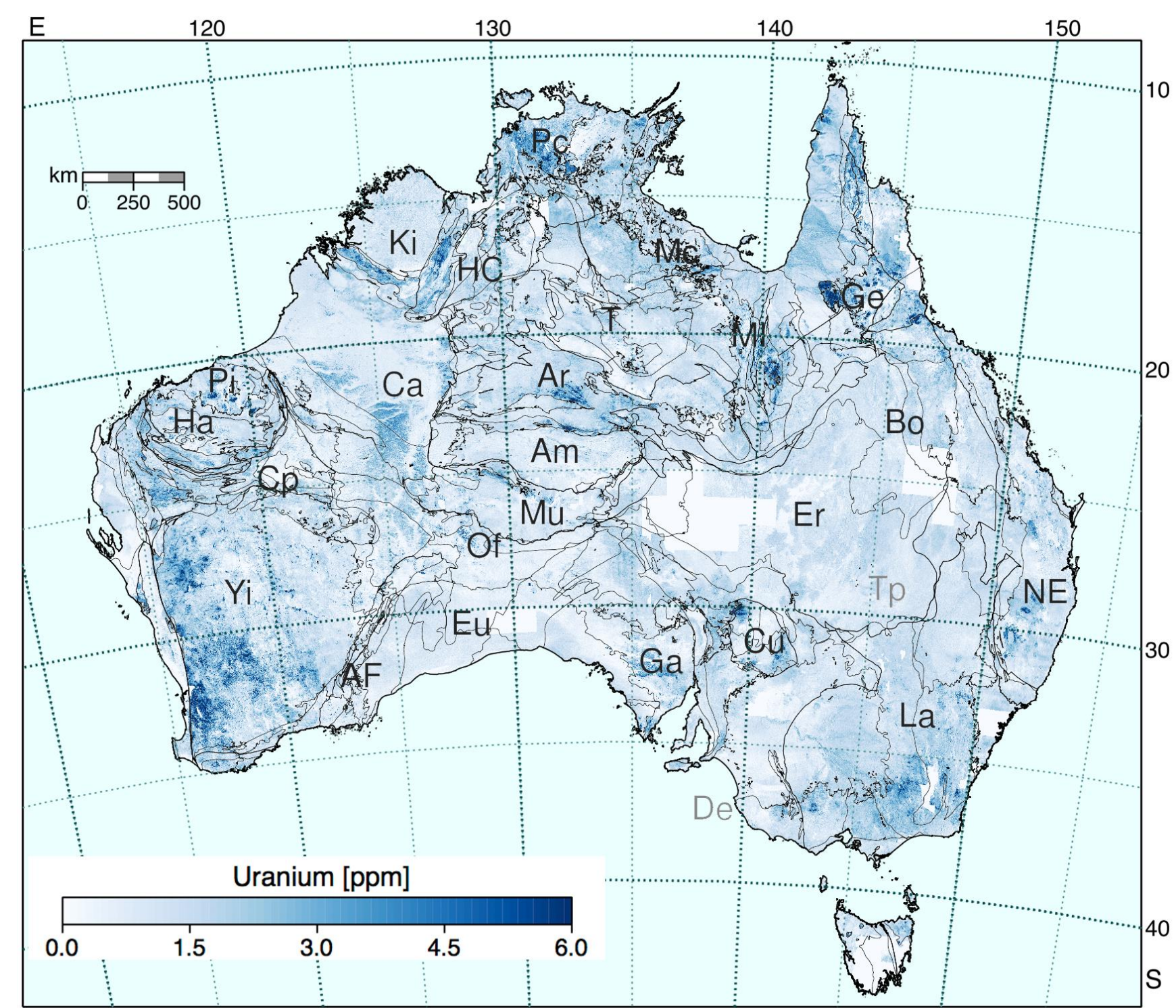

Figure 3.5: (a) Uranium concentration with geological provinces.
Yet, there are differences in the concentrations. For example, the lower uranium concentration compared to thorium in the Officer Basin, covering the eastern Yilgarn Craton, and the localised stronger patches in the Phanerozoic fold belts of eastern Australia.

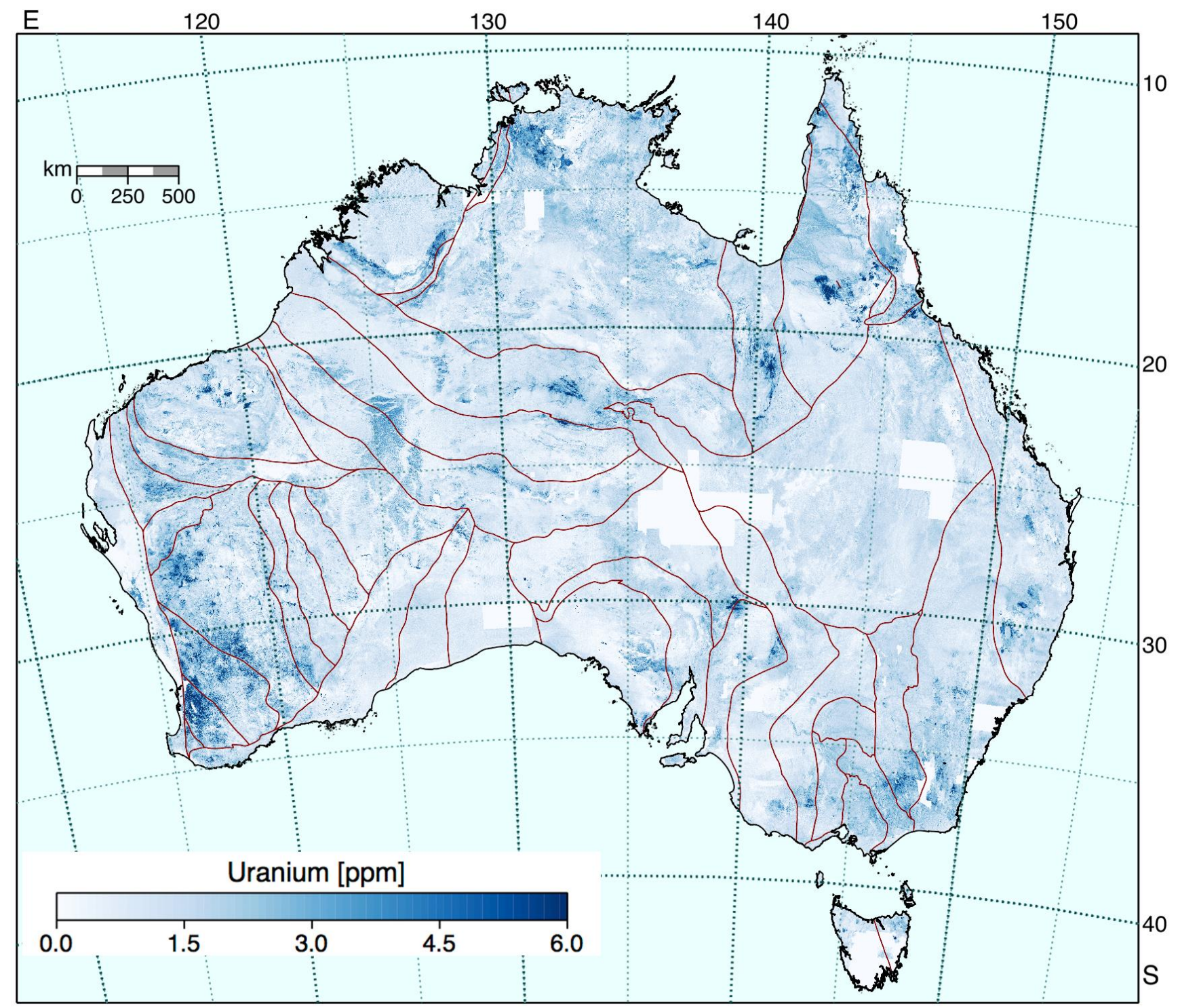

(b) With major crustal boundaries from Korsch and Doublier (2016). 


\subsection{The Nature of the Radiometric Signal}

The radiometric detectors in a low-flying aircraft register the gamma rays from naturally occurring radioisotopes and their intermediate decay products near the surface of the crust, but also the gamma rays produced by isotopes created by the interaction of cosmic rays with the atmosphere and those occasionally generated during thunderstorms.

During radioactive decay, the radioisotopes of only three elements in the Earth's crust emit gamma radiation that can be readily detected: potassium (K), uranium (U), and thorium (Th). Although other elements have naturally occurring radioisotopes that emit gamma radiation, their levels of radiation are too low to be measured using airborne sensors (Minty, 1997). Direct gamma ray emission from the ${ }^{40} \mathrm{~K}$ potassium isotope is detected. In contrast, the gamma rays associated with uranium and thorium arise from daughter products in their radioactive decay chains, so there is a less direct relation to element concentrations.

The estimates of the concentration of the radioelements in the crust presented in Figures 3.3-3.5 are based on the strengths of the spectral lines associated with different energies of gamma rays, as detected from a low-flying aircraft. Early forms of radiometric processing relied on just the use of the strongest energy components associated with each of the elements. Currently, a broad range of energy channels are considered, and the proportions of the different elements $(K$, $U$, Th) are determined by matching models of the energy spectra to the observations.

Even at slow flight speeds in areas with low radioelement concentrations, the number of gamma ray counts in a single counting interval can be quite low and so extraneous noise can play a significant influence. Estimates of the background noise due to cosmic rays and similar factors can be obtained by, e.g., flying over a body of water where no emissions are expected from below.
Careful calibration of the radiometric detectors is carried out, using known sources on the ground with, e.g., absorption by plywood deployed to compensate for the loss of gamma rays due to passage through the air to the height of the aircraft. It is not possible to achieve a full simulation of the aircraft in flight, since the gamma rays emitted from the ground impinge on the airframe somewhat differently than in the calibration geometry. When information from different radiometric surveys is being combined, corrections need to be applied to bring all observations to a common survey level.

The compilation of the latest continental radiometric map has been aided by the availability of a national radiometric background grid collected by Geoscience Australia, with north-south flight lines spaced $75 \mathrm{~km}$ apart, and east-west tie lines spaced $400 \mathrm{~km}$ apart. Gamma-ray spectrometric data were acquired at 80 $m$ height. The estimates of the concentrations of the radioelements $(K, U, T h)$ along these flight lines provide a consistent basis for tying together older surveys conducted with varying equipment and processing. The older surveys are tied to the new national framework by minimising both the differences in radioelement estimates between surveys and the crossing national traverses, as well as the differences between overlapping surveys.

The processes whereby gamma rays emerge from the near-surface are complex and very hard to model without prior knowledge of the details of geological structure and mineralogy. The generally mild variations in topography across the continent are helpful, but there can be significant effects associated with local strong topography when the usual assumption that the path of the gamma rays is near vertical is no longer satisfied. 


\section{Magnetics}

The south magnetic pole at which a freely suspended compass needle points vertically lies relatively close to Australia, and is currently situated off the coast of East Antarctica. The pole has moved substantial distances in the last century from the continent to offshore. On 16 January 1909 a party comprising Edgeworth David, Douglas Mawson and Alastair Mackay from Shackleton's Nimrod expedition made a close approach to the pole location on land when the pole was at approximately $72.25^{\circ} \mathrm{S}, 155.15^{\circ} \mathrm{E}$. In 2000 an even closer approach (within $1.6 \mathrm{~km}$ ) was made at sea (Barton, 2002) when the pole was situated at $64.67^{\circ} \mathrm{S}, 138.12^{\circ} \mathrm{E}$. The estimate for the beginning of 2017 is $64.21^{\circ} \mathrm{S}, 136.25^{\circ} \mathrm{E}$ which provides some indication of the current rate of drift of the pole.

The proximity of the south magnetic pole to Australia means that there is significant variation in the character of the magnetic field across the continent, which has to be taken into account when comparing magnetic results in different locations. In addition to the main geomagnetic field that comes from the interior through the action of the geodynamo in the Earth's core, substantial magnetic influences come from outside due to currents induced in the ionosphere. Variations over a day are commonly around 25 nanoTeslas (nT) about one part in 2000 of the internal field. Short term variations are commonly around $1 \mathrm{nT}$.

The magnetic field at any point can be represented as a vector in three dimensions. The convention is to work with the components in the direction of true north $(X)$, true east $(Y)$ and vertically downwards $(Z)$, with total field vector $\boldsymbol{F}$ and horizontal projection $\boldsymbol{H}$. The vector $\boldsymbol{H}$ points in the direction of magnetic north. The total field strength $F$ is measured in nanoTeslas (nT), and its annual rate of change in $\mathrm{nT} / \mathrm{yr}$. Figure 4.1 illustrates the situation for Australia where the total field vector points upwards and so the vertical component $Z$ is negative.

The magnetic declination $D$ is the angle between the magnetic field in the horizontal plane and true north. $D$ is positive when a compass points east of true north, and negative when it points west of true north. Thus the value of the magnetic declination $D$ should be added to a magnetic compass bearing to give the bearing relative to true north.

The magnetic inclination $I$ is the angle between the magnetic field and the horizontal plane. $I$ is negative when the magnetic field points up, as it does for Australia in the southern hemisphere.

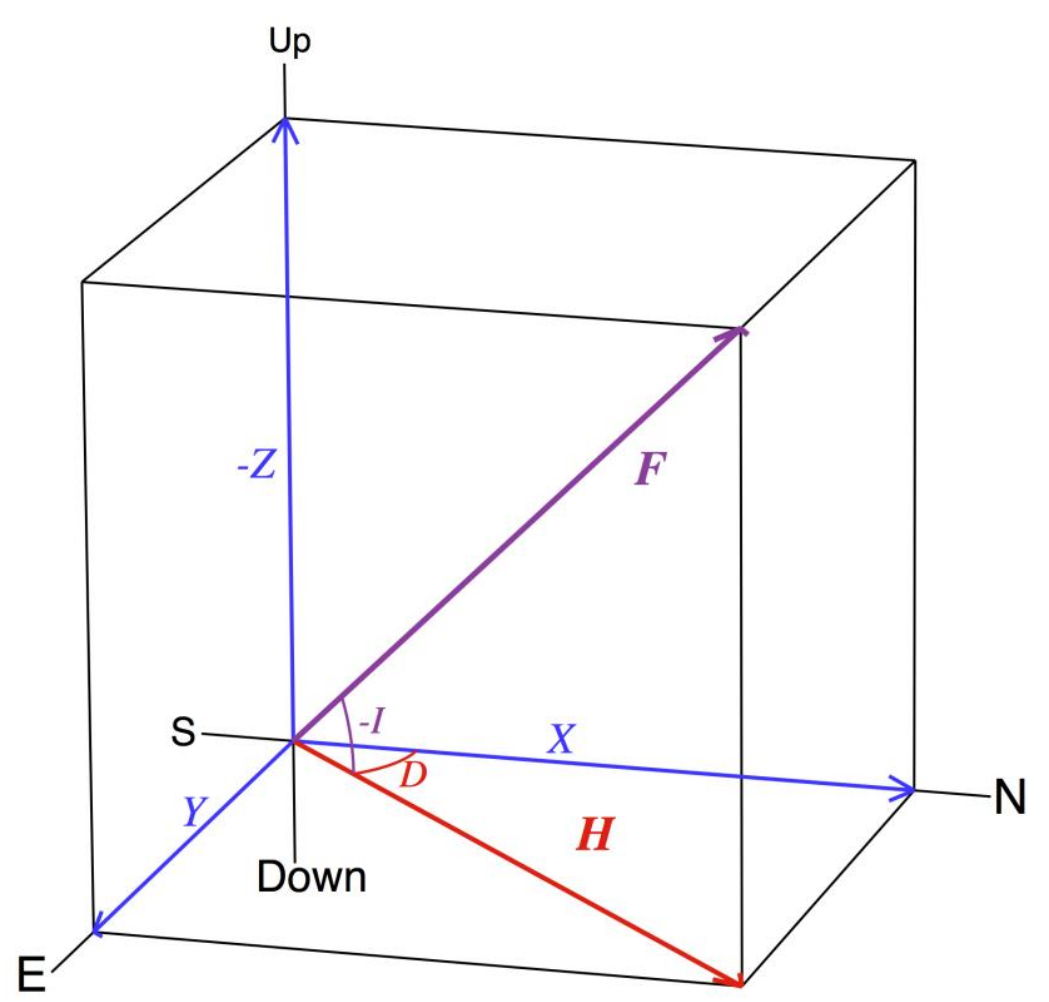

Figure 4.1: Components of the magnetic field for Australia in the southern hemisphere where the total field points upwards.

\subsection{Magnetic Reference Field}

Because the Earth's magnetic field varies quite rapidly, the reference model of the magnetic field across Australia needs to be updated periodically. Since 1990 this has been done at five-yearly intervals. The Australian Geomagnetic Reference Field model (AGRF) is represented by a set of spherical cap harmonics, and is linked to the International Geomagnetic reference field outside the specific Australian region. The AGRF model represents the Earth's main magnetic field originating from the core and the broad-scale crustal field. The AGRF does not model short-term variations of the magnetic field with time, such as those caused by solar activity or from electrical currents in the ionosphere. The reference field is derived from vector magnetic data measured with ground level, aircraft and satellite surveys, as well as the network of geomagnetic observatories and repeat stations run by Geoscience Australia and neighbouring countries.

The AGRF model is produced for each five-yearly epoch, along with a prospective secular variation model to extend the life of the model. Figures 4.2-4.6 show aspects of the AGRF field at 2015.0 in red, together with the predicted annual rate of change in blue. 
In the images for the magnitude components $(F, H)$ we display the main field (red contours) in nanoTesla (nT) and the annual change (blue contours) in nT per year. The angular components ( $D$ and $I$ ) show the main field (red contours) in degrees and annual change (blue contours) in arc-minutes per year. The circular boundary shows the limit of the AGRF model; contours outside the boundary are from the International Geomagnetic Reference Field model (IGRF-12) at 2015.0.

Figure 4.2 shows the total field $F$ in nT from the AGRF and its annual rate of change (nT/yr). There is a strong gradient in the magnitude from north to south with a range from $45000 \mathrm{nT}$ in the north to $60000 \mathrm{nT}$ at the southern margin of the mainland. The magnitude of the horizontal field $H$ shown in Figure 4.3 also shows a significant gradient from north to south but with the opposite sign to the total field. $H$ decreases from $35000 \mathrm{nT}$ in the north to less than $20000 \mathrm{nT}$ in Tasmania.

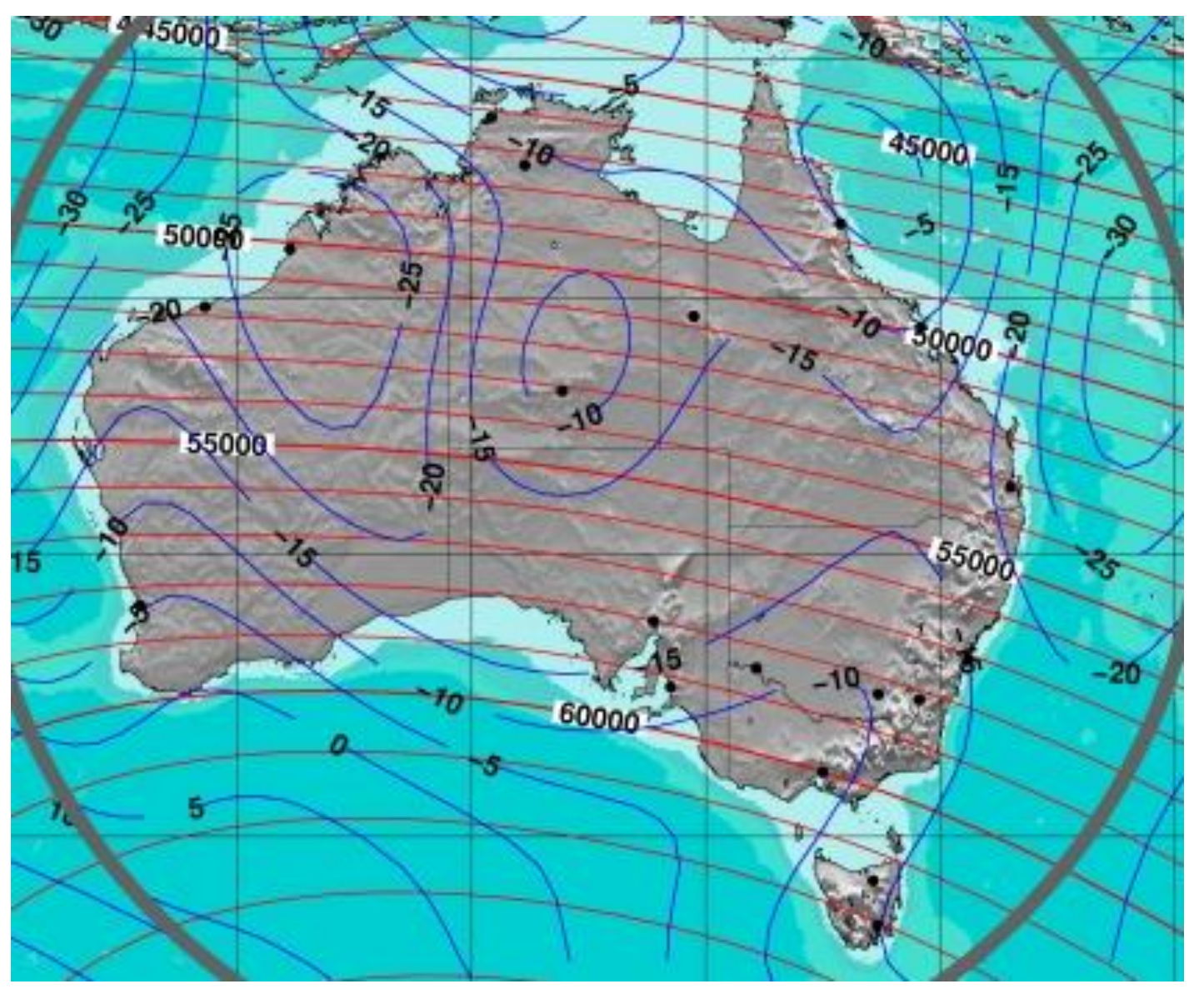

Figure 4.2: Total field $F$ from the AGRF, with red contours for the field in nT at 2015.0, and blue contours for the annual rate of change nT/yr. The domain of the AGRF is shown by the grey circle.
The consequence of these opposed variations in the field strength for the total field and horizontal field is that there are notable gradients in the angles of declination $D$ and inclination $I$.

The strong gradient in the declination $D$ (Figure 4.4 ) is associated with the proximity of the south magnetic pole. Currently the line of null declination passes through the very western part of the continent, with tight contours of negative declination further west. Most of Australia shows positive declination, reaching $15^{\circ}$ in southern Tasmania. The rate of change of the declination is sufficient that the pattern is expected to shift further west than the five-year epoch described by the 2015.0 AGRF model. The strong variation in the declination angle $D$ across Australia means that it is important to apply the correction from magnetic to true north when taking compass bearings.

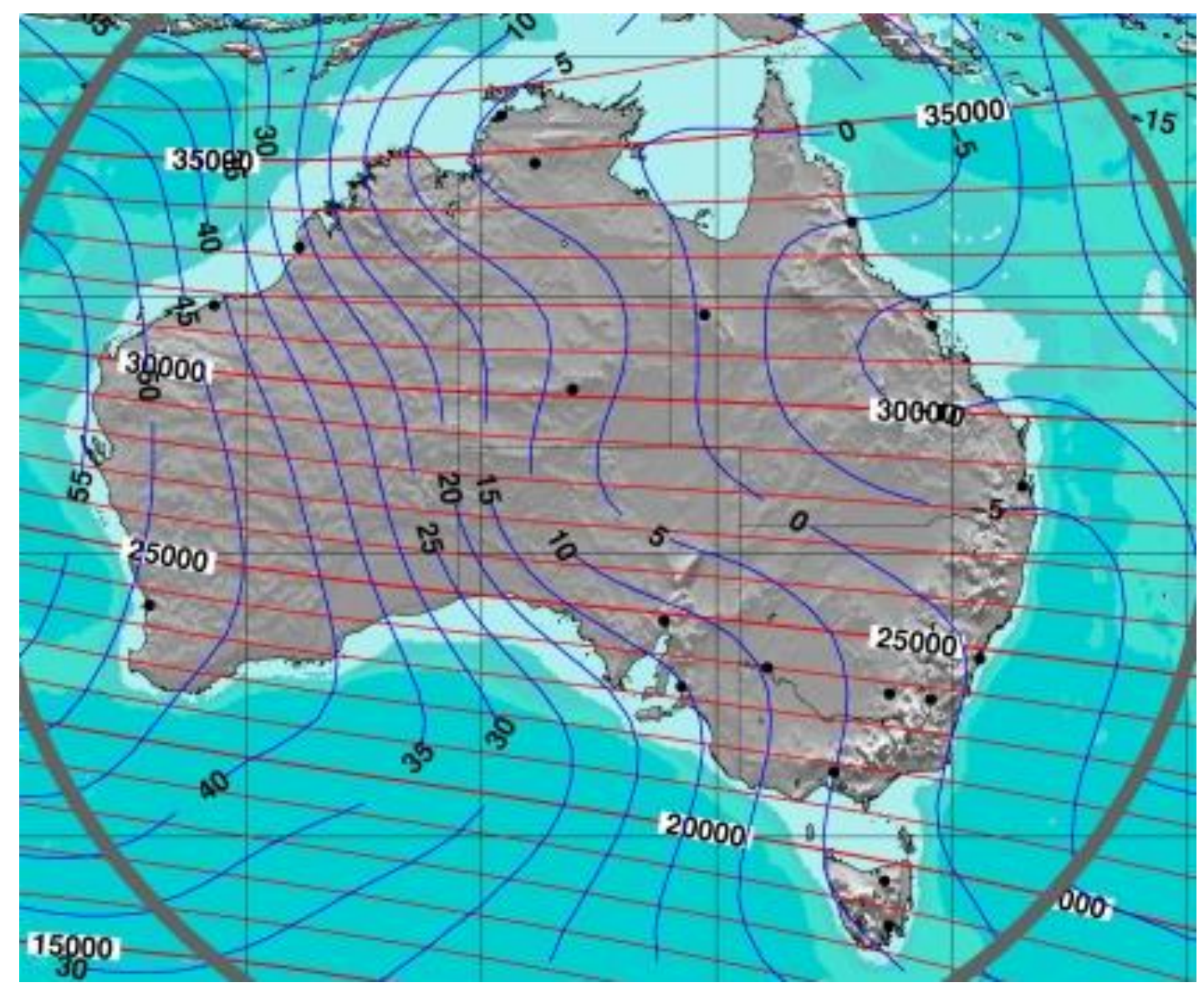

Figure 4.3: Horizontal field $H$ from the AGRF, with red contours for the field in $\mathrm{nT}$ at 2015.0, and blue contours for the annual rate of change nT/yr. The domain of the AGRF is shown by the grey circle. 


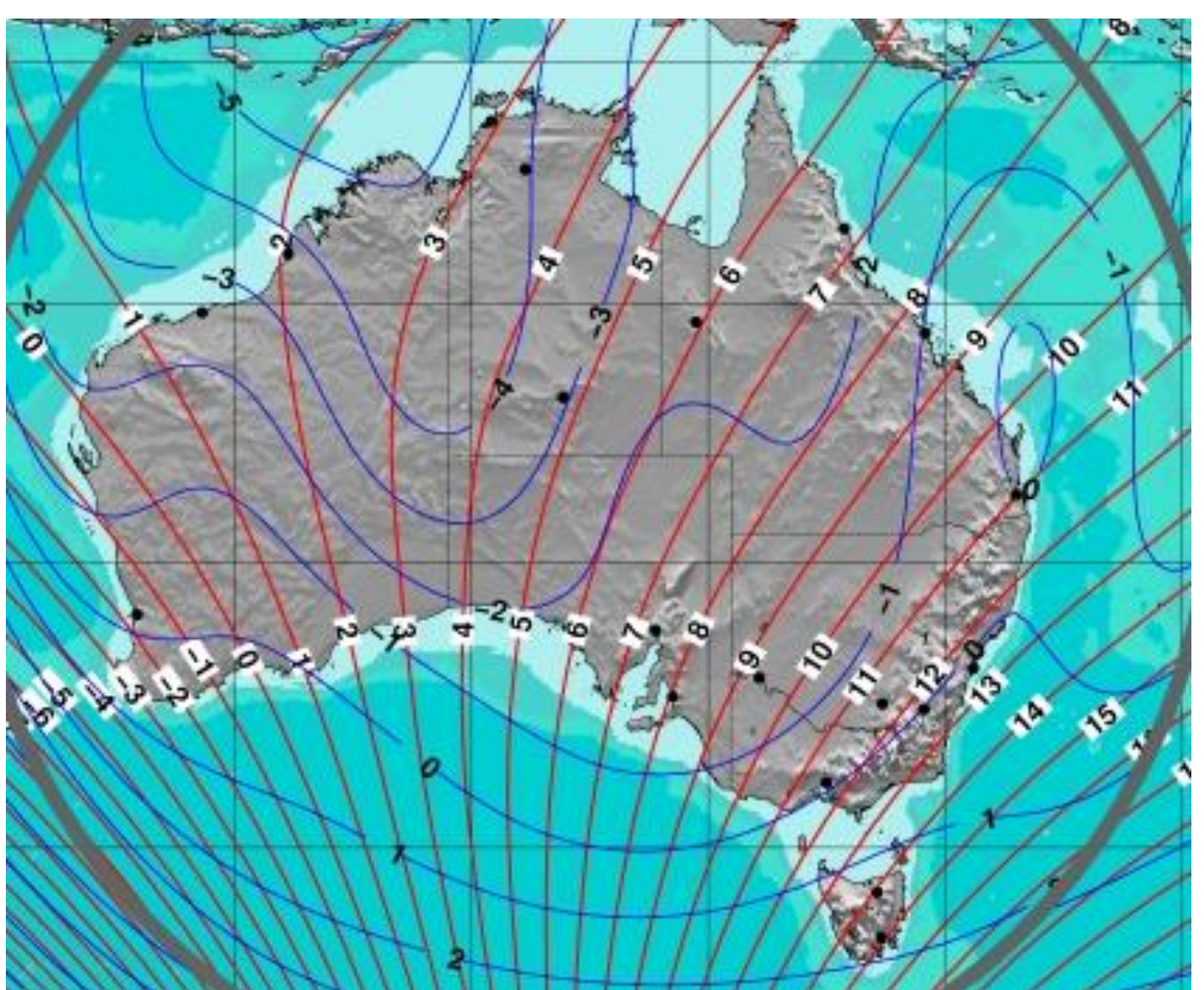

Figure 4.4: Declination $D$ from the AGRF, with red contours for the declination in degrees at 2015.0, and blue contours for the annual rate of change in arc minutes per year.

The variation in inclination I (Figure 4.5) is also strong across continental Australia with the dip of the magnetic field increasing significantly from north to south as the south magnetic pole is approached. The inclination is around $40^{\circ}$ in northern Australia and exceeds $70^{\circ}$ in southern Tasmania. The rate of change is generally a little less than for declination since the current motion of the south magnetic pole is dominantly towards the west.

The strong variation in the main magnetic field across Australia means that care needs to be taken when combining magnetic results from different parts of the country and different time periods, because the relationship to the pole will vary. Such compensation is built into the latest version of the magnetic anomaly map of Australia (Nakamura and Milligan, 2015).

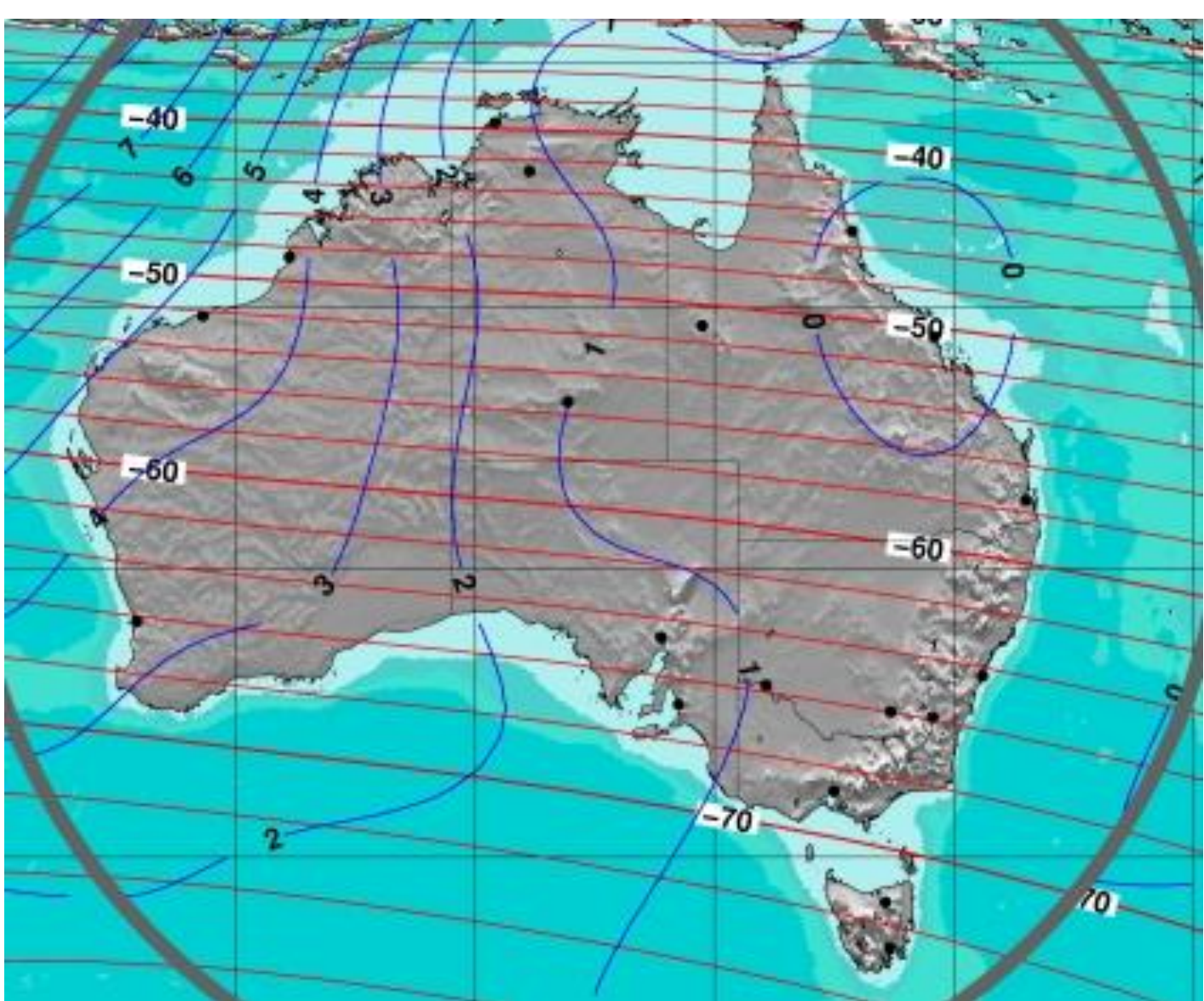

Figure 4.5: Inclination I from the AGRF, with red contours for the inclination in degrees at 2015.0, and blue contours for the annual rate of change in arc minutes per year.

Further, the relative proximity of Australia to the south magnetic pole has the effect that ionosphere variations are strong in Australia with consequent rapidly varying induced magnetic fields, which are strongest in daylight hours. This means that it is critical that detailed magnetic surveys are tied to a high quality, continuously recording, reference station, so that compensation can be made for the external field.

In periods of geomagnetic storms, the auroral bands of the Aurora Australis can be seen from the southern parts of mainland Australia. Under normal circumstances, the auroral band lies south of Tasmania. 


\subsection{Magnetic Anomalies}

As a result of the collective efforts of Geoscience Australia and the State and Northern Territory Geological Surveys, most of Australia has been covered with airborne magnetic surveys with high quality data that provide valuable information on the upper part of the crust. The aircraft carry sensitive magnetometers and commonly record the total magnetic intensity. The relative variations along the flight paths are determined by comparison with a reference station, so that effects due to the fluctuations of the external geomagnetic field can be compensated. Early surveys were carried out with widely spaced flight lines, but recent work uses relatively tight line spacing (e.g. $100 \mathrm{~m}$ ). Nevertheless the sampling along the flight path is much tighter than between paths and this can leave an imprint in the magnetic signature.

The full continental dataset as of 2016 contains around 31.5 million line-kilometres of acquired magnetic survey data. Since this dataset has been acquired over more than 50 years, the underlying broad features of the geomagnetic field have been changing, and hence it is necessary to compensate for such effects in the data reduction. The sixth edition of the Total Magnetic Intensity (TMI) Anomaly Grid of Australia, illustrated in Figure 4.6, uses the technique of variable reduction to the pole (Cooper and Cowan, 2005), which makes adjustments to the location and shape of magnetic anomalies due to the variation in the inclination of the Earth's magnetic field with latitude. This approach allows the matching of surveys carried out at different times. By using reduction to the pole, magnetic anomalies are adjusted so that simple features are mapped directly over the magnetic bodies. Without such corrections, magnetic anomalies appear shifted relative to their true position.

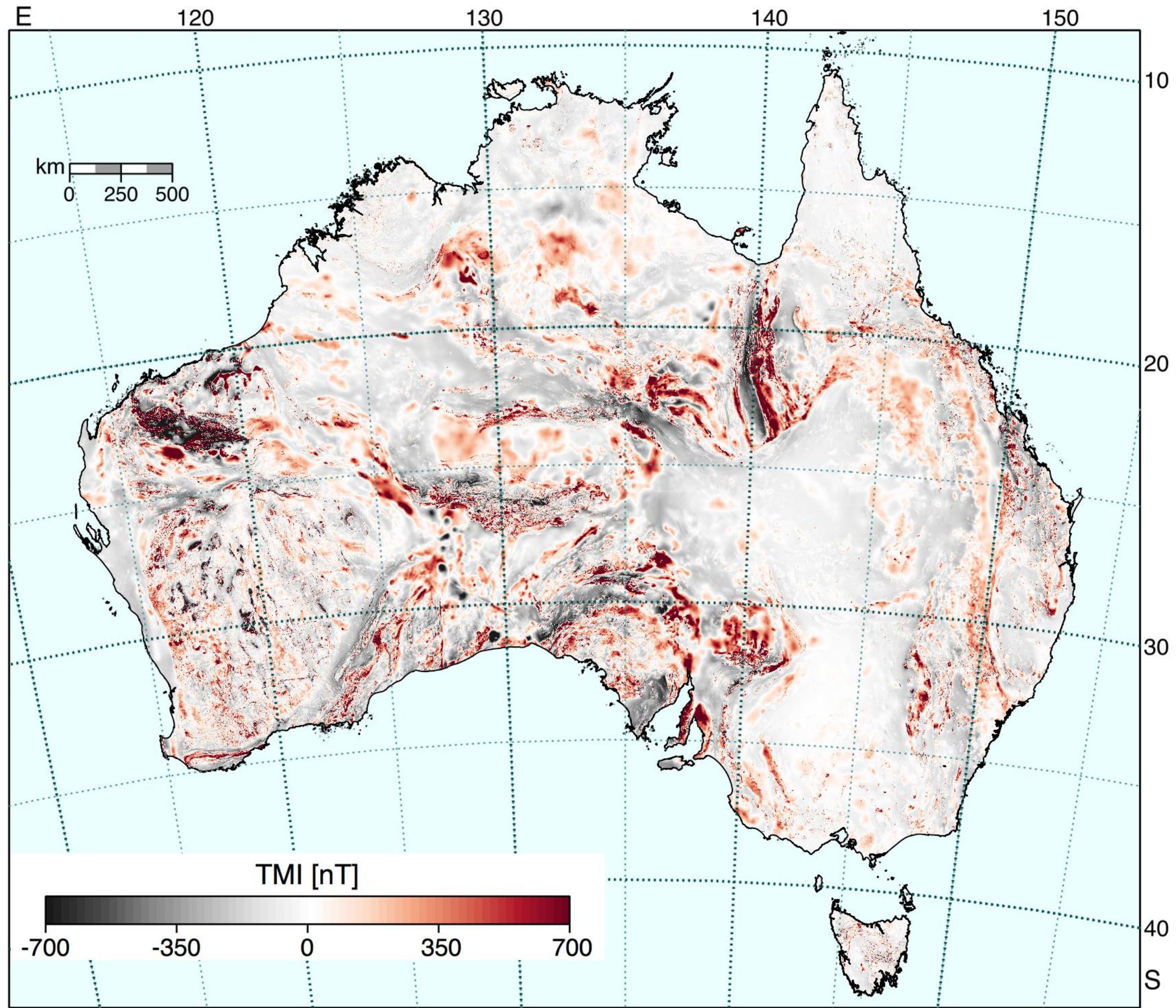

Figure 4.6: Total magnetic intensity across the Australian continent. 
For the low elevations employed in airborne magnetic surveys, the variations in the magnetic field along the flight track are predominantly due to differences in the magnetic susceptibility of the underlying rocks. The variations in susceptibility depend on the amount and type of iron-rich minerals in the rocks, particularly the presence of the iron-bearing mineral magnetite, which is strongly magnetic and frequently found in small quantities in the crust.

The variations in the total magnetic intensity provide information on the structure and composition of the magnetic basement, since different rock types commonly have distinctive magnetic signatures characterised by the magnitude, heterogeneity and fabric of the magnetic signal. When calibrated with known geology, terranes can be mapped under a cover of sedimentary rock and/or water. This feature has proved to be particularly valuable in Australia due to the extensive regolith.

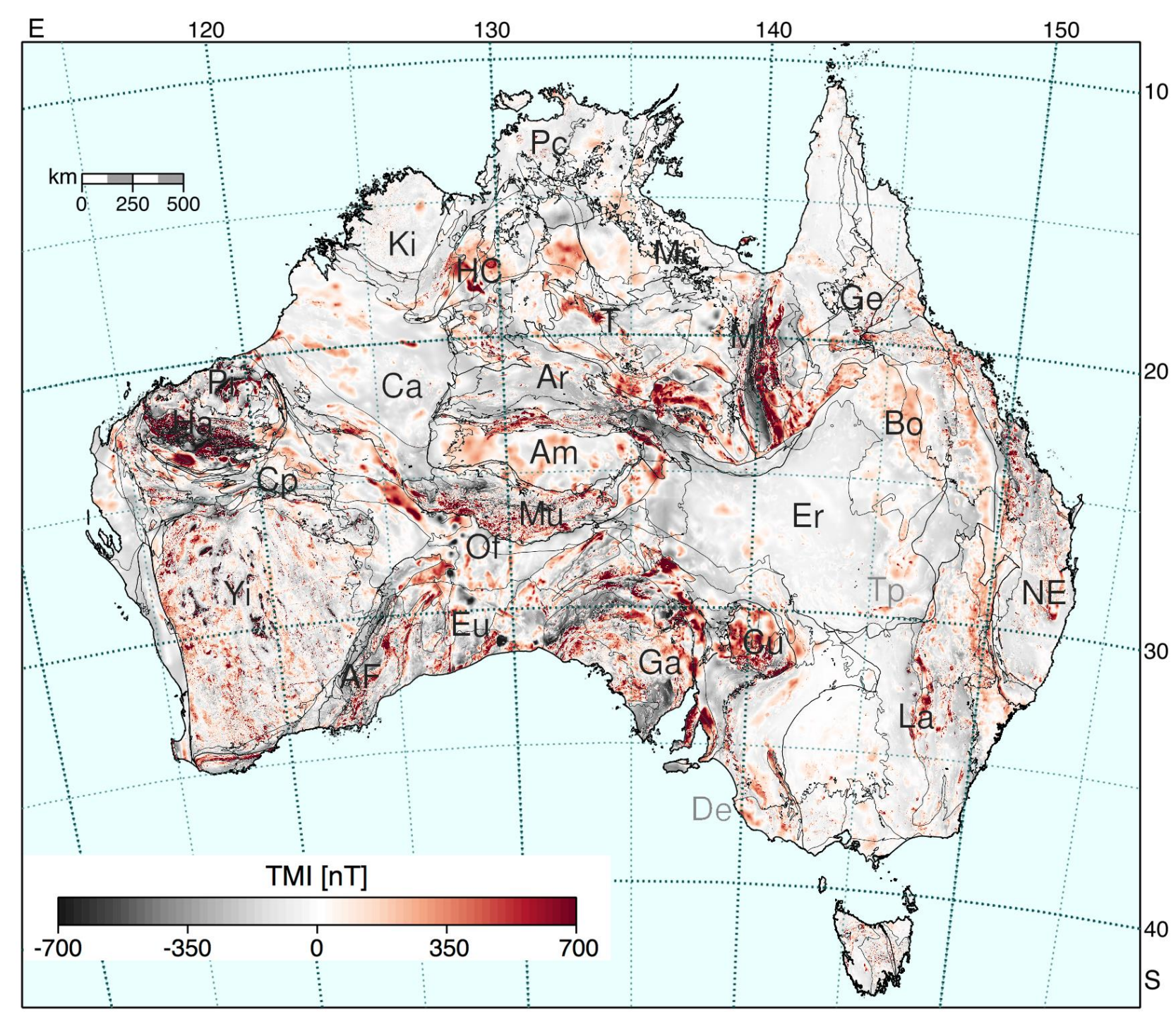

Figure 4.7: Total magnetic intensity with geological provinces.
Figures 4.7 and 4.8 illustrate the relation of the magnetic anomalies with the geological provinces and the major crustal boundaries from the compilation by Korsch and Doublier (2016). The strongest magnetic anomalies are concentrated in the cratonic areas or their margins, with the very largest negative anomalies associated with banded iron formations as in the Hamersley Basin to the south of the Pilbara Craton. The magnetic signature is subdued below areas of thick cover, but in a number of areas it is still possible to recognise the continuation of structures well beyond where outcrop occurs. A particular example is provided by the Mt Isa Province where the pattern of alternating magnetic anomalies is truncated by the Cork Fault, well to the south of the geological outcrop, as can be seen by comparison of Figures 4.8 and 2.7.

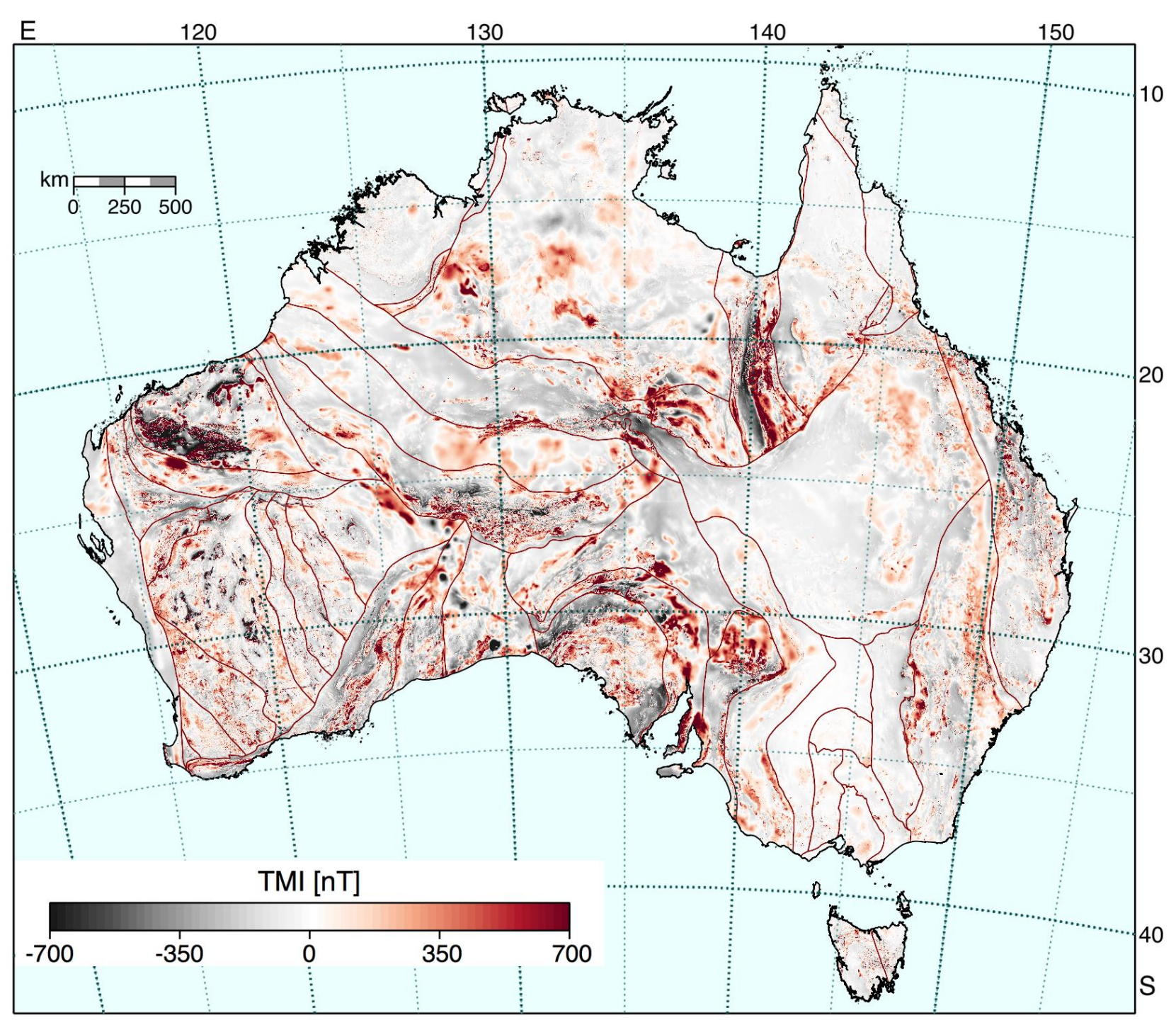

Figure 4.8: Total magnetic intensity with major crustal boundaries. 
The large span of magnetic variations across the continent means that some significant detail is suppressed when the full range of anomalies is plotted. Therefore, a more useful representation is produced by working with a more compact span of values, so that the gradients in the variations of total magnetic intensity are enhanced, as in Figure 4.9.

Now it is possible to see smaller contrasts in the magnetic anomalies than in Figures 4.6-4.8. For example, the contrast between the New England region and its surroundings is now very marked.

The grain of structure is revealed through the localised variations, as in the arcuate features linked to the Georgetown Inlier. In the Yilgarn Craton, near north-south streaks mark the greenstone belts, which are highly mineralised.

With the enhancement, the contrast between the core of the Gawler Craton and its rim becomes more distinct, as is the contrast in style with the Curnamona Block.

The magnetic anomalies associated with the Iron oxide-copper-gold (IOCG) deposits near Tennant Creek and in the Olympic Dam belt on the northwestern edge of the Gawler Craton have distinctive strong positive values.

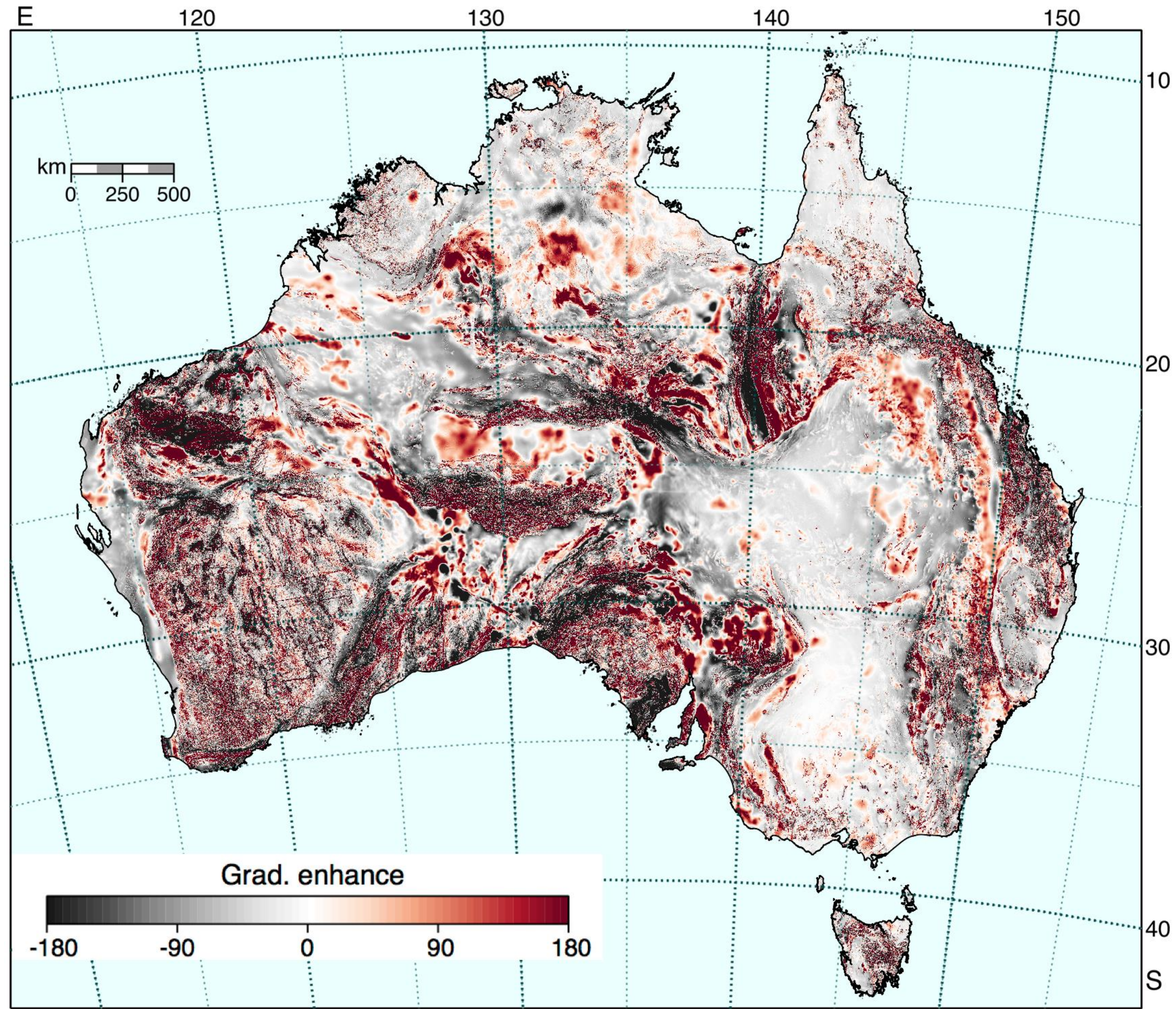

Figure 4.9: Enhancement of magnetic anomalies to emphasise gradients. 
The perturbation to the magnetic field produced by a localised magnetic body drops off as the inverse cube of distance. As a result, the magnetic anomaly pattern tends to be dominated by near-surface features such as magnetic dykes. The longer spatial wavelengths still contain information on structures at greater depth and their influence can be enhanced by examining the upward continuation of the magnetic intensity field, as shown in Figure 4.10. The extrapolation of the magnetic field is carried out in the spectral domain, where the short wavelength features are suppressed at the expense of the longer wavelengths.

The result emphasises the contrast between the relatively bland signature of the Yilgarn Craton and its surroundings. Further, the North and South Australian cratons are distinctive in their character.

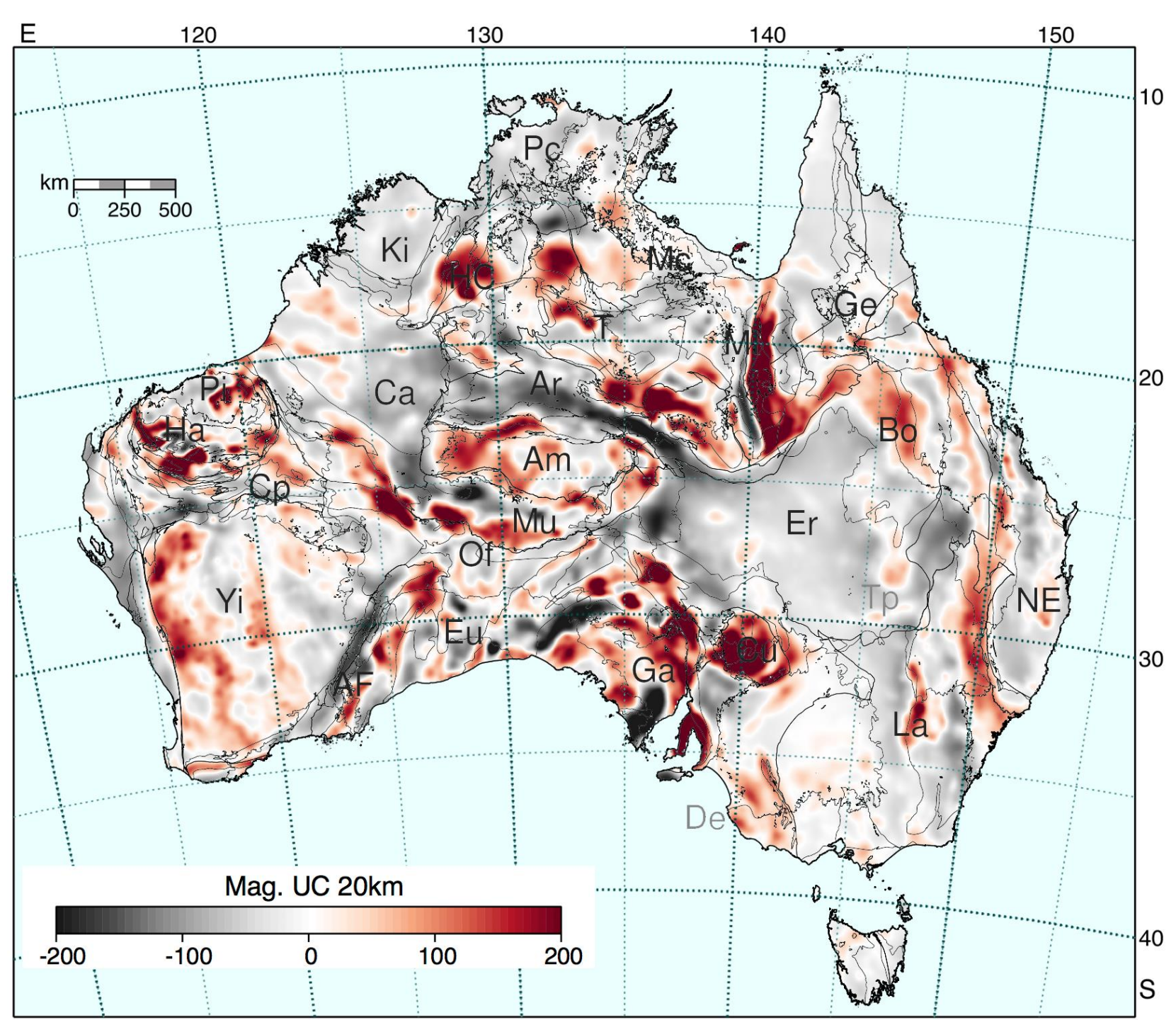

Figure 4.10: Total magnetic intensity with upward continuation to $20 \mathrm{~km}$.
An alternative approach is to emphasise the short wavelengths to concentrate attention on shallow structure. This again can be accomplished in the spectral domain, by taking derivatives of the magnetic intensity, or downward continuation. The computation of the derivatives is a more stable process, and hence such products are generally preferred.

A commonly used form for accentuating fine-scale structure is the half-vertical derivative of the total magnetic intensity, as illustrated in Figure 4.11. This particular product is often used in combination with other fields, e.g. as an underlay layer, because the enhancement of sharp gradients in magnetic properties tends to highlight changes in near-surface geology.

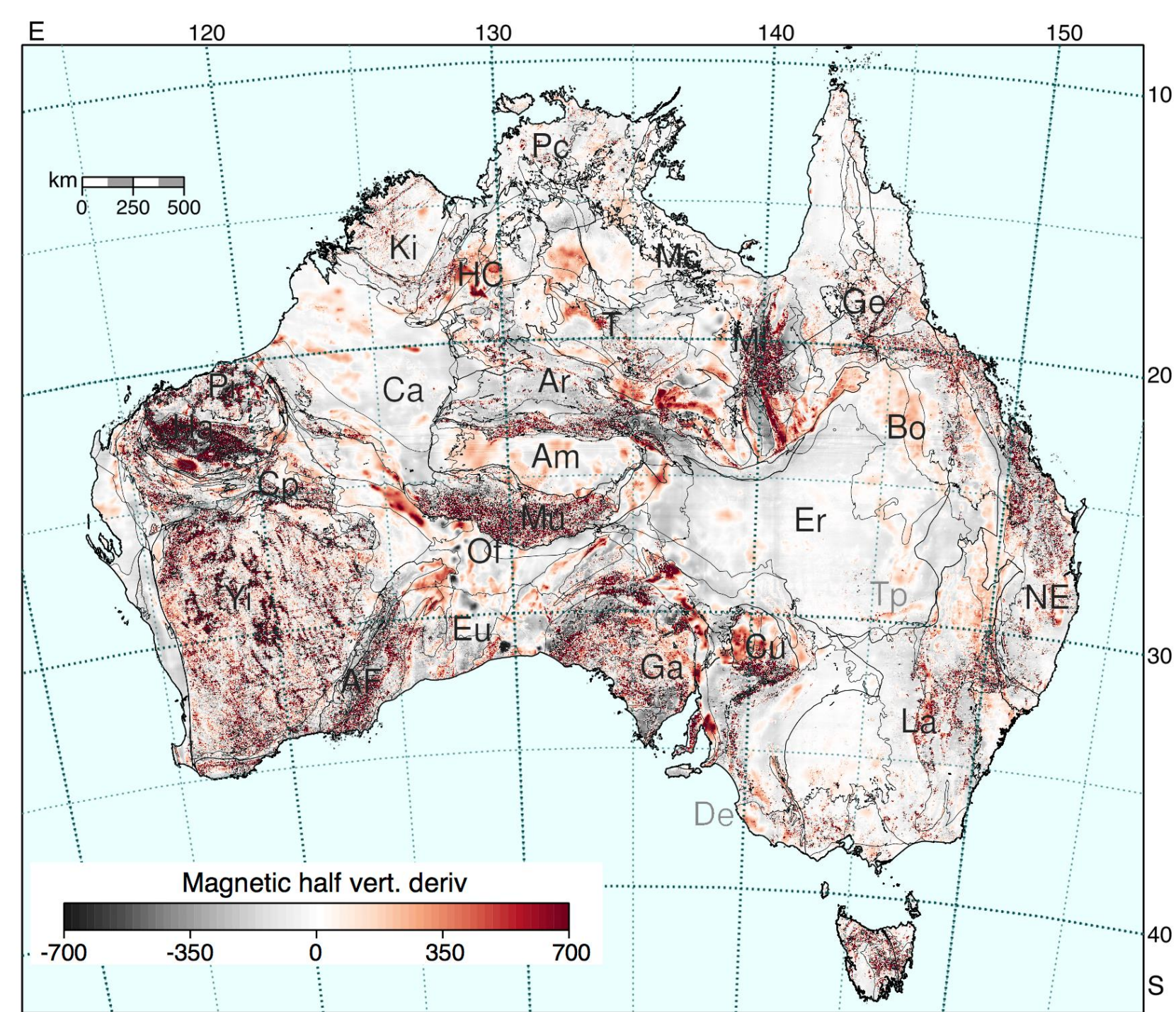

Figure 4.11: Half-vertical derivative of total magnetic intensity. 
As an illustration of the application of the enhanced magnetic intensity products, we display in Figure 4.12 the surface geology draped over the half-vertical derivative of the magnetic intensity. In this mode, the extension of geological features beneath cover can often be distinguished.

A significant example of undercover extension in Figure 4.12 is provided by the Mt Isa Province. The magnetic lineations clearly indicate that the well-mapped surface features continue to the south. There is then an abrupt truncation against the trace of the Cork Fault. The area lying under sedimentary cover is at least one-third of the exposed zone and clearly continues the same geological trends. There is thus the potential for further mineral resources of the various types that have already been found in the Mt Isa Province to be present in the undercover zone to the south.

Another area where the combination of surface geology and magnetic information provides intriguing clues is in the west of South Australia, where outcrop of basement is rather limited. Nevertheless, the correlation of features in the magnetic anomalies with the available exposure helps in extrapolation of structure under cover and out into areas with negligible outcrop.

The edge enhancement feature of the derivative products also enhances trends associated with different classes, and ages, of magnetic dykes. Thus, for example, the Gairdner dykes from about $830 \mathrm{Ma}$ are very evident in the southern part of the continent, with a grain running from southeast to northwest.

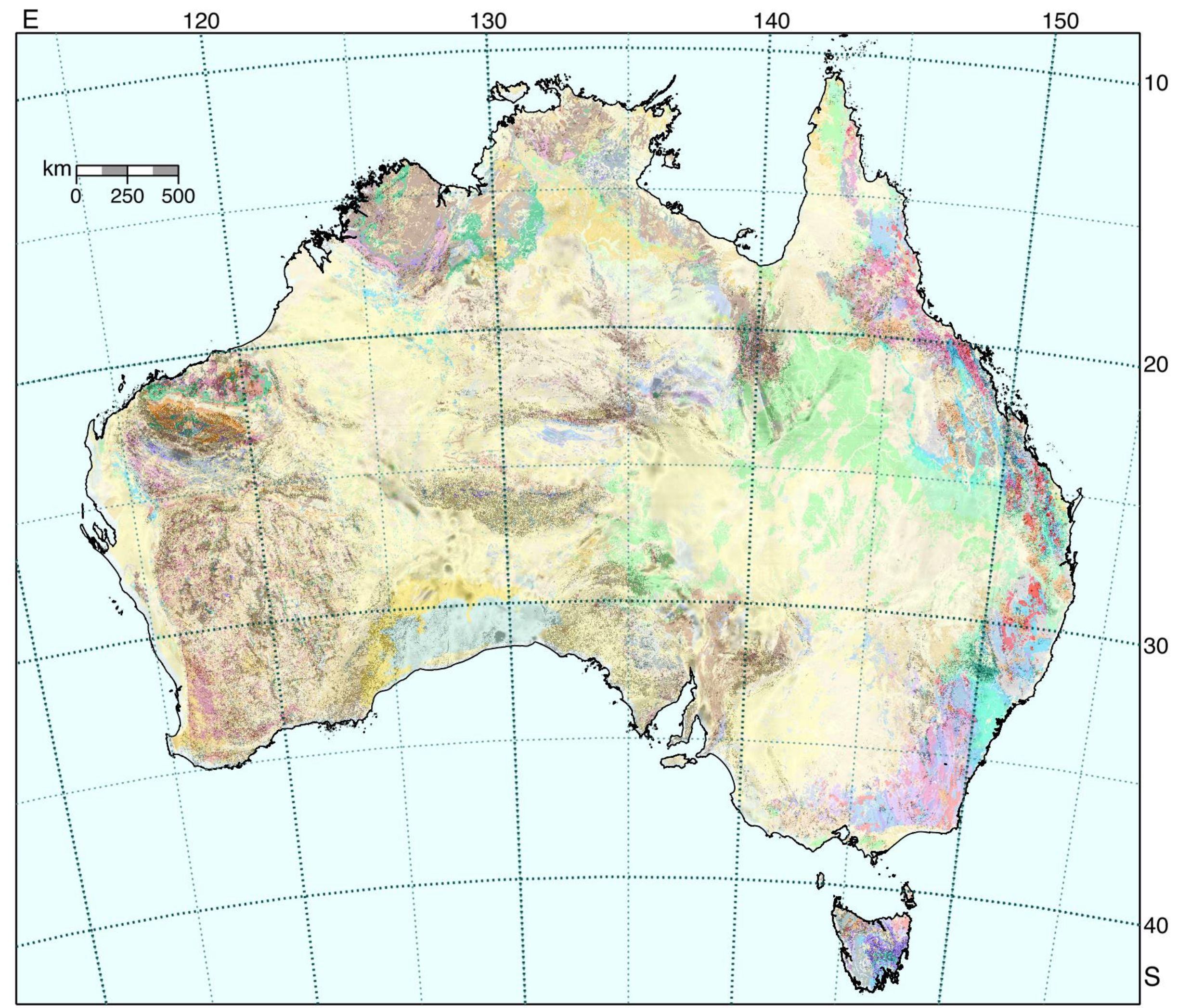

Figure 4.12: Surface geology draped over half-vertical derivative of magnetic field. 
Another useful way of looking at the variations in the magnetic field is through the spatial integral of the total magnetic intensity. This integral is displayed in Figure 4.13, with the geological provinces superimposed.

A merit of the use of the spatial integral is that the dependence of the field on anomalies is more similar to that for gravity, with influence from greater depth than in the magnetic field itself. This means that the use of this ancillary field can aid in interpretation of structures at depth.

Because of the enhanced response from deeper features, the blanketing effect of sedimentary cover is less pronounced than for the magnetic field itself. Indeed, we see in Figure 4.13 clear substructure in the Canning and Eromanga basins that is not evident in even the enhanced field in Figure 4.9.

An interesting feature of the spatial integral is the rather clear separation between positive and negative values along a line oriented roughly northwest-southeast extending from the eastern edge of the Pilbara Craton past the Rudall Province, south of the Musgrave Block and then linking to the north of the Murray Basin.

Certain areas of common properties are also more easily recognised in the spatial integral than in the upward continuation shown in Figure 4.10. In particular, the concentrated positive feature to the east of the Bowen Basin, and the weaker signal from the Sydney Basin.

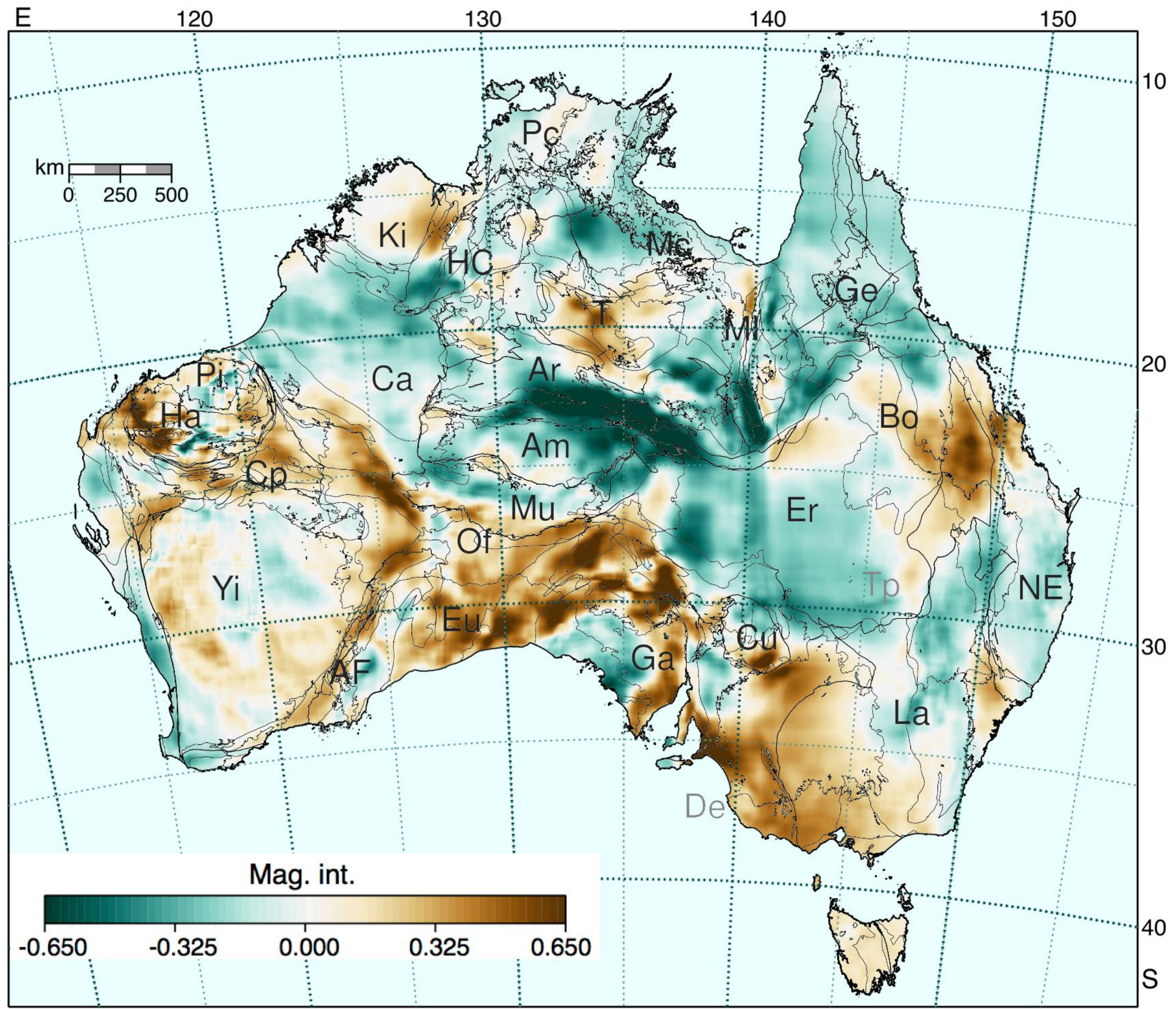

Figure 4.13: Spatial integral of the magnetic intensity with geological provinces. 


\subsection{Character of Magnetisation}

As a consequence of the increase of temperatures with increasing depth, eventually any magnetic mineral will cease to be ferri- or ferro-magnetic since they have passed their Curie point. The depth at which this occurs is termed the Curie depth, and depends on the Curie points of the individual minerals in the assemblage.

The local Curie depth thus reflects both the thermal regime and the mineralogy of the magnetic minerals in the area. Thus, with knowledge of the mineralogy, Curie depth estimates can help constrain the geothermal state away from drill holes and other direct observations. Variations in Curie depth can also provide information on the boundaries between different geological regions. The variations can arise from changes in mineralogy that produce changes in the Curie point and hence Curie depth, or through different geothermal regimes in different geological regions.

Since magnetite is the most magnetic mineral, the Curie depth is often interpreted to reflect the depth to the temperature at which the Curie point of magnetite is reached, approximately $580^{\circ} \mathrm{C}$. However, other mineralogies can affect the appropriate temperature, for instance, the addition of titanium to magnetite greatly reduces the Curie point.

Commonly the depth of the base of magnetisation is taken as a measure of the Curie depth. This basal depth is not an easy quantity to determine, because of the rapid decay of the magnetic response and the intrinsic non-uniqueness of a potential field inversion. All approaches employed for estimating the Curie depth depend to varying degrees on the implicit assumption that long wavelength features result from deep sources. However, such long wavelength features can also result from shallow yet spatially extensive sources, such as volcanic sills.

A particular difficulty comes from adequate specification of the longest wavelength components of the magnetic field. Where data windowing is employed to provide localisation of the results, the window widths should be at least 4-5 times larger than the expected maximum depth of magnetisation. As a result only the broad-scale features across the continent can be extracted. The most difficult zones are those where the geothermal gradient is low and hence temperatures at depth will be relatively cool with a greater depth of magnetisation than in warmer areas.
Chopping and Kennett (2015) have used a local one-dimensional, fractal model of magnetisation, as a representation of the magnetic source. This model provides an analytic representation of the power spectrum without any explicit assumptions about the magnetic susceptibility. With the aid of a hierarchical approach, they have been able to extract stable representation of the longest wavelength features for each window scale, and a measure of the uncertainty of the 1-D power spectra (see Appendix). The stabilised magnetic anomaly data are used in $400 \mathrm{~km} \times 400 \mathrm{~km}$ tiles, with the window centre moved by $60 \mathrm{~km}$ for successive windows. This approach yields 3600 windows across the continent, and in each a 1-D spectrum is extracted that can be compared with the forward model.

The inversion for the depth of base of magnetisation and fractal character for each window was undertaken with a uniform contracting grid search in a twostage process. An initial reconnaissance search was performed over a broad domain to define limits that are then used for a finer search. This style of inversion produces an ensemble of tens of millions of models for each window, so that it is possible to characterise both a suitable model and its uncertainty. The ensemble averages used were weighted towards models that provide a better fit to data, but exploit all models that can adequately explain the observed data.

The results from the individual tiles are then collated and interpolated to produce a final map of the depth of the base of magnetisation (Figure 4.14) and its uncertainty across the continent (Figure 4.15). The weighting used in the ensemble estimates will tend to produce a slightly deeper depth of magnetisation than simple choice of the individual best fitting model for each window. The uncertainty measure mapped in Figure 4.15 is the standard deviation of the results after the weighting of all models in the inversion ensemble for each window. We include the outlines of the geological provinces on both Figures 4.14 and 4.15 , so that the major features can be recognised. The correspondence of the changes in Curie depth with geological structures is often quite close. However, it must be remembered that the intrinsic resolution of these maps can be no better than $60 \mathrm{~km}$, which is the incremental distance between window boundaries.

The depth to the base of magnetisation ranges from $10-12 \mathrm{~km}$ beneath the Cooper Basin to as deep as $80 \mathrm{~km}$ beneath the Yilgarn Craton and other areas of Australia. The uncertainty estimated from the inversion procedure, is $7-10 \mathrm{~km}$, for most of Australia, so minor variations should be treated with caution. 


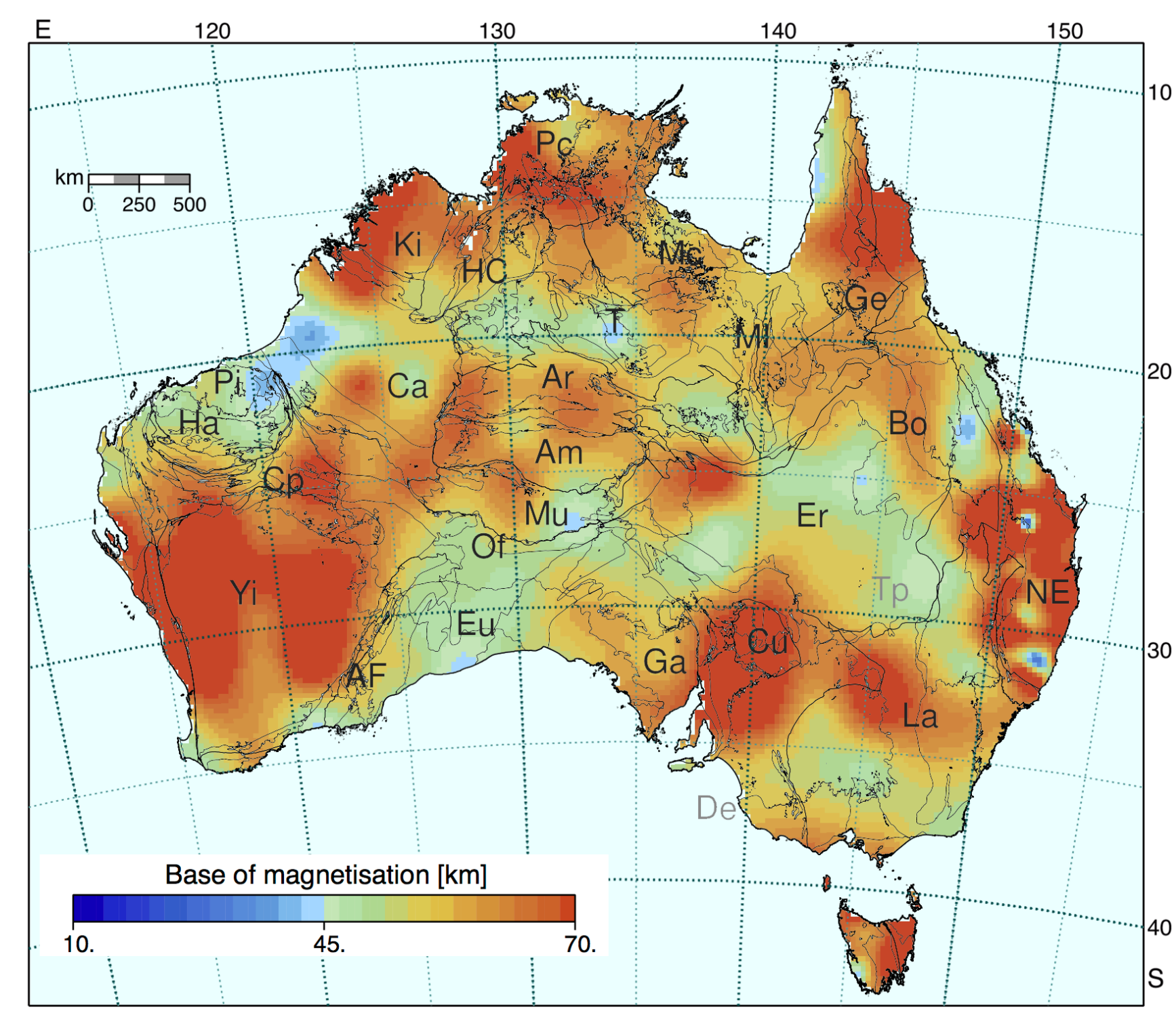

Figure 4.14: Depth to base of magnetisation with geological provinces.

In general, the Archean regions and many Proterozoic cratons show the largest depth to the base of magnetisation in the range $55-70 \mathrm{~km}$. These results suggest that the base of magnetisation is an effective proxy for the Curie depth in these long-lived cratons with relatively low geothermal gradients.

However, the Pilbara Craton has a much shallower depth to the base of magnetisation than other cratons, at 20-30 km compared with up to $80 \mathrm{~km}$ depth in the Yilgarn to the south. The very strong magnetic response of the Hamersley Basin, with extensive iron ore deposits, may well mask a more subtle signal from the deepest magnetic sources. The strong magnetic intensity gradients also contribute to the uncertainty in the depth estimate.

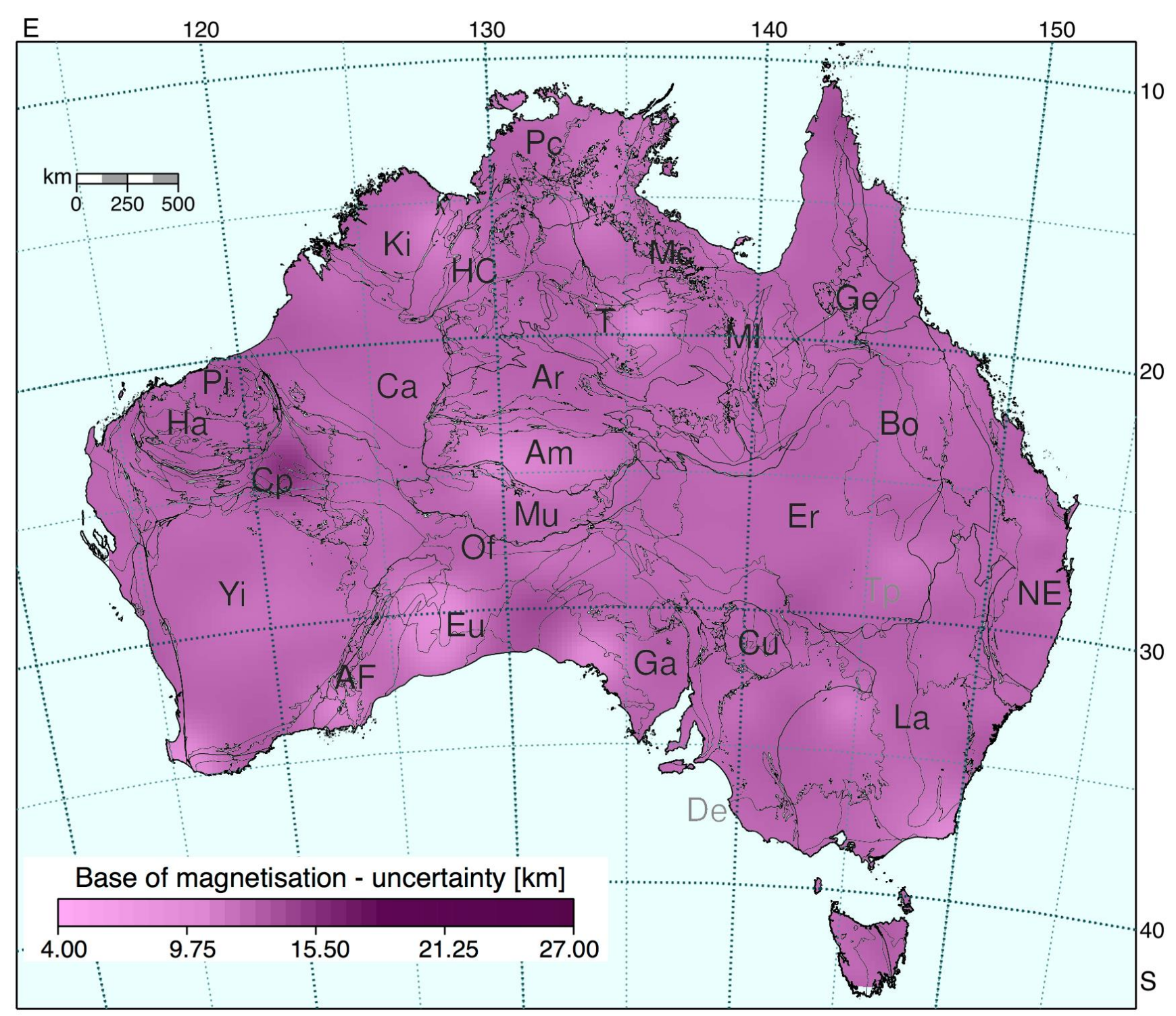

Figure 4.15: Uncertainty in estimate of depth to base of magnetisation.

The deep base of magnetisation results that characterises the Yilgarn Craton extends to the northeast, linking to the Proterozoic Musgrave, Arunta and Warumpi provinces of the southern Northern Territory. Within the Yilgarn Craton, a zone of slightly shallower depths runs north-south in the central zone. The southern and eastern margins of the Yilgarn Craton with the Albany-Fraser Orogen are well defined by a contrast in depth to base of magnetisation.

Large depths for the base of magnetisation also characterise the region around the Curnamona Province. In contrast, the Gawler Province of the South Australian Craton, to the west of the Curnamona Province, is characterised by only moderate $(40 \mathrm{~km})$ depths to the base of magnetisation, which are restricted to the known outcrop of the core of the Gawler Province. 
The shallowest depths to the base of magnetisation are found beneath the Cooper Basin in central Australia. This result is consistent with the drill hole data for this region where high temperatures are encountered at shallow depth (see Chapter 9).

\section{Magnetic Character}

The mode of analysis of the spatial variation of magnetisation adopted by Chopping and Kennett (2015) yields a further useful result, with a continental-scale map of the fractal dimension of the magnetic anomalies that provides a summary of differences in the magnetic character of the crust. This fractal dimension is plotted in Figure 4.16 with, again, the geological provinces superimposed.

Low fractal dimension implies a strongly disordered state, whereas high fractal dimension would be associated with spatially coherent behaviour. Thus, as might be expected, the fractal dimension is quite high in the sedimentary basins of eastern central Australia, notably the Eromanga Basin, but with spatial variations that reflect the complex superposition of sedimentary sequences in these areas. A substantial component of the North Australian Craton exhibits high fractal dimension, providing a differentiation between the north part and the southern margin in the Arunta Province. The feature associated with the Mt Isa Province appears to link to the northwest under the Macarthur Basin.

Both the Pilbara and Yilgarn cratons display relatively low fractal dimension. It is interesting to note that the low fractal dimension also extends into the AlbanyFraser Orogen and the western Eucla Basin, transcending the change in depth to base of magnetisation that is so evident in Figure 4.14. The change in nature across the Nullarbor Plain appears to correlate with the prominent north-south magnetic anomaly at about $127^{\circ} \mathrm{E}$ associated with the Munderabilla shear zone (Figures 4.7 and 4.9). A broad block of lowered fractal dimension to the east links through the Officer Basin into the Musgrave and Amadeus provinces. However, the Gawler Craton and the Curnamona Craton remain distinct.

In the east, the patterns are more complex with an apparent distinction between the Lachlan and the Thomson orogens, and an even stronger contrast between the Lachlan and New England orogens. It should however be noted that local resolution issues may affect the results in New England and Tasmania, where spectral uncertainty is enhanced by the lack of neighbouring windows.

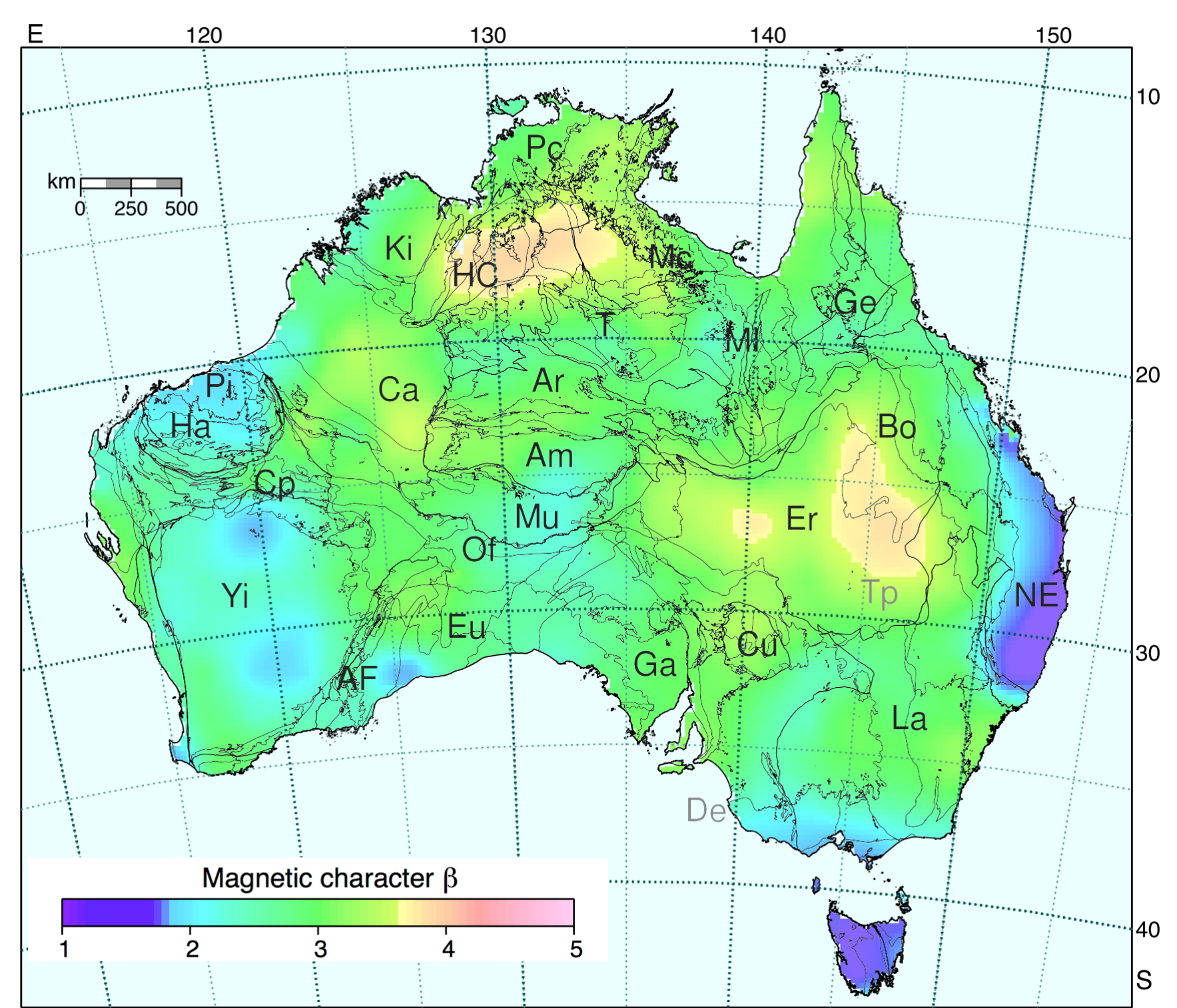

Figure 4.16: Magnetic character via fractal dimension of magnetisation. 


\section{Gravity}

Gravity data map subtle changes in the Earth's gravitational field caused by variations in the density of the underlying materials. Deep-seated variations in mass distribution affect the broad-scale variations in gravity, and are reflected in the shape of the geoid.

\subsection{Geoid Variations}

A geoid is a three-dimensional surface of equal gravitational potential which is perpendicular to the direction of the gravity vector at all points. The term 'geoid' is generally used to describe that equipotential surface which best corresponds with mean sea level. Since the mass distribution of the Earth is not uniform, the direction of the gravity acceleration changes accordingly. In consequence, the resultant shape of the geoid is irregular (Figure 5.1), with noticeable variations to the north of Australia associated with subduction beneath the western Pacific and Indonesia. The net effect is a significant gradient in the equipotential surface across the Australian continent.

The equipotential surface is also affected by the variations in the density of seawater between the tropics and lower latitudes. The difference amounts to approximately one metre between the warmer, and hence less dense, water off the coast of northern Australia and the cooler, denser water off the coast of southern Australia. The result is that mean sea level, determined from 32 tide gauges around the Australian coasts and its extrapolation onshore (the Australian Height Datum, or AHD), lies about $0.5 \mathrm{~m}$ above the geoid in northern Australia and about $0.5 \mathrm{~m}$ below in southern Australia.

Heights obtained from Global Navigation Satellite System (GNSS) receivers are referenced to a simplified mathematical representation of the Earth in the form of an ellipsoid. Such ellipsoidal heights differ from heights relative to the geoid/AHD by between $-30 \mathrm{~m}$ and $+70 \mathrm{~m}$ across Australia as a consequence of the geoid variations illustrated in Figure 5.1. The difference can be compensated by applying a geographically varying correction, as shown in Figure 5.2, which varies from a positive correction of $33 \mathrm{~m}$ in southwestern Australia to a negative correction of up to $72 \mathrm{~m}$ in northeast Australia.

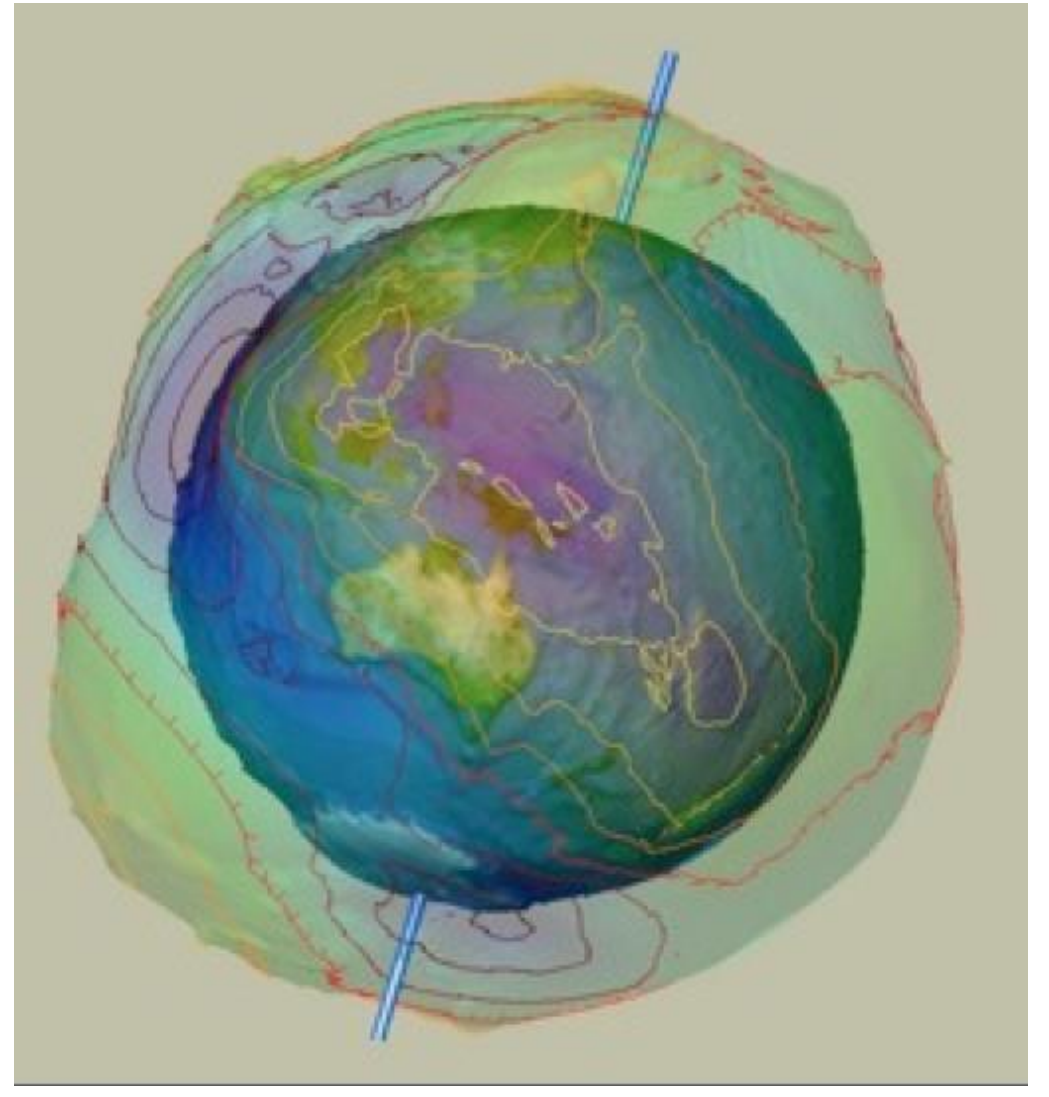

Figure 5.1: Representation of the geoid surface in the Australian region with strong exaggeration of the deviations from an ellipsoid (courtesy of M. Sandiford).

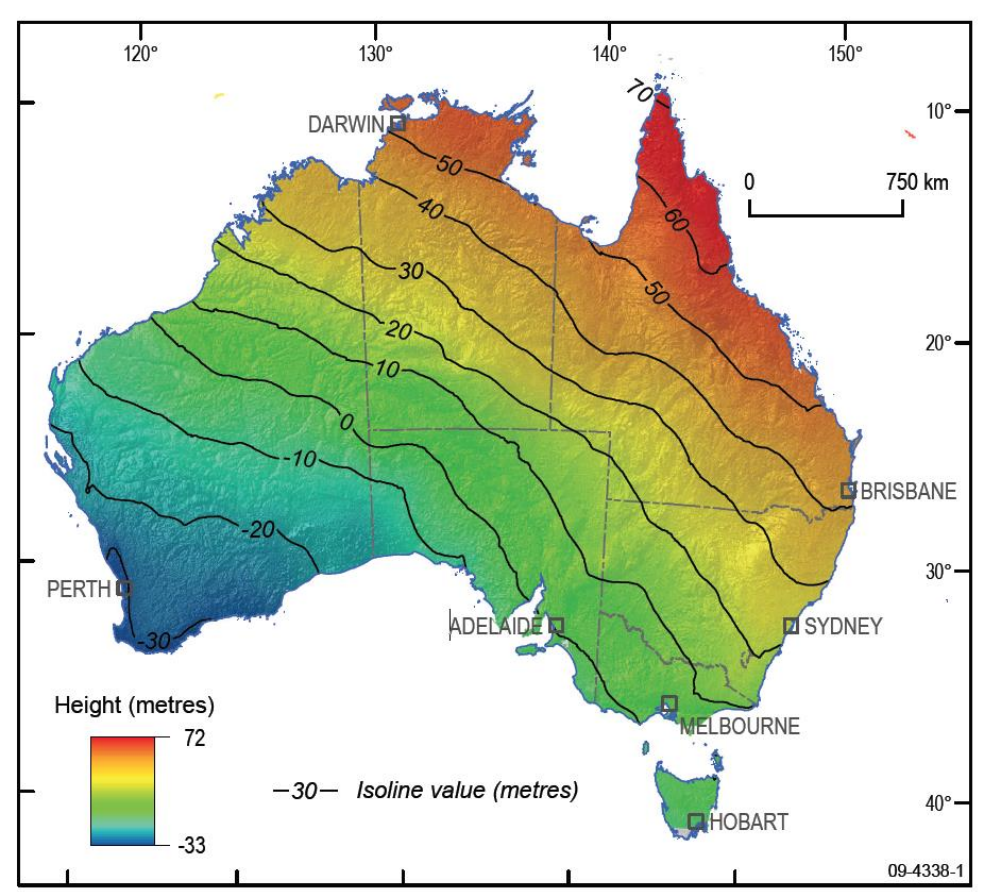

Figure 5.2: Corrections to height determined from GNSS receivers to correspond to the Australian Height Datum (AHD). In southwest Australia, the AHD is up to $33 \mathrm{~m}$ below the ellipsoid and in northeast Australia the AHD is up to $72 \mathrm{~m}$ above the ellipsoid. 


\subsection{Absolute Gravity}

A consequence of the shape of the Earth as an oblate spheroid is that there is a significant variation in the absolute gravitational acceleration at the Earth's surface between $9.780 \mathrm{~m} / \mathrm{s}^{2}$ in northern Australia and $9.805 \mathrm{~m} / \mathrm{s}^{2}$ in southernmost Tasmania (Figure 5.3). The presence of density variations in the subsurface introduces perturbations in the smooth variation of gravity with latitude.

Some features, such as the anomalies in central Australia and those associated with the Eastern Highlands, are large enough to be clearly visible in the pattern of variation of absolute gravitational acceleration across the continent (Hirt et al., 2013) as shown in Figure 5.3.

This high-resolution estimate of the absolute gravity variation across the continent is based primarily on satellite information on gravitational variation, supplemented by results from NASA's Shuttle Radar Topography Mission. The influence of specific geological provinces becomes even more apparent when we superimpose the pattern of geological provinces as in Figure 5.4. Further, a number of the major crustal boundaries are linked to strong gravitational contrasts, as in the contact of the AlbanyFraser Orogen with the Yilgarn Craton (see Figure 5.5).

Figure 5.3: Variation in the absolute (free-fall) acceleration due to gravity across the Australian continent [units $\mathrm{m} / \mathrm{s}^{2}$ ], based on the GGMplus model of Hirt et al. (2013).

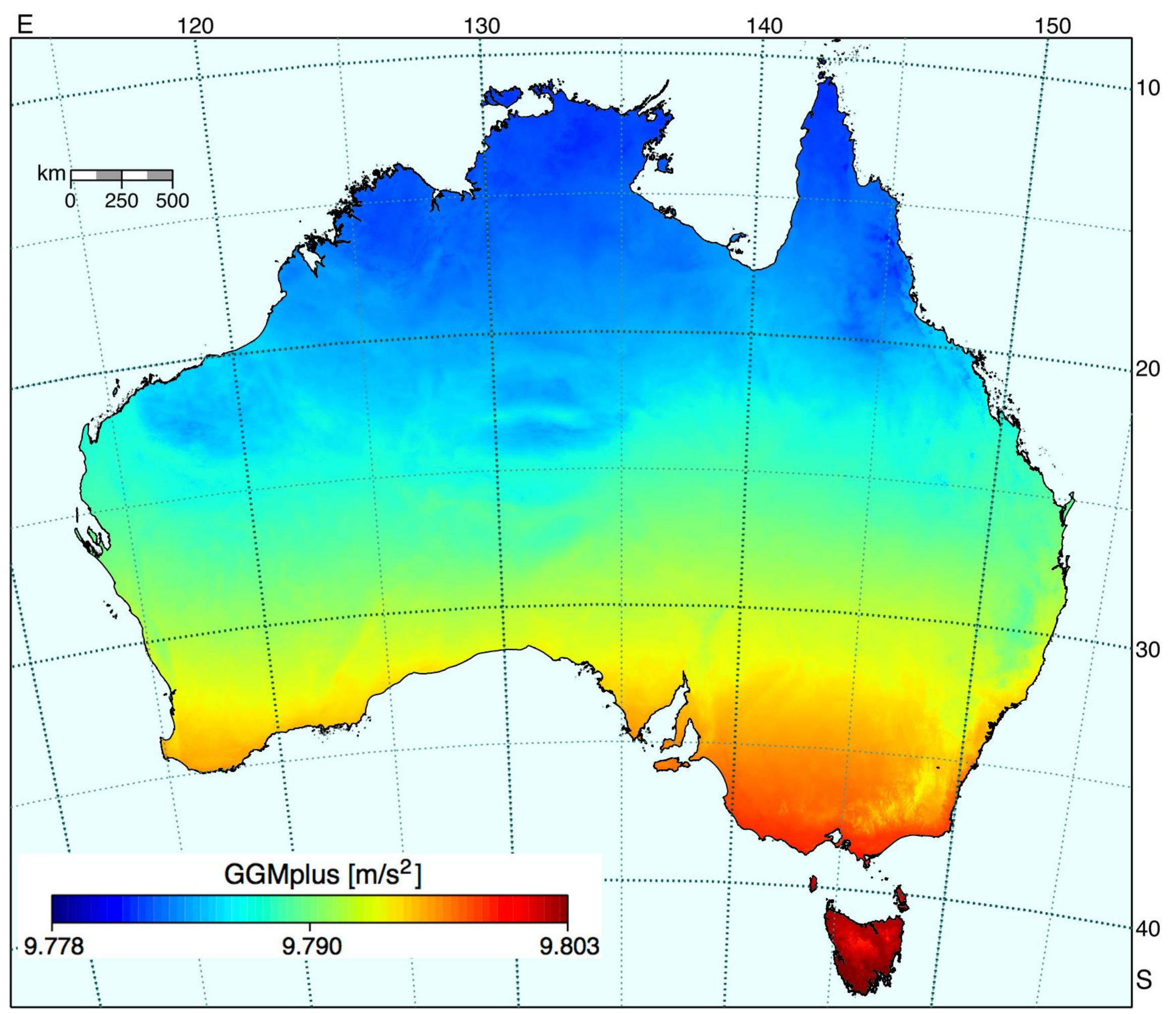




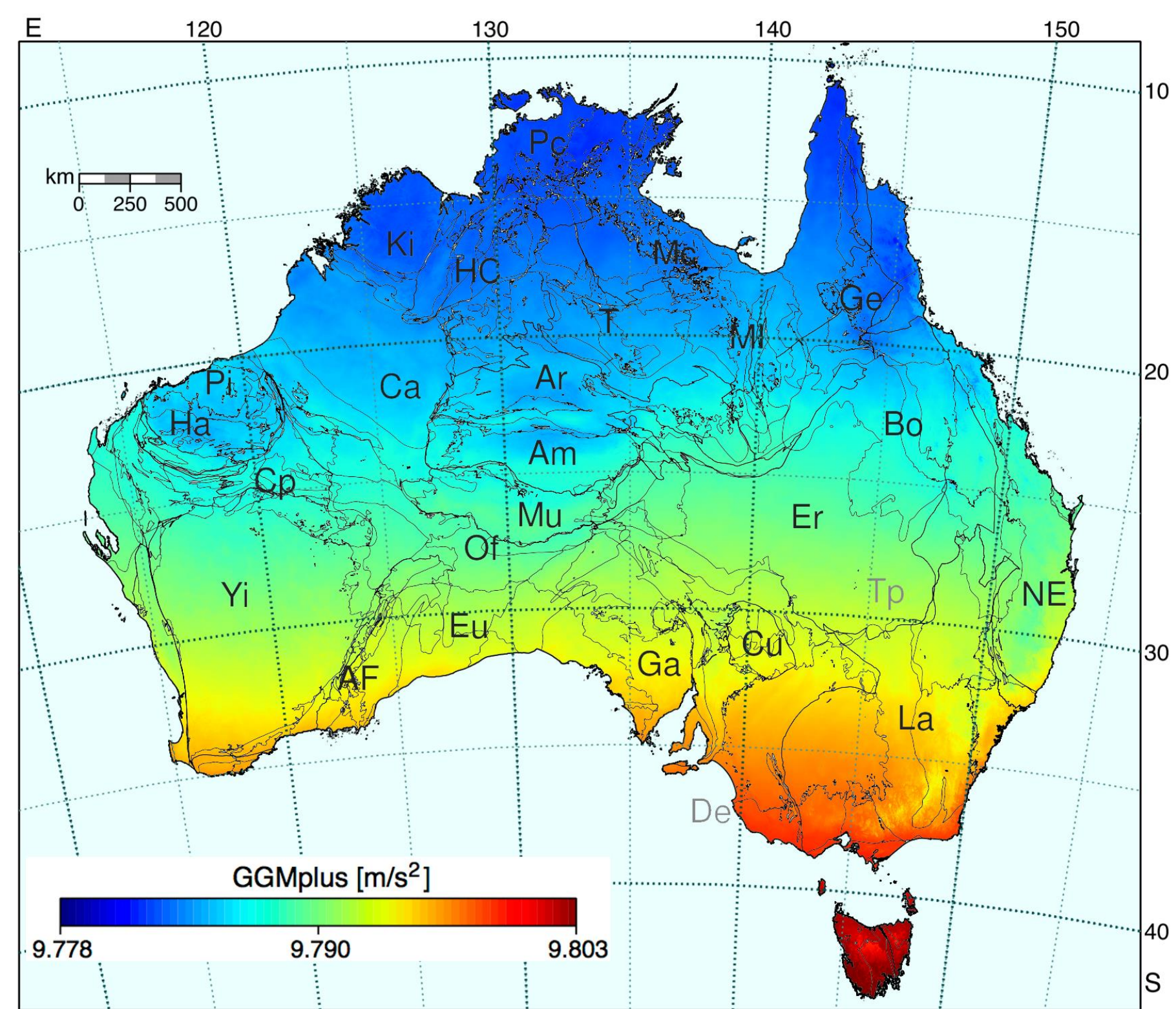

Figure 5.4: Absolute gravity distribution with geological provinces.

In order to isolate the contributions to the gravity field due to structure at depth within the Earth, the large-scale variations in gravitational acceleration so clearly displayed in Figures 5.3-5.5 have to be removed. The reference gravitational acceleration, at a given latitude, is determined from a standard gravity formula based on the configuration of a rotating oblate spheroid, which produces a smooth progression in latitude.

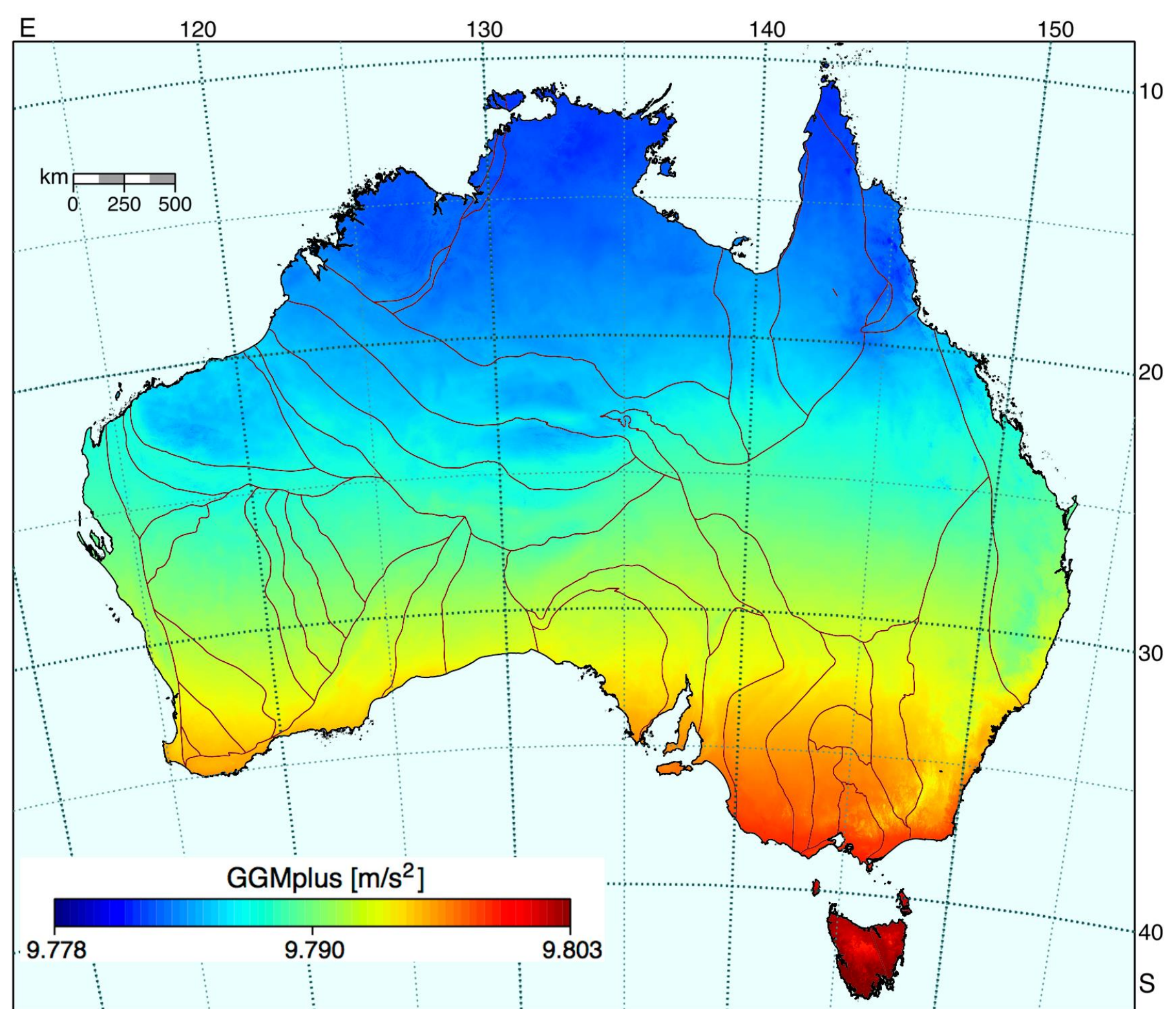

Figure 5.5: Absolute gravity distribution with major crustal boundaries.

When the reference gravity field is removed, we are left with gravitational anomalies that link to the presence of topography, as in the eastern Highlands, or to variations in density structure at depth, as in the strong variations in Central Australia and the arcuate southern boundary of the Hamersley Basin. 


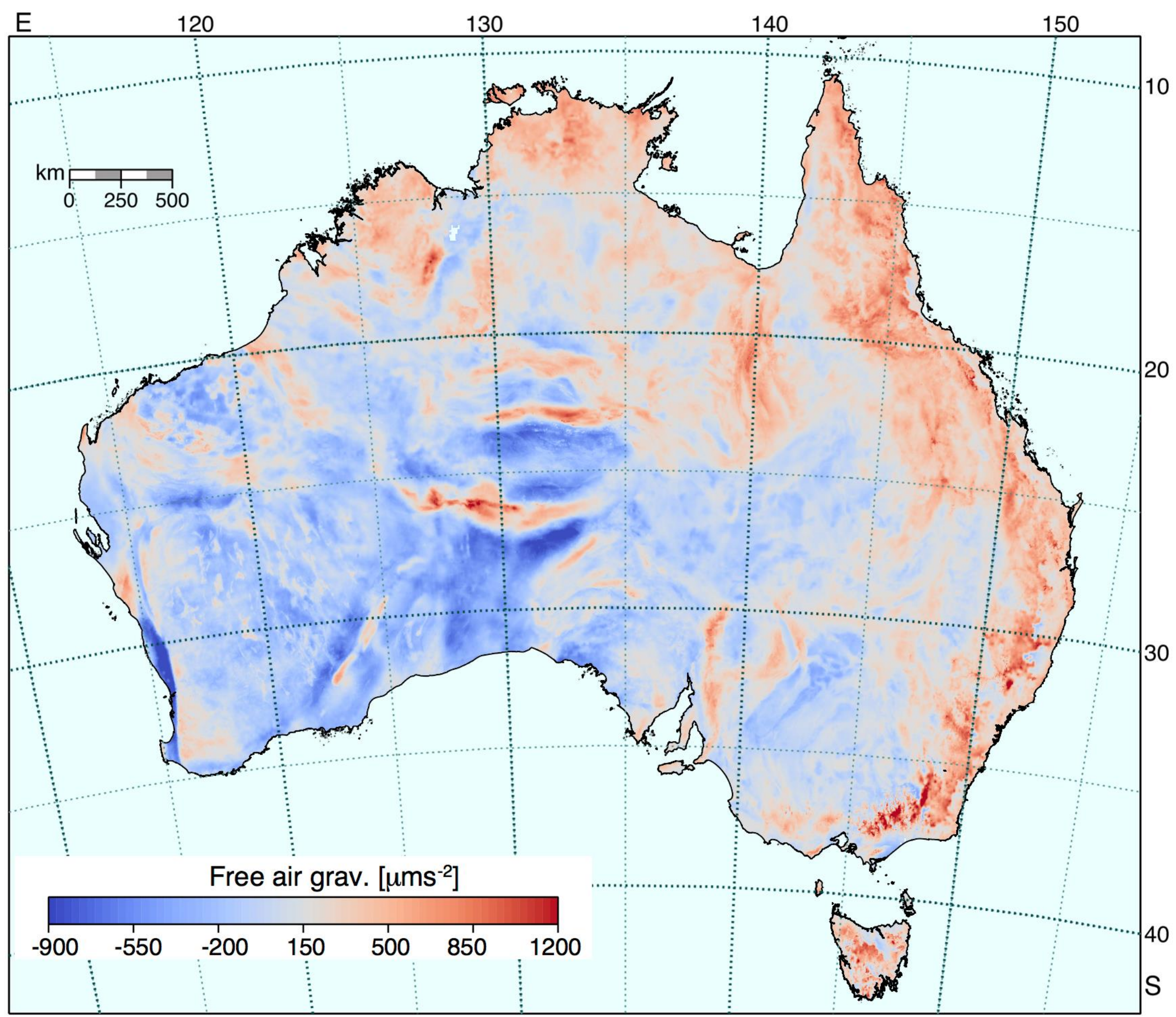

Figure 5.6: Free-air gravity anomaly.

\subsection{Gravity Variations}

Most terrestrial measurements of the gravity field represent relative variations from a base station that is regularly revisited in the course of a survey. The recent development of portable instruments that measure the absolute value of gravitational acceleration provides the means of improved ties between different surveys, but still only a limited number of absolute reference points have been established across the Australian continent.

In contrast to magnetic data, gravity measurements are made at the Earth's surface and are affected by the variations in topography around the observation point. Continental Australia has a basic gravity station spacing coverage of $11 \mathrm{~km}$, with South Australia, Tasmania and part of New South Wales covered at a spacing of $7 \mathrm{~km}$. Victoria has station coverage of approximately $1.5 \mathrm{~km}$. Over the last 10 years, the Australian, State and Northern Territory governments have funded exploration initiatives for the systematic infill of the continent at a grid spacing of $2 \mathrm{~km}, 2.5 \mathrm{~km}$ or $4 \mathrm{~km}$, to provide improved coverage in areas which are of scientific or economic interest.

Although the spatial resolution of the gravity data at the continental scale is much coarser than that from aeromagnetic data in most areas, the nature of the dependence of the gravity field on density means that gravity data has a stronger sensitivity to anomalies at depth than magnetic data.

Because the gravitational acceleration reduces with height, compensation needs to be made for the elevation difference between the observation point and the spheroid. 
The simplest procedure for gravitational corrections is to allow for the decrease in gravity with height as if there was only air between the observation point and sea level. This free-air anomaly represents the difference between the observed value and the reference field with correction for the elevation. A further correction that is often applied is the Bouguer correction, which makes an allowance for the gravitational attraction of the rocks lying between the point at which the measurement is taken and sea level. A full correction depends on the local density beneath the observation point, but at the continental scale it is common to take an average crustal value.

On land, the Bouguer anomaly represents the influence of the gravitational attraction of the material lying below sea level, and can be related directly to free-air anomalies at sea which use the same sealevel datum. However, the linkage of the two classes of anomaly needs to be conducted carefully because of the influence of zones of shallow water on the continental shelf.

The free-air gravity anomaly across the Australian continent is illustrated in Figure 5.6, exploiting over 1.7 million onshore gravity stations, and the corresponding Bouguer anomaly is shown in Figure 5.7. The relatively subdued topography of the Australian continent means that the pattern of anomalies is similar for both free-air and Bouguer. The full gravity field clearly displays the contrasts associated with the various cratonic elements with the presence of notable substructure. The western portion of the continent has pronounced negative gravity anomalies associated with the deep and buoyant cratonic roots in the mantle. There is a north-south band of positive anomalies near $140^{\circ} \mathrm{E}$, and a zone of weak positive anomalies towards the eastern seaboard.

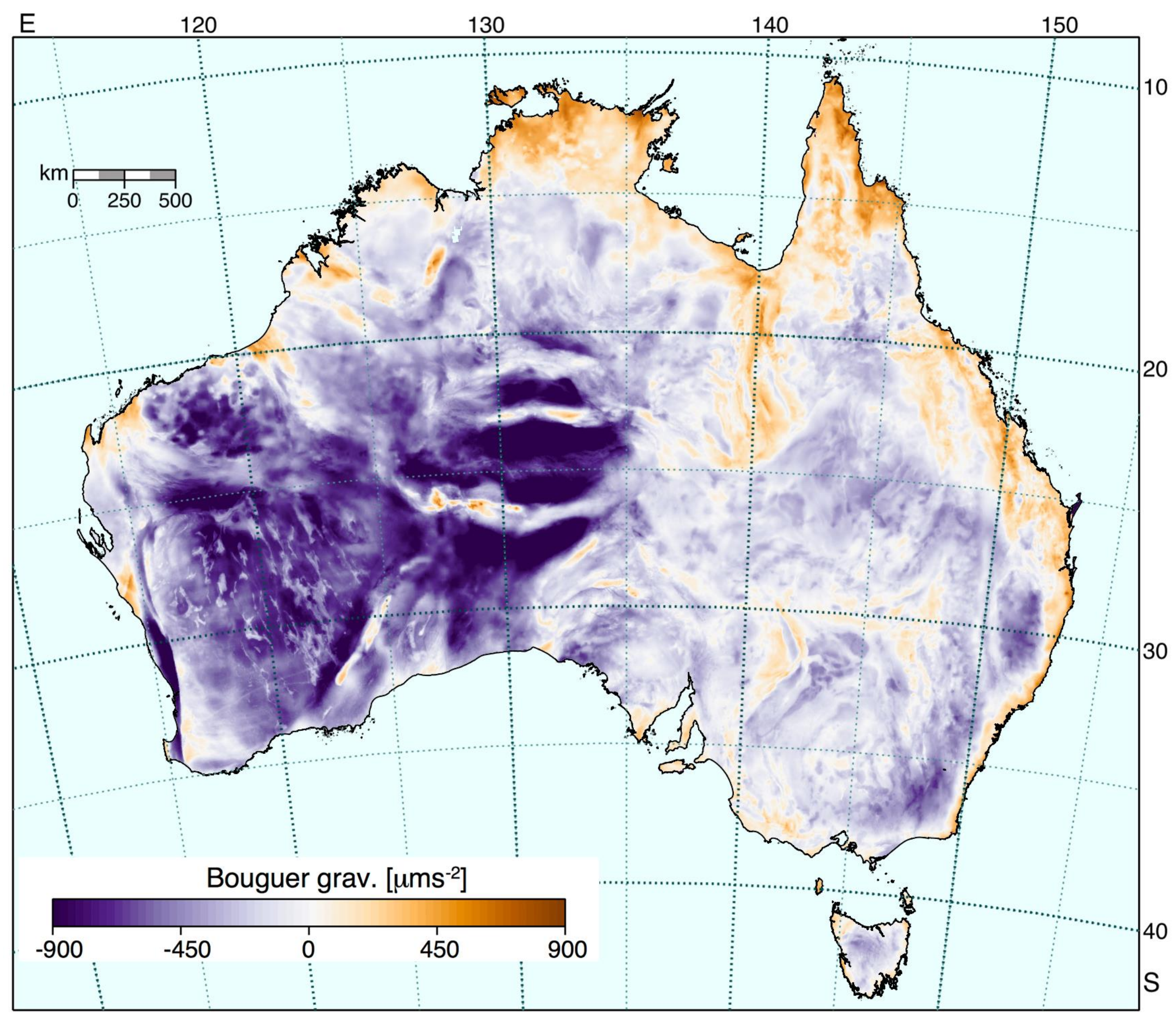

Figure 5.7: Bouguer gravity anomaly. 
In Figure 5.8 we superimpose the boundaries of the geological provinces on the Bouguer anomaly pattern, and in Figure 5.9 we show the major crustal boundaries of Korsch and Doublier (2016), so that the relations between the gravity field and the major geological structures are more clearly displayed. In particular, we note that many of the major features are outlined by gravity anomalies, e.g. the strong negative in the Albany-Fraser Orogen on the southeastern side of the Yilgarn Craton.

The group of alternating bands of east-west trending low and high gravity anomalies in central Australia dominate the gravity images, and are associated with substantial localised changes in crustal thickness in the zone affected by the Petermann and Alice Springs orogenies. These variations in the depth to the Moho have been directly imaged using full crustal seismic reflection (see Chapter 7), and involve offsets of $15 \mathrm{~km}$ or more on the Moho. In places, dense lower crustal and upper mantle material has been brought close to the surface.

Similar, but weaker, bands of alternating northsouth trending gravity anomalies in eastern Australia are interpreted to be associated with a series of island arcs and a succession of accretion events onto the evolving eastern margin of the continent.

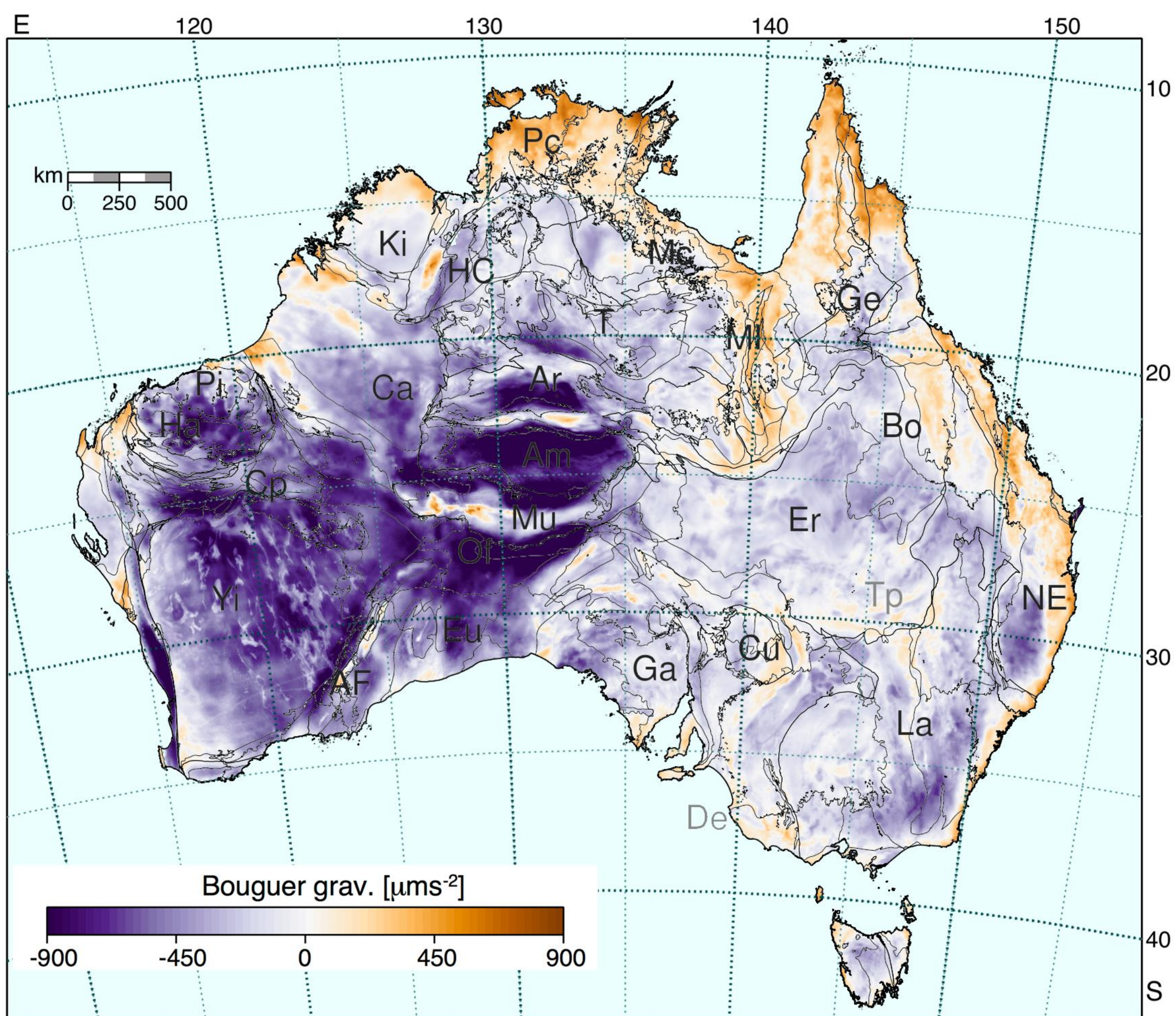

Figure 5.8: Bouguer gravity anomaly with geological provinces. 
The major mineral province around Mt Isa has strong positive gravity anomalies which trend north-south, a tectonic grain imparted during the Mesoproterozoic. These gravity anomalies associated with the Mt Isa Province extend south of the region of outcrop. The positive anomalies are sharply truncated in the south, resulting in a strong gravity gradient that most likely formed during the latest Proterozoic break-up of the supercontinent Rodinia, when it would appear that Laurentia (North America) rifted from Australia to form the palaeo-Pacific Ocean.

In the west of Australia, we see contrasting features in the different Archean domains. In the northern part of the Pilbara Craton, the gravity patterns are ovoid to circular, reflecting the presence of granite bodies and greenstone belts that encircle them. In contrast, in the Yilgarn Craton, distinctive elongate features arise from the gravity response to the dense mafic rocks in the nearly north-south oriented greenstone belts and elongate granite batholiths.

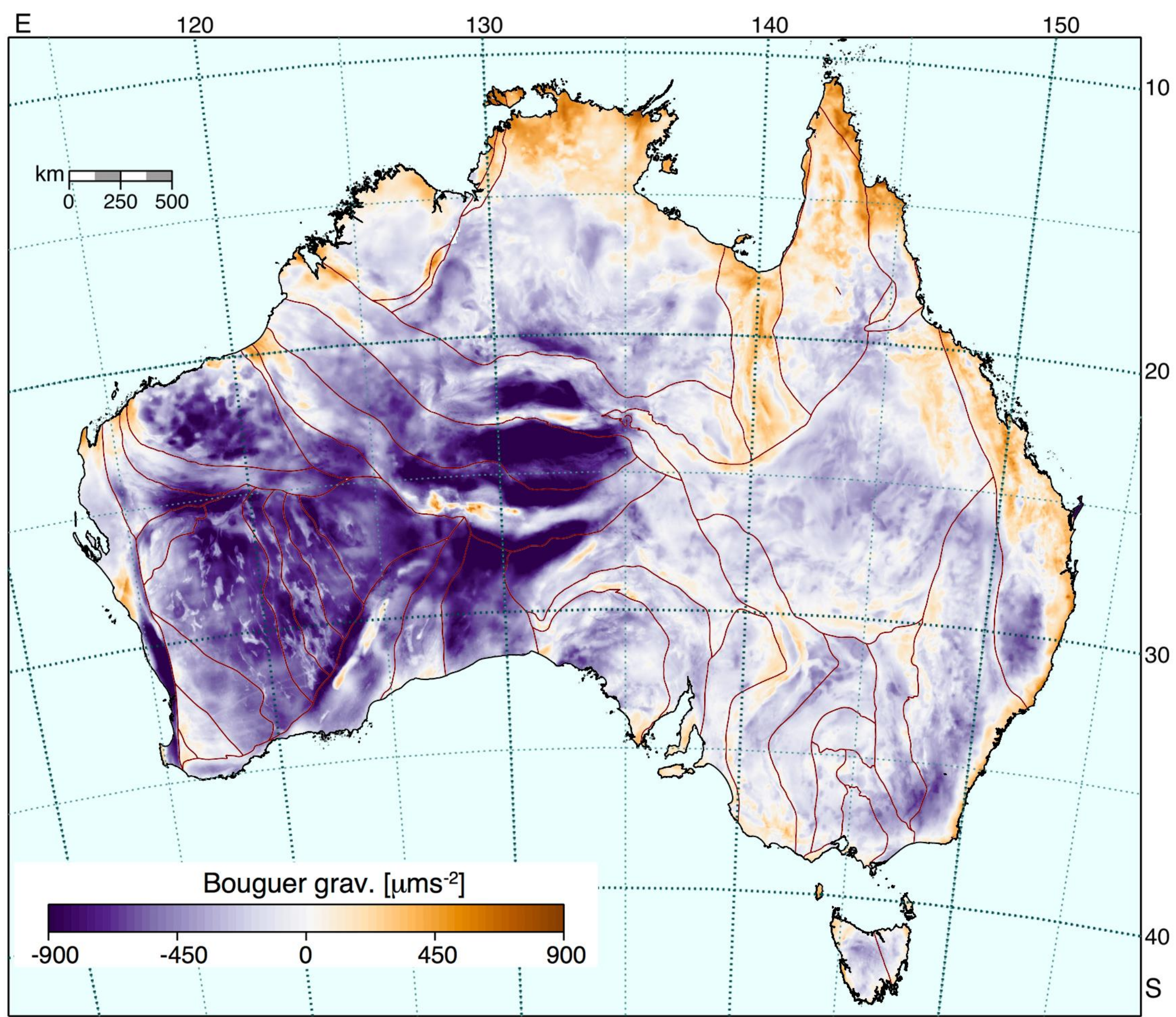

Figure 5.9: Bouguer gravity anomaly with major crustal boundaries. 
Most of the western part of the continent shows a negative gravity anomaly and this feature dominates the continental pattern. When attention needs to be drawn to localised anomalies, it is convenient to remove this long-wavelength background, e.g. by spectral filtering as in Figure 5.10, where all wavelengths longer than $250 \mathrm{~km}$ are removed.

This procedure reveals more detail in the variation of gravity, and accentuates the localised strong features in central Australia. We also see that the edge feature associated with the Albany-Fraser Orogen is in fact a gravity doublet, with a prominent negative trough adjacent to a prominent high. Similar prominent edge structures can be seen at the western edge of the Yilgarn Craton across the Darling Fault into the Pinjarra Orogen, and at the western edge of the Gawler Craton.

The filtered image also emphasises large-scale but narrow features, such as the significant northward extension of the Munderabilla fault zone from the south coast near $127^{\circ} \mathrm{E}$. This continental-scale feature appears to cut across a number of prominent features including the link from the Musgrave Province into the Rudall-Paterson zone on the eastern edge of the Pilbara Craton.

In the east, the complex pattern of the New England Orogen from $25^{\circ} \mathrm{S}$ to $33^{\circ} \mathrm{S}$ becomes more clearly defined. We also see the emergence of distinctive structures beneath the cover of eastern Australia, in particular those associated with the transition from the Lachlan Orogen to the Thomson Orogen.

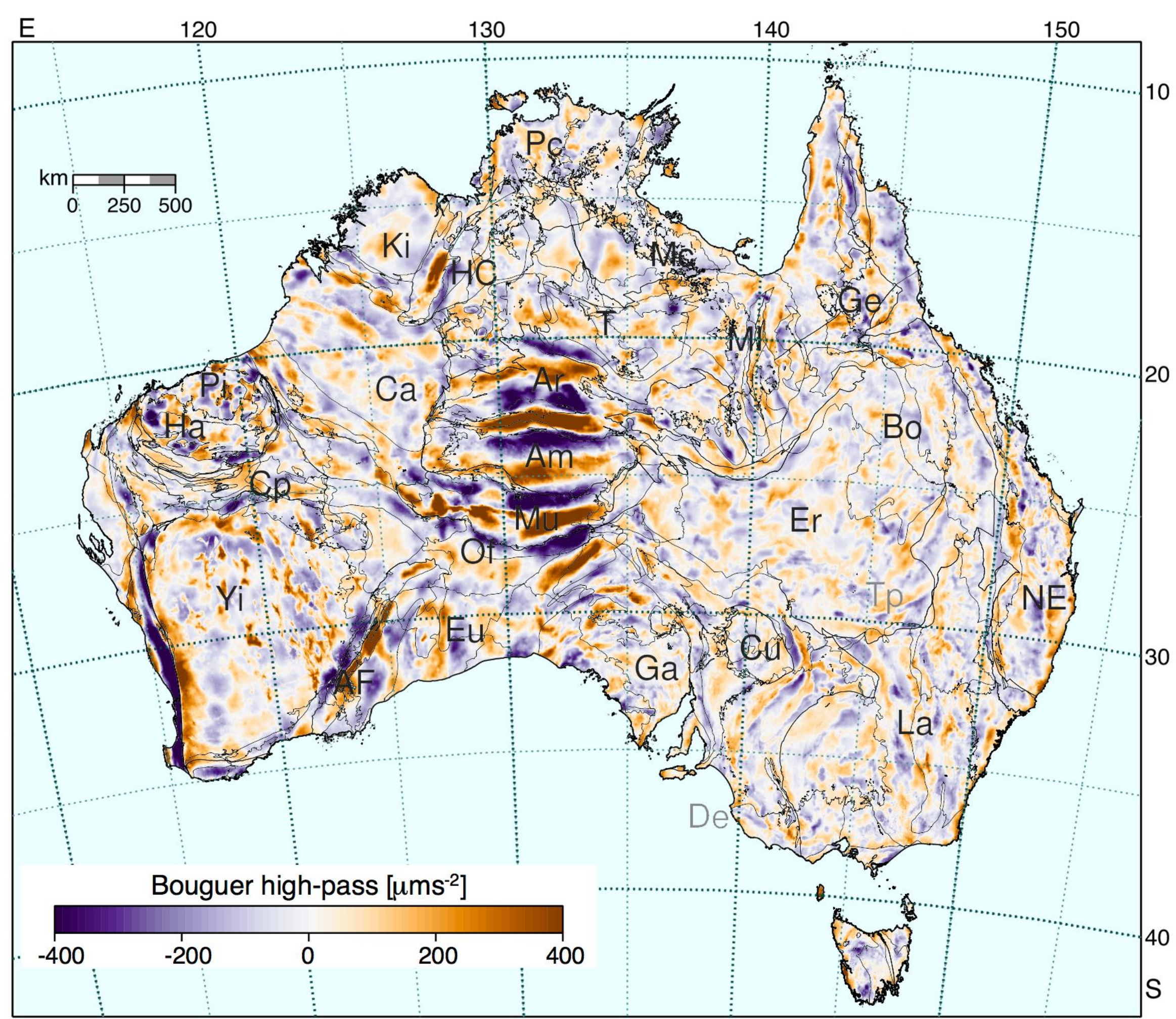

Figure 5.10: Bouguer gravity anomalies after application of a spectral filter to remove spatial wavelengths longer than $250 \mathrm{~km}$. 


\section{Earthquakes and Stress Field}

Although a few seismological observatories were established in Australia early in the 20th century, the development of an extensive national seismological network came rather late. The current network was substantially enhanced by investment following the Sumatra-Andaman Mw 9.3 earthquake on 2004 December 26, and resultant destructive tsunami. A major goal in the improved network was early identification of tsunamigenic potential, particularly in the Indian Ocean and events in the subduction zones to the north and east of Australia.

Data from all the stations in the national network are transmitted to Geoscience Australia in Canberra, where continuous monitoring and analysis is undertaken for event location and character. The national facilities include three medium aperture arrays: WRA and ASAR in the Northern Territory, and PSAR in the Pilbara region of northwestern Australia. WRA and ASAR are primary seismological stations in the monitoring network established under the 1996 Comprehensive Nuclear-Test-Ban Treaty. The broadband array PSAR, was established as a major component of the tsunami warning system.

As a result of investment through the AuScope infrastructure program since 2012, a secondary national network has been established exploiting research-grade seismometer systems deployed in schools across the country. Data from this AuSIS network is made available to Geoscience Australia and the international community. Noise levels at these stations tend to be rather higher than in the vault instruments in the national network, but still provide useful additional geographic coverage and have often been used in improving the locations of recent events.

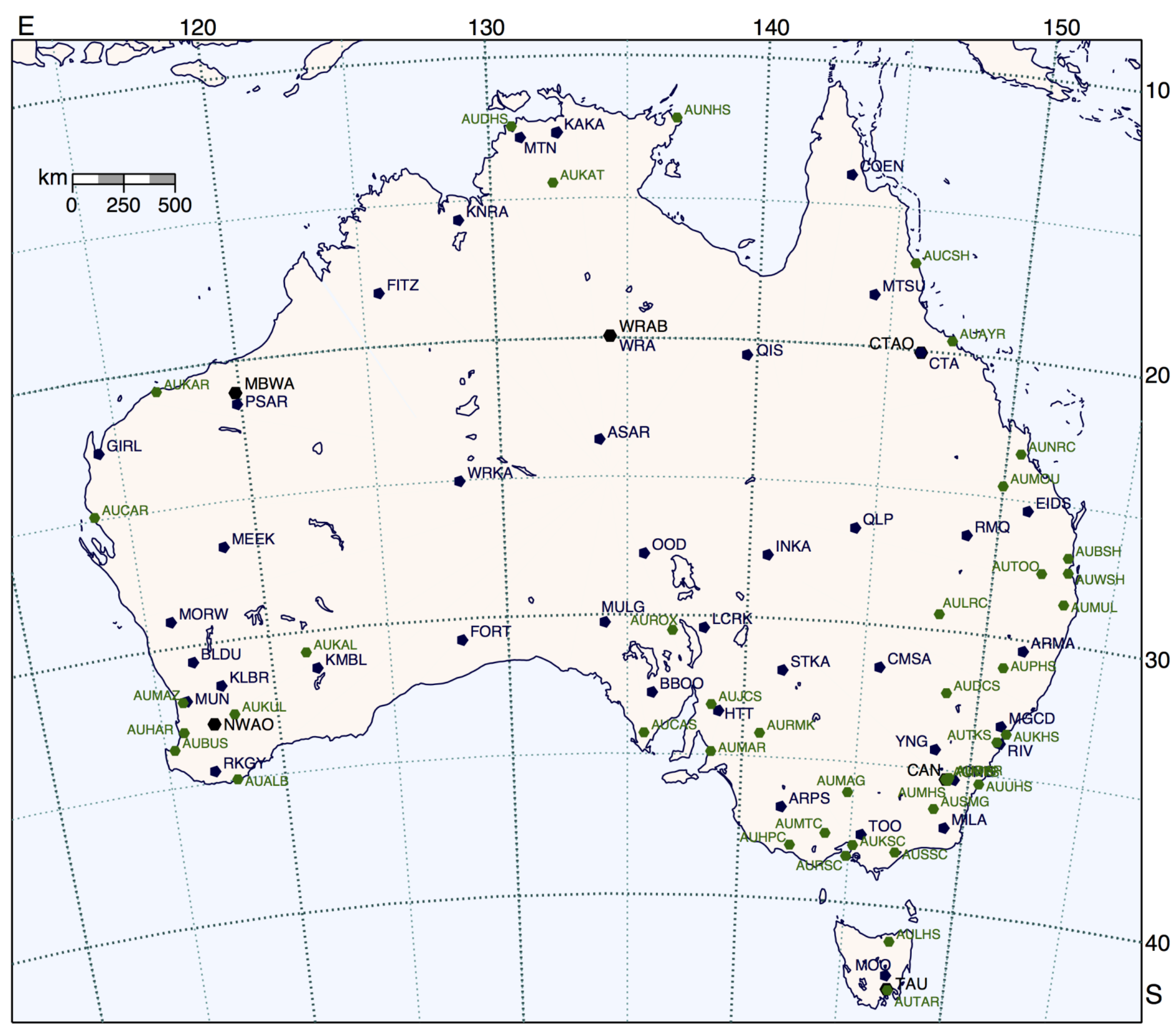

Figure 6.1: Seismological stations in the Australian network and international networks hosted in Australia (shown in black). Stations in the Australian Seismometers in Schools network (AuSIS) have the prefix $\mathrm{AU}$ and are displayed in green. 


\subsection{Earthquake Activity}

With the latest improvements in the national seismological networks, all magnitude 3 events across the continent should be reliably located. However, the coverage is much patchier in the past. From 1920, events above magnitude 6 should be captured, and from 1959 events above magnitude 5. However, the threshold of completeness would have been higher than magnitude 4 well into the 1990s. As a result, the distribution of known events is skewed towards larger magnitude.

Earthquake activity in Australia is widespread (Figure 6.2), though the largest events onshore in the last century have not exceeded magnitude 7 . The largest energy release was the group of three events ( $M w$ 6.2, 6.5 and 6.7) in just 12 hours near Tennant Creek in the Northern Territory $\left(20^{\circ} \mathrm{S}, 135^{\circ} \mathrm{E}\right)$ in January 1988 . The largest of these events was felt from coast to coast as a consequence of the very low attenuation of seismic waves in the cratonic regions.

The pattern of seismicity across the continent indicates concentrations of events in fairly well-defined zones, with some regions having little obvious activity. However, absence of events does not necessarily imply that future earthquakes are not possible. Prior to 1987, the region around Tennant Creek had no known seismicity, but then activity started with two magnitude 5 events culminating in the group of Mw 6 events followed by a long sequence of aftershocks. The return period for intracontinental earthquakes can be very long, e.g. over 10,000 years from trenching evidence at Tennant Creek, and so the historical record needs to be supplemented with information from neotectonic studies

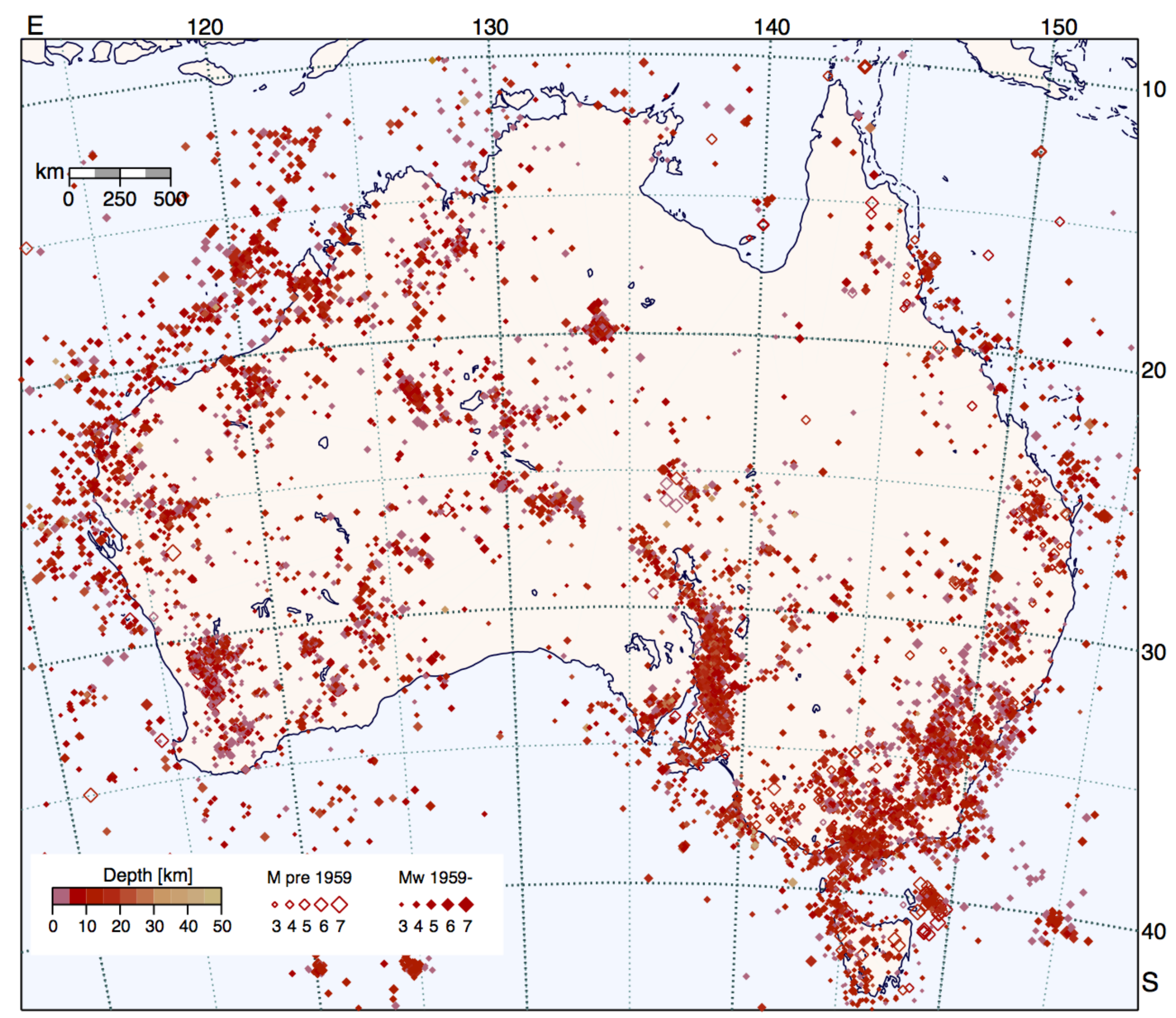

Figure 6.2: Distribution of earthquakes across Australia from historical and instrumental catalogues. The size of the symbols is scaled with magnitude and colour coding indicates depth. The strong subduction zone activity to the north of Australia is largely suppressed to aid clarity. 
Earthquakes in Australia are generally quite shallow. Even the largest events rarely appear to initiate deeper than $12 \mathrm{~km}$ and generally faulting propagates upward towards the surface. Depth control for older events is rather poor because of the sparse national network of the time.

\section{Geographic Distribution of Earthquakes}

The Phanerozoic domains of eastern Australia show a generally diffuse zone of seismicity with some concentration around the Sydney Basin and southern Victoria. Although seismicity in the instrumental period has generally been quite weak in Queensland, a number of larger events have occurred in recent years, with a Mw 5.8 event offshore from Gladstone in August 2016. In the late 19th century there were many events to the east of Flinders Island, north of Tasmania, but little recent activity.

A small cluster of events occurs in the southern Tasman Sea near $40^{\circ} \mathrm{S}, 155^{\circ} \mathrm{E}$, which is close to the location where the projection of the Tasmantid seamount chain would occur, as a consequence of the northward movement of the Australian plate over a fixed hotspot.

A relatively tight band of seismicity occurs through the Adelaide Fold Belt and the Flinders Ranges, with many events at greater depth than is common elsewhere across the continent. This belt of earthquakes may well link to the Simpson Desert, where a number of larger events occurred in the 1940s.

Through central Australia, most events reflect a compressive regime associated with the ongoing collision of Australia with the Pacific Plate to the north. In recent years there have been a number of sizeable events aligned roughly east-west from the Musgrave towards Yulara. The detailed study of Bowman (1992) for the Tennant Creek events to the north indicates the complexity of faulting and differences between nearby faults. Such features are not readily captured in the summary centroid moment tensors that show an equivalent point source. Although most of the faulting at Tennant Creek was associated with south over north thrusting, a segment of the second fault to fail had the reverse behaviour. Surface faulting has also been found associated with the 1986 Marryat Creek event in northern South Australia and the 2016 Petermann Ranges event in the sooth of the Northern Territory.

A range of different styles of earthquake activity occurs in Western Australia. A concentrated zone of activity to the west of Perth has produced a number of events above magnitude 6 with distinct surface fault traces. This zone has a nearly north-south trend parallel near the eastern edge of the Yilgarn Craton. To the west, a zone of modest size events with a southwest to northeast orientation follows the edge of the Yilgarn Craton, linking into the Musgrave Province and the central Australian earthquake belt. A number of events have occurred in the fold belts surrounding the Kimberley Block in northwestern Australia, with a Mw 6.3 event near Derby WA in 1997. The trend of the King Leopold Belt towards the southeast leads into a distinct group of events that appears to be associated with continuing deformation at the northeastern margin of the Canning Basin. The western edge of this basin, where it meets the Pilbara Craton, is also marked by a modest number of events.

The western and northwestern margins of the Australian continent show a moderate amount of long-term activity. The events mostly lie close to the transition between thinned continental and oceanic crust. To the south the earthquakes lie much further offshore with ongoing activity along a belt close to $37^{\circ} \mathrm{S}$.

The seismicity of the region is dominated by the earthquake activity associated with subduction along the Indonesian arc and in New Guinea. Strong and continuing activity occurs both in the subduction zone itself, and leading into the trench. Limited location accuracy for older events means that some of this activity on the seaward side of the subduction trench may be placed closer to Australia than their true locations.

\subsection{Earthquake Source Mechanisms}

For well-recorded seismic events, waveform information can be employed to help to characterise the nature of the seismic source represented as a point in time and space. The simplest approach to source characterisation employs the polarity of arrivals linked to a double-couple model for the earthquake mechanism. This approach can work well with a good azimuthal distribution of stations covering a range of distances. More sophisticated methods match seismic waveforms for a postulated source to observed waveforms, and use a moment tensor representation for the source without any explosive or implosive component. Frequently, attention is concentrated on the large amplitude surface waves that are least affected by seismic noise. Such methods for source determination can be quite sensitive to the choice of Earth model, particularly at regional ranges (Young et al., 2012; Sippl et al., 2015), but have been successfully used with combinations of permanent and temporary stations for sources in Western Australia. 
The Global Centroid Moment Tensor Project (www.globalcmt.org) undertakes source mechanism inversions for events larger than Mw 5.5, using the long-period surface wave records at stations across the globe. Only the largest Australian events are big enough to be included in this database. The frequency limits used (highest frequency $0.0125 \mathrm{~Hz}$ ) mean that there is indeterminacy for some moment tensor components for very shallow events. The shallow depth limit in the inversions is therefore set at $15 \mathrm{~km}$. In consequence, there can be some bias in the results for events that are actually shallower than $15 \mathrm{~km}$. Nevertheless, the catalogue provides an invaluable record for events going back to 1977 with a common style of moment tensor evaluation.

Figure 6.3 shows the available moment tensor solutions from the global centroid moment tensor database, supplemented by recent results for events in the Kalgoorlie region of Western Australia from Sippl et al. (2015). The compressive domains for each event are shown in dark brown. In addition, the highest quality focal mechanisms for smaller events within the continent, mostly determined from polarity studies, are shown in lighter brown.

The various clusters of events across the continent show locally consistent source mechanisms, but we see a significant change in regime in different parts of the continent.

The source character of the smaller events is generally comparable to the moment tensor inversions for the larger events. Some early studies were based on aftershocks to avoid saturation of analogue signals. Such results have to be used with care, since aftershock sequences can show a wide variety of mechanisms, reflecting the rebalancing of the stress state around the location of the main shock.

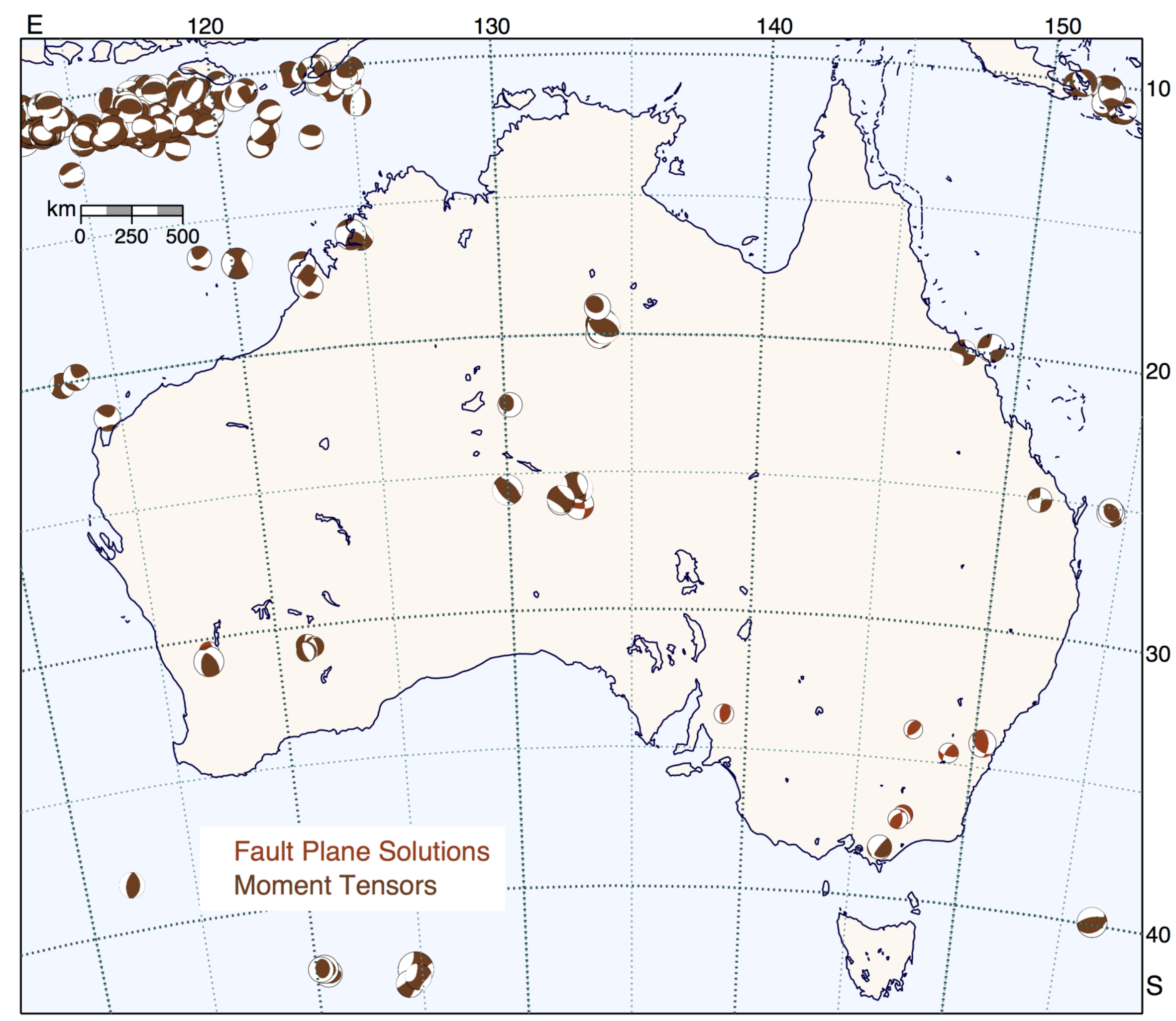

Figure 6.3: Focal mechanism solutions across Australia from the Global Centroid Moment Tensor project (www.globalcmt.org) supplemented by recent results in Western Australia from Sippl et al. (2015), and the best determined focal mechanisms from Leonard et al. (2002). 


\subsection{Neotectonic Features}

As previously noted, the long return period for intracontinental earthquakes means that the historic record needs to be supplemented with information from neotectonic features to provide a more complete picture of the state of the continent.

During the last few decades, a number of earthquakes in Australia have been sufficiently large to rupture the Earth's surface. The largest fault traces are little more than $30 \mathrm{~km}$ long, but relatively young features in the Australian landscape show much longer scarps. For example, the Cadell Scarp over $70 \mathrm{~km}$ long and $15 \mathrm{~m}$ high lies across the former path of the Murray River that has been deflected around the end of the feature. The field evidence suggests that 3-4 events of magnitude 7.2-7.3 would be needed to create the observed topography, with the last event at about 20 ka (Clark et al., 2011). No events of this magnitude have occurred since European settlement.

A major effort has been made by Geoscience Australia to assemble a database of neotectonic features across the continent (Figure 6.4) and a significant number are of definite association (Class A) or probable association (Class B) with seismic events.

Since the Miocene, the Australian continent appears to have tilted downwards to the northwest (Sandiford, 2007), as also seen in the deviation of the Australian Height Datum from the geoid (Figure 5.2). The geological evidence comes from systematic variations in the extent of Neogene marine inundation. Thus, on the southern Australian margin, Miocene limestones of the Nullarbor Plain have been uplifted and subjected to marine erosion to form impressive cliffs along the Great Australian Bight.

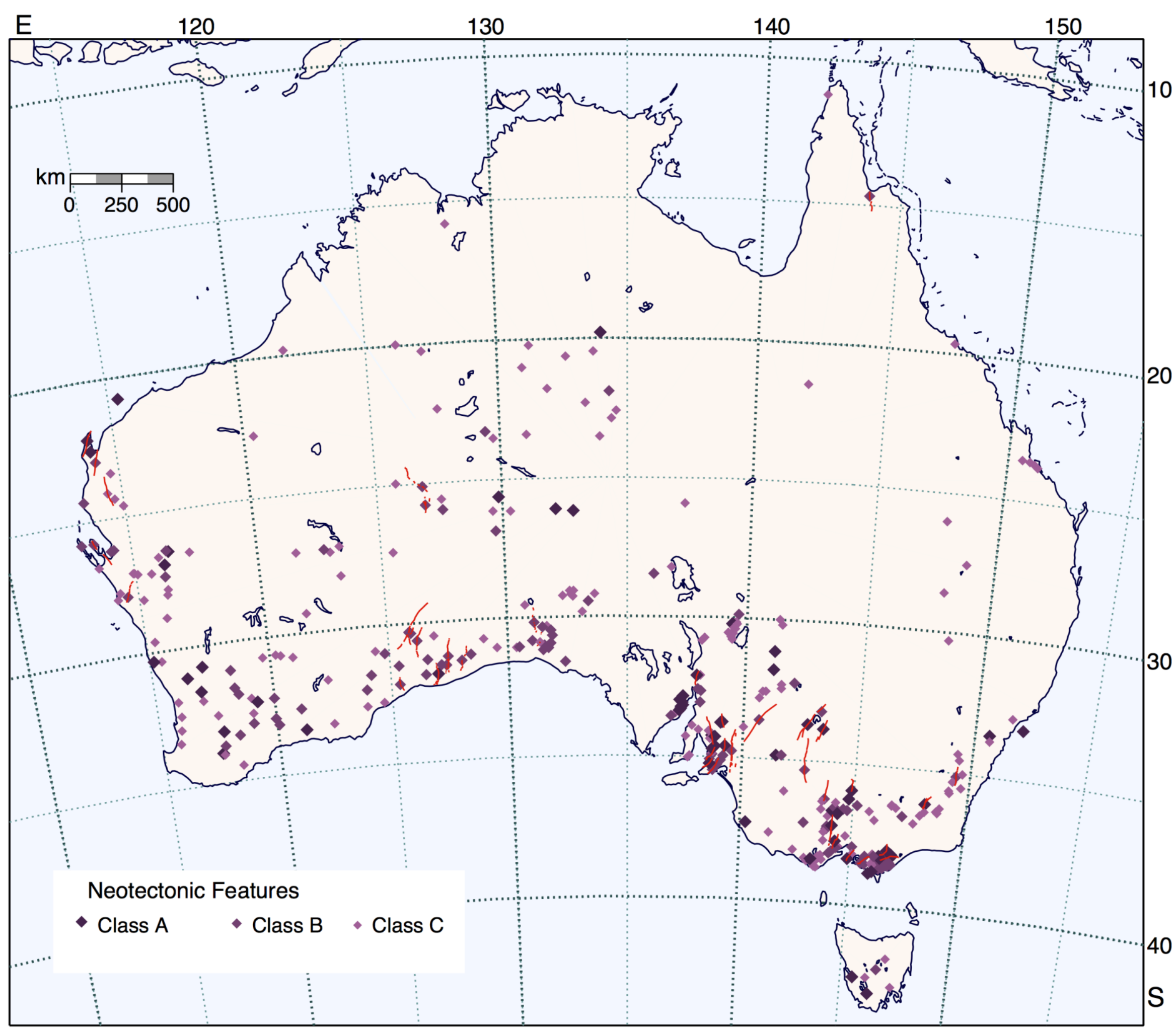

Figure 6.4: Neotectonic features across Australia. Class A have definite association with earthquake events, Class $B$ are probable and Class $C$ are possible (Clark et al., 2011). Faults longer than $60 \mathrm{~km}$ associated with Class $A$ and $B$ features are shown. 
In the last few million years it appears that the lithosphere has buckled slightly, giving rise to undulations of the order of $100 \mathrm{~m}$ on wavelengths of a few hundred kilometres. This has changed the drainage patterns of a number of basins, such as those containing Lake Torrens and Lake Frome.

The most distinct neotectonic features in the landscape come from fault motions. Locally uplift rates can be large, as in the Flinders Ranges where up to 50 per cent of the current topography appears to have developed in the last 5 million years. One of the strongest lines of evidence for generation of neotectonic features by faults is that the majority have comparable geomorphological effects to those associated with the scarps generated in recent events that have broken the surface. Thus the neotectonic features rated in Classes $A$ and $B$ are accompanied by localised modifications of drainage including ponding, diversion or incision of channels or terrace formation.

Because the rates of erosion across Australia are generally low outside the wet tropics, it is possible for neotectonic features to be preserved for long periods of time. In eastern Australia and the Flinders Ranges, features may be recognisable for up to 50,000 years, but in central and western Australia where erosion rates are lower, features could survive for 100,000 years or more. For the lowest erosion rates, as on the Nullarbor Plain, many scarps can be preserved even longer, possibly for several million years.

The neotectonic database illustrated in Figure 7.4 has been compiled from a combination of remote sensing information particularly digital elevation models, and field based mapping. The coverage across the continent is somewhat heterogeneous and biased towards the south, but still provides a better measure of the long-term deformation of the Australian continent than is provided by the historic record of seismicity.

Many of the Class A and Class B neotectonic features are associated with long scarps that are much bigger than those produced by any historic events. Only fault traces longer than $60 \mathrm{~km}$ are shown in Figure 6.4, since only these large features are visible when mapped at the continental scale. In most cases, several large seismic events would seem to be the likely cause.

The many features designated as Class $C$ have a possible association with seismogenesis but the evidence is not as compelling as for Class B. Several of these features are very long with displacements too large for any single seismic event.
When allowance is made for the likely preservation of the neotectonic features, we see a good general correspondence with the current-day pattern of seismicity, though with events in some regions that have not had any historical activity. The results suggest that the general stress pattern across the continent has remained reasonably stable in the last 100,000 years or so.

\subsection{Continental Deformation}

The dominant motion of continental Australia is rigid body motion as a part of the Australian Plate with a direction of absolute plate motion slightly to the east of north and a velocity of about $6.7 \mathrm{~cm} / \mathrm{yr}$. The size of the continent means that the simple rigid rotation on the sphere is reflected in a systematic variation in direction across the continent with a stronger easterly component in the west.

Direct measurements of continental deformation using space geodetic techniques indicate that there are no significant changes in the dimensions of the Australian continent as part of the Australian Plate (Tregoning, 2003). Since 2000 there have been five recent earthquakes in the region which have produced considerable coseismic displacement at thousands of kilometres from the epicentre:

2004 December 24, Mw 8.2 Macquarie Ridge,

2004 December 26, Mw 9.3 Sumatra-Andaman,

2005 March 28, Mw 8.7 Northern Sumatra,

2007 April 1, Mw 8.1 Solomon Islands,

2007 September 12, Mw 8.4, Southern Sumatra (Nias).

The size of these coseismic displacements is consistent with the predictions from source models. In addition, in the GPS time series at sites along the eastern side of Australia there has been a small, nonlinear deformation due to post-seismic relaxation from the 2004 Macquarie Ridge event decreasing with distance from the epicentre. The size of the signal on the north component is comparable to the coseismic effects.

Once allowances are made for these effects by excluding GPS stations in the southeast regions of New South Wales and Victoria as well as Tasmania, the deformation across the rest of the continent is less than $0.2 \mathrm{~mm} / \mathrm{yr}$ on top of the rigid motion of the Australian Plate (Tregoning et al., 2013). This makes much of continental Australia one of the most stable regions of crust across the globe. 


\subsection{Current Stress Field}

The orientation of horizontal stress in the crust can be estimated from many different types of information. A major source is earthquake focal mechanisms, although there is the possibility that fault-planes may align with zones of pre-existing weakness rather than lie in the expected relation to the stress axis. Measurements in boreholes such as the orientation of breakout, drilling failures and the results of hydraulic fracturing are important indicators of the shallow stress state. As a result of the Australian Stress Map project (Hillis and Reynolds, 2003), and the ongoing efforts of the World Stress Map (Heidbach et al., 2016), a wide range of stress indicators have been collected for the Australian region. Figure 6.5 displays the indicators with the highest level of confidence, together with an indication of their stress regimes.

Stress orientations across Australia continent are more variable than is common on other continents, and do not parallel the absolute plate motion of the Australian Plate (north-north-northeast: DeMets et al., 2010). However, stress orientations are broadly consistent within individual areas, at the scale of hundreds of kilometres.

This makes it possible to define regional stress averages, with an indication of their reliability (Hillis and Reynolds, 2003). In Figure 6.5 these regional stress averages are marked with grey open symbols superimposed on the stress data. The regional symbols are scaled to indicate the level of reliability.

The regional stress directions rotate across the continent. In western Australia the maximum horizontal stress lies west-east. This direction rotates to northwest-southeast along the northern continental margin and eastwards into central Australia.

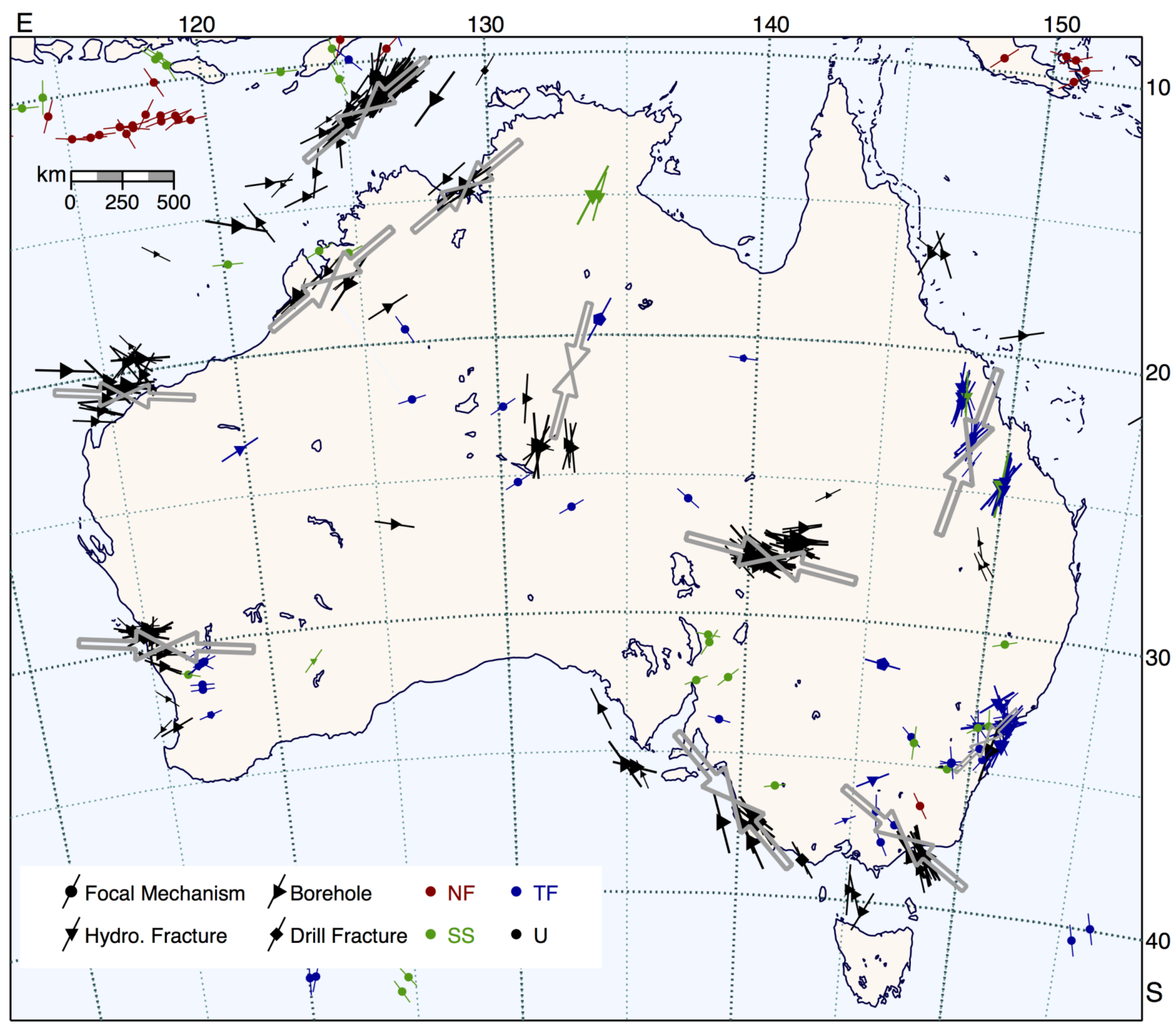

Figure 6.5: Stress directions for the Australian continent from the World Stress Map (Heidbach et al., 2016), with indication of domains: NF-normal faulting, TF-thrust faulting, SS-strike-slip, $\mathrm{U}-$ undetermined. The markers increase in size with confidence. The regional stress indicators from Hillis and Reynolds (2003) are shown in grey; symbol size increases with confidence. 
There are stronger variations in direction in the eastern half of Australia. The stress regime in Queensland mirrors the trend in central Australia. Further south, there is a rotation towards west-southwest-east-northeast in the Sydney Basin. In both the Gippsland and Otway basins, the maximum horizontal stress orientation is northwest-southeast. In central eastern Australia there is a zone where there is a rapid change in stress orientation and stresses tend to be eastwest or poorly defined.
The patterns of stress orientation across the whole Australian continent are consistent with the primary controls arising from plate-boundary forces along the complex boundary of the Australian Plate, with differing senses of subduction in Indonesia, Tonga and New Zealand. Stress focusing due to the continental collision in New Guinea has a particularly strong influence (Reynolds et al., 2003) 


\section{Seismic Structure - Crust}

\section{Active Source Seismology}

Australia has had an extensive involvement in active source seismology, with early experiments carried out in the 1930s. The Bureau of Mineral Resources conducted a number of major refraction experiments from the 1960s into the 1980s. These results still provide an important control on seismic wavespeeds across the continent. There has been little such refraction work since, except some offshore/onshore experiments, mostly in Western Australia. In Figure 7.1 , the locations of the recording stations are shown with lilac triangles and shot points with purple circles. Experiments exploited quarry blasts in addition to explosive shots specifically for refraction work.

Reflection studies of the whole crust have grown from short experimental spreads in the 1960s to large-scale transects. A nearly $2000 \mathrm{~km}$-long reflection transect with $20 \mathrm{~s}$ recording was built up across southern Queensland in the 1980s using explosive sources. Explosive sources continued to be used until 1997 and such lines are shown in orange in Figure 7.1. After 1997, reflection work on land has relied on the use of three or four powerful vibrator sources used together as a source array. Since 2004 there has been a major national investment in seismic reflection work, funded through investment from Geoscience Australia, State and Territory Geological surveys and, since 2007, the AuScope infrastructure initiative. Over $16,000 \mathrm{~km}$ of full crustal reflection profiles have been acquired with recording to $20 \mathrm{~s}$ or more. This very large effort in reflection profiling has covered many different parts of the continent and provides new insights into crustal structure, architecture and evolution.

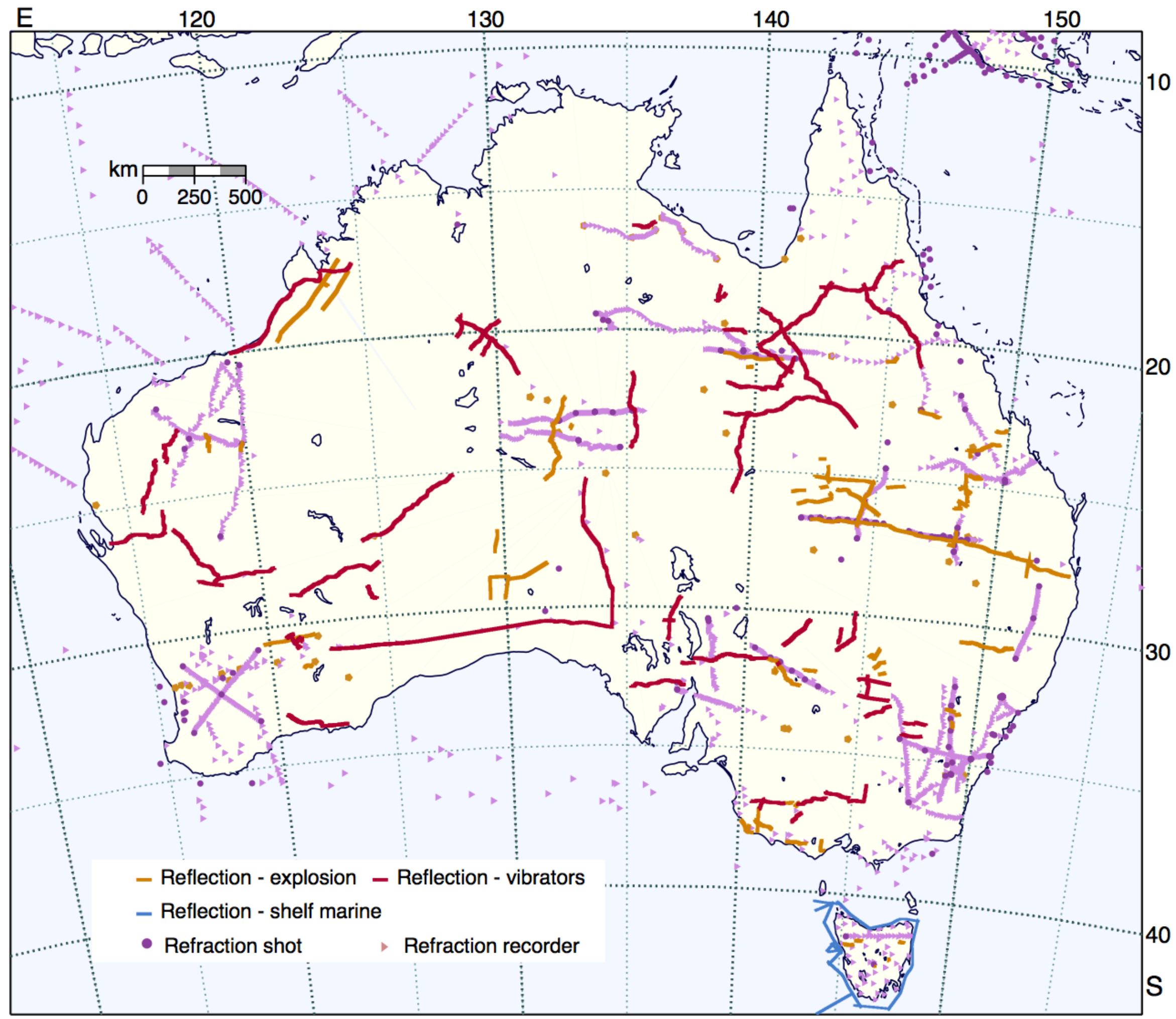

Figure 7.1: Location of reflection and refraction experiments across Australia to the end of 2016. The refraction experiments were conducted with explosive sources up to the 1990s. Earlier reflection profiles also used explosive sources, but since 1997 vibrator sources have been employed. 


\section{Full Crustal Reflection Transects}

The following pages present a suite of full crustal reflection transects covering the entire width of the Australian continent, the main geological domains, and a wide range of styles of crustal architecture. The transects are built up from the results of a number of reflection lines collected at different times, so that there is some variation in the quality of the results. For each transect, the individual reflection surveys are identified by year and line code. Full displays of the results for each survey accompanied by geological strip maps are to be found in Kennett et al. (2016).

Each of the reflection transects is presented as a record section to $20 \mathrm{~s}$ two-way reflection time at approximately true-scale (for crustal velocity of $6 \mathrm{~km} / \mathrm{s}$ ). In order to provide adequate resolution of the different character of crustal reflectivity and crustal architecture along the profiles, each transect is broken into panels approximately $550 \mathrm{~km}$ wide. Overlap is provided between successive panels.

The transects are presented from west to east. Figure 7.3 displays the WA-EW transect that crosses the Yilgarn Craton and links to the Musgrave Province in Central Australia. The AF-EG transect (Figure 7.4) starts just at the edge of the Yilgarn Craton and crosses the Nullarbor Plain with almost no surface rock exposure. The next two transects, $\mathrm{SN}$ and $\mathrm{V}$ (Figure 7.5), stretch from the Gawler Craton through to the Phanerozoic Lachlan Orogen. The final transect (Figure 7.6) is taken from the surveys in Northern Queensland and traverses the Proterozoic to Phanerozoic transition starting in the Mt Isa Province with very thick crust and ending near Charters Towers.

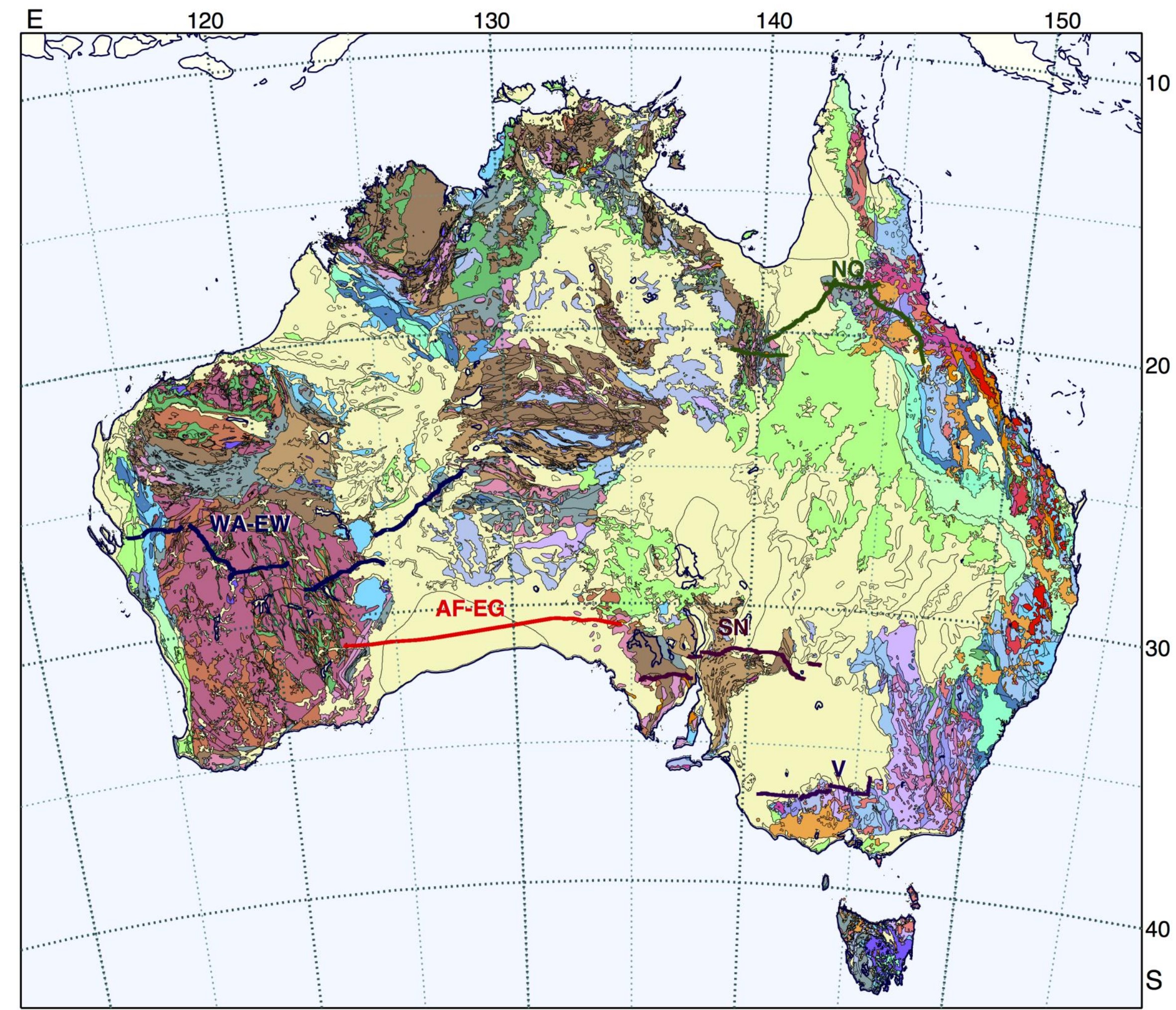

Figure 7.2: Location of west-east reflection transects superimposed on solid geological map. 


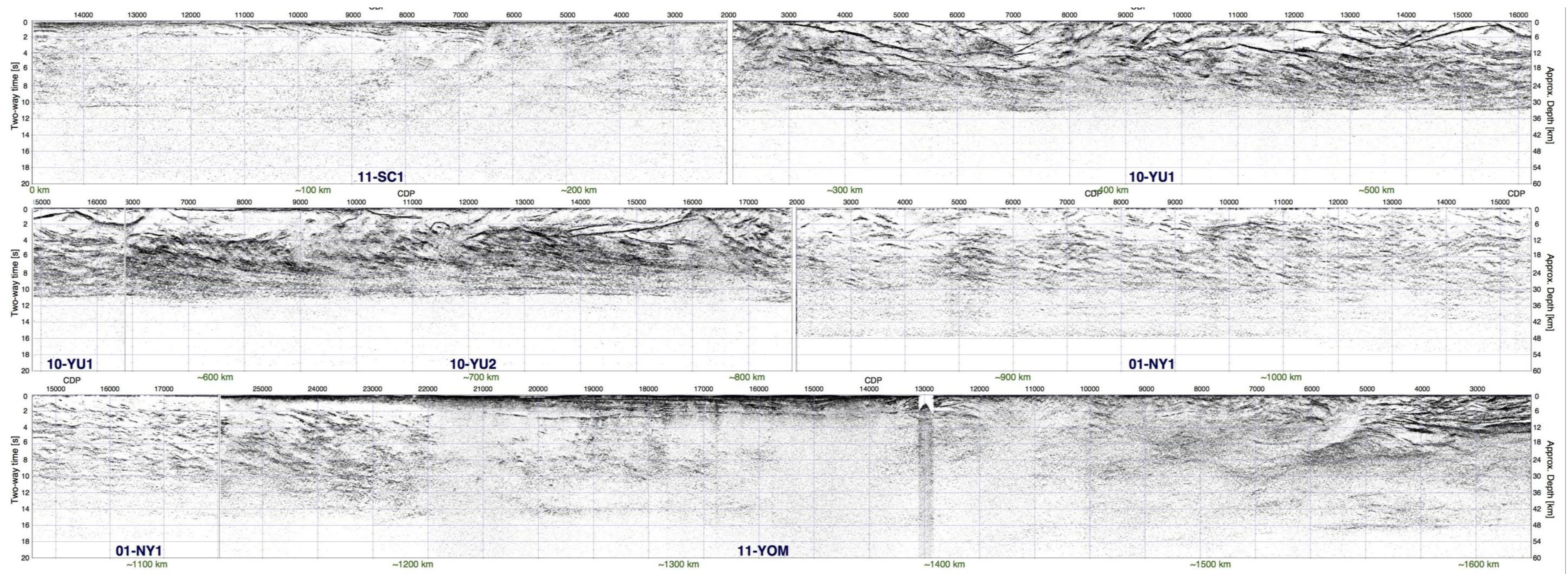

Figure 7.3: WA-EW transect starting in the west near Shark Bay, crossing the Yilgarn Craton and ending in the Musgrave Province.

The west-east transect across Western Australia (Figure 7.3) starts at the coast in the Pinjarra Orogen and crosses the edge of a potential meteorite impact feature on line 11-SC1. The weaker crustal reflectivity lies in the zone associated with the impact. Line 11-SC1 ends in the Yilgarn Craton and nearly links to the end of the 10-YU1 line. Both the reflection lines 10-YU1 and 10-YU2 traverse the Youanmi Terrane of the Yilgarn Craton, and are notable for a very sharp reflection Moho. Very distinct bands in shallow reflectivity on these two lines are likely to be extensive dolerite sills, which occasionally outcrop in the region. This portion of the transect shows a very clear separation in the nature of upper and lower crustal reflectivity. The deeper part of the crust on lines 10-YU1 and 10 YU2 displays extended shallowly dipping features that appear to have a counterpart in the western end of line 01-NY1.
Further east on line 01-NY1, the dips of reflectors through the whole crust steepen and link to the reflection character seen at the west of line 11-YOM to the north. The first part of the 11-YOM line traverses the eastern portion of the Yilgarn Craton under cover, but relationships become more difficult to discern as the sediments of the Officer Basin thicken. At the far end of line 11-YOM, in the Musgrave Province, the crust has a rather deep Moho at around $48 \mathrm{~km}$ depth. This thick crust appears to underthrust the extended Yilgarn margin with crustal thicknesses exceeding $55 \mathrm{~km}$ in the central zone. This distinctive imbricate Moho topography appears to be ancient, and is interpreted to be a result of the amalgamation of the main Australian cratonic elements at around $1200 \mathrm{Ma}$. This reflection profile has been interpreted by Korsch et al. (2014). 


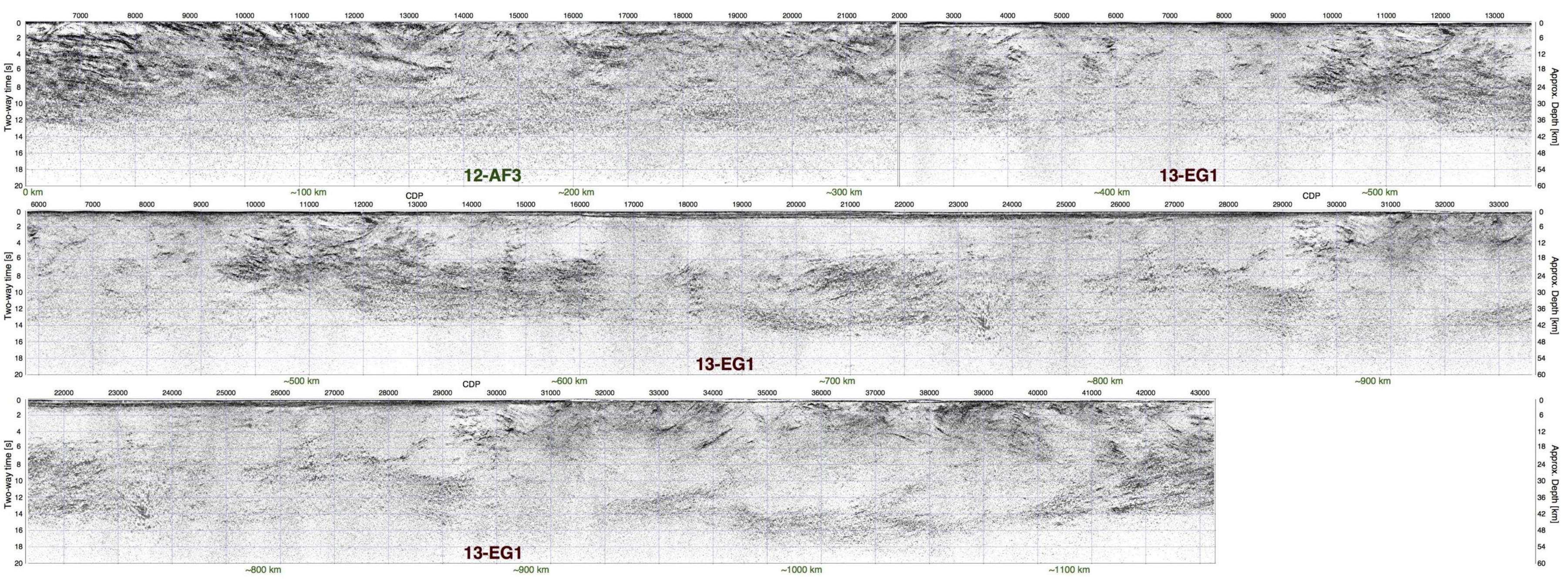

Figure 7.4: AF-EG transect from the Albany-Fraser Orogen at the edge of the Yilgarn Craton across the Nullarbor Plain through the Coompana Province (beneath the Eucla Basin) into the Gawler Craton.

The transect from the Albany-Fraser Orogen to the Gawler craton (AF-EG, Figure 7.4) starts at the western edge of the Yilgarn Craton. Just beyond the craton margin, the crust thickens, and this may again be associated with material thrust from the east below the crust of the Yilgarn Craton. Much of this long transect crosses a region with thin Miocene limestones and no basement outcrop. Fortunately, the quality of the reflection data obtained using powerful vibrator sources is generally high, though there are a few patches where surface coupling issues appear to have diminished the seismic energy penetration. There are a number of changes in styles of crustal reflectivity that can be linked to major faults recognised in potential field data. The Rodona shear zone crosses the transect near CDP 19000 on line 12-AF3, with braided east-dipping structures that continue into $13-E G 1$.
An even more striking change occurs just beyond CDP 9000 on the line 13-EG1, where a distinctly different pattern of reflections occur on the west and east side of the near-vertical Munderabilla shear zone. This shear zone is a major feature that can be traced well to the north in both the magnetic and gravity fields. These contrasting patterns of crustal reflectivity suggest the presence of distinct crustal blocks beneath the cover, rather than an extended margin of the South Australian Craton. The crustal thickening at the western edge of the Gawler Craton (around CDP 28000 on 13-EG1) is comparable to that under the Albany-Fraser Orogen. However, the second zone of thickened crust (up to $55 \mathrm{~km}$ thick) within the Gawler Craton has no counterpart anywhere in the West Australian Craton. Initial interpretations of this transect are discussed in Dutch et al. (2015). 

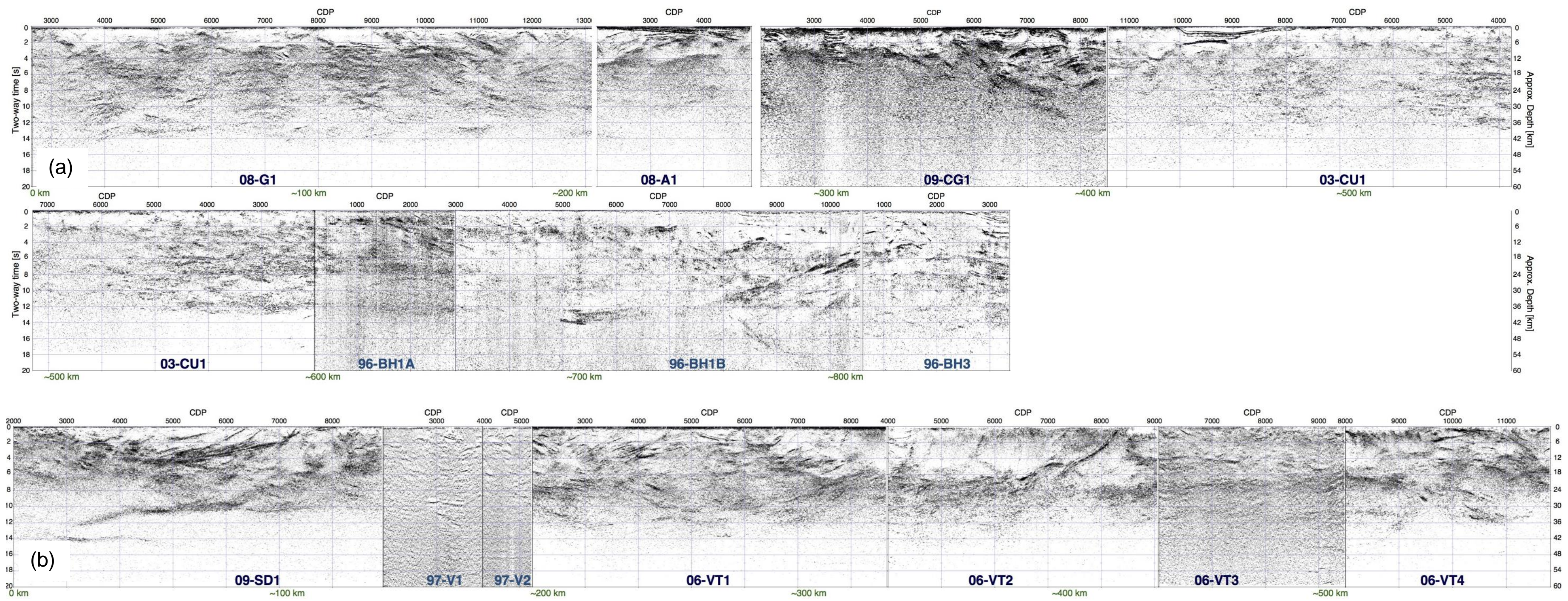

Figure 7.5: West-east transects (a) SN-across the Gawler Craton into the Curnamona Block and across the transition into the Phanerozoic through Broken Hill, NSW; (b) V-from the limestone belt of South Australia through to central Victoria.

The two reflection transects displayed in Figure 7.5 link from the Precambrian domains of the South Australian craton across to the younger Phanerozoic terranes in the east. The SN transect crosses the Eyre Peninsula through the Gawler Range Volcanics; the profile is then displaced to the north crossing the Curnamona Province through to Broken Hill and beyond. The eastern end of the $\mathrm{SN}$ transect was collected with explosive sources, but careful reprocessing has produced record sections that match well with the vibrator lines to the west. The visibility of the crust-mantle boundary varies noticeably along the transect: from a gentle fade in reflectivity at the base of the crust on lines $08-\mathrm{G} 1$ and $08-\mathrm{A} 1$, to a distinct reflection Moho on 03-CU1 and 96-BH1A.
The $\mathrm{V}$ transect starts in South Australia, but most of the reflection profile lies in Victoria. An intriguing feature at the western end (09-SD1) is the relatively thick crust with what appears to be a duplication of the Moho. The reflector at about $14 \mathrm{~s}$ was captured in 3-D with a crossing profile and dips gently to the north. To the east, the crust thins quite rapidly and a characteristic lower crustal assemblage begins to appear without any distinct base. Most of the prominent fault zones have a reflection signature that can often be tracked well into the lower crust. 

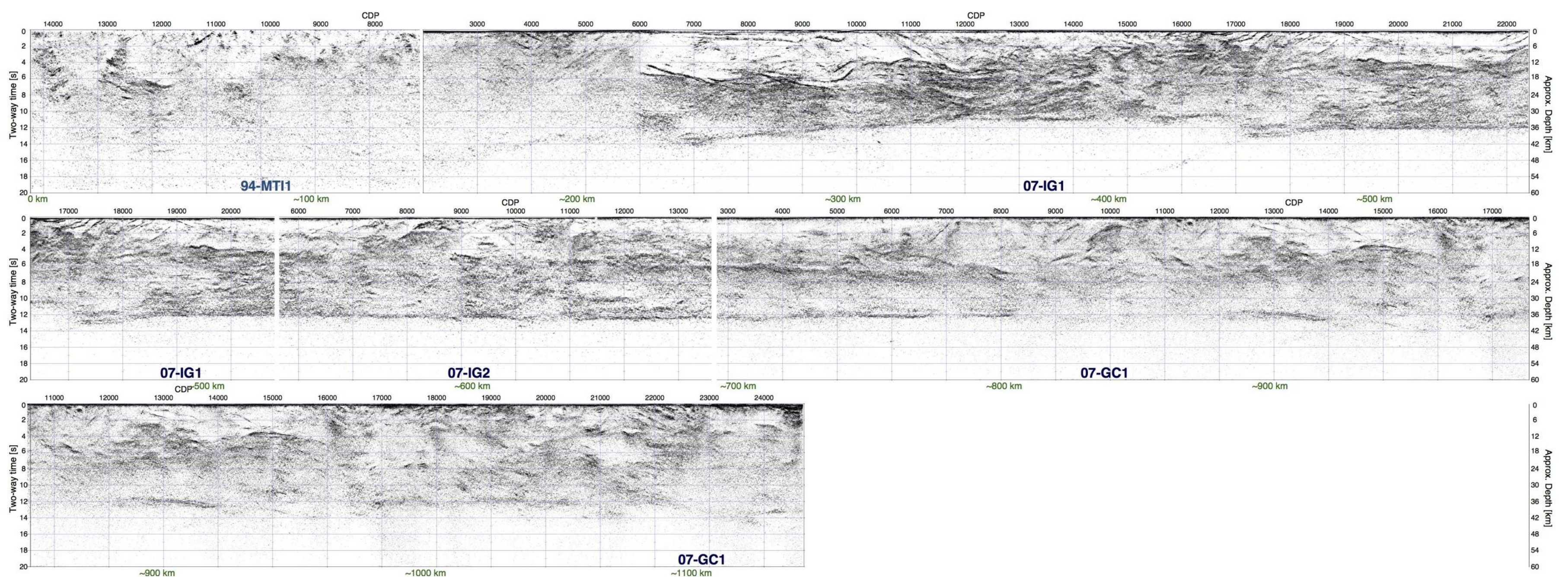

Figure 7.6: West-east transect NQ starting in the Mt Isa block with thick crust, linking to the Precambrian Georgetown Inlier and then crossing into the Phanerozoic, with line completion close to Charters Towers.

The transition from the Proterozoic to the Phanerozoic in northern Queensland is covered by the NQ transect shown in Figure 7.6. The western portion of the transect crosses the Mt Isa Province on line 94-MTI1, where shallow reflections tend to be locally strong but without great spatial extent. The diffuse lower crustal reflectivity makes it difficult to distinguish a base to the rather thick crust, but at the western end of line 07-IG1 the crustal thickness definitely exceeds $50 \mathrm{~km}$ in agreement with refraction results. To the east, the crust thins steadily with the development of a distinct base to crustal reflections. A jump in the reflection Moho at around CDP 17000 on line 07-IG1 can be linked to weak reflections extending into the mantle, and might be linked to ancient subduction. In the crustal domain to the east on line 07-IG1 there is a prominent mid-crustal reflector that extends under the outcrop of the Precambrian Georgetown Inlier on line 07-IG2.
The 07-GC1 segment of the transect has a northwest-southeast configuration starting in the Precambrian and ending in the northern part of the Paleozoic Thomson Orogen near Charters Towers. Precambrian outcrop ceases at around CDP 8000 on line $07-G C 1$, but there is little indication of the transition into Phanerozoic crust in the character of the reflection record in the upper crust, even though the Lynd Mylonite zone presents a very clear feature at the surface (Korsch et al., 2012). The distinct lower crust that can be tracked from 07-IG2 through 07-IG2 into the northern end of 07-GC1 thins along this line, and finally appears to sole out on the Moho at about CDP 14000. On the southern portion of the line there is a redevelopment of a mid-crustal reflectivity band, but now with a somewhat undulating character. 


\section{Passive Seismology}

The configuration of earthquake belts around the margins of Australia provides a wealth of events at suitable distances to be used as probes into the seismic structure of the upper mantle. There is also a relatively good distribution of events at teleseismic distances over a wide range of depths that can be exploited in receiver-based studies (Figure 7.7). The earthquake belts to the north and east are both more active and provide larger events than the mid-ocean ridges to the south and west.

Until recently, there were only a few permanent highfidelity seismic stations on the continent. Much data collection has therefore been acquired through extensive deployments of portable broadband stations for periods of a few months at each site. This approach was pioneered with the SKIPPY experiment (van der Hilst et al., 1994) where a group of stations were progressively moved across the continent in a sequence of deployments. This style of experiment has inspired many similar efforts worldwide (such as major deployments in South Africa, James et al., 2001; and the US Array, www.usarray.org).

The combination of a long duration of recording at the permanent stations and the broad spatial coverage of the portable stations provides an excellent resource for studies of the lithosphere using recordings of both natural events and ambient noise. A wide range of techniques, which exploit different aspects of the seismic wavefield, can be used to gain information on the 3-D structure in the crust and mantle.

After the initial reconnaissance survey of the continent in the SKIPPY experiment, a wide range of more localised deployments have been made across the continent using portable seismic recorders with highfidelity broadband seismometers (Figure 7.8).

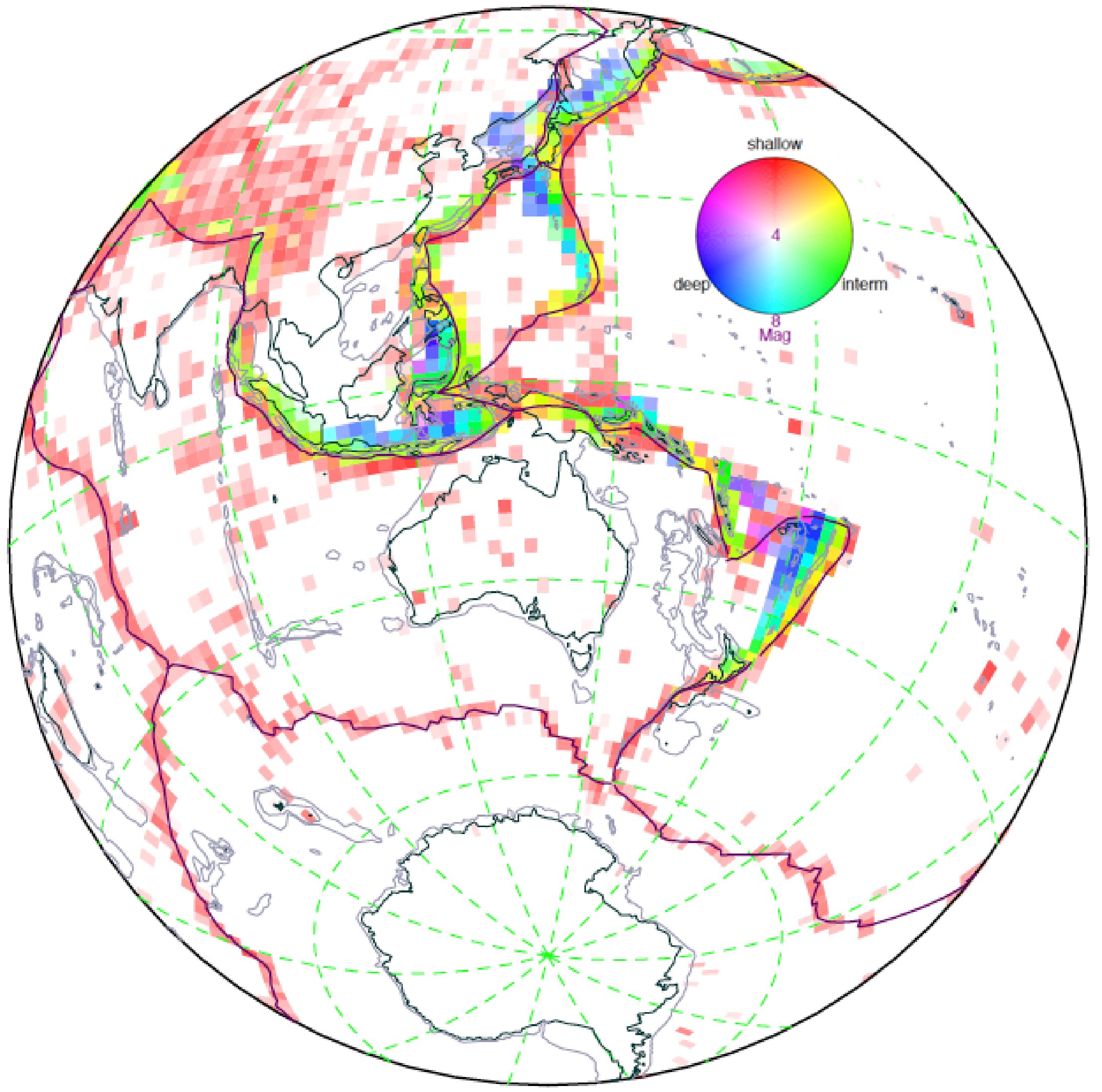

Figure 7.7: Configuration of earthquake belts relative to the Australian continent, illustrated by 10-year energy release, colour-coded by depth and effective magnitude (Kennett, 2001). 
A number of different experiments have built up a relatively dense coverage in Western Australia over the last 20 years. In a similar way, a combination of broad-scale and more closely spaced instrumental deployments have helped to provide good areal coverage in the east. However, the extensive areas of desert remain sparsely sampled by rather short-term deployments because of complex access and logistic issues. The enhancement of the national network has provided a stronger base of permanent stations with long-term recording, which helps to tie together the results from the portable broadband station deployments.

In southeastern Australia, a dense coverage of stations has been built up by a combination of modest deployments, with typically around 40 stations deployed at a time. Initially these studies used shortperiod vertical component instruments, but later moved to 3-component seismometers with greater bandwidth. This collective project (WOMBAT) has been built up with support from the Australian Research Council, The Australian National University and the AuScope infrastructure project so that now over 1000 stations have been deployed in all, including a dense experiment in the Albany-Fraser Belt in Western Australia.

The full range of seismic stations, both permanent and portable, deployed across Australia up to the end of 2016 is shown in Figure 7.9. Achieving full continental coverage with a comparable station density remains a considerable challenge. Currently, coverage allows the broad features of the continent to be well delineated, such as the zone of generally thickened crust in central Australia. But the finer-scale features such as the details of sutures between the cratonic elements, which may well be of economic interest, cannot be resolved.

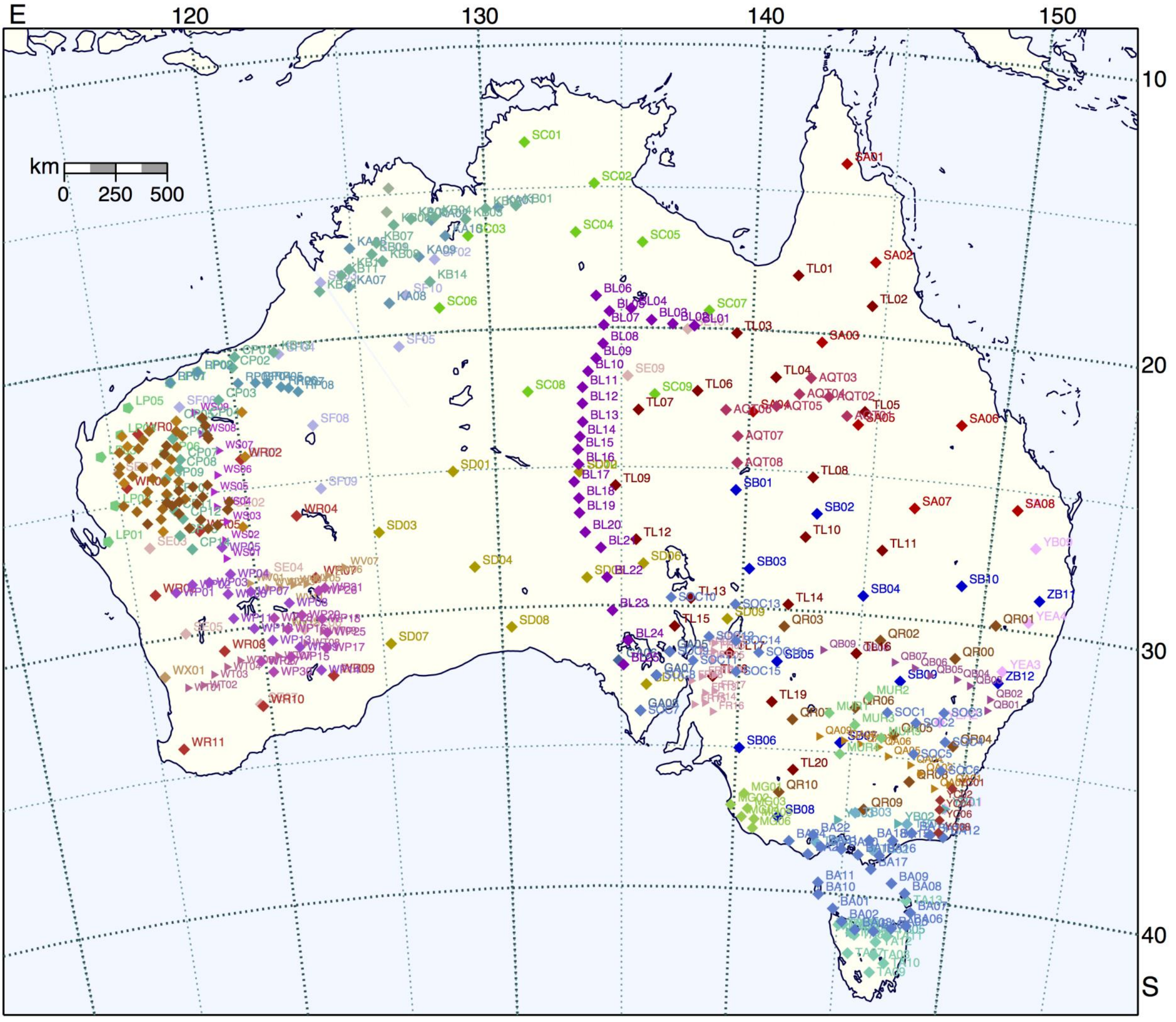

Figure 7.8: Portable broadband station deployments to end 2016. 
Most of the structural studies exploit seismograms from earthquakes, either from the regional belts of events to the north and east of Australia, or from more distant sources. The largest amplitude features of such seismograms are the surface waves with dominantly horizontal propagation. These surface waves have been extensively exploited to map out the large-scale variations in seismic wavespeed structure in the mantle beneath Australia (see, e.g. Kennett et al., 2013). The arrival times of the body waves from the various events, which arrive relatively steeply at the seismic stations, are used in seismic tomography to provide considerable detail of variations within the lithosphere (e.g. Rawlinson et al., 2014). Body wave arrivals can also be exploited in studies at individual stations, as for example in the use of receiver functions that exploit the conversions and reverberations associated with major seismic phases to extract information on the crust and the uppermost mantle (e.g. Reading et al., 2007).

All of the different styles of seismic deployments provide continuous recording of ground motion, and this resource continues to be exploited in many different ways. A relatively new technique, which is of particular value for crustal studies, exploits the ambient noise field, by working with the stacked correlation of records at pairs of stations. The resultant stacked traces are equivalent to having a virtual source at one of the stations with a receiver at the other. The surface wave energy is the most prominent feature of the stacked correlation and has been exploited by Saygin and Kennett $(2010,2012)$ to map the upper and middle crust across the entire continent. The dense WOMBAT network has also been exploited by Young et al. (2011) and Pillia et al. (2015), to provide detailed images of structure in southeastern Australia.

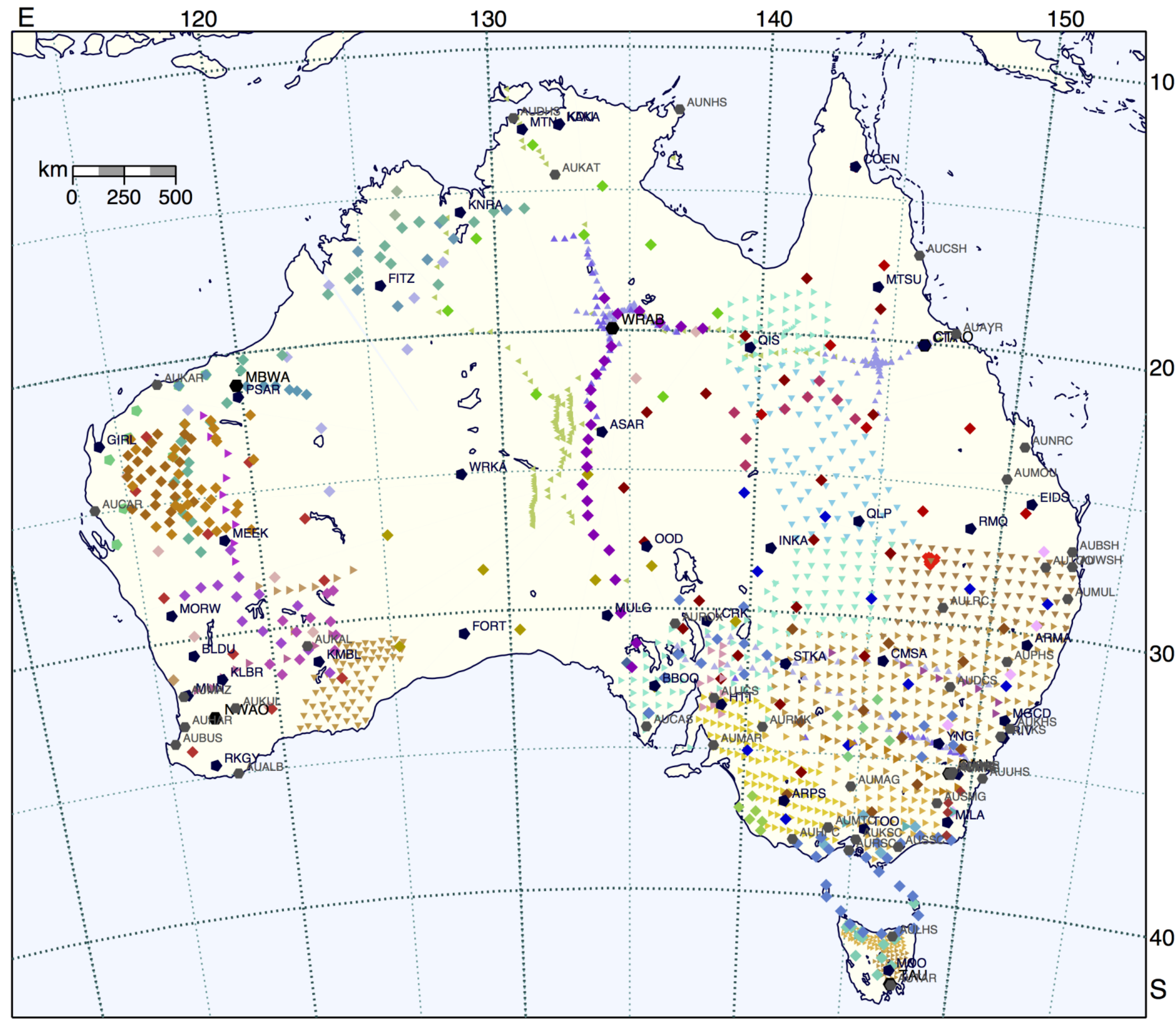

Figure 7.9: Distribution of permanent and portable seismic stations to end 2016. 


\subsection{Crustal Structure}

Information on crustal structure comes from both active source and passive seismic methods. We have already seen the details of crustal architecture revealed by seismic reflection profiling. Yet, except in the shallower part of the crust, particularly in the sediments, it is not possible to extract reliable seismic velocity information from even the $6 \mathrm{~km}$ spreads of geophones currently employed for full crustal work. Much larger offsets are needed to provide sufficient curvature on deep reflection trajectories to extract any detail of velocity structure.

Seismic refraction experiments with sufficient density of shots can provide good control on the seismic wavespeeds both horizontally and vertically. However, many of the earlier experiments in Australia were carried out with limited shot control and results were presented as a 1-D velocity profile with depth. A consequence is that the information available from seismic refraction studies is rather heterogeneous in character and, although carried out in a number of different parts of the continent, rather patchy in control on the $\mathrm{P}$ wavespeed $(V p)$.

The results from the suite of deployments of portable seismic recorders have been extensively used in different studies of the structure in the neighbourhood of the seismic stations. The primary approach has been the use of receiver functions from incident $P$ waves from distant earthquakes. The influence of the source is minimised by deconvolving the radial component (along the great-circle path to the source) by the vertical component of motion at the same station. This process isolates the conversions and reverberations following the main $\mathrm{P}$ wave arrival; many arrivals are stacked to stabilise the results at each station. The principal sensitivity of the receiver function is to the presence of discontinuities, but the receiver function traces do contain wavespeed information that can be extracted with care. Inversion of the receiver functions in terms of 1-D wavespeed profile provides primary control on the $S$ wavespeed $(V s)$ distribution with depth including major discontinuities, with some constraint on the $V p / V s$ distribution in depth. An alternative approach exploits the relative timing on the primary conversion at the base of the crust and surface multiples; stacking provides a estimate of the depth to Moho and the average $V p / V s$ for the whole crust. The sampling achieved in receiver function studies with a good azimuthal distribution of events extends to about a $45 \mathrm{~km}$ radius around the station.
The exploitation of ambient noise through stacked cross-correlations of the records at pairs of stations has made a major difference to determining the structure of the upper part of the crust on a broad scale. Data mining of the archives of continuously recorded ground motion provides many pairs of stations within individual portable deployments and, with the aid of permanent stations, ties between different experiments enhance the coverage. Many broadband stations were kept away from the coast to ensure good signal-to-noise for weaker earthquake sources. As a result, continental coverage tends to be limited in a zone about $100 \mathrm{~km}$ wide along the coasts. Nevertheless, a good pattern of crossing paths is achieved at the continental scale that enables tomography using the group velocity of surface waves, and then the extraction of the 3-D shear wavespeed distribution to at least $25 \mathrm{~km}$ depth (Saygin and Kennett, 2010, 2012).

For a single seismic station, the stacked autocorrelation of the seismic wavefield provides information on the structure beneath the site (Gorbatov et al., 2013). Such results give an estimate of $P$ wave reflectivity rather than any velocity control. With the dense deployments of stations in southeastern Australia, it has proved possible to use spatial stacking to provide control on the depth to Moho across a broad zone (Kennett et al., 2015).

\section{Crustal Seismic Model}

The construction of a suitable model for crustal seismic velocities at the continental scale requires the combination of the full range of classes of information. From seismic refraction experiments, we extract localised $\mathrm{P}$ wavespeed $(V p)$ profiles. The interpretation of $\mathrm{P}$ wave receiver functions gives constraints on the shear wavespeed $(V s)$ structure beneath a seismic station, together with some control on the $\mathrm{Vp} / \mathrm{Vs}$ ratio.

Fortunately, we are able to supplement the localised information from refraction experiments and receiver functions with the broader coverage from ambientnoise tomography. However, we then need to convert the crustal shear wavespeed distribution to a $\mathrm{P}$ wavespeed result. 

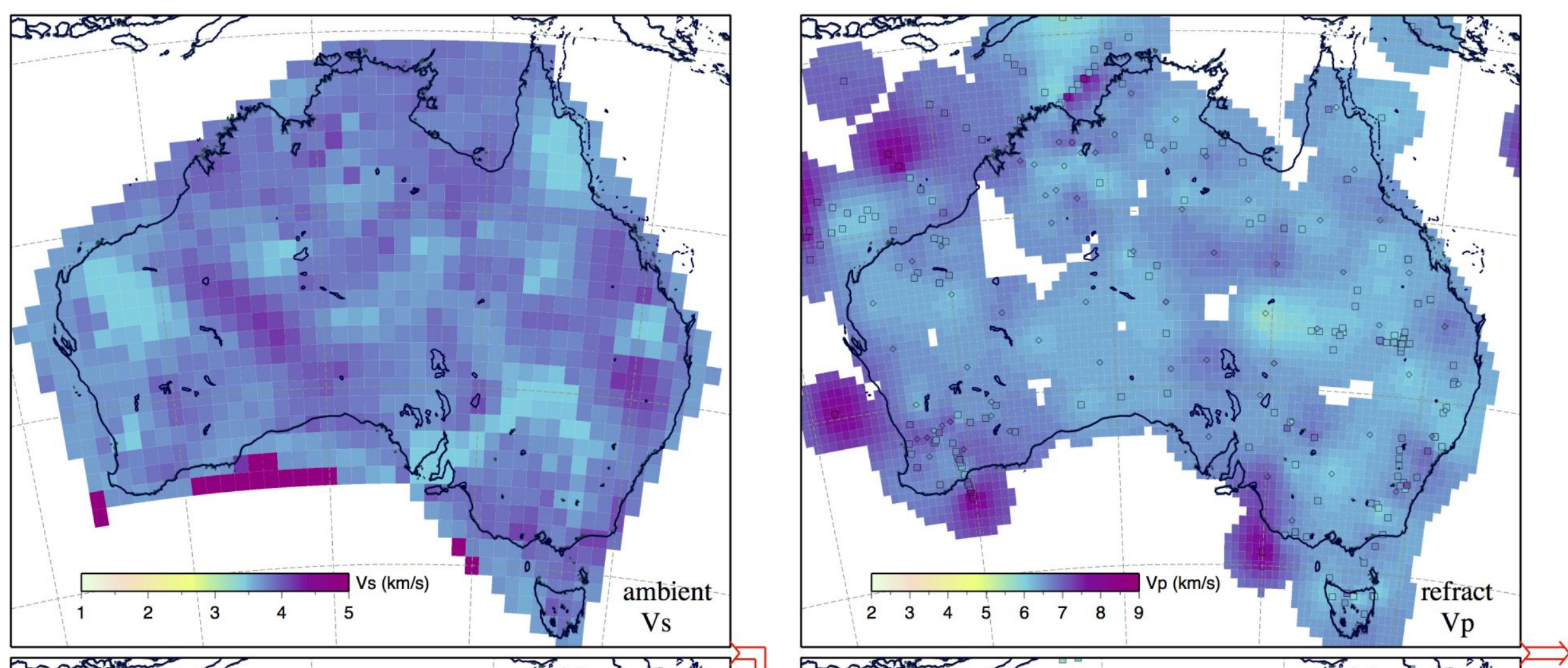

Construction of $\mathrm{Vp}$ field at $20 \mathrm{~km}$ depth from refraction and ambient noise results
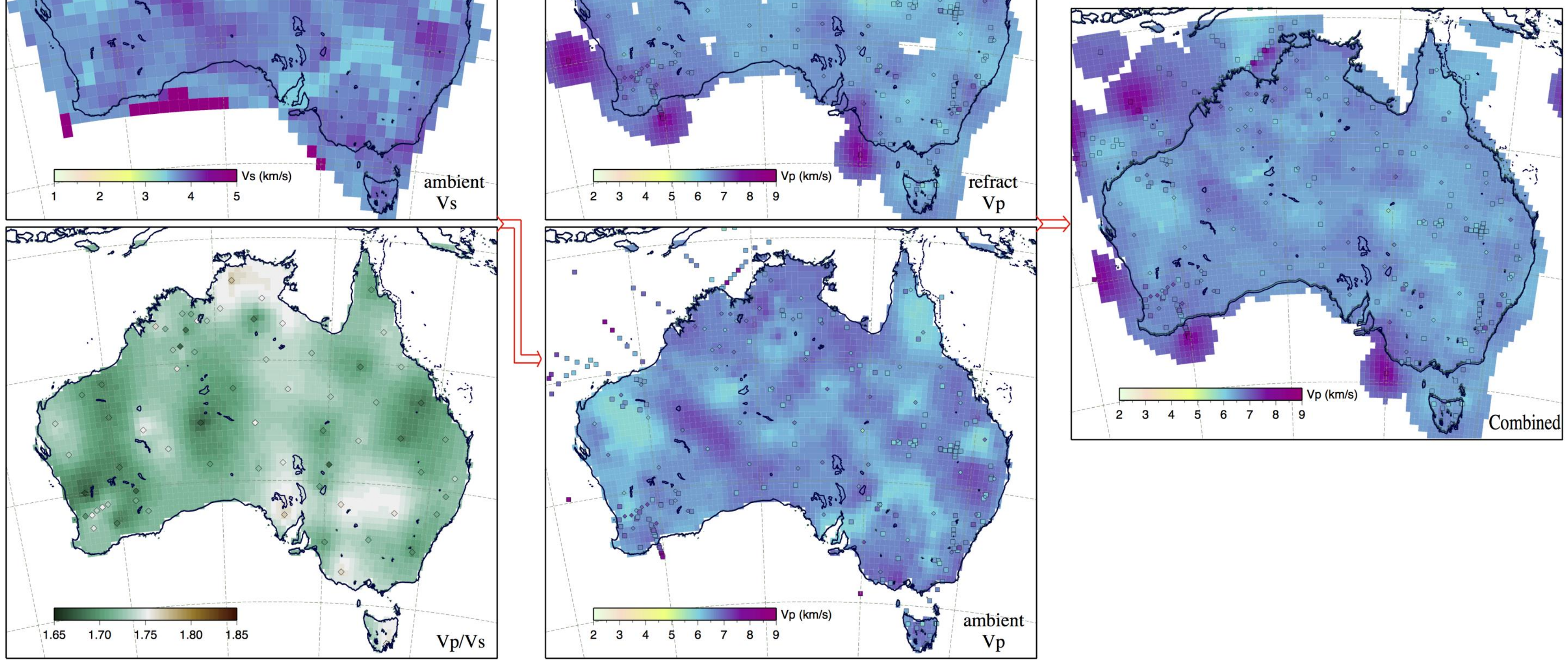

Figure 7.10: Construction of a continent-wide Vp field from ambient noise information and localised results from refraction and receiver function studies. Results from individual stations are superimposed on the interpolated distributions using the same colour scheme so that the controls can be identified. 
The crustal component of the Australian Seismological Reference Model (AuSREM) (Salmon et al., 2013a) exploited the available sources of information to build a digital 3-D model of the crust. The $P$ wavespeed is used as the primary control on seismic structure in the crust.

In this work, one of the early steps was to construct a smooth rendering of the $V p / V s$ ratio as a function of position and depth across the continent, exploiting the properties of the receiver functions. This allows the construction of a $\mathrm{P}$ wavespeed profile for each receiver function, and then a $V p$ field can be created from all of the local observations. In a similar way, a $P$ wavespeed distribution can be constructed from the ambient noise $V s$ results that contain information for the gaps between the various recording stations. The combination of the two continent-wide fields provides a good constraint on the $P$ wavespeed structure. The process is illustrated in Figure 7.10. Gaps in the $P$ wavespeed distribution from refraction and receiver function results occur because extrapolation has only been carried out to $100 \mathrm{~km}$ from any observation point. Such gaps are filled by the ambient noise results down to $25 \mathrm{~km}$ depth. At greater depths, the ambient noise coverage is insufficient so that some gaps remain.

In Figure 7.11 we display the $\mathrm{P}$ wavespeed from the AuSREM model as a number of depth slices through the crust across the Australian continent and into the near offshore regions. The equivalent $S$ wavespeed distribution is illustrated in Figure 7.12, and the $V p / V s$ ratio used to convert between the wavespeeds is displayed in Figure 7.13. The interpolation needed to produce the 3-D wavespeed model means that narrow features ( $<100 \mathrm{~km}$ wide) will only be represented if actually sampled by observations.
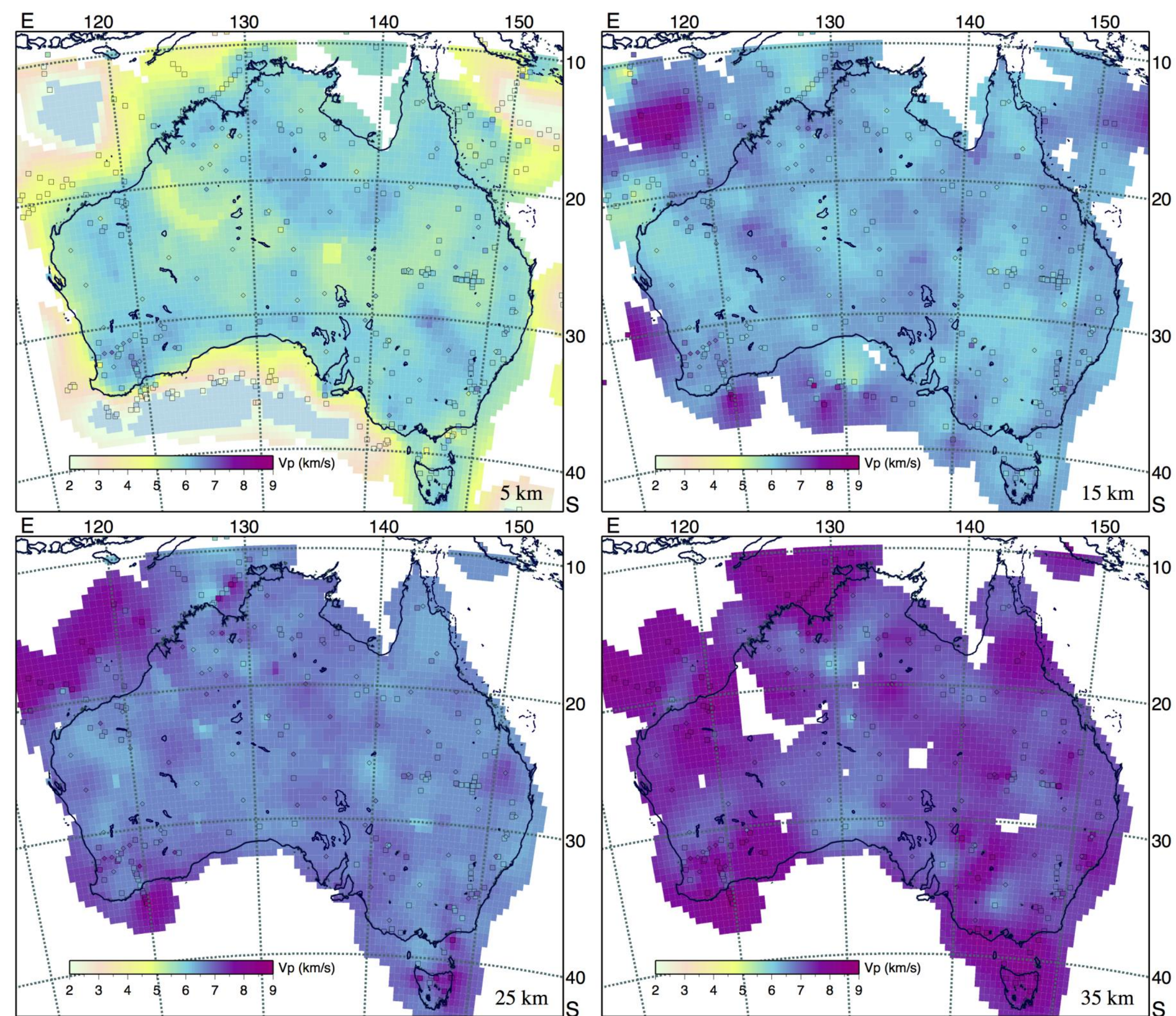

Figure 7.11: $\mathrm{P}$ wavespeed distribution through the crust from the AuSREM model. 

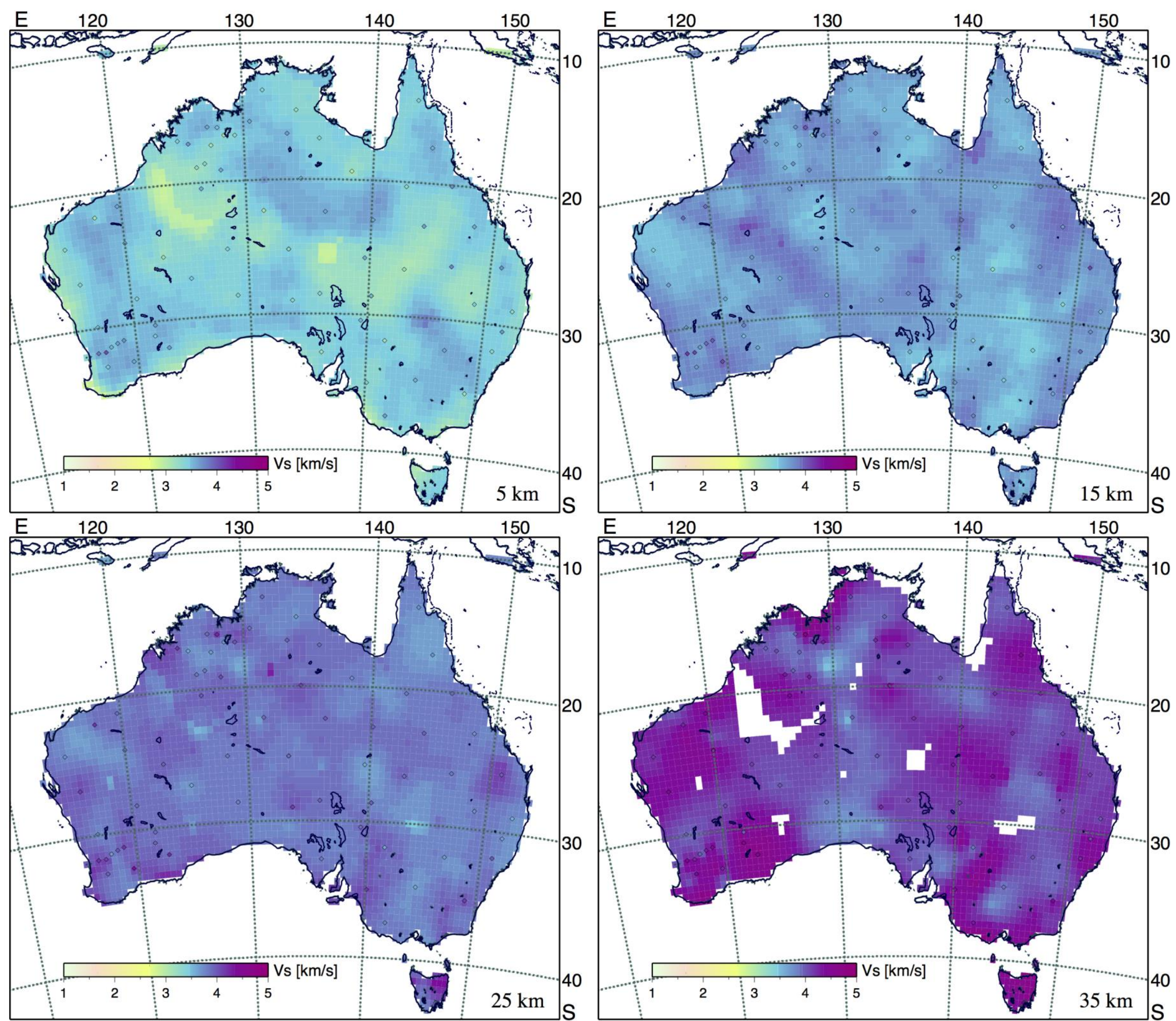

Figure 7.12: $\mathrm{S}$ wavespeed distribution through the crust from the AuSREM model.
Because many different types of geological materials have rather similar seismic velocities, the patterns of seismic wavespeeds often do not have any direct correspondence with geological features. Thus there is no obvious division in crustal properties between the older west and younger east.

In each of the displays of the structure from the AuSREM crustal model, we plot the wavespeed or velocity ratio estimates from the refraction and receiver function controls on top of the representative field, using squares for refraction results and diamonds for receiver functions. In general, we see a strong correspondence between the AuSREM crustal mode and the point constraints so that the symbols are often hardly visible. Nevertheless, a number of significant features in the depth slices down to $25 \mathrm{~km}$ can only be mapped because of the availability of the ambient noise tomography. In the depth slices at $35 \mathrm{~km}$ in Figures 7.11-7.13 we rely solely on the point information from refraction and receiver functions and blank out areas which lie more than $250 \mathrm{~km}$ from any direct control.

The $S$ wavespeed distribution shown in Figure 7.12 shows strong similarities with the patterns of $P$ wavespeeds, because of the relatively gentle variations in the $V p / V s$ ratio. However, we note differences such as higher relative $S$ velocities at $5 \mathrm{~km}$ in the Pilbara and along the eastern seaboard. The largest differences between the patterns of the $P$ and $S$ wavespeeds arise in the depth slice at $35 \mathrm{~km}$ where, e.g. the upper mantle is being sampled beneath the thin crust of the Pilbara. 
At $5 \mathrm{~km}$ depth we see influences from thick sediments (cf. Figure 2.9), and pick up lower wavespeeds in the Canning Basin, though the thick sediments in the narrow Fitzroy Trough are not adequately represented. Low wavespeeds are also seen beneath the Simpson Desert. The wavespeeds across the continent are quite high even at $5 \mathrm{~km}$ depth, with $\mathrm{P}$ wavespeed approaching $6 \mathrm{~km} / \mathrm{s}$.

Variations in both $\mathrm{P}$ and $\mathrm{S}$ wavespeed are more muted, at 15 and $25 \mathrm{~km}$ depth. A few strong local variations in wavespeed correlate with areas where the control is only provided by ambient noise tomography results.

In the $35 \mathrm{~km}$ depth slice, we see a generally good correlation of the pattern of $\mathrm{P}$ wavespeed with the depth to Moho (Figure 7.15). In a few areas, e.g. the Pilbara and to the north of Lake Eyre, we are already sampling the upper mantle at this depth. Areas with thicker crust commonly have lower $V p$ at the base of the crust than where the crust is thinner. Nevertheless, relatively high wavespeeds are seen in the Lachlan Orogen, where it is likely that a thickened lower crust has been assembled by underplating. Rather high velocities are found in the southern part of the Yilgarn Craton, where reflection profiling confirms that the $35 \mathrm{~km}$ depth slice resides in the crust (see the western edge of Figure 7.4).

The $V p / V s$ ratio distribution shown in Figure 7.13 shows a marked shift to higher values as a function of depth. $V p / V s$ ratios around 1.8 are characteristic of the uppermost mantle, but can be encountered towards the base of the crust in regions with a gradational transition from crust to mantle, as in the Northern Australian craton at around $20^{\circ} \mathrm{S}$.
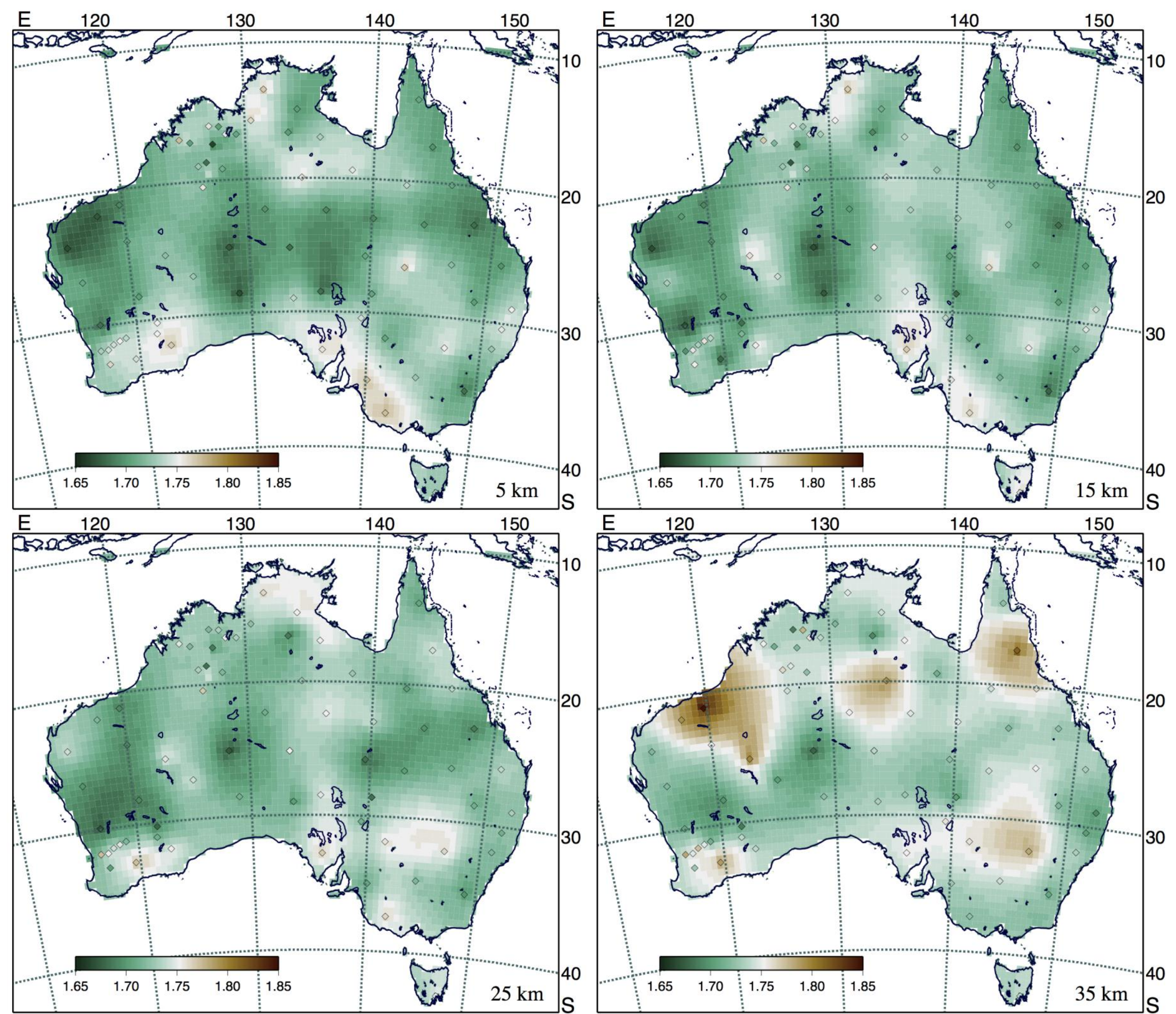

Figure 7.13: Vp/Vs ratio distribution through the crust from the AuSREM model. 
The AuSREM crustal model does not include any specific separation into upper and lower crust, even though many of the data sources incorporate subdivisions of the crust. As illustrated in the reflection transects in Figures 7.3-7.6, there are a number of localities where there is a very clear distinction between the reflectivity at shallow levels and that at depth. Such differences in reflection character may persist for a hundred kilometres or so, but are by no means universal.

Kennett et al. (2011) made an assessment of the different types of seismic discontinuities found in the various datasets across the continent and found few consistent patterns. Some areas show multiple discontinuities, whilst others show no obvious stratification.
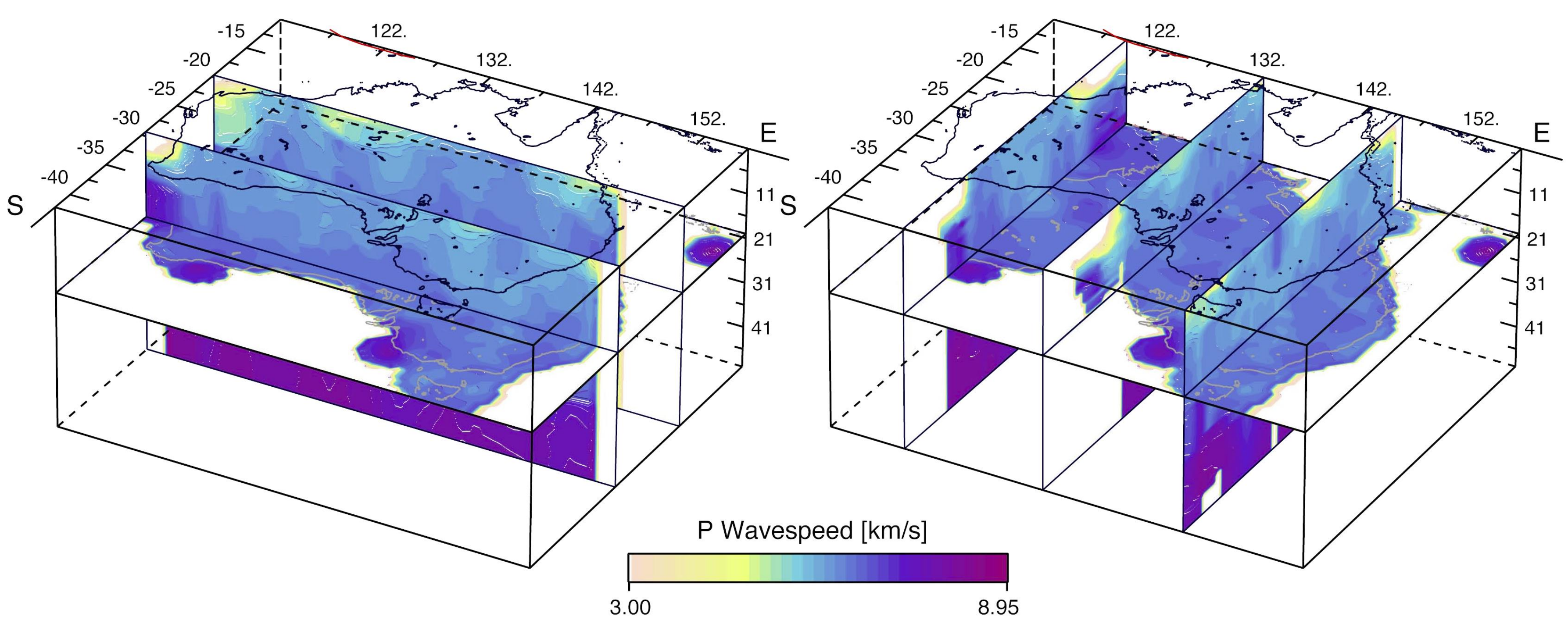

Figure 7.14: Slices at constant latitude and constant longitude through the 3-D AuSREM crustal model, together with a depth slice at $21 \mathrm{~km}$.
In Figures 7.11-7.13 above, we have illustrated the character of the crustal model with depth slices for different physical properties ( $V p, V s$ and $V p / V s$ ), but this AuSREM crustal model is a full 3-D digital product. Figure 7.14 attempts to display the full 3-D character by combining slices at constant latitude and constant longitude with a depth slice taken at $21 \mathrm{~km}$ depth, on which a grey outline of the continent is repeated to allow orientation.

The vertical sections in Figure 7.14 help to provide an indication of the significant contrasts in structure encountered across the continent. The vertical scale in Figure 7.14 is strongly exaggerated, but this is necessary if any detail is to be presented at the continental scale. 


\subsection{Moho}

Direct information on the depth to the Moho is available from seismic refraction experiments and the analysis of receiver functions. This information forms the backbone of the constraints on the Moho, but as we have seen in the discussion of crustal seismic wavespeeds the control is patchy across the continent. Refraction results provide most of the control offshore. For consistency with earlier results, the Moho depth values in Figure 7.15 define the base of the crust as the boundary where the velocities on the lower side are greater than $7.8 \mathrm{~km} / \mathrm{s}$ for $P$ waves and $4.4 \mathrm{~km} / \mathrm{s}$ for shear waves. Where the transition from crust to mantle occurs through a velocity gradient the base of the transition is chosen as the Moho.

To enhance continental coverage, we are also able to draw on the extensive network of full crustal reflection profiles. Along the lines illustrated in Figure 7.1, Moho picks have been made at 20 or $40 \mathrm{~km}$ intervals, as the base of prominent crustal reflections using a consistent style of display (similar to that illustrated in Figures 7.3-7.6). Conversion to depth has been made with the assumption of an average velocity of $6 \mathrm{~km} / \mathrm{s}$ through the whole crust. Cross-calibrations of this Moho depth can be made with the results of other methods including refraction work in southern Queensland and receiver functions in Western Australia. Despite the simple approximation used for depth conversion of the reflection Moho picks, the crustal thickness estimates are in good agreement with those obtained from other methods (Figure 7.15).

In southeastern Australia, the dense network of portable station deployments has been exploited to provide estimates of the $\mathrm{P}$ wave reflectivity across a network of stack points, with a reflection Moho picked at the base of crustal reflectivity.

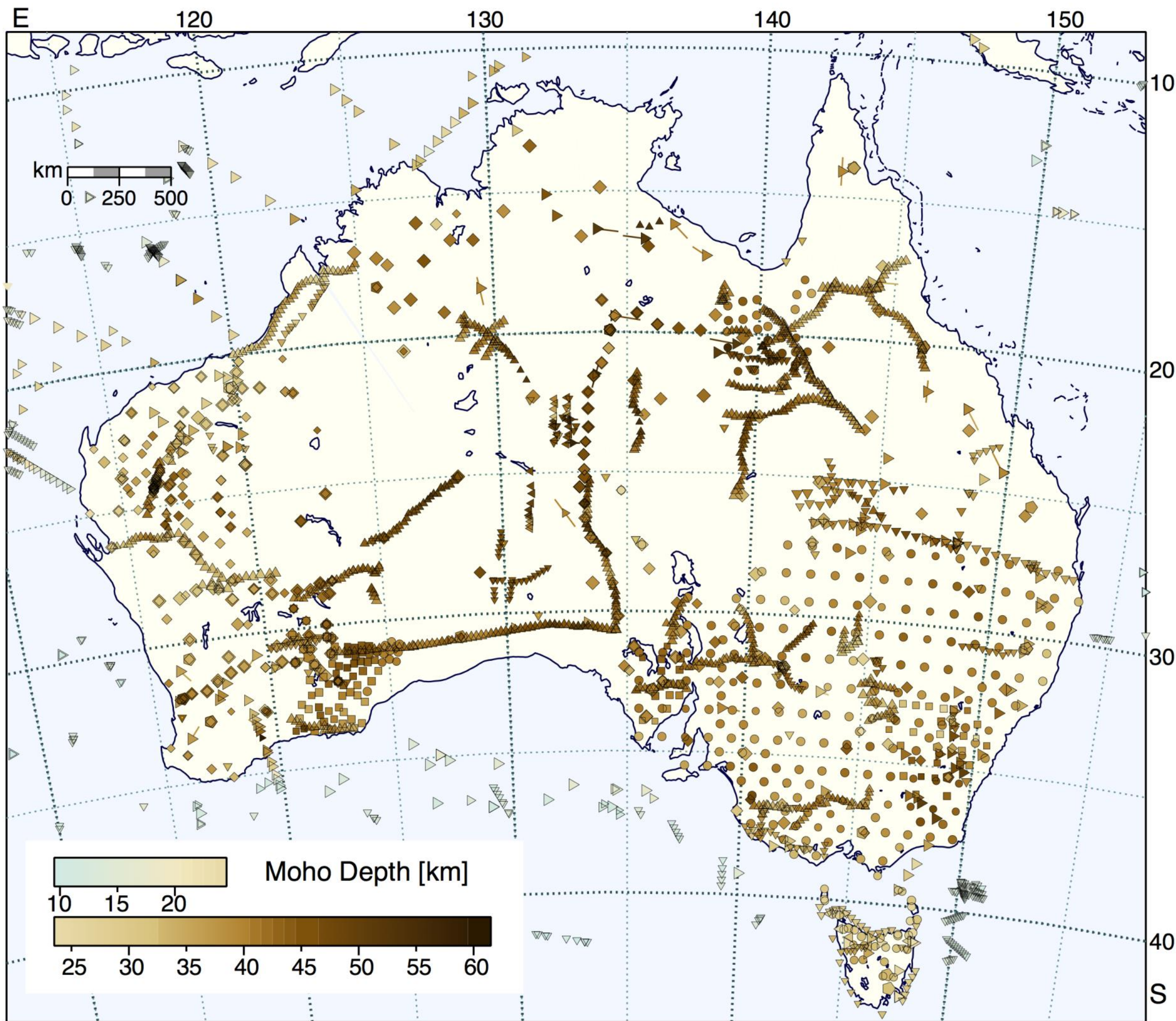

$\nabla$ Refraction $\triangleleft$ Tomography $\nabla$ Historic reflection $\nabla$ Reflection: explosives $\triangle$ Reflection: vibrators RF - permanent stations $>$ RF - broadband $\square$ RF - high frequency $\bigcirc$ AC - high frequency

Figure 7.15: Estimates of the depth to Moho across the continent and the offshore region. The different styles of symbols distinguish the methods employed. 
The tie between the autocorrelation results and the reflection profiling results in southeast Australia is good. The autocorrelation method can also provide Moho estimates in areas such as the Nullarbor Plain where reverberations from the complex near-surface structure overwhelm receiver function traces.

The various seismic datasets provide multiple estimates of the depth to Moho in many regions. The consistency between the different techniques is high, as can be seen in Figure 7.15, where distinctive symbols are used for each data type. In a number of instances, differences in the estimates for Moho depth can be associated with the aspects of the structure highlighted by the particular methods. Thus, for example, receiver functions may see a discontinuity at the top of a reflection package, whilst the reflection Moho pick would be made at the base.

The distribution of Moho picks in Figure 7.15 is based on the full range of available information at the end of 2016, including many data points that were not available for the model produced by Salmon et al. (2013b). These new data include nearly $4000 \mathrm{~km}$ of additional reflection profiling, the autocorrelation results and many new results from portable instrument deployments in Western Australia. Data coverage still remains low in the Simpson and Great Sandy deserts

The full Moho surface illustrated in Figure 7.16 is derived from the data points in Figure 7.15 using the interpolation tools from the GMT package (Wessel and Smith, 1998), with a conservative approach targeted at $0.5^{\circ}$ resolution across the continent. In Figure 7.16 we show the individual data points with the colour code associated with their specific data value, overlain on the interpolated surface of Moho depth-in most cases they are barely visible, indicating a successful interpolation to produce the model.

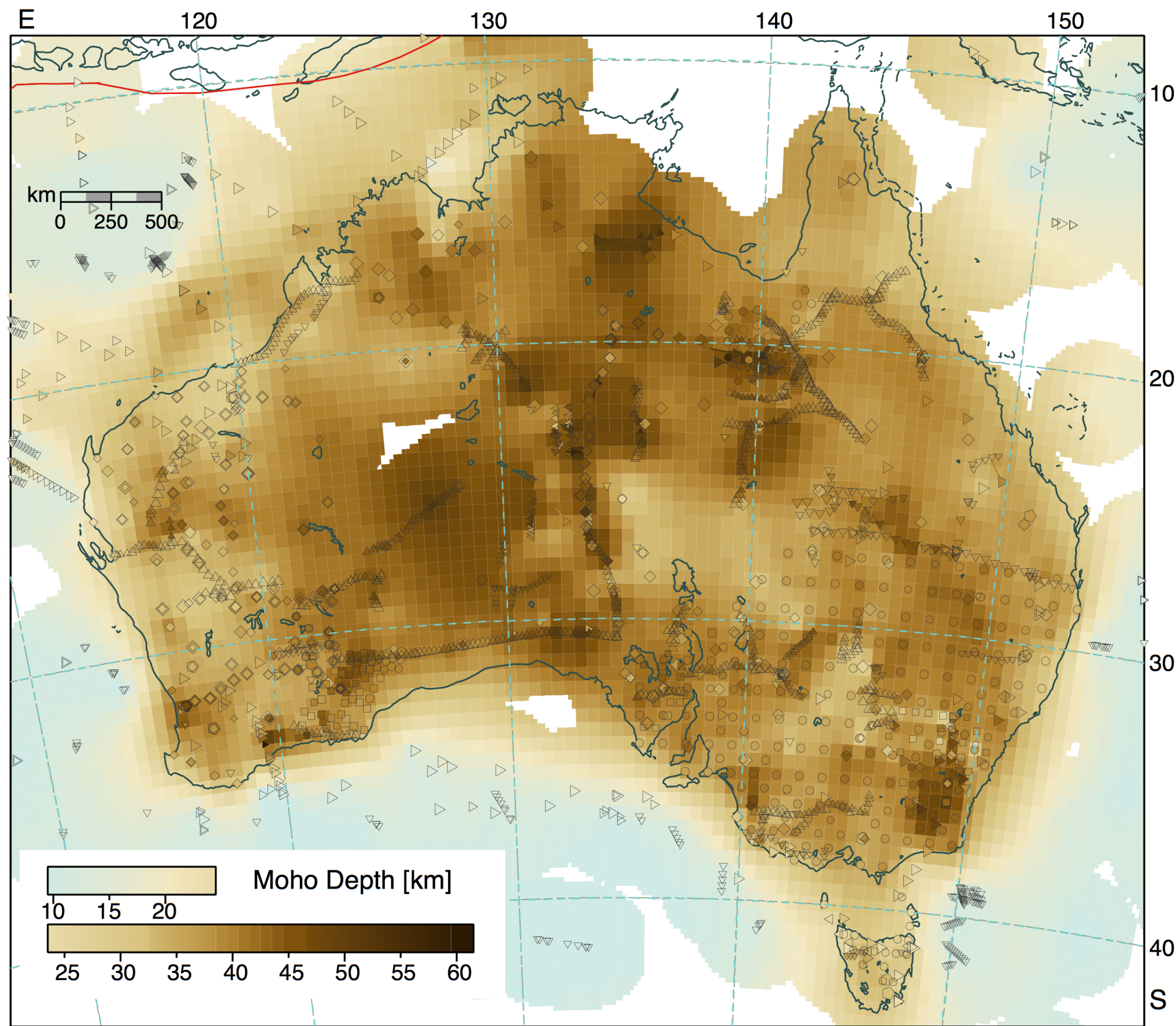

Figure 7.16: Moho surface across Australia utilising the full range of seismic information 
Within each $0.5^{\circ} \times 0.5^{\circ}$ cell the weighted, mean Moho depth from all relevant Moho depth estimates is extracted, with weighting of the individual data points based on estimates of the data reliability. The weighted means for each cell are then interpolated using an adjustable tension continuous curvature gridding algorithm (Smith and Wessel, 1990). The tension factor is set to 0.45 to allow for steep Moho topography. The resulting surface is displayed, allowing the influence of each cell to extend no further than $250 \mathrm{~km}$. Even with this generous choice of data point influence there are still regions in the deserts of Western Australia without control on the Moho depth. The error associated with the representative surface can be expected to be less than $2 \mathrm{~km}$ where there is good data control and may perhaps reach $5 \mathrm{~km}$ in the least well-sampled areas, which are smaller than before. As noted by Kennett et al. (2011), the controls on the Moho are sufficient that the pattern of Moho depth is not sensitive to the particular interpolation scheme employed.

There is evidence in a number of parts of Australia, e.g. Central Australia (Goleby et al., 1989) for localised jumps in the Moho of $10 \mathrm{~km}$ or more. Such features cannot be represented directly in a smooth model, but by allowing strong local gradients, the contrasts in Moho structure can be included. The control on the Moho depth is now better than for seismic wavespeeds, particularly where seismic reflection profiles cross regions with sparse velocity constraints. Future work will be aimed at improvng the concordance between the Moho and wavespeed structure.

\section{Patterns of Moho Depth}

The oldest portions of the West Australian Craton, the Pilbara Craton and the northern Yilgarn Craton have Moho depths ranging from $30 \mathrm{~km}$ to $35 \mathrm{~km}$. The crust thickens slightly beneath the Neoarchean Hamersley Basin at the southern edge of the Pilbara, which has extensive banded iron formations. However, the main change in crustal thickness occurs in the Capricorn Orogen where the Moho depth exceeds $40 \mathrm{~km}$. Control in the Capricorn region is strong from a combination of refraction experiments, receiver functions and recent reflection transects. The thickest crust with a rather indistinct base is found in the Glenburgh Terrane at the western edge of the Capricorn Orogen. In the Yilgarn Craton itself, Reading et al. (2007) have noted a progression in crustal structure with greater Moho depth associated with younger parts of the craton in the west. This trend can be seen very clearly in Figure 7.16, and in Figure 7.17 where the geological provinces are superimposed on the Moho surface.

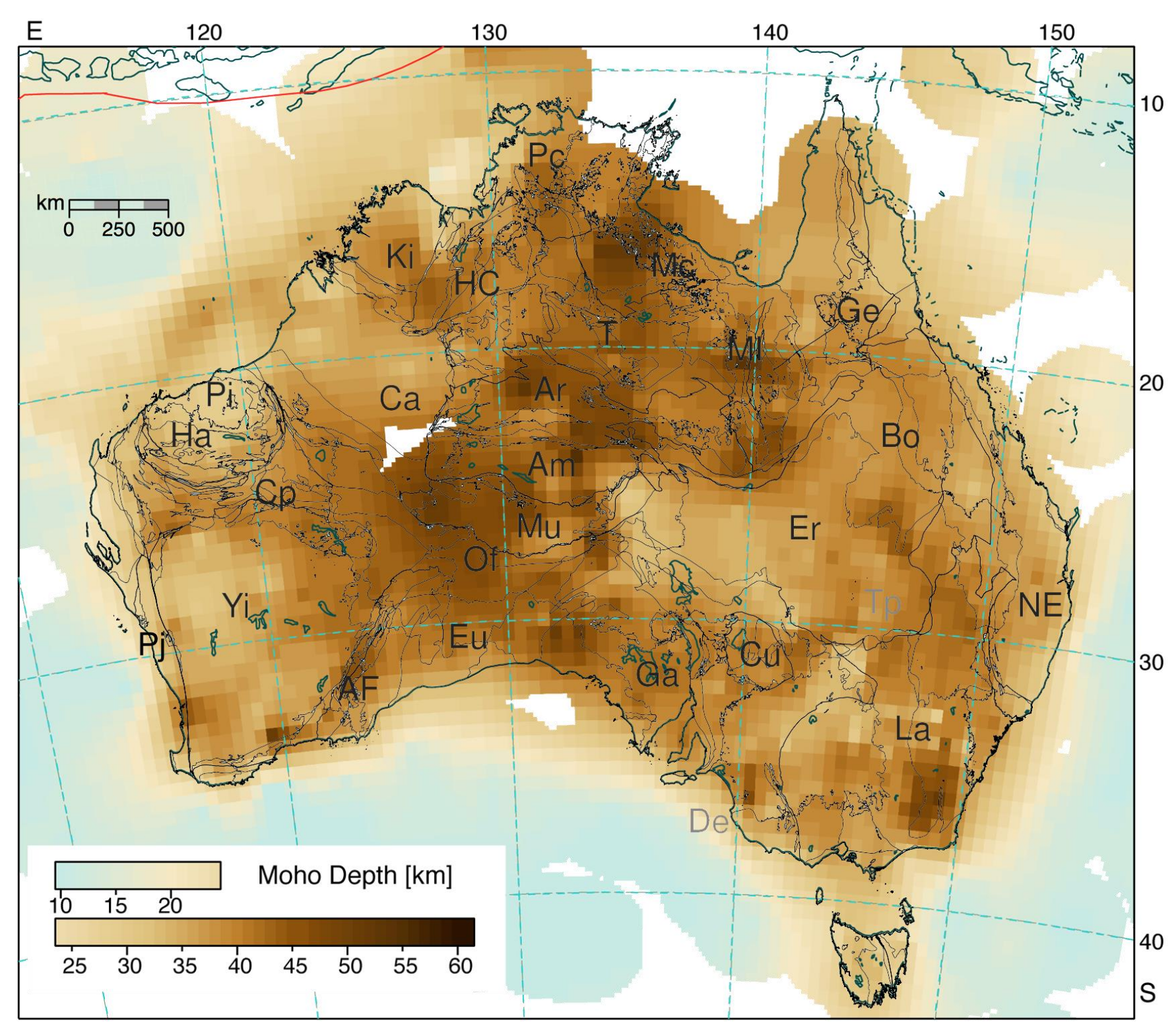

Figure 7.17: Moho surface with geological provinces.

There is little control on the Moho in the very narrow strip of the Pinjarra Orogen along the western coastline of Australia; just a few receiver functions sit in this zone. Moho depth appears to be about $30-35 \mathrm{~km}$, with thick sedimentary piles in places.

In the Kimberley Block, the gravity field results exploited by Aitken et al. (2013) suggest that Moho depth greater than $40 \mathrm{~km}$ extends across the entire block, extending the zone of thickened crust seen in the seismic results (Figure 7.17).

Reflection profiling across the Officer Basin from the eastern edge of the Yilgarn Craton to the Musgrave Province in 2011 (see Figure 7.3) revealed a zone of thick crust near $26^{\circ} \mathrm{S}, 126^{\circ} \mathrm{E}$ that was not expected from previous sparse receiver function sampling. The thickening may be due to mantle underplating in the 
suture zone between the Western and Northern Australia cratons. The 2012 reflection profiling across the Albany-Fraser Belt indicates localised thickening of the crust at the edge of the Yilgarn Craton (Figure 7.4), and this has been confirmed with additional results from a portable seismic instrument deployment (Sippl et al., 2017), which indicates a continuous zone of thickened crust just at the craton margin.

The major features of crustal thickness variation through Central Australia are well delineated from a combination of reflection profiles and receiver function studies, with some major early refraction experiments. The thickest crust in Australia occurs in this region, but is somewhat fragmented. On the reflection transects, distinct sharp jumps in the Moho of up to $20 \mathrm{~km}$ are associated with the major east-west gravity anomalies (e.g. Goleby et al., 1989; Korsch et al., 1998). In the north of the Central Australian zone, the crust appears to thin in the Pine Creek Inlier to less than $35 \mathrm{~km}$ thick, but we have currently no direct control in the structure in Arnhem Land to the east. In the Proterozoic MacArthur Basin, a little further south, refraction and reflection work indicates localised very thick crust. The Tennant Creek Inlier also has crust thickness up to $50 \mathrm{~km}$, but the base of the crust shows an extended gradient from crust into mantle (Bowman and Kennett, 1991). Much of the Arunta Province also has rather thick crust (more than $50 \mathrm{~km}$ ) with a gradational base and a weak reflection Moho (e.g. Korsch et al., 1998). A prominent feature of the southern part of Central Australia is the strong gradient in Moho depth close to $135^{\circ} \mathrm{E}$ that juxtaposes $30 \mathrm{~km}$ crust against much thicker material (45 km or more). The area with the thinnest crust is broadly coincident with a topographic low containing the Lake Eyre basin, which lies below sea level.

Although the Gawler Craton in the south has Archean material, some as old as the Pilbara, the Moho depth is greater than for the older parts of the Western Australian cratons at more than $40 \mathrm{~km}$, with good control from reflection profiling. The Curnamona Craton also appears as a distinct entity with thicker crust than its surroundings.

In northern Queensland, the Mt Isa Province has rather thick crust (greater than $40 \mathrm{~km}$ ) with relatively sharp edges to the south and the northeast. There is a strong gradient in seismic velocities at the base of the crust and the Moho is only moderately distinct in reflection data. As seen in the reflection transect in Figure 7.6, towards the Georgetown Inlier, the crust thins rapidly to around $35 \mathrm{~km}$ with a very clear reflection Moho. Under the Georgetown Inlier distinct domains of consistent seismic character can be recognised and the transition between domains are marked by Moho steps of up to $8 \mathrm{~km}$ (Figure 7.6).

Control on the Paleozoic structures in the east is mostly from refraction and receiver function studies, but extensive reflection and refraction work in the 1980s provides good control along a $1200 \mathrm{~km}$ transect from the Eromanga Basin to the coast. In the southern part of the Lachlan Orogen, the presence of thick crust with a basal crustal gradient is well established from refraction experiments. There is only modest seismic control on the New England Orogen, but this zone appears to have thinner crust (around $35 \mathrm{~km}$ thick) than the Lachlan Orogen.

The patterns of Moho depth across the Australian continent do not display any clear dependence on surface or basement age, though Mesozoic-Cenozoic cover limits the available sampling. However, there is a tendency for thicker crust in the Proterozoic orogens, such as the Capricorn of Western Australia and the Arunta of Central Australia. Strong local contrasts in Moho thickness can be recognised in a number of places from the extensive reflection profiles, but cannot be readily represented in a continent-wide Moho surface as in Figure 7.15.

The strong east-west gravity anomalies in the centre of the continent are associated with rapid changes in crustal thickness. The Arunta example is presented in Goleby et al. (1989), and an equally prominent change is seen in the Musgrave Province on the 2008 reflection profiling (Korsch and Kositcin, 2010). At the southern margin of the Capricorn Orogen it appears that the Moho from the Proterozoic domain is wedged beneath the Yilgarn Craton. A similar pattern is seen at the Yilgarn/Musgrave contact.

We note also localised thickening at the Yilgarn Craton margin associated with the $\sim 1390$ Ma Albany-Fraser Orogeny, and at the western margin of the Gawler Craton. In northeastern Australia there is a rapid transition from the very thick Mt Isa Block ( 1900 Ma) into thinner crust to the east that then thickens again into the Georgetown Inlier (of similar age to Mt Isa)-this zone may have been rifted and then inverted during compression to give the present-day configuration.

The range and diversity of such Moho features in regions not subject to orogenesis since at least $500 \mathrm{Ma}$ implies considerable longevity of Moho topography. Indeed, in the Australian environment, many features may well have survived from their time of formation. 


\subsection{Crustal Attenuation}

A prominent feature in the seismograms from continental earthquakes is the $\mathrm{Lg}$ phase, which can be described as either a superposition of multiply reflected $S$ waves within the crust or as a combination of the higher modes of seismic surface waves. The phase follows the $S$ wave arrival with a group velocity around $3.5 \mathrm{~km} / \mathrm{s}$, and is usually the largest contribution to higher frequency seismograms at regional distances, out to $1500 \mathrm{~km}$ or more.

The Lg phase samples the whole crust and provides valuable complementary information to other seismic probes. As frequency increases, the sensitivity of the phase tends to be focused towards the shallower zone.

Wei et al. (2017) have used 469 events, recorded at 203 stations with sourcestation separation from $200 \mathrm{~km}$ to $2000 \mathrm{~km}$, in a tomographic study of the properties of the Australian crust. The frequency dependence of the $\mathrm{Lg}$ phase was exploited to produce maps of seismic attenuation in the crust as a function of frequency. We summarise this source of information on crustal properties in Figures 7.18-7.20.

We display the average $\mathrm{Lg} Q$ in the frequency band $0.6-1.0 \mathrm{~Hz}$ in Figure 7.18, and the frequency exponent $\eta$ for the frequency dependence of attenuation in Figure 7.19. For this frequency band, $\mathrm{Lg}$ waves provide a sample of the entire crust, with some modest emphasis on the shallower regions. Figure 7.20 shows estimates of the spatial variation of the group velocity of the $\mathrm{Lg}$ waves Each of these various aspects of $\mathrm{Lg}$ propagation has a strong correlation with the patterns of geological provinces across Australia, but in different ways.

As we can see from Figure 7.18, much of the Australian continent has relatively high $\operatorname{Lg} Q$ values indicating low attenuation, though there are regions with quite low $Q$ in the east. The Archean Yilgarn Craton has very high $Q$ values, though the average $Q$ is a little lower in the Archean Pilbara Craton with thinner crust (around $30 \mathrm{~km}$ thick). There is a tendency for $Q$ to rise with the age of the crust.

The tomographic images of $\mathrm{Lg}$ attenuation structure indicate a good tie between the patterns of variation in Lg-wave $Q$ and the main tectonic features of the Australian continent, and the average $\mathrm{Lg} Q$ values increase with increasing frequency. The regions in central and western Australia show weak attenuation (high Q). At all frequencies, there is a distinctive anomaly with relatively high attenuation (low $Q$ ) in a north-south belt through the Tasman Orogen.

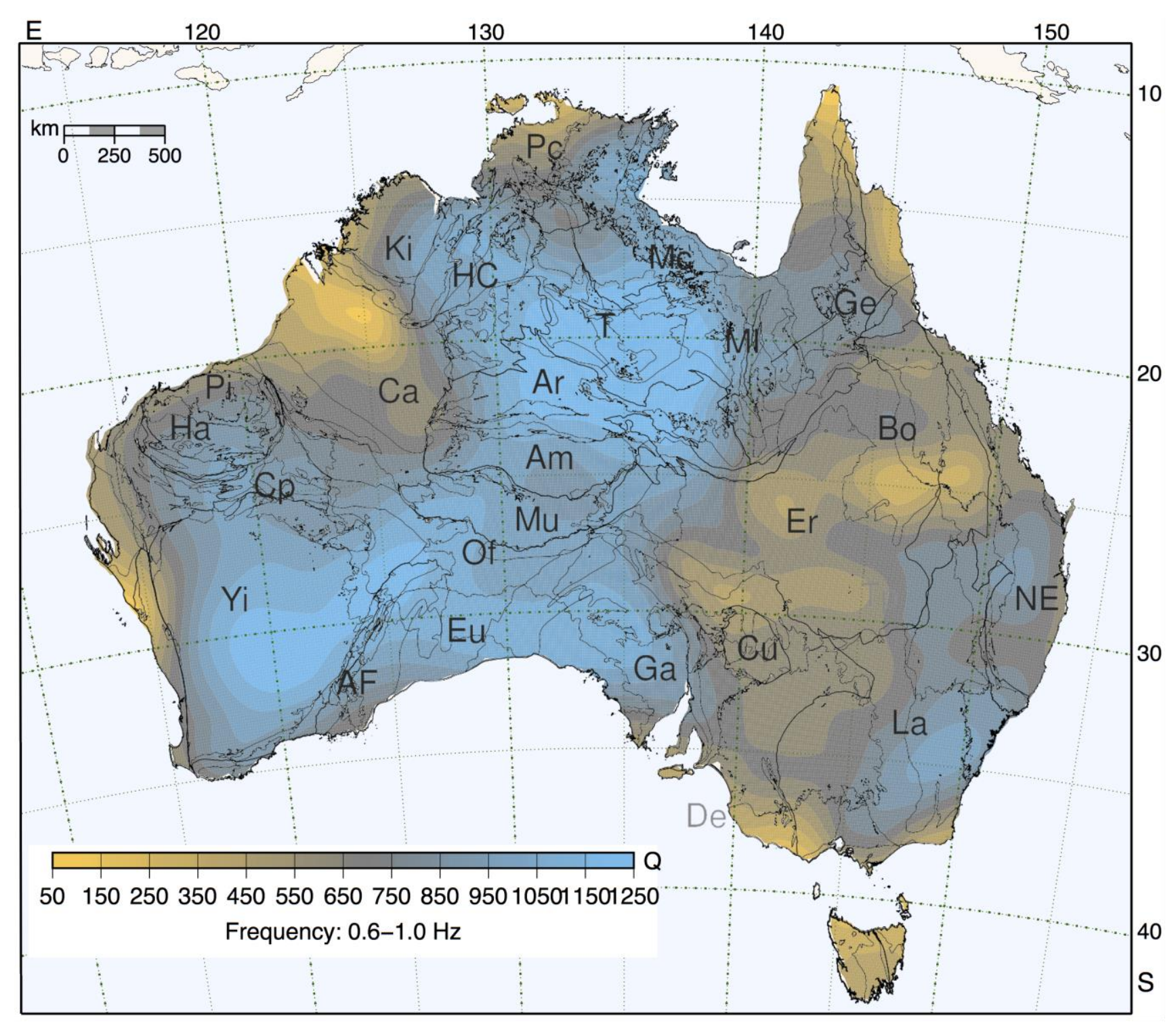

Figure 7.18: Spatial variation of $\mathrm{Lg}$-wave $\mathrm{Q}$, with geological provinces.

Much of the South Australian Craton displays low Lg attenuation (higher Q), though the Curnamona Craton shows only moderate $Q(\sim 600)$. Large portions of eastern Australia are dominated by moderate $\mathrm{Lg}$-wave attenuation, though areas with thinner crust tend to show lower Q. The Lachlan Orogen and New England Orogen have relatively high $Q(>800)$, similar to the cratons in Western Australia. Tasmania is not adequately resolved with the available data.

Lg-wave attenuation is sensitive to the presence of areas with locally higher temperature. The regions where geothermal effects are well recognised, such as the corner between Queensland and South Australia in the Eromanga Basin, show extremely strong $\mathrm{Lg}$-wave attenuation whose $Q$ values are even less than 200. Variations in temperature are expected to play a large part in controlling attenuation behaviour, with a decrease in temperature leading to increased $Q$. 


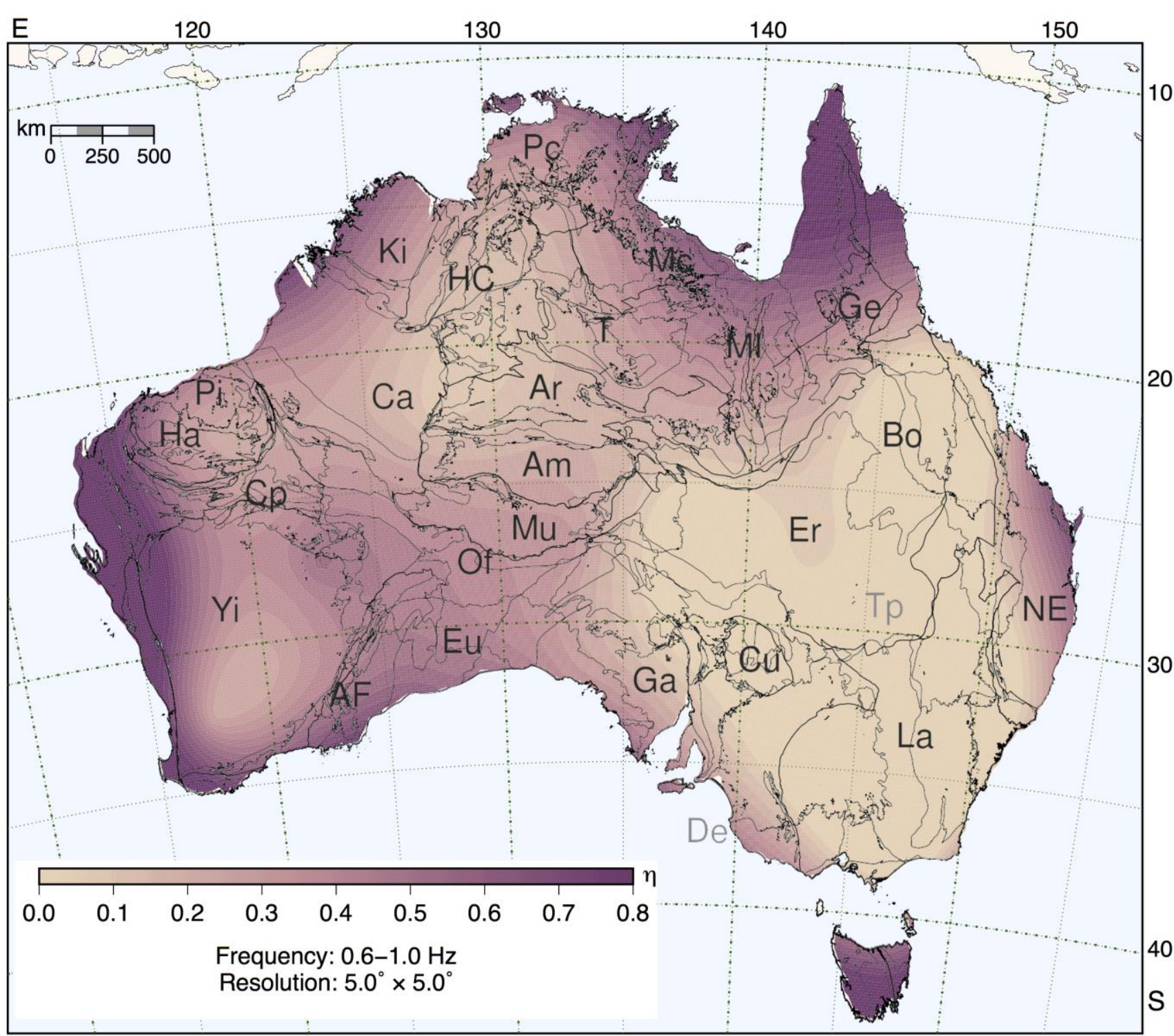

Figure 7.19: Spatial variation of the frequency exponent for attenuation $(\eta)$.

The relation between seismic wave attenuation, seismic wavespeeds and temperature is highly nonlinear (e.g. Jackson and Faul, 2010), especially as the solidus is approached.

The frequency dependence of $\mathrm{Lg} Q$ across the continent is quite complex, as can be seen in Figure 7.19. The Pinjarra Orogen along the southwestern coast of Australia shows a distinct stripe of lower $Q$ (Figure 7.18), but this is too narrow to be fully resolved in the other images, though there is tendency to more rapid frequency variation in this area. The Canning Basin also stands out as a zone of lowered $\mathrm{Q}$, with somewhat less frequency dependence and mildly reduced $\mathrm{Lg}$ group velocity (Figure 7.20). In the frequency dependence plot, the Kimberley Block has a notable difference from its surroundings with rapid frequency variation of $Q$, but this is not reflected in the other fields.

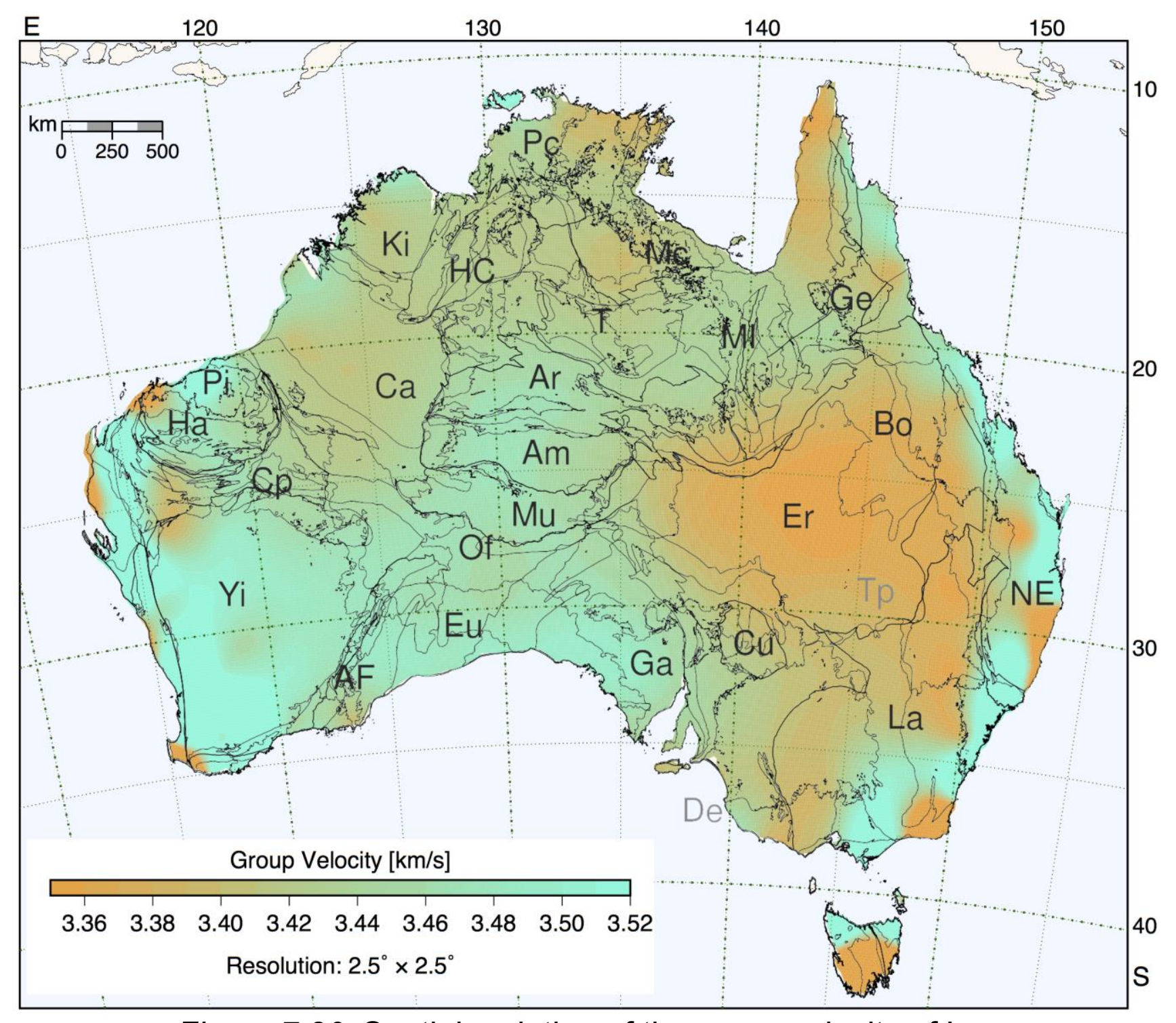

Figure 7.20: Spatial variation of the group velocity of $\mathrm{Lg}$.

Similarly, the eastern part of the North Australian Craton shows strong frequency variation of $Q$ with a sharp boundary to the south of Mt Isa. The area to the south of this boundary, with low frequency variation of $Q$, also largely corresponds to a zone of rather low $\mathrm{Lg}$ group velocity. The eastern boundary in $Q$ itself is closer to $140^{\circ} \mathrm{E}$ and the regions of lowered $\mathrm{Q}$ are more localised, most likely reflecting temperature variations at depth beneath the sedimentary basins. The AlbanyFraser Orogen, Eucla Basin and southern Officer Basin separating the West and South Australian cratons have more frequency variation in $Q$ than the cratons, indicating a change in crustal character. A further prominent feature in the frequency variation of $Q$ between $0.6 \mathrm{~Hz}$ and $1.0 \mathrm{~Hz}$ is the high exponent in the New England Orogen, which distinguishes it from the Lachlan Orogen to the west. The Lachlan Orogen shows relatively high $Q$, but the group velocities are rather slow towards the north, and faster in the south. 


\section{Seismic Structure: Mantle}

A distinctive feature of the structure in the mantle component of the lithosphere beneath the Australian continent is a strong contrast in character between the Precambrian areas in the west and centre and the younger east. The west has a much thicker lithosphere with rather high shear wavespeeds, whereas beneath the Phanerozoic east the lithosphere is quite thin and there is a prominent zone of lowered seismic wavespeeds below.

The differences in wavespeed structure are reflected in the character of the seismic wavefield as illustrated in Figure 8.1, with the seismograms from the 2012 Ernabella earthquake in central Australia recorded at stations in the national network.

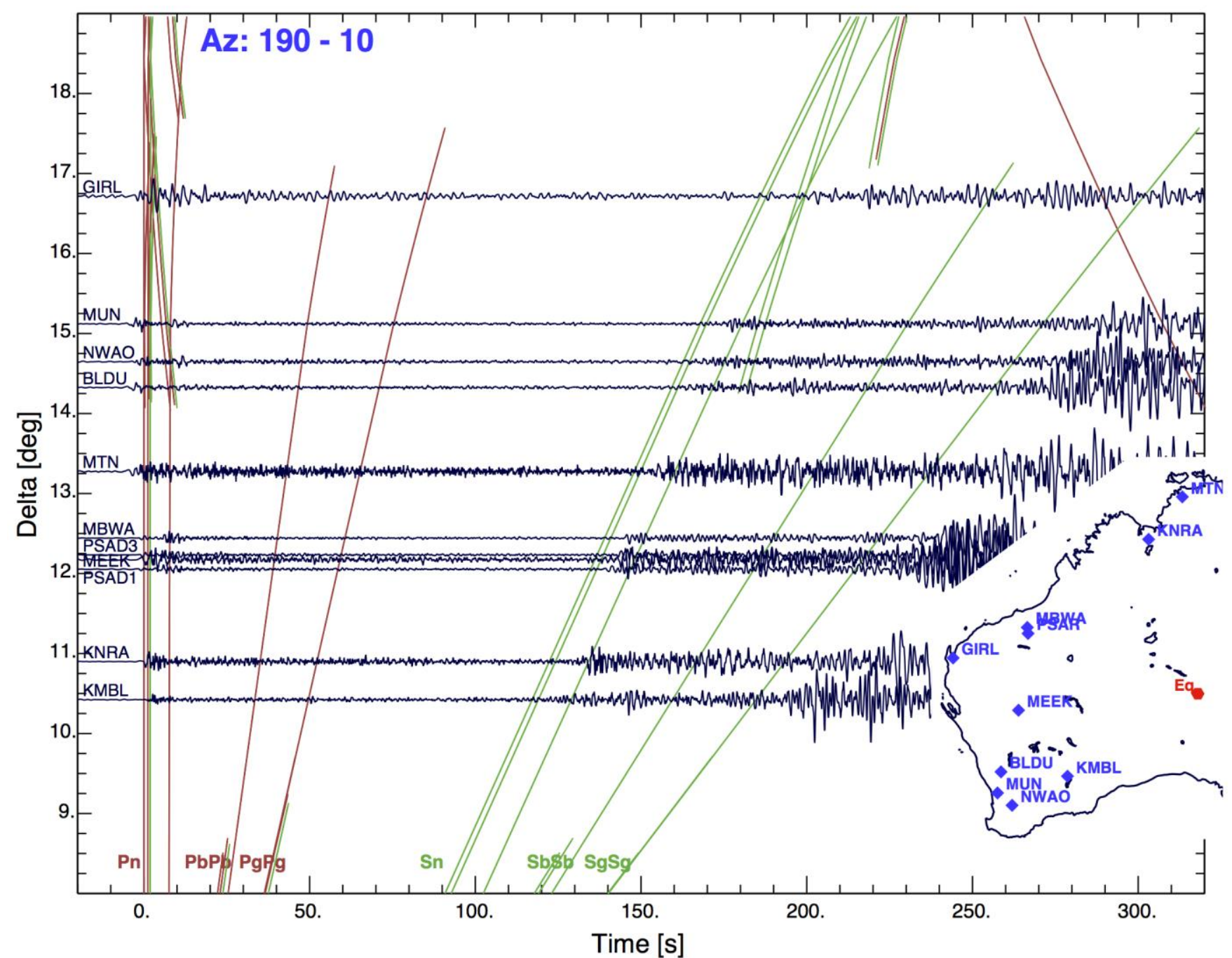

In Figure 8.1, we separate western stations for which the paths cross cratonic regions from the eastern stations, which mostly reside on the Phanerozoic. There is a substantial difference in the appearance of the seismograms. Not only do the $\mathrm{P}$ wave arrivals at western stations (left panel) arrive slightly early compared with the reference travel times, the $P$ and $S$ signals are relatively high frequency with sustained coda. For the eastern stations (right panel), the $\mathrm{P}$ and $S$ arrivals are slower compared with the times predicted by the same reference model, and the frequency of $S$ is lower because of increased attenuation in the east.

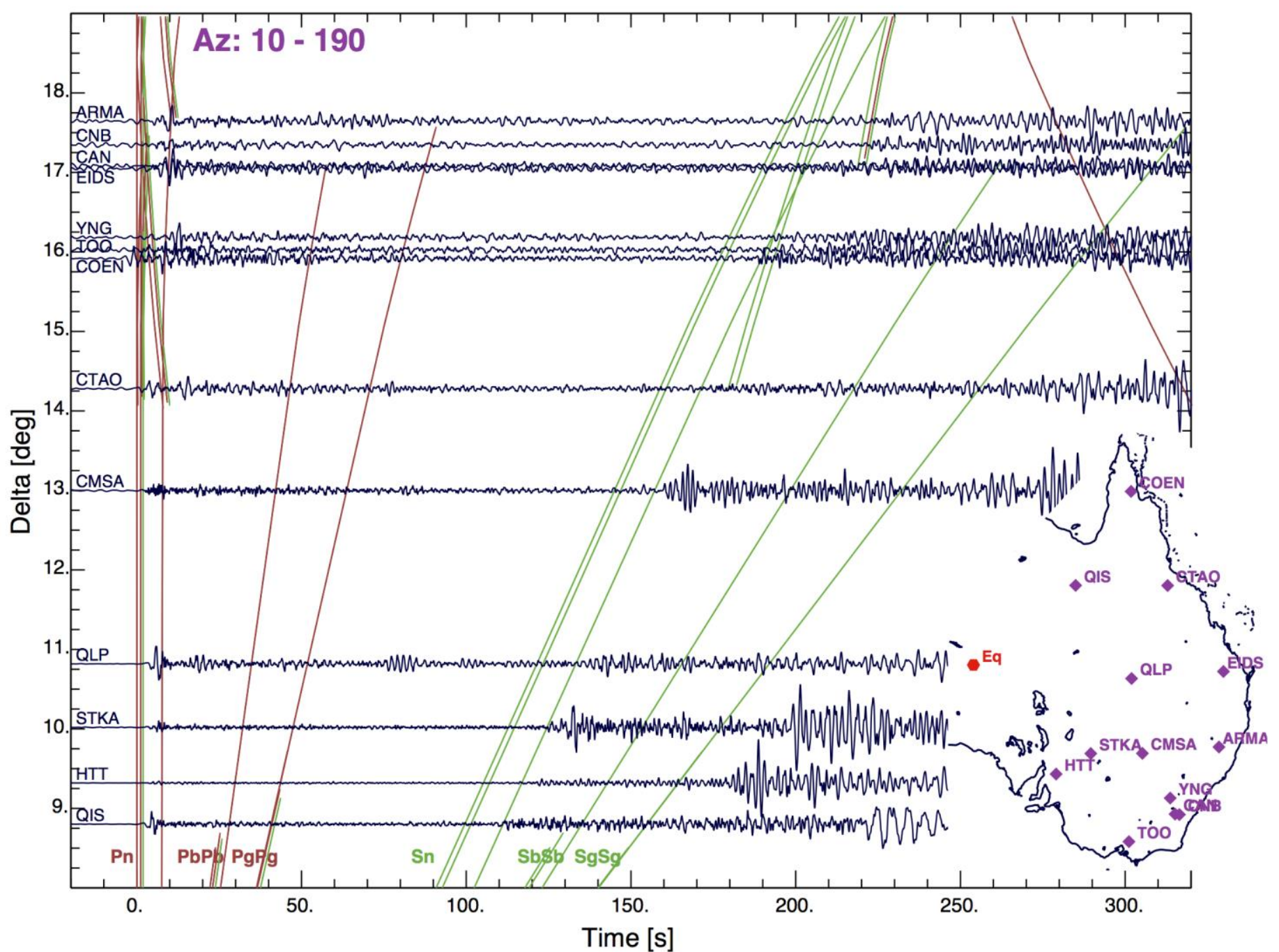

Figure 8.1: Seismograms from the Ernabella earthquake of 2012 March 24, as recorded at stations in western and eastern Australia. To the west (left panel), both $P$ and $S$ wave arrivals show similar levels of high frequencies and sustained coda. Whereas to the east (right panel), there is a more distinct difference with generally lower frequency $S$ wave arrivals and surface waves. 


\subsection{Mantle Lithosphere}
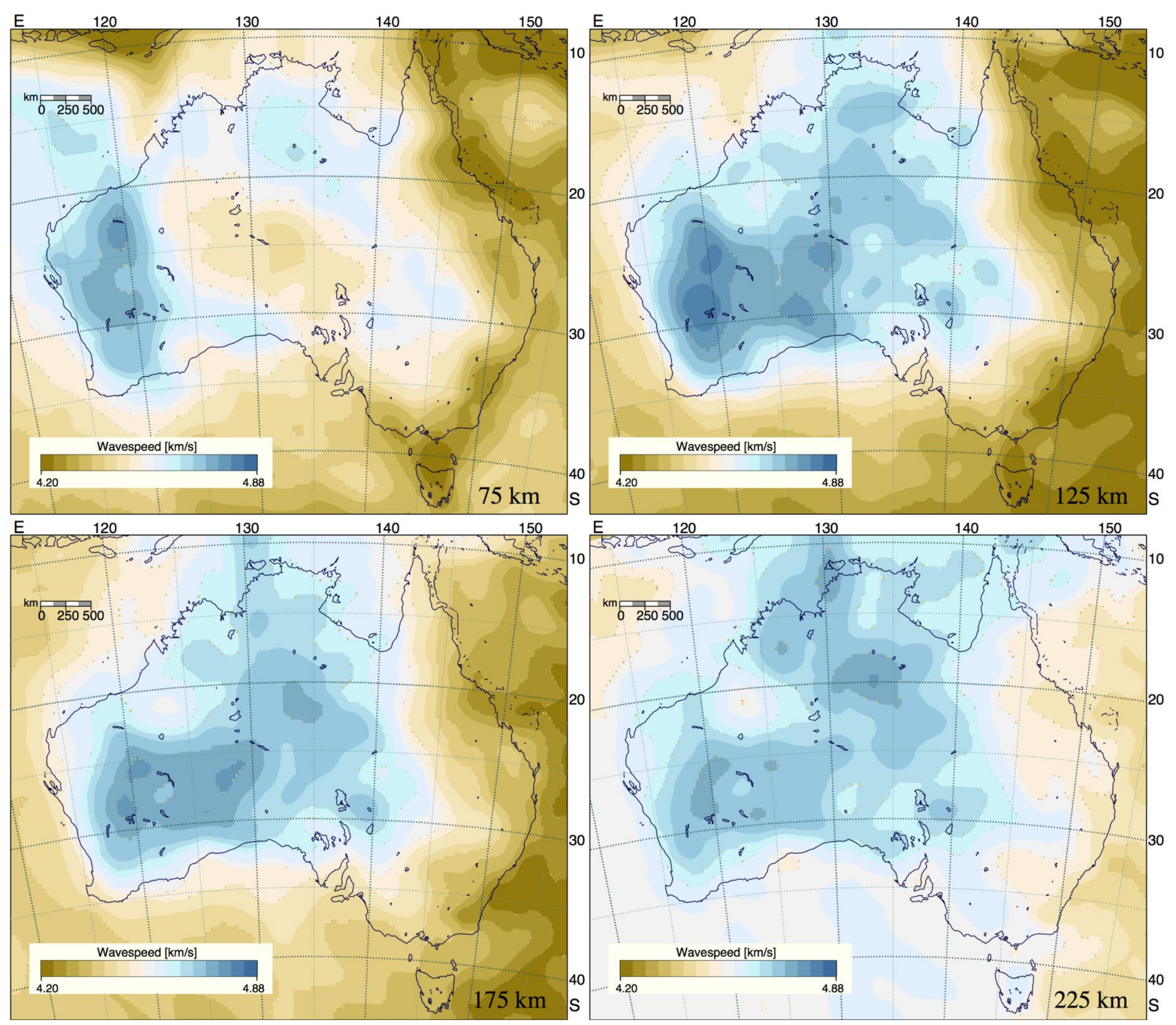

Figure 8.2: Depth slices through the AuSREM mantle SV wavespeed model.

\section{Upper Mantle Model}

In a similar way to the crustal model, the mantle component of AuSREM has been constructed to provide a representative 3-D structure building on the results from earlier studies (Kennett et al., 2013). The final model is represented through the SV wavespeed distribution, and other properties are defined through appropriate remapping.

The primary source of information on structure in the mantle lithosphere and asthenosphere beneath comes from seismic surface wave tomography. This approach exploits the large amplitude Rayleigh and Love waves that arrive late in the seismograms from regional earthquakes, together with the previous portion of the seismogram which can be regarded either as the superposition of multiple $S$ waves returned from the mantle or higher modes of the surface waves. A number of different styles of analysis were considered, but all aimed to match the observed seismograms with synthetic seismograms for a suitable class of models. The simplest procedure is a two-stage approach, in which a radially stratified Earth model is created for each source-receiver path, and these models are regarded as averages of an underlying 3-D model, which can be reconstructed by inversion. A threestage approach uses such radially stratified models as summaries of the dispersion properties of multi-mode surface waves to construct maps of the behaviour as a function of mode number and frequency. Dispersion curves are constructed at a regular grid of points, and a 3-D model is then built from the 1-D profiles determined from inversion of the surface wave dispersion at each point. The most direct, but computationally expensive, approach is to employ a full 3-D inversion for structure with 3-D calculation of synthetic seismograms. 


\section{SV Wavespeed:}

The AUSREM SV wavespeed model represents a balance between these different styles of analysis, which produce very similar results for the longwavelength component of the wavespeed model (Fichtner et al., 2012), but differ more at shorter wavelengths. In Figure 8.2 we display depth slices at $50 \mathrm{~km}$ intervals through the portion of the SV wavespeed AuSREM model that lies beneath the Australian continent. It is immediately apparent that rather high shear wavespeeds persist to a depth of $225 \mathrm{~km}$ - indicative of a thick cratonic lithosphere. On the eastern margin of the continent we encounter quite low shear wavespeeds in the depth range from 75$175 \mathrm{~km}$, associated with thinner lithosphere and a consequent shallow asthenosphere. The Tasman Sea region displays quite low SV wavespeeds (down to 4.2 $\mathrm{km} / \mathrm{s}$ ), probably as a result of residual heat left from failed rifting around $80 \mathrm{Ma}$.

Compared with the Western Australian Craton, the shear wavespeeds in central Australia are somewhat lower at $75 \mathrm{~km}$ depth. However, by $125 \mathrm{~km}$ depth fast wavespeeds occupy the same zone. The seismic wavespeeds in the Gawler Craton are noticeably lower than in the other cratonic components, possibly as a result of thermal alteration in the emplacement of extensive Proterozoic volcanics in this region.

The AUSREM mantle model has been constructed for a larger domain than the crustal model, extending to the neighbouring subduction zones. A 3-D rendering of the full model is shown in Figure 8.3, with sections at both constant latitude and longitude. The results indicate the very strong contrast between the high SV wavespeeds beneath most of the Australian continent down to depths exceeding $200 \mathrm{~km}$, and the much lower wavespeeds in the surroundings.

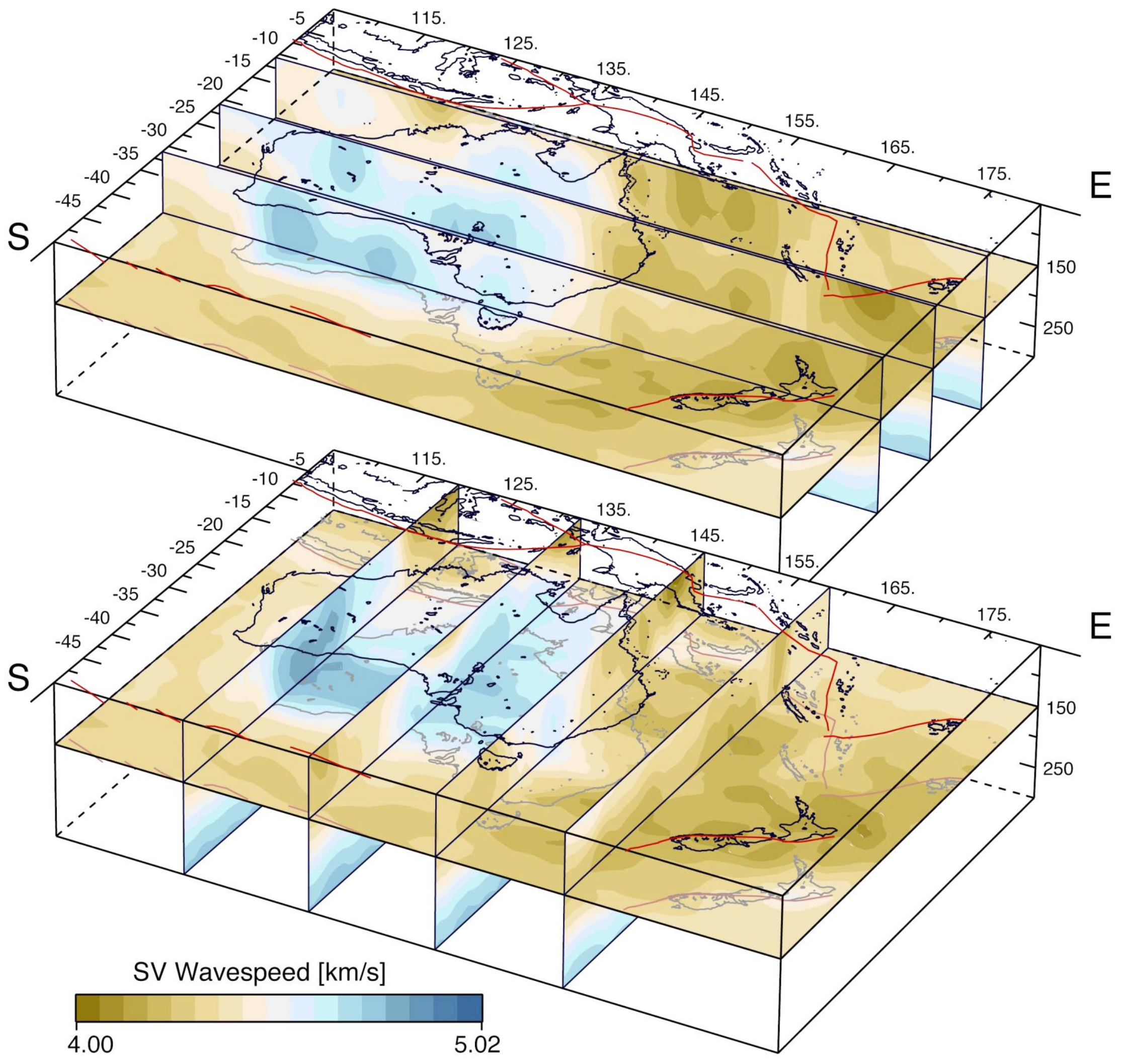

Figure 8.3: Slices at constant latitude and constant longitude through the 3-D AuSREM mantle mode for SV wavespeed, together with a depth slice at $150 \mathrm{~km}$. 

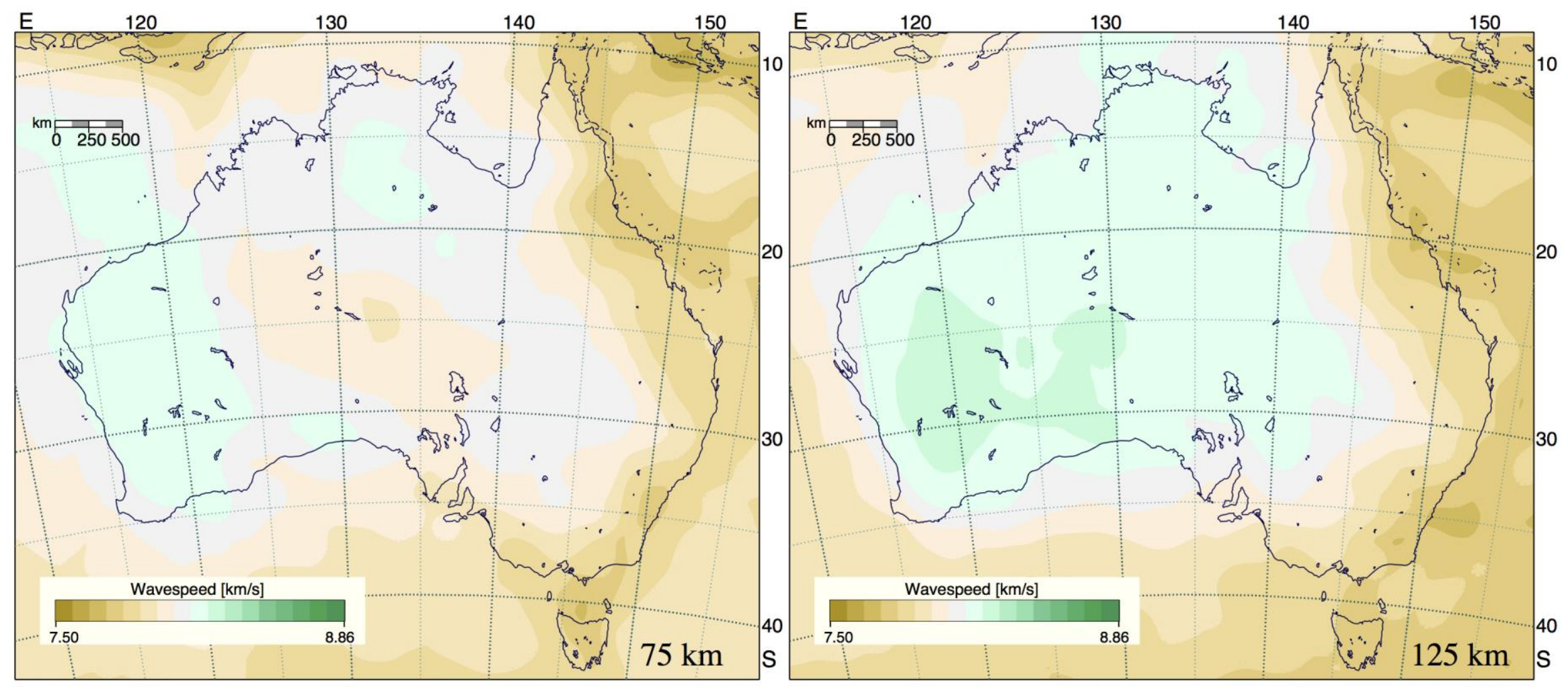

The low wavespeeds in the back-arc regions of the subduction zones can be well explained by the decrease in seismic velocity with increasing temperature. Yet, the very high cratonic wavespeeds are very difficult to reproduce even with a combination of a very cool lithosphere and extreme melt depletion.

\section{$P$ Wavespeed:}

The main direct information on the $P$ wavespeed distribution in the mantle component of the lithosphere comes from the analysis of refracted waves and from body wave tomography. The relative variations in $P$ wavespeed across the Australian continent are typically between a half and one-third of the corresponding $S$ variations. The detailed analysis by Kaiho and Kennett (2000) provides useful constraints on the $V p / V s$ ratio, and captures differences between the Phanerozoic fold belts and the cratonic regions in the north of Australia. This information has enabled Kennett et al. (2013) to construct a full $P$ wavespeed model from the SV model illustrated in Figures 8.2-8.3 with a $V p / V s$ ratio that varies both laterally and in depth.

The resulting estimate for the $\mathrm{P}$ wavespeed distribution is shown in Figure 8.4 for the same set of depth slices employed for the SV wavespeed (Figure 8.2). The variations in $\mathrm{P}$ wavespeed are generally more muted than for $S$. Nevertheless, at both $75 \mathrm{~km}$ and $125 \mathrm{~km}$ depth, the lowered wavespeeds on the eastern margin of the Australian continent and in the Tasman Sea are prominent. The contrast between the east and the centre and west of the continent diminishes with depth.

Figure 8.4: Depth slices through the AuSREM P wavespeed model. 

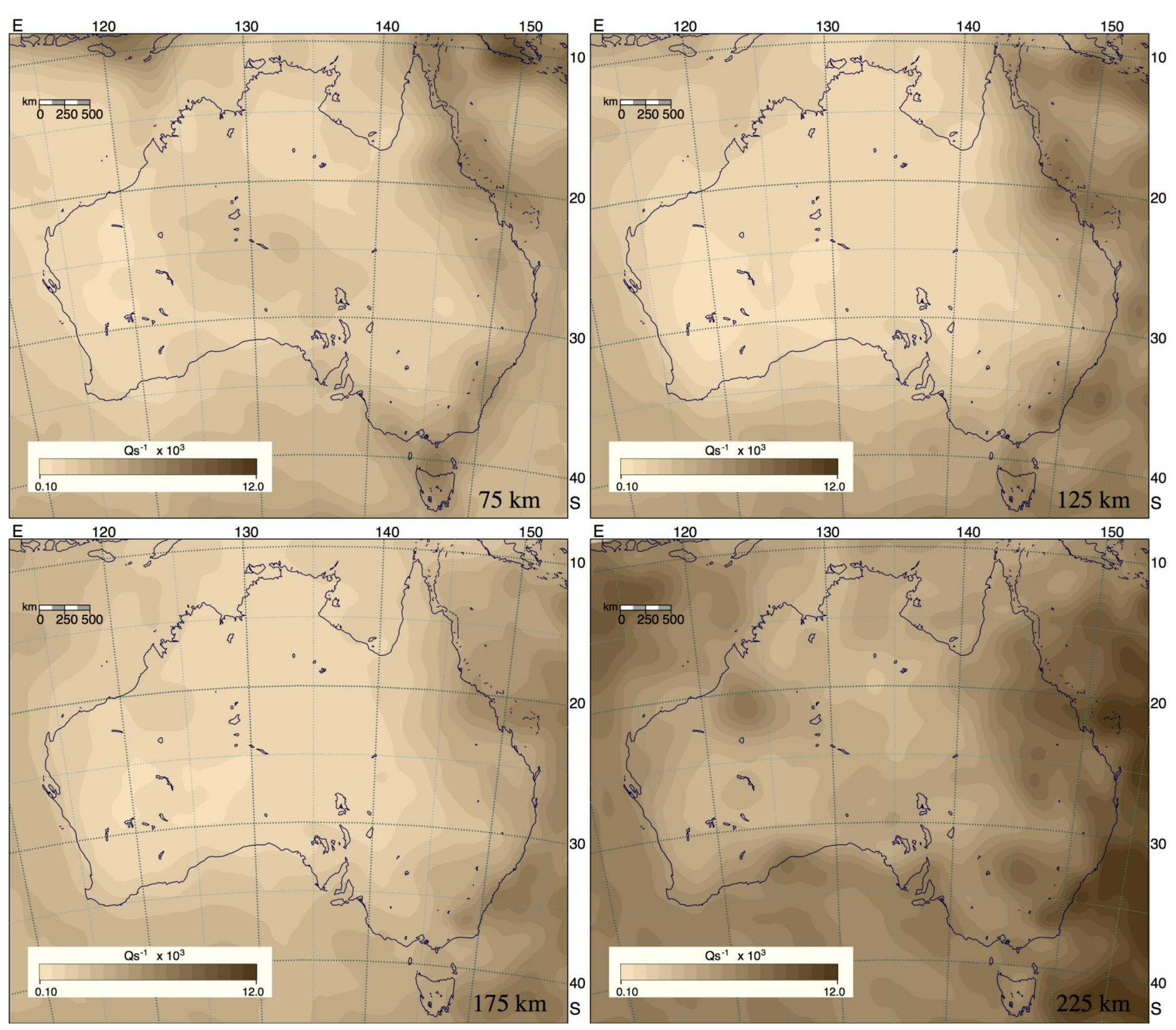

Figure 8.5: Depth slices through the AuSREM $Q_{s}{ }^{-1}$ attenuation model.

\section{Attenuation:}

In a similar way, estimates of $S$ wave attenuation $Q_{s}^{-1}$ have been developed from the shear wavespeed model. This attenuation model incorporates the very low loss of seismic energy in the cratonic lithosphere (Kennett and Furumura, 2008), and enhanced asthenospheric loss. The model builds on the strong correlation between reduced seismic wave speeds and enhanced attenuation due to the influence of increased temperature or volatiles (Faul and Jackson, 2005). A nonlinear scaling relation has been used for the lithosphere tuned to match the attenuation results for northern Australia (Kennett and Abdulah, 2011).

The resulting $S$ wave attenuation distribution is displayed in Figure 8.5 using the same depth slices as we have used for the other physical parameters. Lighter colours indicate weaker $S$ attenuation. This illustrative model is frequency independent.

The strong contrast in seismic attenuation between the cratonic core and the eastern margin of Australia is evident in the slice at $75 \mathrm{~km}$ depth. The centres of attenuation on the continent in northern Queensland and Victoria are spatially coincident with centres of Cenozoic volcanism. The north Queensland anomaly extends into the Coral Sea, a prominent feature in the Kennett and Abdulah (2011) results.

At $125 \mathrm{~km}$ depth we see the strong cratonic zone with little attenuation, bordered to the east by a welldeveloped higher attenuation corridor and a shallower asthenosphere. At greater depth, we see a shift of the whole attenuation distribution to larger loss of seismic energy, with only a few areas of lower attenuation that appear to be associated with cratonic roots. 


\section{Transition from Lithosphere to Asthenosphere}

The lithosphere forms the outer, relatively rigid shell of the Earth. It is underlain by mantle material participating in mantle convection: this rheologically weak zone is referred to as the asthenosphere (Figure 8.6). There are many contrasting definitions for the base of the lithosphere associated with different aspects of the physical properties of Earth materials (Artemieva, 2011). The situation is rendered more complex by the strong heterogeneity of the lithosphere, both laterally and vertically, and the variety of different geophysical and geochemical proxies that have been employed to define a specific lithosphere-asthenosphere boundary (LAB) rather than a rheological change. Except in a few circumstances, there is no sharp, distinctive discontinuity and it is more appropriate to refer to a lithosphere-asthenosphere transition (LAT).

The transition from the conductive to the convective regime provides a thermal definition of the lithosphere, e.g. through the depth to a constant geotherm (e.g. $1300^{\circ} \mathrm{C}$ ) or the intersection of the extrapolation of the conductive geotherm to intersect the mantle adiabat. Mantle xenoliths are employed to provide a petrological definition based on the transition from depleted, lithospheric minerals to a more fertile, asthenospheric, composition, often using proxies such as garnet concentrations. The temperature conditions for the transition are similar to those for the thermal case. The change in mineral properties has a stronger effect on the $V p / V s$ ratio than on the velocity variations themselves and so the position of change in the $V p / V s$ ratio with depth can be interpreted as the base of the petrological lithosphere.

Another approach is based on the mechanical properties, such as the depth where the yield stress becomes less than a specific value. This mechanical layer will normally be thicker than that of the load-bearing component, the elastic lithosphere, whose thickness is estimated from the correlation of topography and gravity (see Chapter 12). The base of the mechanical lithosphere is often assumed to be associated with a temperature of around $650^{\circ} \mathrm{C}$, which commonly corresponds to the peak values of shear wavespeed (Figure 8.6). In consequence, its thickness is usually around half the values for the thermal or petrological definitions.

The most direct association of seismological results with rheology would be through attenuation. Unfortunately, it is difficult to achieve tight definitions of the heterogeneity in attenuation (cf. Kennett and Abdulah, 2011) and so most seismic interpretations are based on seismic wavespeed variations, e.g. a level of perturbation from a reference wavespeed profile, but such interpretations depend strongly on the choices of parameters.

As an alternative, more objective approach, Yoshizawa (2014) has made use of the vertical gradients of absolute shear wavespeed in the mantle to provide shallow and deep bounds on the extent of the LAT (Figures 8.7-8.8). The shallow bound (red dashed line) is taken at the point of maximum negative gradient and the deeper bound (blue dashed line) at the minimum in wavespeed with depth. This means that the entire span of the transition lies in a region of lower shear wavespeeds than the regions above and below.

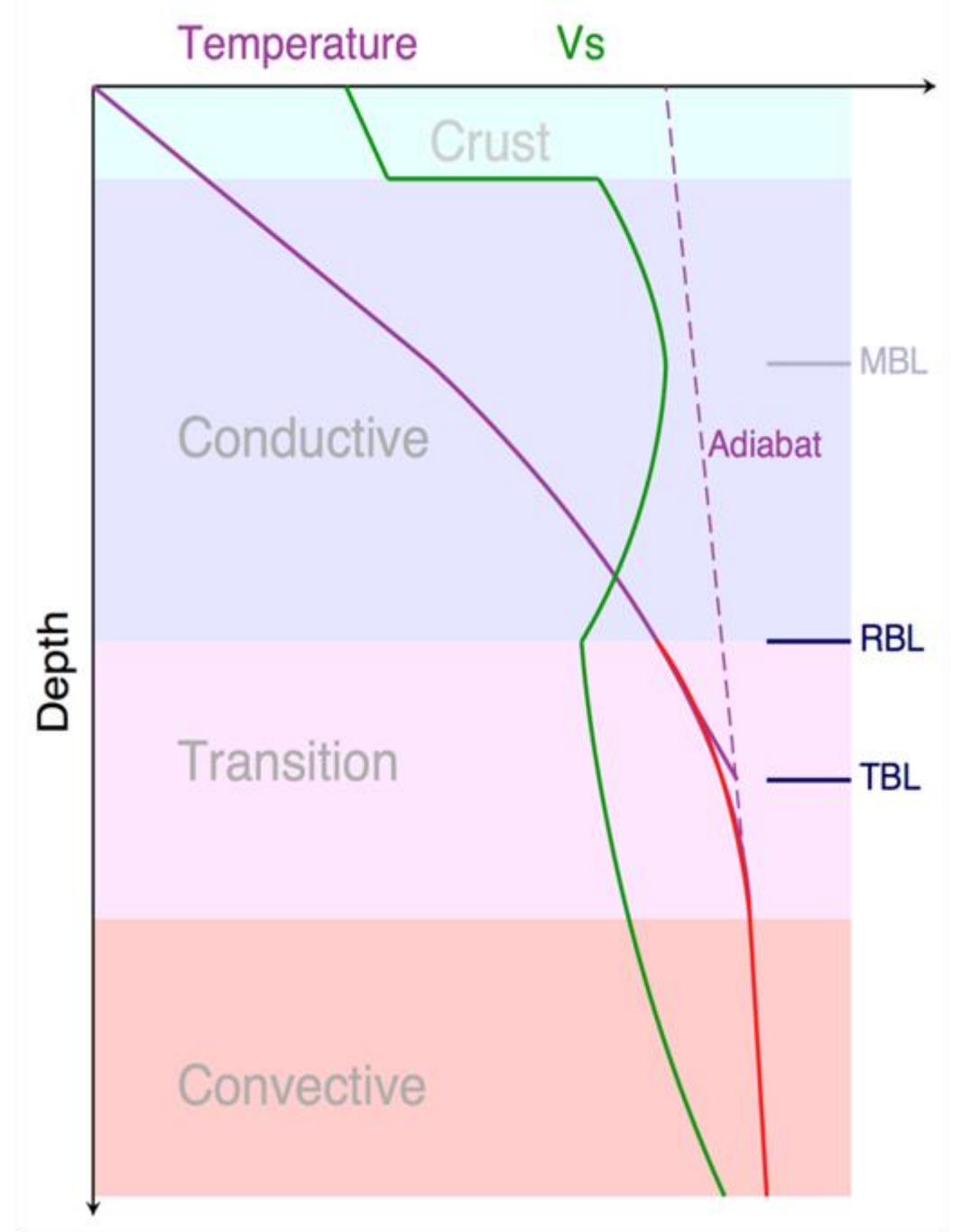

Figure 8.6: Schematic diagram for definitions of the lithosphere with representative shear wavespeed and temperature profiles, and locations of boundary layers: MBL- mechanical boundary layer, $\mathrm{RBL}$ — rheological boundary layer, $\mathrm{TBL}$-thermal boundary layer. 

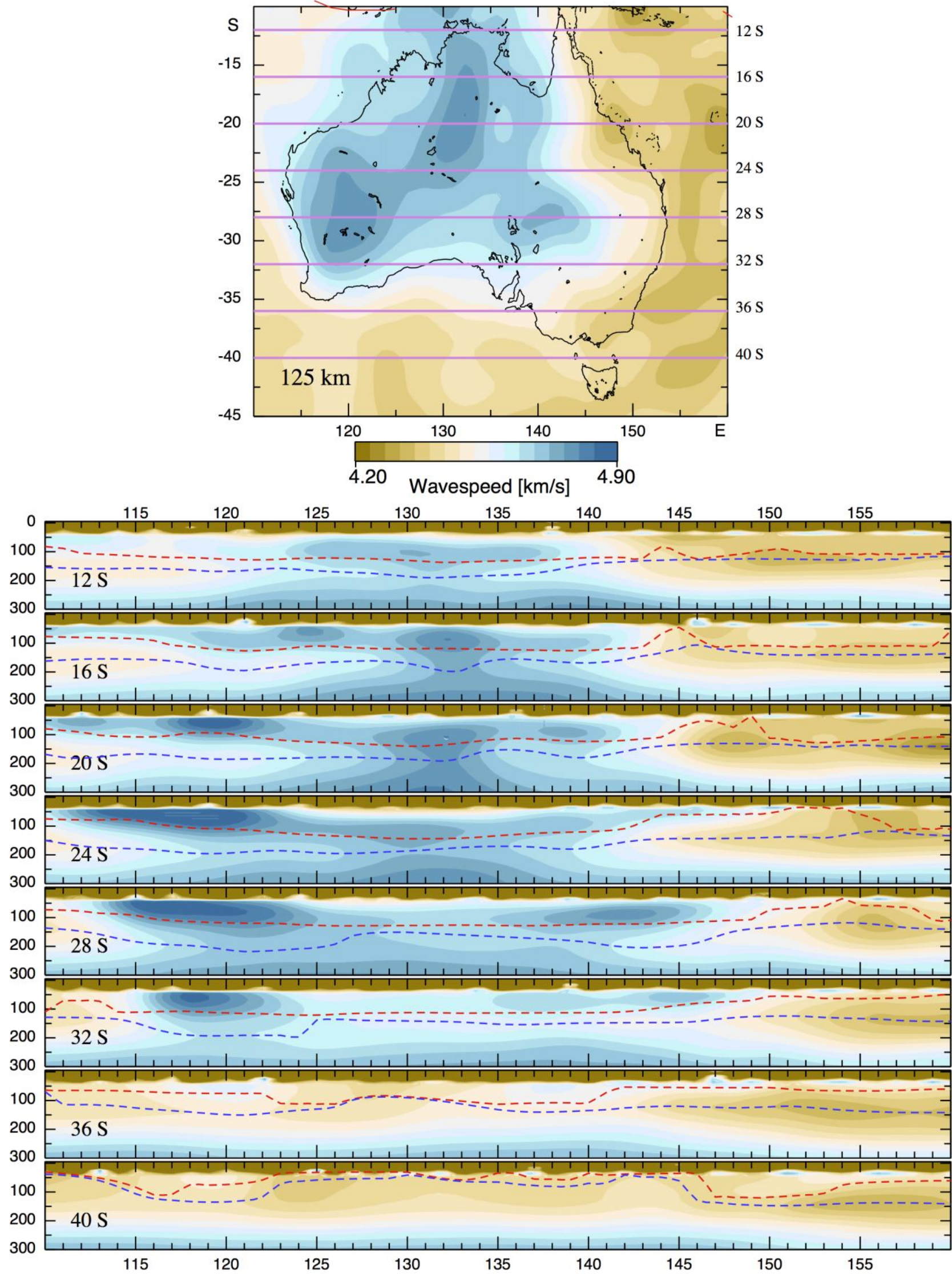

Figure 8.7: Isotropic shear wavespeed (Yoshizawa, 2014) with superimposed bounds on the LAT.
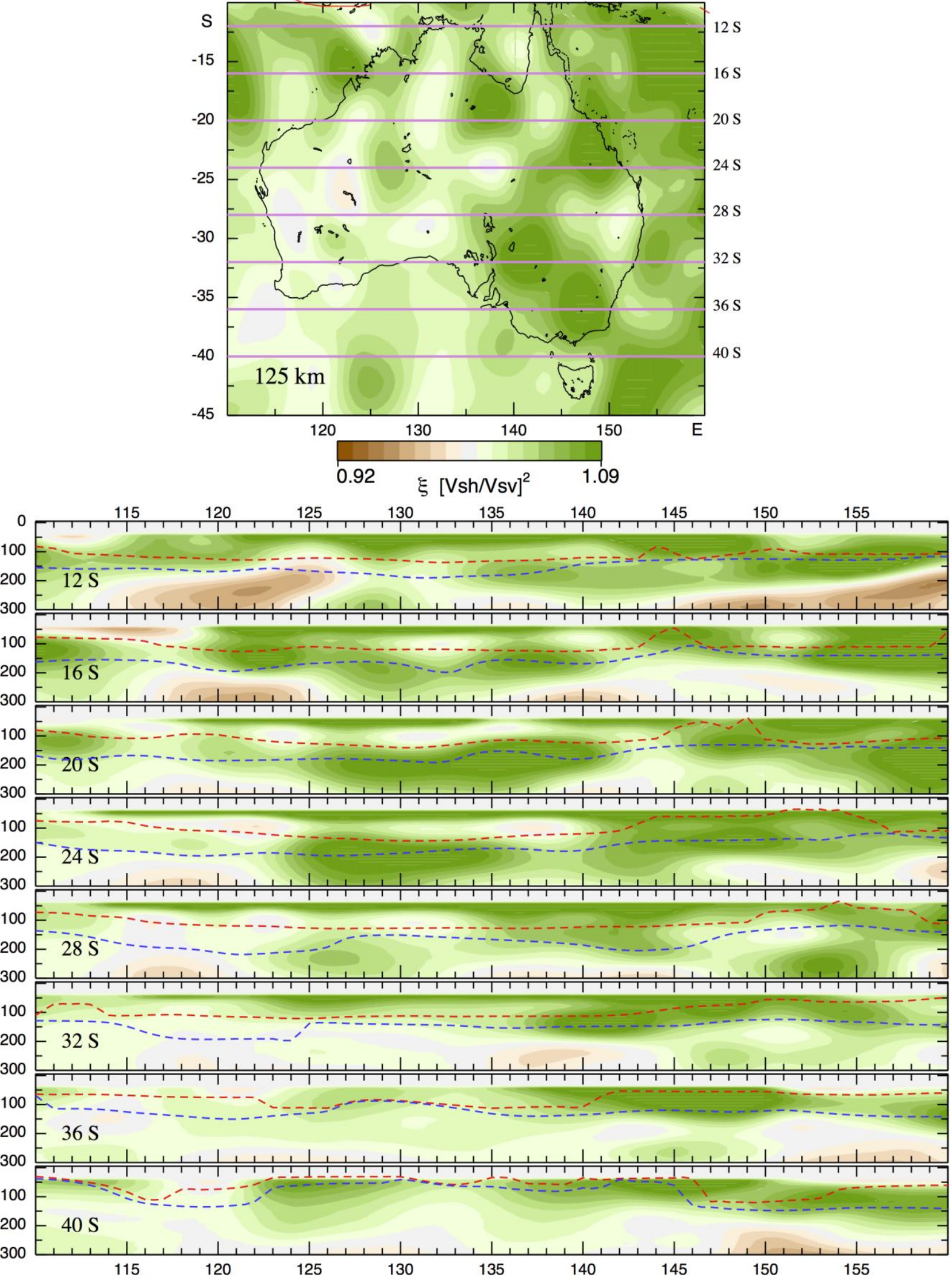

Figure 8.8: Radial anisotropy (Yoshizawa, 2014) with superimposed bounds on the LAT. 
The 3-D shear wavespeed model of Yoshizawa (2014) is an extended version of one of the components used in the AuSREM model. This work exploits both the vertical and horizontal components of ground motion for many thousands of events across the region to construct models of both the SV and $\mathrm{SH}$ wavespeeds. The SV wavespeed is extracted from the analysis of the fundamental and higher Rayleigh modes from the vertical components, and the $\mathrm{SH}$ wavespeed from inversion of Love modes recorded on the transverse component to the great-circle path between source and receiver. The $\mathrm{SH}$ wavespeeds are generally higher than the corresponding SV wavespeeds with notable polarisation anisotropy, often also called radial anisotropy.

For the gradient estimates of the LAT we use the isotropic $S$ wavespeed, a weighted average of the SV and SH wavepeeds $V_{\text {iso }}=\left[(2 / 3) V_{\mathrm{sv}}{ }^{2}+(1 / 3) V_{\mathrm{sh}}{ }^{2}\right]^{1 / 2}$. Cross-sections through this isotropic wavespeed distribution are shown in Figure 8.7 with the bounds on the LAT superimposed.

Figure 8.8 summarises the radial anisotropy in the Yoshizawa (2014) model using the square of the ratio of $\mathrm{SH}$ to SV wavespeeds $(\xi)$. Once again the bounds on the LAT are displayed on the cross-sections. In general, the horizontally polarised shear waves (SH) travel faster than the vertically polarised waves (SV). One of the strongest concentrations of radial anisotropy occurs at the western edge of the Musgrave Province where the three main cratonic blocks amalgamated. Much of the radial anisotropy signal resides in the LAT zone and below in the west and centre of the continent. Yet in the east, beneath the younger terranes, the radial anisotropy becomes shallower. The switch largely corresponds to the edge of the zone of highest shear wavespeeds.

In the case of a sharp base to the lithosphere the bounds proposed by Yoshizawa (2014) will somewhat overestimate the thickness of the transition. Further, in the east of Australia the development of a thick zone of lowered seismic wavespeeds means that the depth of the minimum velocity used as the deeper bound will overestimate the depth at which the asthenosphere is reached. In such areas with a strong negative gradient in seismic wavespeed with depth, the shallower bound is likely to be a better measure of lithosphere thickness, and indeed fits well with independent estimates (Yoshizawa and Kennett, 2015).

Figures 8.7-8.8 make it clear that there are significant variations in the thickness of the LAT even within the cratonic areas. A relatively broad transition is characteristic of the West Australian Craton. A sharp change in the thickness of the transition can be seen at $32^{\circ} \mathrm{S}$ to $28^{\circ} \mathrm{S}$, moving from $125^{\circ} \mathrm{E}$ to $127^{\circ} \mathrm{E}$. This change lies slightly east of the surface expression of the Yilgarn Craton, and correlates with the Rodona shear zone at the eastern edge of the Albany-Fraser Orogen. The Coompana Block to the east, beneath the Eucla basin, has a distinctly different character. The seismic wavespeeds beneath the North Australian Craton do not show as rapid a reduction with depth as in the West, and are accompanied by rather strong radial anisotropy through the LAT zone and to greater depth.

The Australian lithosphere displays azimuthal anisotropy in addition to polarisation anisotropy between SV and SH waves. Above $120 \mathrm{~km}$ the direction of fast propagation of Rayleigh waves is roughly east-west, particularly in the centre of the continent. This fast direction has been attributed to anisotropy produced by past tectonic activity. There is a fairly rapid transition of the fast direction with depth to an orientation roughly mirroring the current motion of the Australian Plate (Debayle et al., 2005). This deeper anisotropy is presumed to be induced by present-day plate motion and mantle flow. Australia is unique among the continents because this change of orientation occurs within the zone of faster wavespeeds that would be naturally associated with the lithosphere. The Australian Plate is the fastest moving of the plates with continents (about $6.7 \mathrm{~cm} / \mathrm{yr}$ ) and it looks as if this rapid motion induces basal drag on the lithosphere and so induces reorientation of the olivine component to produce perceptible anisotropy.

\section{Relative Thickness of Lithosphere}

As we have noted above there is, in general, no sharp transition between the lithosphere and asthenosphere. The presence of the asthenosphere is, however, manifest in enhanced seismic attenuation. The fast lithospheric wave speeds are accompanied by little loss of seismic energy, enabling high-frequency waves for both $P$ and $S$ to propagate readily from subduction zones into continental Australia (Kennett and Furumura, 2008) with extended scattered codas. The high-frequency $S$ waves are suddenly lost when the seismic waves penetrate into the asthenosphere, because of its much higher attenuation of shear waves than the lithosphere (Gudmundsson et al., 1994). Unfortunately, such studies can only provide a broad-scale picture of the behaviour, but confirm the presence of enhanced attenuation below $210 \mathrm{~km}$ depth. 
A consistent style of lithospheric thickness estimate across the Australian continent can be made by exploiting a combination of multiple estimates of the location of the base of the lithosphere. These include results from refracted waves as well as the wavespeeds and gradients deduced from surface wave and body wave tomography. The resulting estimate of the depth to the base of the lithosphere is shown in Figure 8.9. The relative variations in the thickness of the lithosphere should be reliable for the continent and its immediate surroundings, but the absolute values depend on exactly where the boundary is drawn in a gradational transition.

Evidence for a rapid wave speed change at the base of the lithosphere is only found in eastern Australia, where the lithosphere is thin (Ford et al., 2010). In this eastern part there is a close correspondence between the composite estimate and the shallower bound on the LAT displayed in Figures 8.7 and 8.8.

Wavespeed structure in central Australia is complex, and the gradation of structure with depth is somewhat different than in the rest of the continent, as can be seen in the cross-sections at $16^{\circ} \mathrm{S}-24^{\circ} \mathrm{S}$ in Figures 8.7 and 8.8. In consequence it is hard to tell whether there may be localised patches of rather deep penetration of lithospheric material. The LAT analysis from Yoshizawa (2014) suggests that the lithosphere in this region does not extend much below $200 \mathrm{~km}$ depth.

The contrast between thick lithosphere in the centre and west and thinner lithosphere in the east is very clear in Figure 8.9. It appears that changes in lithosphere thickness can occur over quite narrow zones, supporting the analysis by Fishwick et al. (2008), with a number of distinct transitions in eastern Australia. Such rapid changes can also be seen in the LAT analysis displayed in Figures 8.7-8.8.

The estimates of the depth to the base of the lithosphere show significant variations across the continent. Davies et al. (2015) have invoked such changes in lithospheric thickness to explain the differences in chemical composition in erupted materials along a very long hot-spot track from Queensland to Victoria.

The irregular base to the lithosphere is also likely to impose complex stress patterns in both the lithosphere and asthenosphere associated with the relative motions of the thick continental lithosphere and the freer-flowing asthenosphere. The presence of lithospheric 'steps' will produce complex flows on the trailing edges to the south, and along the shallower side to the east.

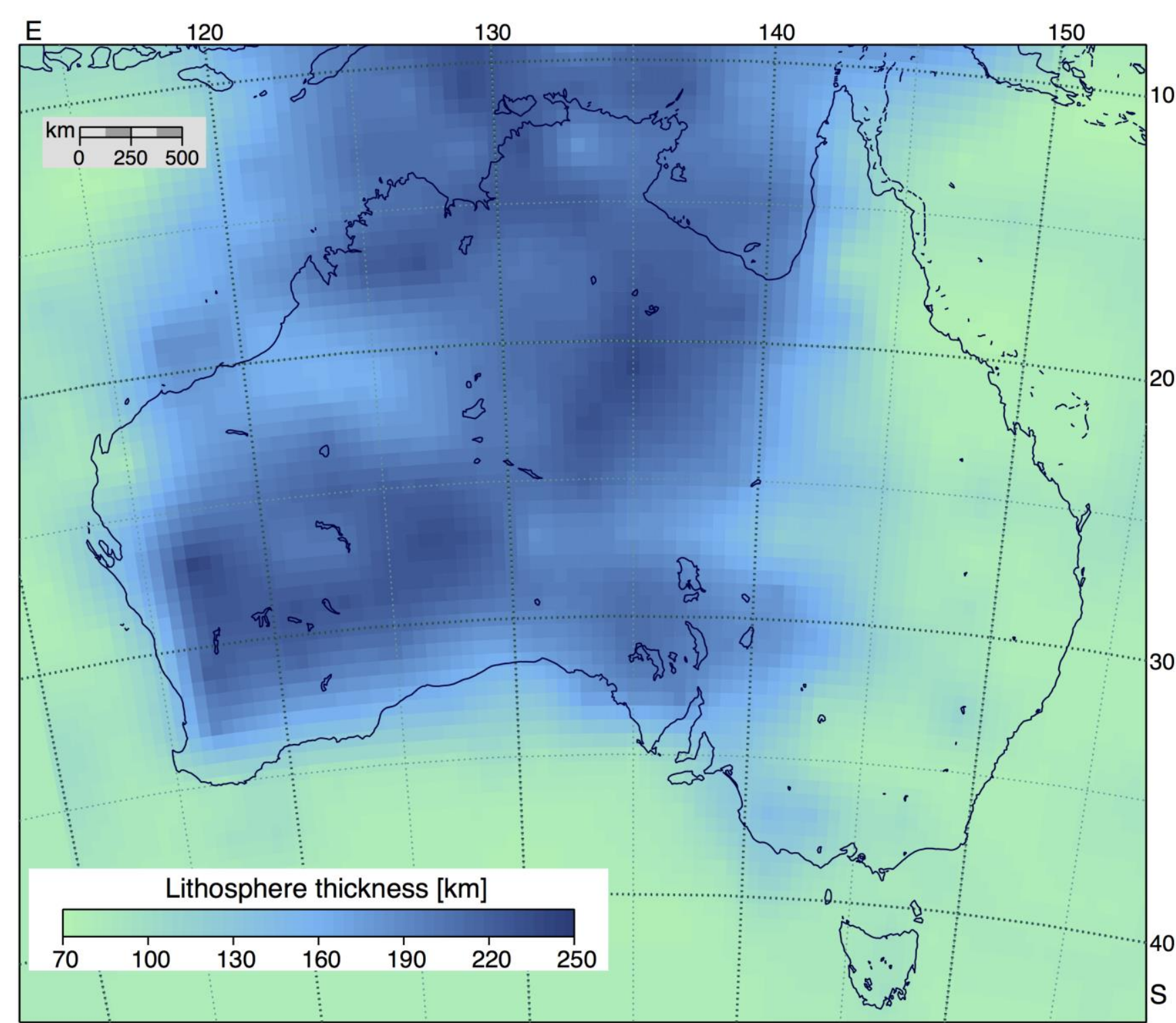

Figure 8.9: Estimate of thickness of the lithosphere across the Australian region.

Farrington et al. (2010) have suggested an edge convection model for the formation of the Newer Volcanic Province in Victoria and South Australia that host the most recent eruptions at $4.6 \mathrm{ka}$. Their concept is that the northward motion of Australia at about $7 \mathrm{~cm} / \mathrm{yr}$ gives rise to a trailing flow from the southern edge of the thick cratonic lithosphere that comes to the surface further south, creating the volcanic province. This view is challenged by Rawlinson et al. (2017), who suggest the influence of plume influx for the Newer Volcanic Province. However, they reiterate the importance of cavities in the lithosphere to generate vigorous mantle upwellings, which can promote decompression melting and eruptive products. 


\subsection{Uppermost Mantle}

The uppermost part of the lithospheric mantle immediately below the crust is not well constrained by surface wave studies, because of potential influence from the crust on the results. Fortunately, alternative probes exist through the properties of the regional phases $\mathrm{Pn}$ and $\mathrm{Sn}$, which travel beneath the Moho and are sensitive to the velocity structure and gradients in this region. Examples of such $\mathrm{Pn}$ and $\mathrm{Sn}$ arrivals are illustrated in the seismograms of Figure 8.1 for the 2012 Ernabella event. In the cratonic regions of the continent, the onsets of $\mathrm{Pn}$ and $\mathrm{Sn}$ have rather higher frequencies. This makes $\mathrm{Pn}$ a rather sharp arrival, but $\mathrm{Sn}$ is more difficult to pick against a background of high-frequency $\mathrm{P}$ wave coda.

A systematic study by Sun and Kennett (2016) has exploited regional waveforms from larger events across Australia recorded at both permanent and portable stations since 1993, supplemented by bulletin arrival times. All events were relocated using the 3-D AUSREM $P$ wave model to compensate for the large variations in wavespeed. After this relocation, consistent patterns of travel time residuals were obtained for $\mathrm{Pn}$, suitable for tomographic inversion. A resolution of $3^{\circ} \times 3^{\circ}$ was achieved, and the resulting $\mathrm{P}$ wave model is illustrated in Figure 8.10 with a series of depth slices from $55 \mathrm{~km}$ to $85 \mathrm{~km}$ depth.

Because the Pn wave traverses the crust near the source and receiver before passage through the mantle, additional information is also extracted on crustal structure. This new information on wavespeed structure helps to fill in some of the former gaps in deep crustal coverage identified in Chapter 7.
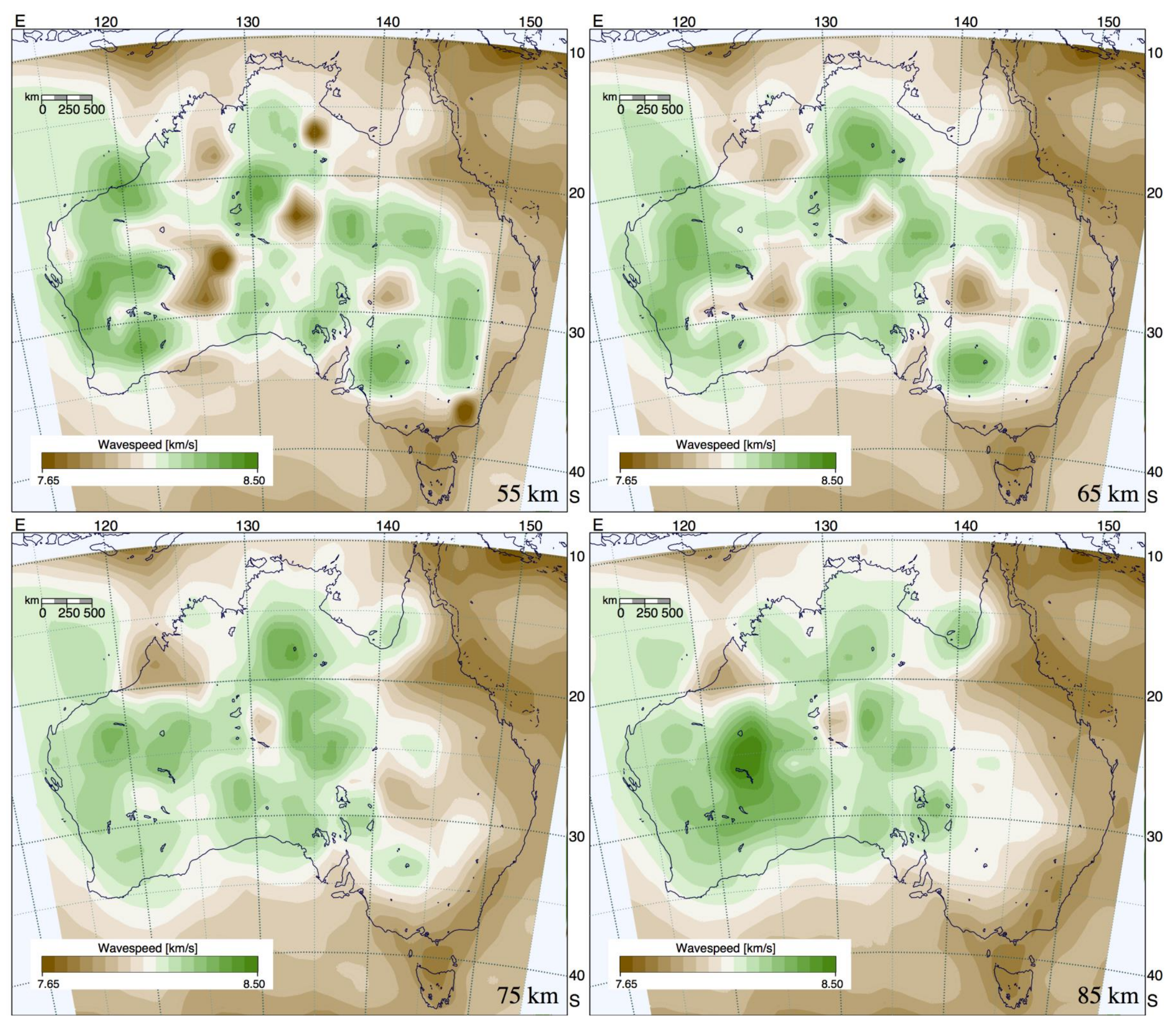

Figure 8.10: Depth slices through the $\mathrm{P}$ wavespeed model for the uppermost mantle derived from Pn tomography. 
In the depth slice at $55 \mathrm{~km}$ the prominent slow anomalies in $\mathrm{P}$ wave velocities are associated with the influence of rather thick crust. Throughout the depth range of $55-85 \mathrm{~km}$ in Figure 8.10, the slowest velocities in the uppermost mantle are found along the eastern margin of the Australian continent beneath the Phanerozoic orogenic belts, with links to Neogene volcanism. Path coverage is limited in Arnhem Land and the northeast of Australia, due to paucity of sources and seismic stations, so that wavespeed variations may be underestimated in these areas.

Across much of the continent, the $P$ wavespeed in the uppermost mantle is a little faster than in AuSREM, suggesting the need for some increase in the VpVs ratio compared with AuSREM. The fastest Pn wavespeeds are found in the cratonic areas, but we note significant substructures in the $P$ wavespeed beneath the cratons. Rather high $\mathrm{P}$ wavespeeds are encountered beneath the Pilbara and Yilgarn cratons, and in patches of the North Australian Craton. The South Australian Craton shows more subdued velocity variations with localised high Pn wavespeeds in the neighbourhood of the Curnamona Province and in the Gawler region to the east. A persistent patch of lowered wavespeeds is found near Alice Springs.

Between the West Australian and South Australian cratons, there are variations in the $\mathrm{P}$ wavespeed beneath the Eucla basin that appear to link to distinct lithospheric blocks with their own signatures of physical properties.

At both $70 \mathrm{~km}$ and $85 \mathrm{~km}$ there is a reduced $P$ wavespeed anomaly associated with the northern part of the Canning Basin. This basin has an active tectonic history over a long interval, with significant accumulations of sediments and minor oil production.

Similar patterns of variation are found for $S$ wavespeed from the tomographic inversion of $S n$ travel times. The $V p / V s$ ratio lies mostly in the range 1.7 to 1.825 with a relatively smooth variation. Relatively low $S$ wavespeeds are found just beneath the crust in the vicinity of Alice Springs, and this anomaly persists somewhat to greater depth with an extension to the south along the western edge of the South Australian Craton. Low $S$ velocities are found at $18^{\circ} S$ on the eastern margin of the continent extending to about $65 \mathrm{~km}$ depth; this feature extends both north and south at shallower depth.

\subsection{Nature of Lithospheric Structure}

The reflection transects displayed in Chapter 7 indicate the complexity of crustal structure, with generally stronger variability in structure at the base of the crust. However, at the frequencies employed in reflection seismology the mantle normally appears to be rather bland with no apparent reflectors. Nonetheless, there is significant evidence for the existence of heterogeneity within the mantle component of lithosphere, but at larger scales.

The broadest-scale features are well mapped by exploiting the properties of surface waves and multiply reflected $S$ body waves as we have seen in Section 8.1. Body-wave tomography exploiting relatively dense deployments of portable seismic recorders provides information on the lithospheric mantle at shorter scales. Potential horizontal resolution is limited by station spacing (Rawlinson et al., 2014), but vertical smearing due to the relatively narrow cone of incoming rays also limits resolution in the upper mantle.

The suite of portable instrument deployments in the WOMBAT project in southeastern Australia reveals the presence of considerable complexity in and beneath the crust (e.g. Rawlinson et al., 2016), with variations down to the available sampling of $50 \mathrm{~km}$. The presence of much finer-scale structure in the mantle is indicated by long trains of high-frequency $P$ and $S$ waves following the phases $\mathrm{Pn}$ and $\mathrm{Sn}$ refracted back from the mantle, as in the seismograms shown in Figure 8.1 for continental paths within Australia. The nature of this extended high-frequency coda, particularly for paths within the Precambrian domains, requires some form of distributed heterogeneity through the lithosphere (Kennett and Furumura, 2008).

Evidence for discontinuities in physical properties within the mantle component of the lithosphere comes from studies of the structure in the vicinity of seismic stations. A commonly used approach exploits the wave conversions and reflections associated with the major seismic phases from distant earthquakes to construct receiver functions. Incident $S$ waves have been favoured for discontinuity studies because the converted $P$ waves arrive as precursors to $S$, though relatively low frequencies have to be used which limits vertical resolution. One of the striking features in $S$ wave receiver function analysis for the Australian cratons is clear signals of discontinuities in the mid-lithosphere at around 70-90 km (Ford et al., 2010), which may indicate a rapid drop in seismic velocity or a change in the character of radial anisotropy in the middle part of the continental lithosphere where the wavespeed is generally at its fastest. The 
estimated depth of the enigmatic mid-lithosphere discontinuity (MLD) from receiver functions corresponds well with a rapid change in the strength of radial anisotropy derived from surface waves (Yoshizawa and Kennett, 2015).

An additional constraint on the nature of lithospheric heterogeneity comes from observations of high-frequency $P$ wave reflectivity profiles derived from the autocorrelograms of vertical component records at seismic stations (Kennett, 2015; Sun et al., 2018). These $P$ reflectivity profiles suggest vertical changes in the character of the fine-scale structures in the Australian continent, indicating stronger reflectivity in the crust and upper lithosphere underneath the cratons. Indications of mid-lithospheric discontinuities are provided by distinct changes in the frequency content of the reflectivity as a function of time.

In Figure 8.11 we show the depths of well-constrained discontinuities from $S$ wave receiver functions at permanent stations across the continent (Ford et al., 2010), autocorrelation studies using distant earthquakes (Sun et al., 2018) in Western Australia and autocorrelation studies exploiting continuous seismic records in Central Australia (Kennett et al., 2017, Kennett and Sippl, 2018). These depth estimates are compared in Figure 8.11 with the shallower bound on the LAT from the model of Yoshizawa (2014). In central and western Australia the discontinuities lie within the lithosphere (MLD - mid-lithosphere discontinuity); whereas beneath the Phanerozoic provinces, and beneath $\mathrm{BBOO}$, the discontinuity most likely marks the base of the lithosphere (LAB). Although the receiver function and autocorrelation results are based on rather different frequency ranges, there is a good general correspondence.

Sun et al. (2018) note that at a number of stations in the West Australian Craton there are indications of a second deeper discontinuity lying close to the depth of the shallower LAT bound shown in Figure 8.11. These results indicate the complexity of lithosphere structure revealed with higher-frequency probes (cf. Figure 8,12).

Such observations of multiple discontinuities are consistent with the presence of fine-scale heterogeneity in the lithosphere superimposed on broader-scale wavespeed variations (Kennett et al., 2017). Where detailed studies have been made in southeastern Australia, there is clear evidence for variability on scales of $50-150 \mathrm{~km}$ shorter than those seen by surface waves (Rawlinson et al., 2014). This intermediate-scale variation is seen beneath both cratonic and Phanerozoic regions and looks to be a pervasive component of lithospheric structure.

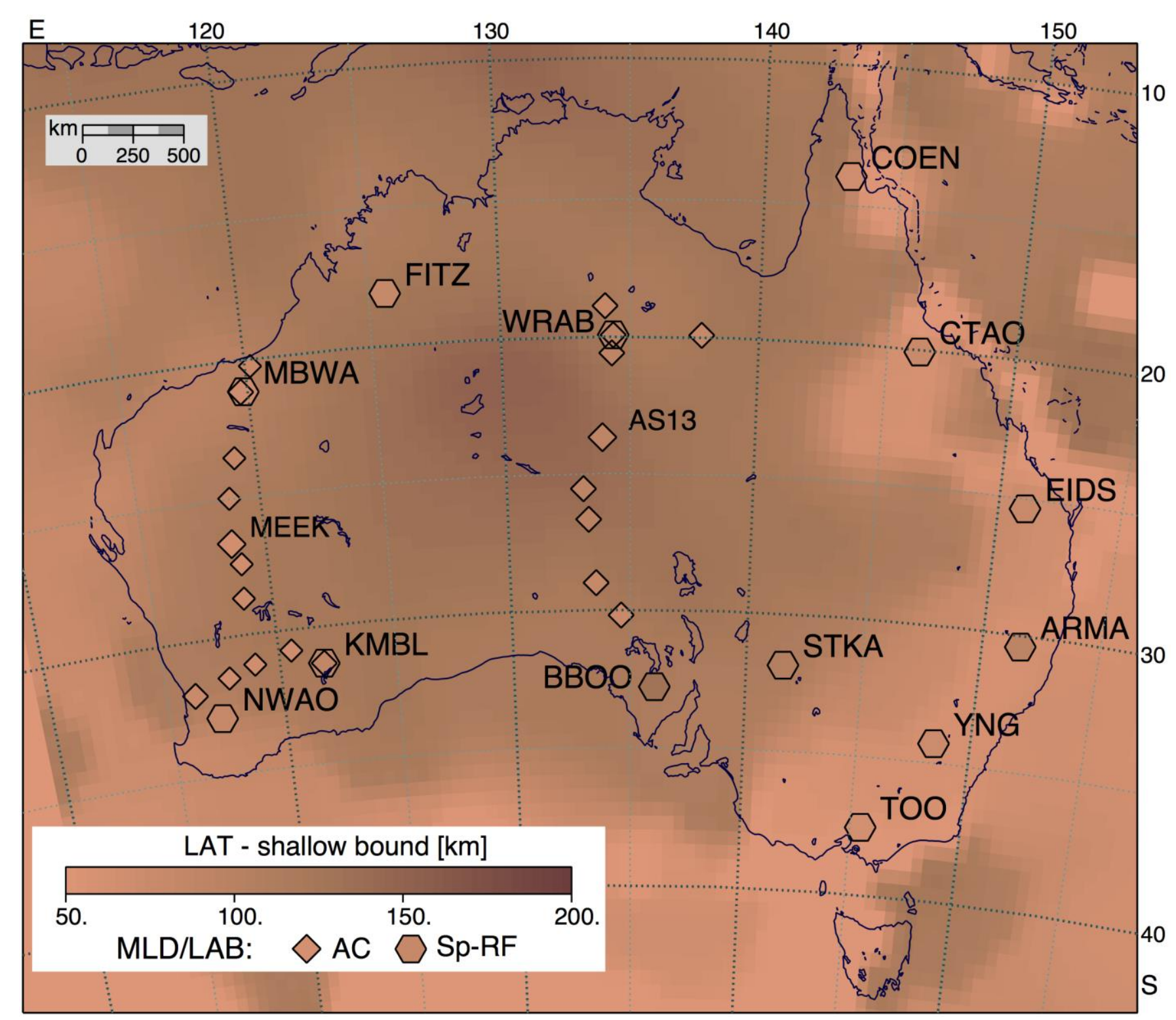

Figure 8.11: Estimated depths for the MLD from receiver-based studies: AC-autocorrelation; Sp-RF-receiver functions for incident shear waves. The symbols at the various stations are superimposed on the shallower bound on the LAT from Yoshizawa (2014).

A variety of lines of evidence suggest that the finer-scale components of lithospheric structure have a quasi-laminate behaviour with much longer horizontal correlation than vertical. Such variation in physical properties has equivalent effects to shape-preferred orientation of crystals, and so vertical variations in the character of the heterogeneity can produce changes in the effective radial anisotropy for long-wavelength surface waves as well as apparent discontinuities in the mid-lithosphere region for higher frequency body waves (Kennett and Sippl, 2018). 
Kennett et al. (2017) have shown that a multi-scale heterogeneity model with broad-scale structure from surface wave tomography, and stochastic intermediate and fine-scale components (see Table 1), provides a good representation of many styles of seismological observations across Australia, including the character of regional seismic phases and the character of receiver functions. When dense seismic networks cover more of the continent it should be possible to include structure derived from body wave tomography, but the finerscale components will remain below practical resolution limits.

This multi-scale model includes heterogeneity in both the crust and the mantle components of the lithosphere, with a change in style of heterogeneity in the lithosphere-asthenosphere transition (LAT) as suggested by Thybo (2008). The character of the heterogeneity in three distinct areas in Australia is indicated in Figure 8.12.
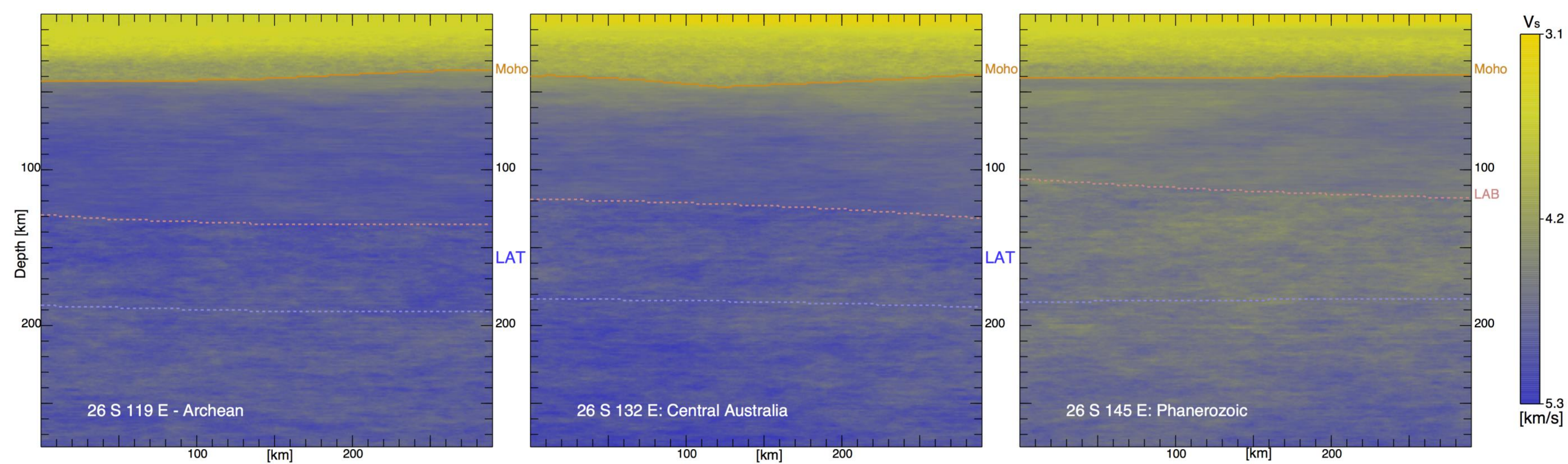

Figure 8.12: Simulations of lithospheric heterogeneity structure along latitude $26^{\circ} \mathrm{S}$ constructed using the multi-scale heterogeneity model described in Table 1. The interactions of the different scales of variation produce somewhat different patterns of structure between the Archean craton in the west and the Phanerozoic domain in the east, with intermediate character beneath the Proterozoic of Central Australia.
Heterogeneity regimes used in multi-scale model: amplitudes and correlation lengths.

\begin{tabular}{lllll}
\hline Depth range & Label & r.m.s. het. & Horiz. correl. [km] & Vert. correl. [km] \\
\hline Medium-scale & & & & \\
$0-300 \mathrm{~km}$ & & $1 \%$ & 100 & 24 \\
Fine-scale & & & & \\
$0-15 \mathrm{~km}$ & $\mathrm{C} 1$ & $0.5 \%$ & 2.6 & 0.4 \\
15-Moho km & $\mathrm{C} 2$ & $1.5 \%$ & 2.6 & 0.4 \\
To top LAT & $\mathrm{L} 1$ & $0.5 \%$ & 10.0 & 0.5 \\
LAT & L2 & $1.0 \%$ & 5.0 & 1.0 \\
Asthenosphere & $\mathrm{A}$ & $1.0 \%$ & 5.0 & 1.0 \\
\hline
\end{tabular}




\section{Density Structure}

Although the primary focus for the development of the AuSREM model was the creation of 3-D seismic wavespeed models, one of the additional products was a density model. For the crust, density was estimated from $\mathrm{P}$ wavespeed using relationships derived from laboratory measurements, implemented as a set of quadratic relations for different ranges of $P$ wavespeed (Salmon et al., 2013b). For the lithospheric mantle, the density distribution was derived from the SV wavespeed, again using a formulaic approach. In this case, allowance was made for the rather low densities associated with high SV wavespeeds in strongly depleted harzburgitic material in the mantle (Kennett et al., 2013).

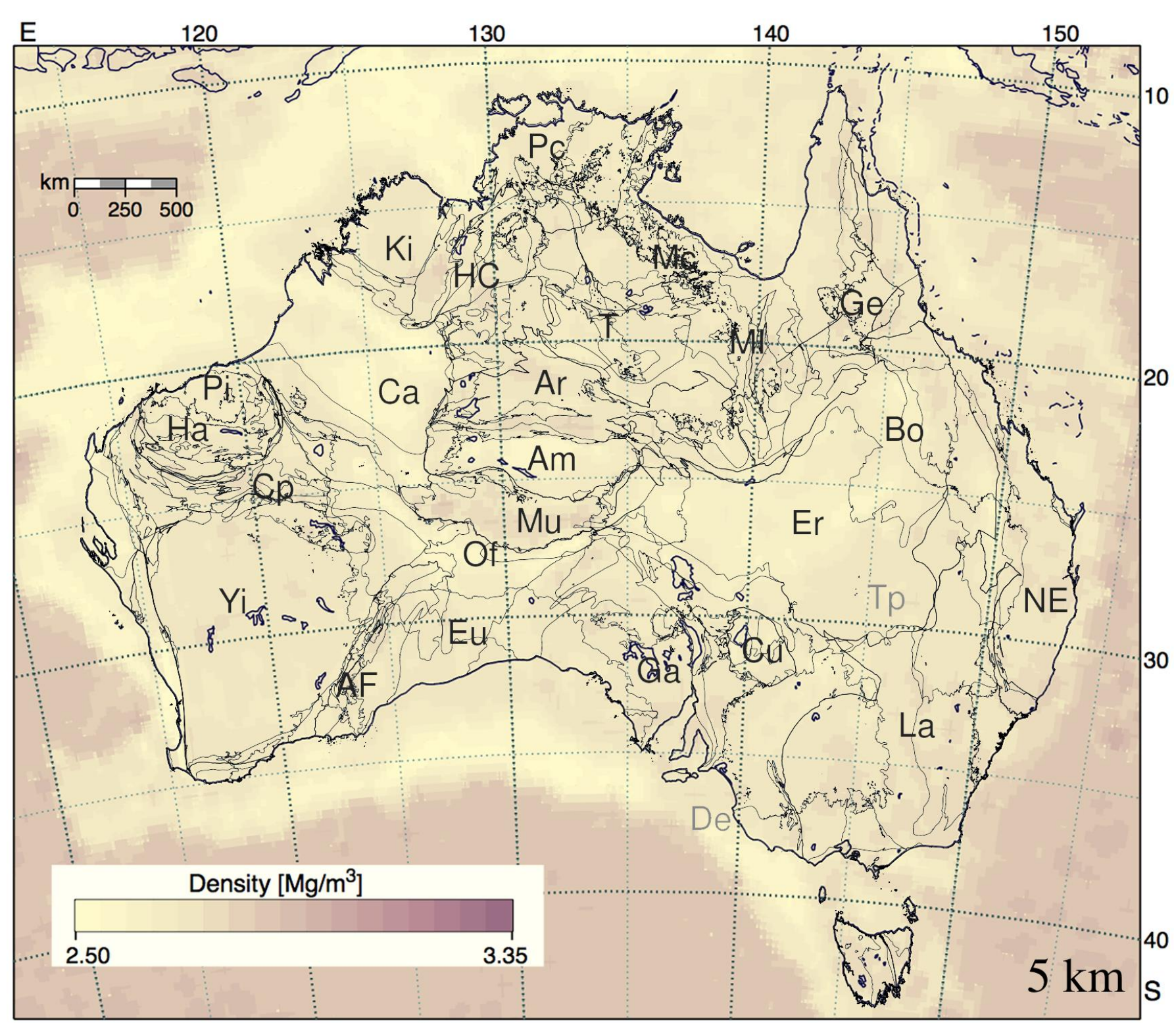

Figure 9.1: Density at $5 \mathrm{~km}$ below the surface from the gravity inversion.
The AUSREM density distribution was taken as starting point by Aitken et al. (2015), who undertook a 3-D inversion to fit the observed gravity field across Australia. The gravity data employed combine both satellite and near-surface gravity observations, with the removal of a continental-scale gravity field linked to the density variations in the upper mantle. The residual gravity disturbance is then carefully corrected to produce a Bouguer gravity anomaly. Effects associated with gridding were minimised by upward continuation, e.g. up to $15 \mathrm{~km}$ for an inversion using $0.25^{\circ}$ cells.

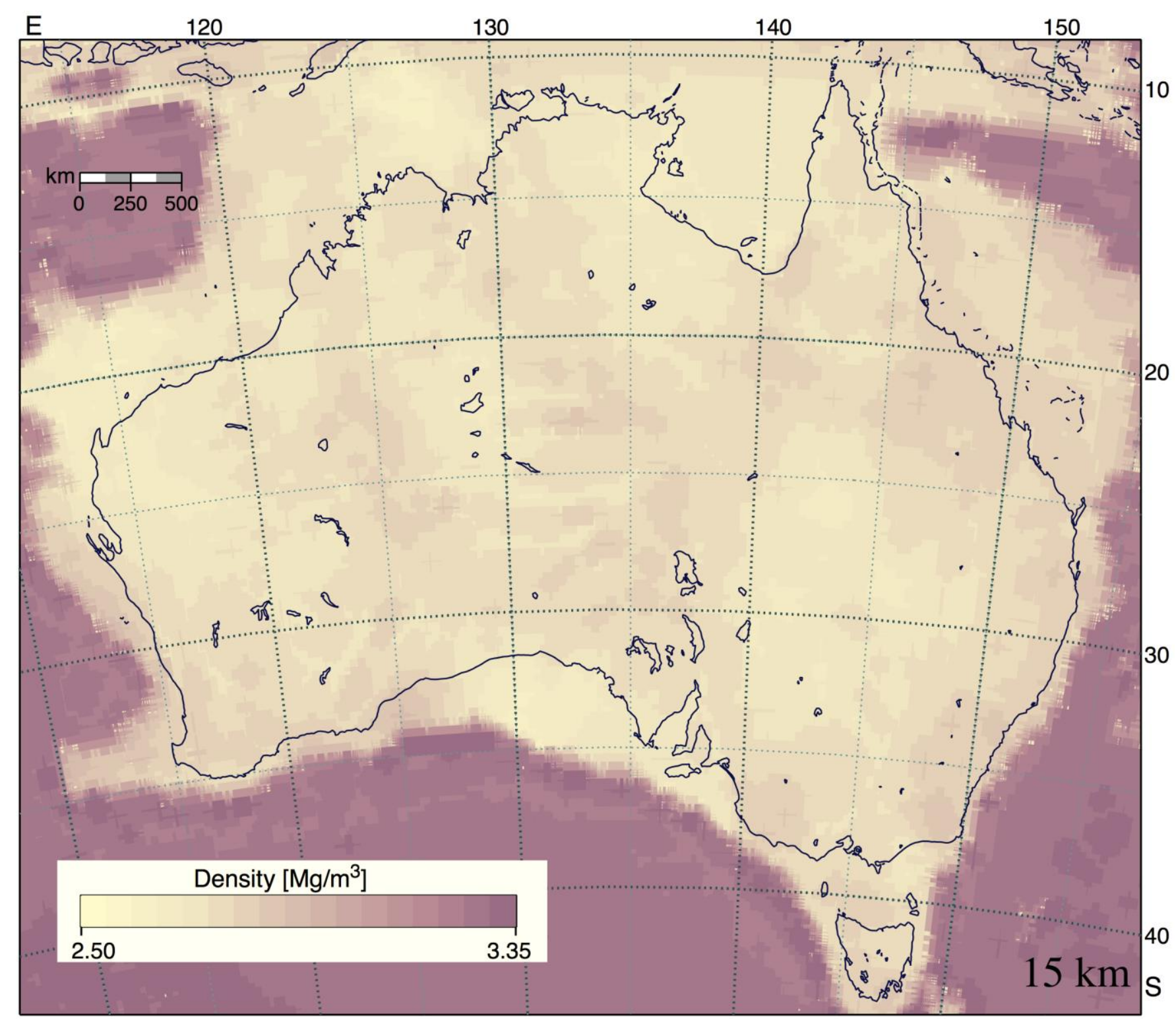

Figure 9.2: Density at $15 \mathrm{~km}$ below the surface from the gravity inversion. 
The initial reference model includes the influence of sediments, the crust and the mantle. On the continent, the Seebase model (Frogtech, 2005) illustrated in Figure 2.9 was employed, with a density model based on compaction, supplemented by CRUST1.0 (Laske et al., 2013) elsewhere. The crustal thickness was taken from the model of Aitken et al. (2013) based on gravity inversion using the Moho database of Salmon et al. (2013b), again supplemented by CRUST1.0. The initial crustal density across the continent uses the crustal component of the AuSREM model (Salmon et al., 2013a). A uniform crustal density of $2890 \mathrm{~kg} / \mathrm{m}^{3}$ is used for oceanic crust. In the mantle below $50 \mathrm{~km}$, the density is based on the mantle component of AuSREM (Kennett et al., 2013), with a simple regression model based on AuSREM above $50 \mathrm{~km}$.

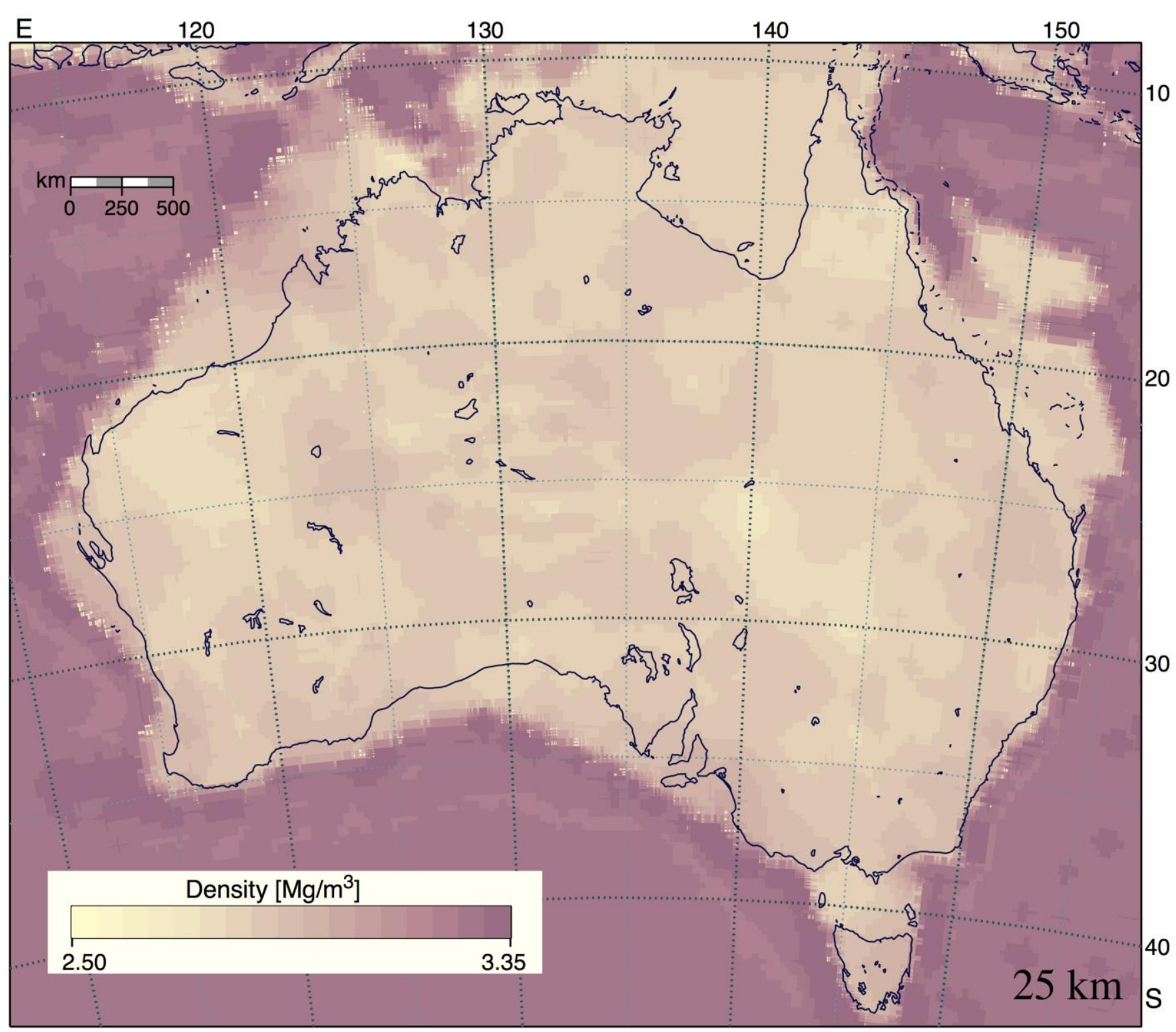

Figure 9.3: Density at $25 \mathrm{~km}$ below the surface from the gravity inversion.
This reference model has root mean square misfit to the gravity data of $343 \mathrm{mGal}$ which is rather more than the $135 \mathrm{mGal}$ variation of the gravity data employed. Much of this discrepancy comes from the absence of smaller-scale structures that can be introduced in a detailed inversion.

At the local and regional scale, most methods for the inversion of gravity data to produce a density model rely on the superposition of the response of polygonal shapes with constant density. However, such methods rapidly become unwieldy at the full continental scale, especially in 3-D. Aitken et al. (2015) have therefore reformulated the problem to work directly in terms of the partial differential equation relating gravitational potential to a continuous density distribution.

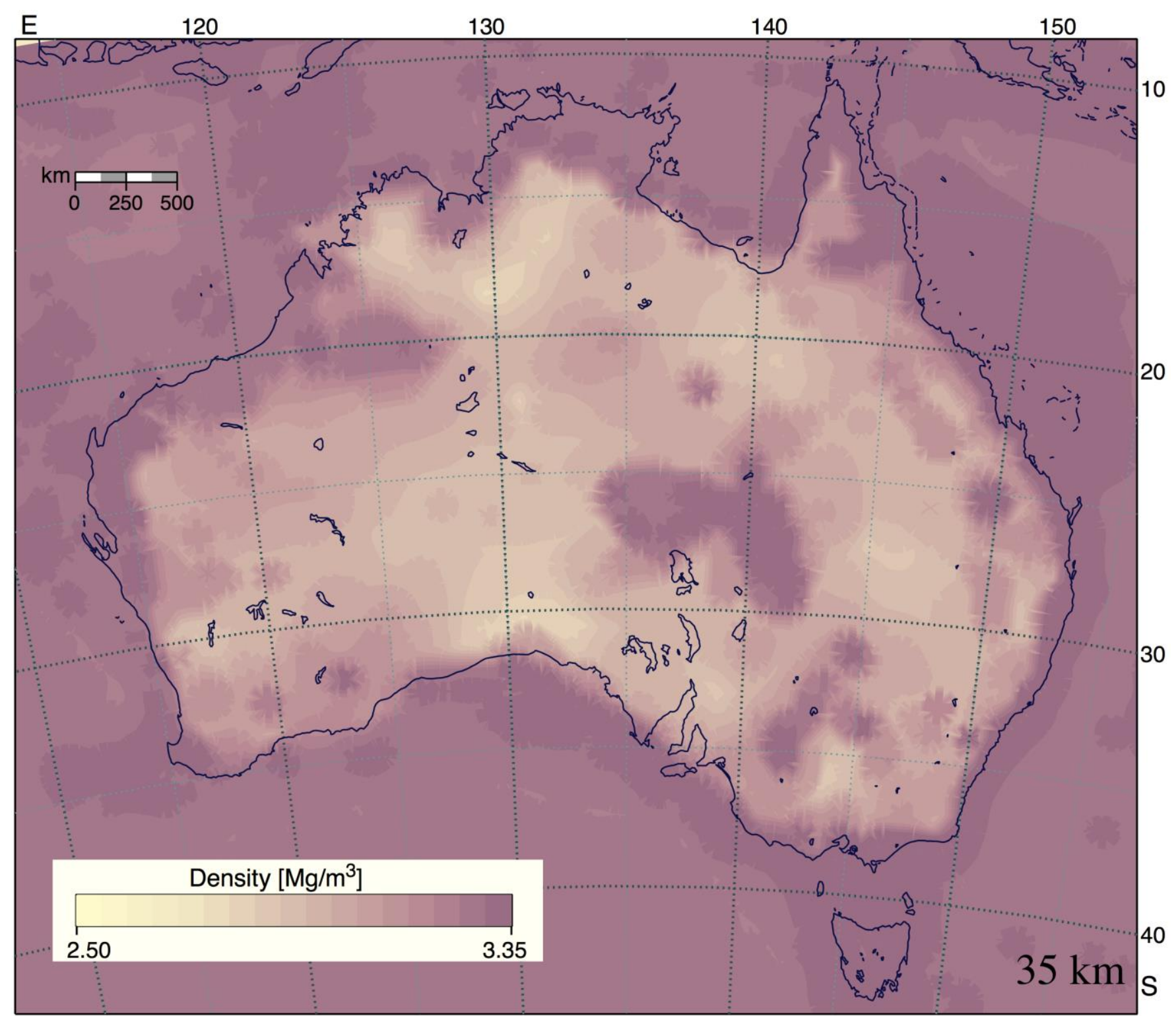

Figure 9.4: Density at $35 \mathrm{~km}$ below the surface from the gravity inversion. 
The acceleration due to gravity at the surface can then be found from the vertical derivative of the gravitational potential. The solution of the partial differential equation is accomplished through a 3-D finite element approach in a geodetic coordinate system that gives a full allowance for the Earth's curvature.

The inversion procedure employs iterative updates of a density correction to the initial reference model using the minimisation of a cost function combining the misfit to the gravity data with smoothness and damping constraints. The inversion is implemented through massively parallel computation. Aitken et al. (2015) describe the careful selection of the parameters defining their choice of cost function that is made possible by the efficient computational procedure.

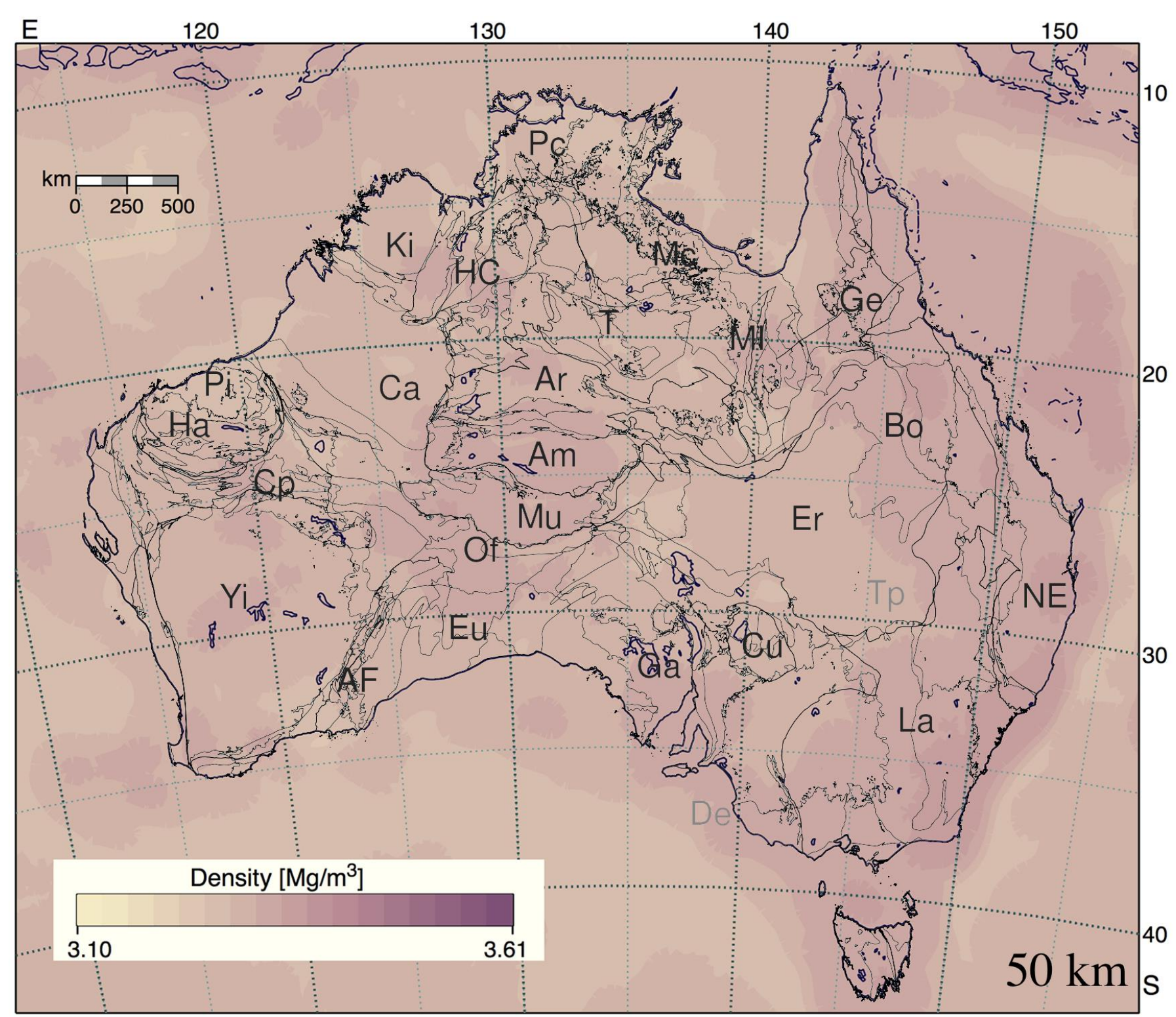

Figure 9.5: Density at $50 \mathrm{~km}$ below the surface from the gravity inversion.
With this inversion scheme, based on the partial differential equations, the root mean square misfit to the gravity data can be reduced below $3 \mathrm{mGal}$ with only mild smoothing and model damping. The resulting density models display noticeable layering in the lithosphere, and a distinct contrast between the continental and oceanic domains at all depths (Figures 9.1-9.9). The deviations from the reference model are not large (median $14 \mathrm{~kg} / \mathrm{m}^{3}$ ), but are able to incorporate scales of heterogeneity not well represented in the reference model. Thus, considerable detail is added in the upper crust, notably in central Australia (Figures 9.1-9.2). The model changes continue into the mantle, reducing with depth and with much less detail.

The crustal component of the density model is displayed in Figures 9.1-9.4, with depth slices at $5 \mathrm{~km}, 15 \mathrm{~km}, 25 \mathrm{~km}$ and $35 \mathrm{~km}$ below the surface; the same set of slices as previously illustrated for seismic velocities (Figures 7.11-7.13). The effect of the sedimentary basins is most pronounced in the zone down to $5 \mathrm{~km}$, but there are also significant influences from the large gravity anomalies in central Australia that decline only slowly with depth. By $15 \mathrm{~km}$ depth (Figure 9.2), the dominant features can be associated with the main tectonic features across the continent. Thus much of the Bouguer gravity anomaly must have its origin in the upper part of the crust. Nevertheless there are significant trends in the density distribution in the middle part of the crust. At $25 \mathrm{~km}$ depth (Figure 9.3), we see lower density beneath the Canning, Amadeus and Eromanga basins that may have influenced the formation and preservation of these basins. By $35 \mathrm{~km}$ depth (Figure 9.4), mantle densities are evident in the areas with thinner crust, e.g. the Pilbara Craton, and the Lake Eyre Basin.

The patterns of density variation differ in the lower part of the crust from the shallower zones. Further, the crustal thickness derived from the depth to Moho (Figure 7.16) has little direct relation to crustal topography or shallow densities, and has weak correlation with the lower crust. Aitken et al. (2015) suggest that the configuration of crustal thickness is largely determined by the thickness of higher density lower crust $\left(>2900 \mathrm{~kg} / \mathrm{m}^{3}\right)$ that may arise from mafic underplating.

The complex configuration of crustal thickness across the continent means that between $30 \mathrm{~km}$ and $55 \mathrm{~km}$ depth there is a distribution of both crustal densities and the higher values, typically greater than $3200 \mathrm{~kg} / \mathrm{m}^{3}$, associated with the mantle. In the depth slices below $50 \mathrm{~km}$ (Figures 9.5-9.9) we have shifted the density scale compared with Figures 9.1-9.4 so that the more subtle features associated with density variations in the lithospheric mantle are evident. 
Despite the presence of thick crust in central Australia, the results of the gravity inversions show only moderate variation in density at $50 \mathrm{~km}$ depth (Figure 9.5). Higher density regions tend to persist to about $100 \mathrm{~km}$ depth beneath the regions with thicker crust (Figure 9.6-9.7), suggesting the presence of distinct domains in the mantle lithosphere.

Aitken et al. (2015) chose not to apply any artificial depth weighting to enhance deeper density variations. As a result, there is a tendency for variations in density to be relatively smooth due to the reduction of the sensitivity of gravity data to shorter wavelength features at depth, unless non-smooth features are present in the original reference model.

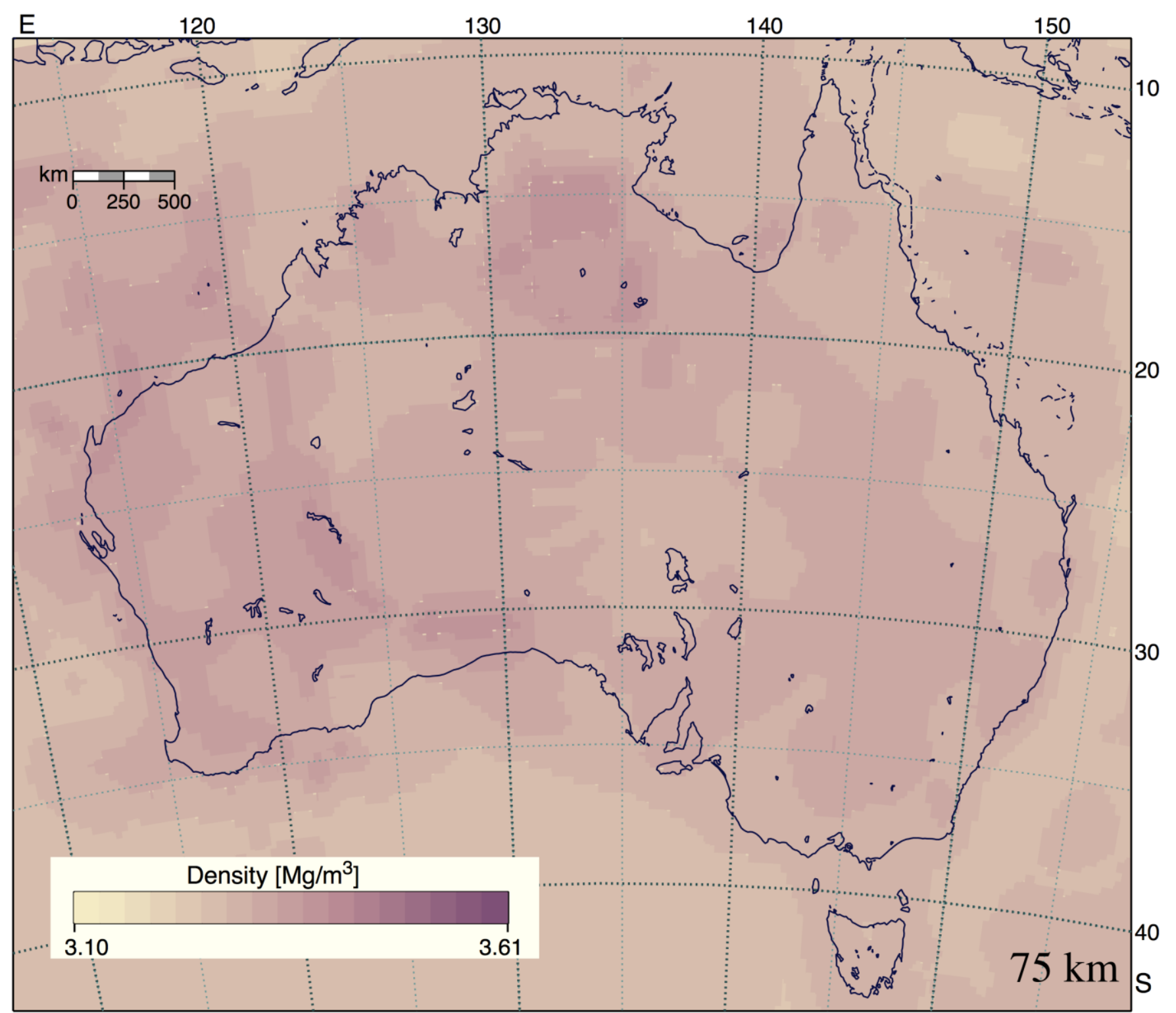

Figure 9.6: Density at $75 \mathrm{~km}$ below the surface from the gravity inversion.
In the AUSREM reference model, lowered densities in the upper mantle are assigned to the zones of highest shear wavespeed, recognising a likely harzburgitic origin with highly depleted mantle. The resulting boundaries of the zone of lowered density, particularly for the West Australian Craton, are not much modified by the inversion procedure, though some additional regions in the North Australian Craton are needed to account for the surface variations in gravity.

The patterns of density variation are compatible with a transition from thicker older lithosphere (Archean to early-Proterozoic) to thinner Phanerozoic lithosphere at around $140^{\circ} \mathrm{E}$, though there is no distinct boundary.

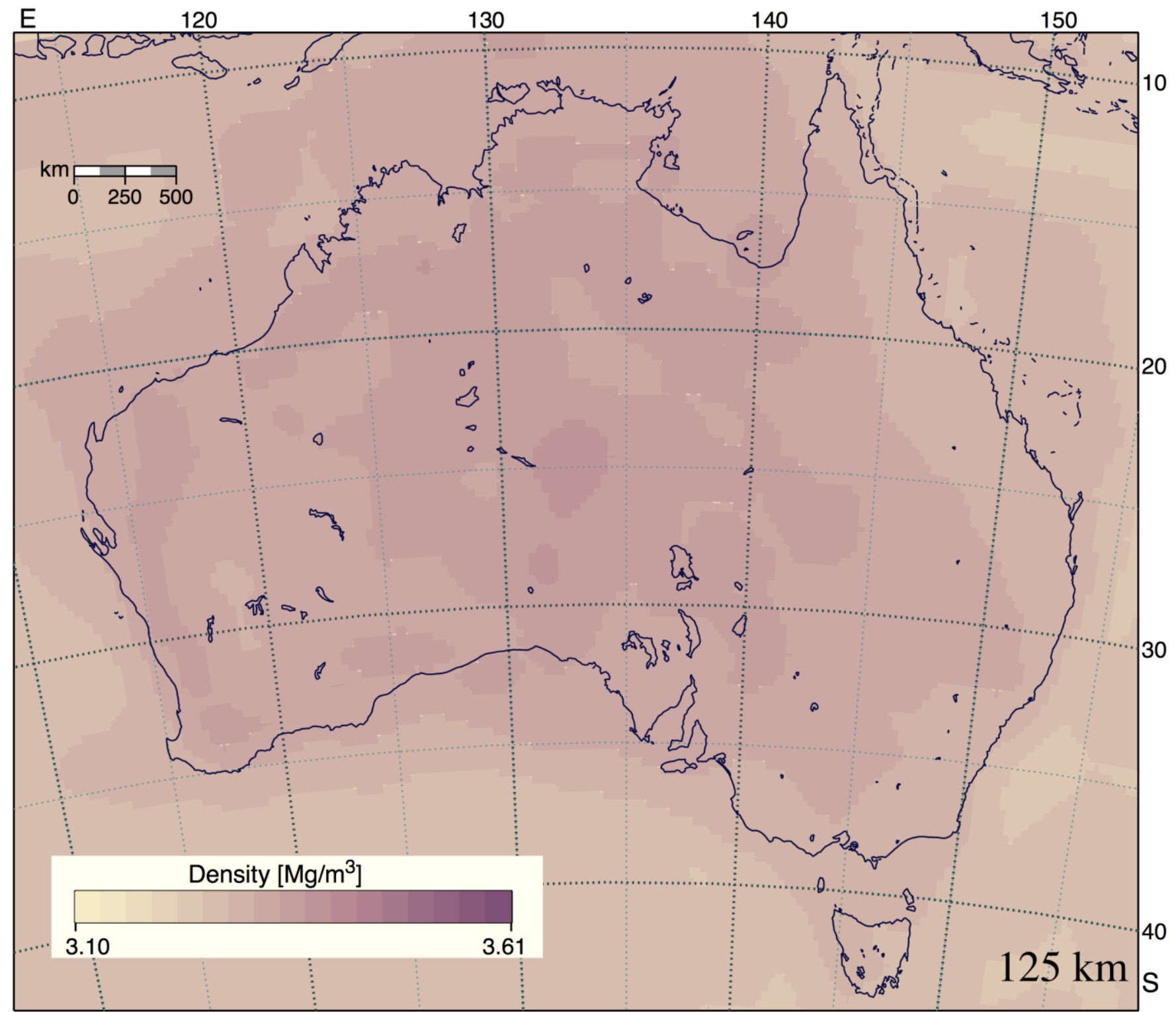

Figure 9.7: Density at $125 \mathrm{~km}$ below the surface from the gravity inversion. 
Apart from the lowered densities beneath the West Australian Craton and parts of the North Australian Craton, the density structure across the continent becomes relatively homogeneous below $150 \mathrm{~km}$ depth (Figure 9.8). However, there is a distinct contrast between the higher density continental regions and the lower density ocean mantle that diminishes at greater depth (Figure 9.9).

The density and gravity variations produce significant pressure variations, which can be extracted from the procedure of Aitken et al. (2015) as a direct product of the solution of the partial differential equations. Their approach excludes influences from upper mantle buoyancy forces and features related to platetectonic movements, as well as ocean loading, but allows a full assessment of the effects of local density and gravity.

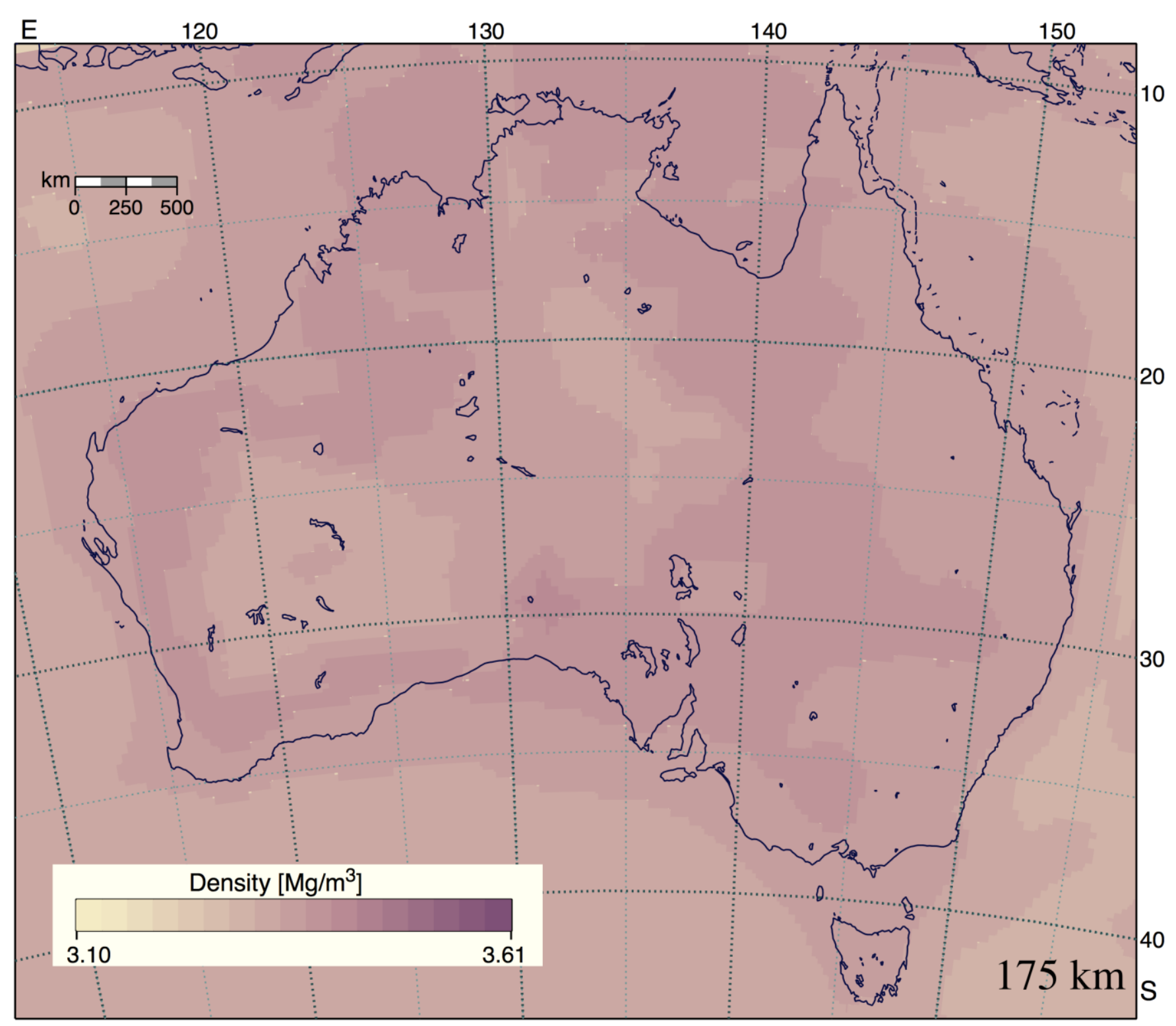

Figure 9.8: Density at $175 \mathrm{~km}$ below the surface from the gravity inversion.
The calculated pressure variations in the continental crust reduce downwards until about $30 \mathrm{~km}$ depth with only modest variability at that depth. This suggests that a significant amount of isostatic compensation has been achieved in the more felsic part of the crust.

Conversely, in the continental mantle, pressure variations strongly reflect crustal thickness, so that the zones of thick crust upset the isostatic balance achieved at shallower levels. The presence of higher density mantle compensates for these crustal effects. By $125 \mathrm{~km}$ depth, the pressure is close to background values, except in Western Australia where higher pressures persist to around $200 \mathrm{~km}$ depth.

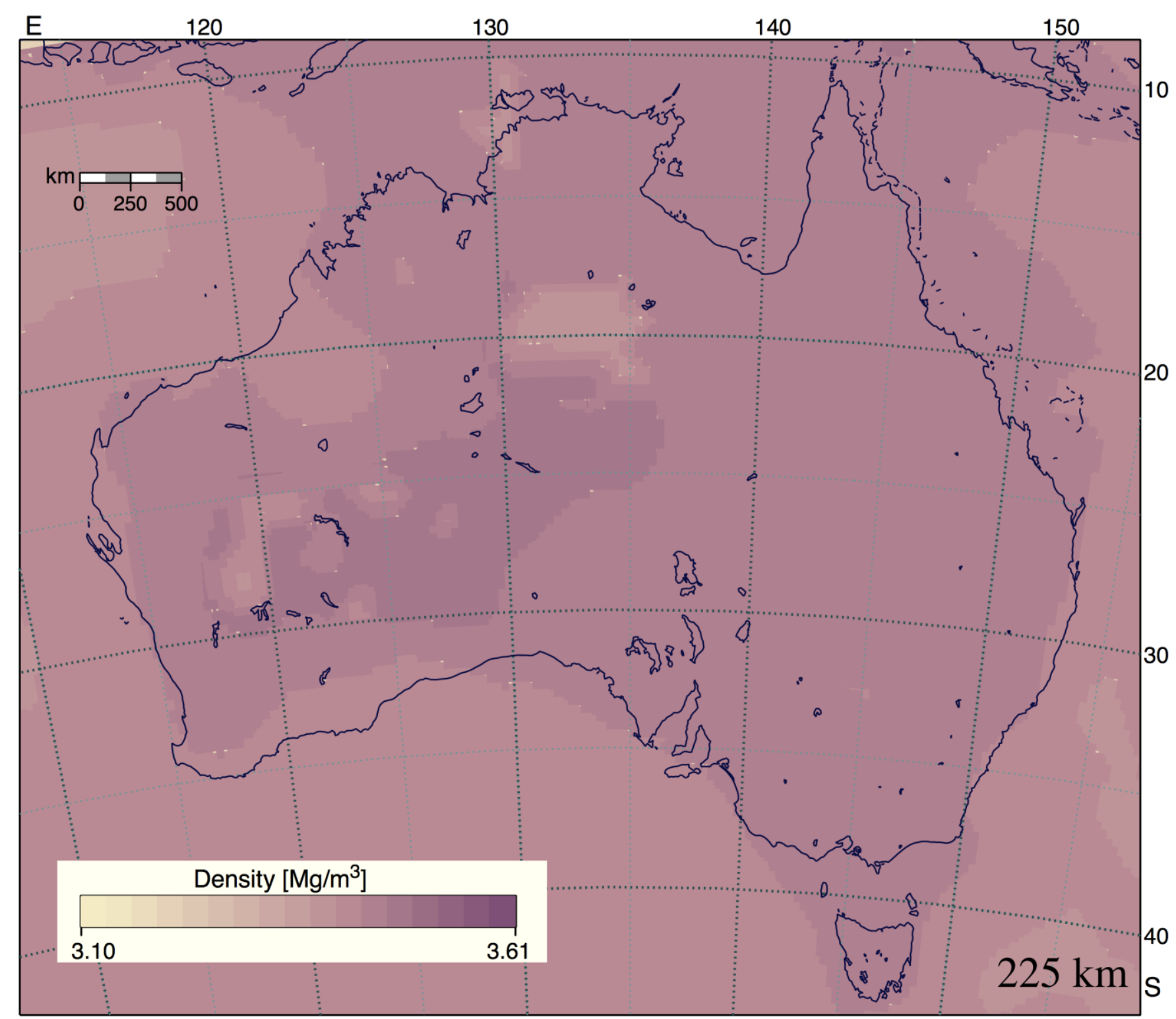

Figure 9.9: Density at $225 \mathrm{~km}$ below the surface from the gravity inversion. 
The pressure models of Aitken et al. (2015) show a very strong contrast between the oceanic and continental domains. Beneath the oceans, lateral variations in pressure generally correlate with bathymetry and thus with the age of the sea floor. The highest pressures are found beneath the youngest regions, particularly at the Southeast Indian Ridge. In the Tasman Sea there is no clear relationship with age, with consistent pressures throughout.
Complete isostatic compensation is never achieved beneath the oceanic domains. But, as on the continent, the pressure variations minimise at around $125 \mathrm{~km}$ depth, which is the thickness of mature oceanic lithosphere. 


\section{Electrical Conductivity}

The electrical conductivity of rocks has strong sensitivity to rock composition, temperature and the influence of fluids. To a greater extent than for seismic wavespeed, minor chemical constituents can have a substantial effect on conductivity. Thus, the presence of a thin zone of a highly conducting phase such as graphite can have a major impact on apparent conductivity.

At the continental scale, studies of electrical conductivity are reliant on variations in natural source of the electromagnetic field. Fortunately, Australia has a favourable location for studies of electromagnetic induction exploiting variations in the external magnetic field of the Earth due to solar and ionospheric activity. Such fluctuations induce electrical field variations and currents.

As an island continent, at a large scale Australia appears as a resistive block embedded in a highly conductive ocean. The contrasts at the edge of the continent produce strong localised effects on the electromagnetic field at the margins. A variety of localised deployments of magnetometers across the continent have exploited electromagnetic induction effects to identify a number of crustal-scale conductivity anomalies. These major features are shown in Figure 10.1 as a set of red lines.

Over the period 1989-1990, the variation of the magnetic field on three orthogonal components was observed simultaneously at 57 sites across the continent in the AWAGS experiment (Australia-Wide Array of Geomagnetic Stations). The four continental geomagnetic observatories operating at that time were supplemented with 53 portable magnetometer systems (Figure 10.1). This achieved a relatively uniform distribution across the continent with a typical station spacing of $275 \mathrm{~km}$.

This continent array of magnetometers has been exploited by Wang et al. (2014) to produce a broad-scale model of the heterogeneous electrical conductivity structure across the Australian continent, making use of the spatial variations in the observed magnetic fields at the stations.

The penetration of an electromagnetic disturbance into the Earth is greater for lower frequencies $(f)$, and depends on the electrical conductivity $\sigma$ as $1 /(f \sigma)^{1 / 2}$. Hence the need for long duration recordings at multiple sites so that low frequencies are well recorded, along with their spatial variations

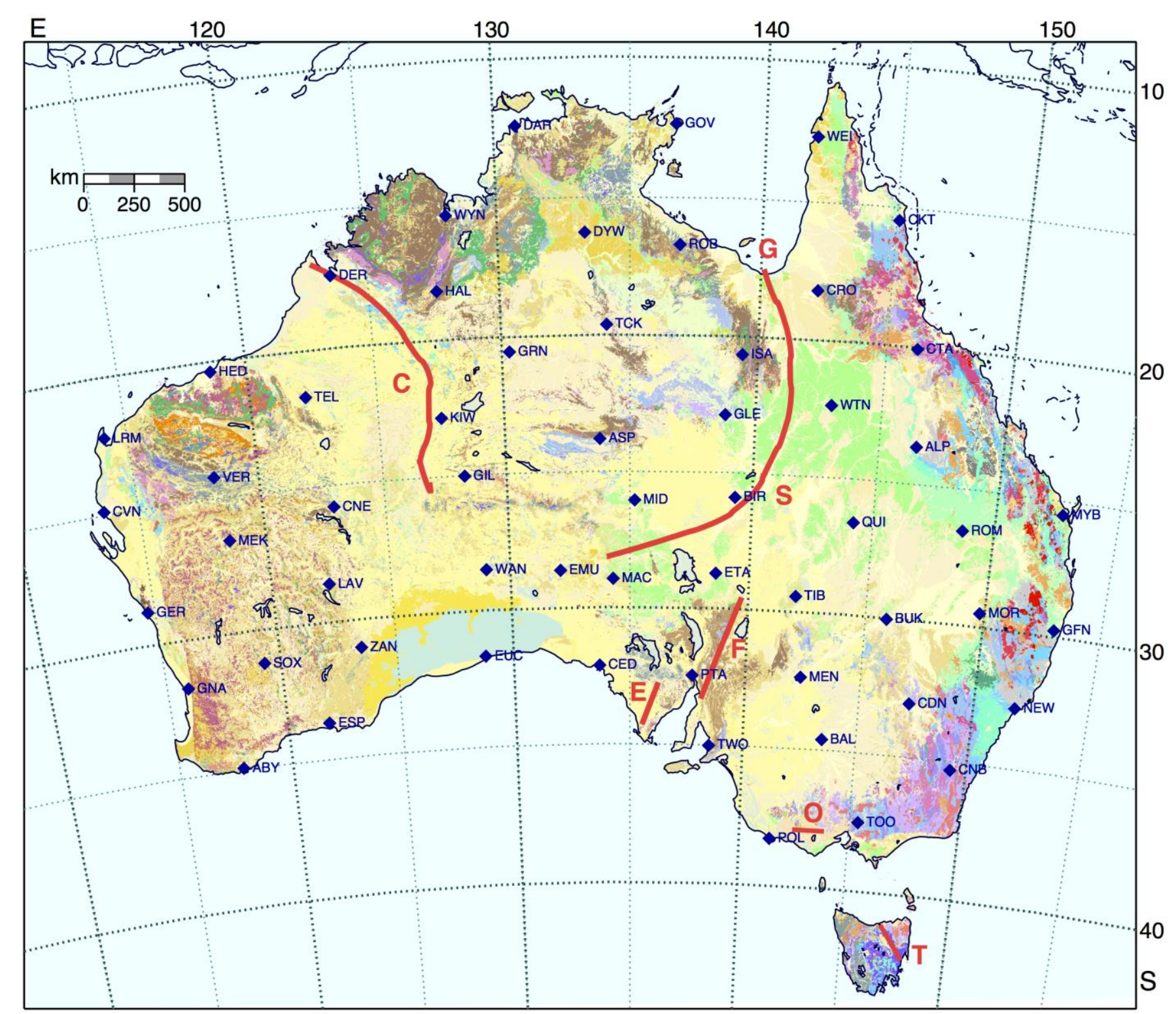

Figure 10.1: Positions of the AWAGS stations (blue diamonds) superimposed on the geological map of Australia, and the location of conductivity anomalies identified from localised experiments in red: C-Canning Basin; S-Southwest Queensland; G-Carpentaria; E-Eyre Peninsula; F-Flinders; O-Otway; T-Tamar.

Fluctuations in the external magnetic field due in large part to solar effects induce electric fields that depend on the local electrical conductivity structure, and these electric fields in turn modify the local magnetic field. This leads to correlation between the vertical component of the magnetic field that has a strong component from external influences and the horizontal components that are most sensitive to induced effects. 
The correlations in the multiple magnetic time series across the AWAGS stations are captured by working with the complex transfer functions between the vertical and horizontal magnetic fields, as a function of frequency. The inversion for electrical conductivity structure across Australia by Wang et al. (2014) used the dataset of such vertical transfer functions at the suite of AWAGS stations for seven frequencies (periods: 338, 660, 1097, 1807, 3072, 5120 and $9480 \mathrm{~s}$ ). These periods were selected to give around two samples per octave, and to stay within the domain for which a plane-wave approximation for the magnetic field variation at each site was appropriate.

The electrical conductivity model comprises a grid of $86 \times 71$ cells, each $55 \mathrm{~km} \times$ $55 \mathrm{~km}$ (approximately $0.5^{\circ}$ ), spanning from $46.5^{\circ} \mathrm{S}$ to $7^{\circ} \mathrm{S}$ and $110^{\circ} \mathrm{E}$ to $157^{\circ} \mathrm{E}$. In depth, 21 layers are used down to a depth of $648 \mathrm{~km}$. The layer thicknesses increase progressively with depth, reflecting the approximately logarithmic sensitivity of the frequency data to depth. The entire model is surrounded by a buffer zone about $2^{\circ}$ wide to avoid edge effects in the forward modelling. The resulting 3-D model of electrical conductivity from the inversion of the AWAGS data captures the broad-scale variations. However, there is inevitably some smearing in depth without the additional constraints that come from recordings of the electric field.

We show four slices through the 3-D model in Figures 10.2-10.5 at depths of $17 \mathrm{~km}, 52 \mathrm{~km}, 92 \mathrm{~km}$ and $172 \mathrm{~km}$. Because the variations in electrical conductivity are very large, we use a logarithmic scale. The shallow portion of the model is sensitive to the assumptions made about the initial structure, e.g. the inclusion of sediments as well as the continent-ocean contrast. But from $17 \mathrm{~km}$ depth, the solutions stabilise and show very similar character. The illustrated model does not include sediments in the initial structure, and provides a good fit to the vertical transfer function in both magnitude and direction at nearly all stations, except for the two on the southern coast of Western Australia where the induction effect is underestimated. This effect may be associated with persistence of low conductivity to great depth beneath the Yilgarn Craton because of low temperature gradients with depth.

The conductivity image at $17 \mathrm{~km}$ depth (Figure 10.2) shows two strong zones of high conductivity along the Halls Creek Belt and in the Rudall component of the Paterson Province to the east of Telfer (station TEL). Both features persist to $25 \mathrm{~km}$ depth. The southwestern margin of the Halls Creek anomaly coincides with the previously identified 'C' conductivity anomaly (Figure 10.1).

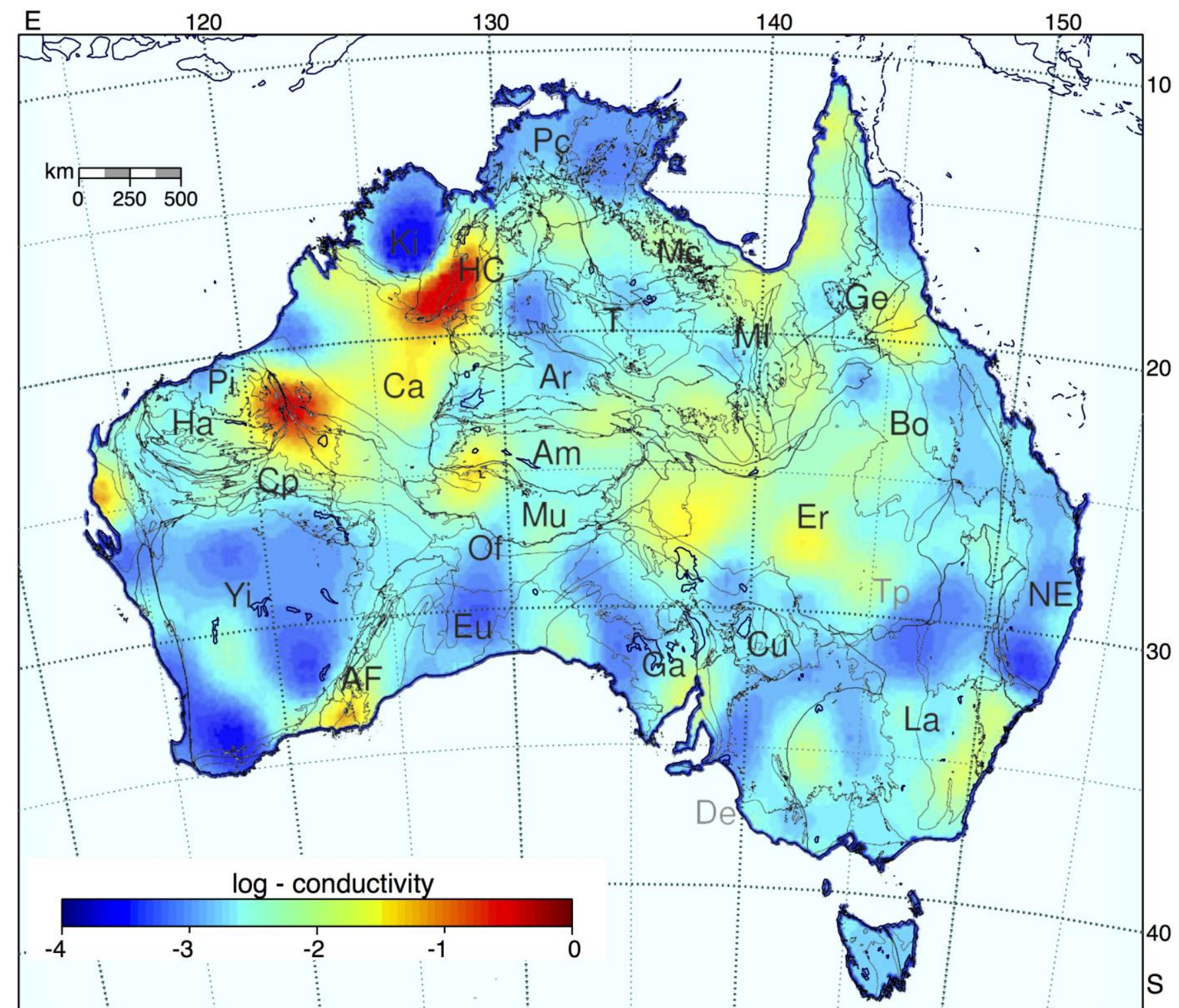

Figure 10.2: Logarithm of electrical conductivity $[\mathrm{S} / \mathrm{m}]$ at a depth of $17 \mathrm{~km}$, with geological provinces superimposed.

The low conductivity of the Yilgarn Craton is truncated at its margins with higher conductivity in the Albany-Fraser Orogen and the Capricorn Orogen. The Eucla Basin appears with a distinct contrast to its neighbours.

Reduced conductivity at the east of the Gawler Craton reflects the presence of the ' $E$ ' and ' $F$ ' anomalies (Figure 10.1). The expression of the ' $C$ ', ' $G$ ' and ' $S$ ' anomalies become more apparent as the base of the crust is reached, and they are still distinct in the image at $52 \mathrm{~km}$ depth (Figure 10.3). 


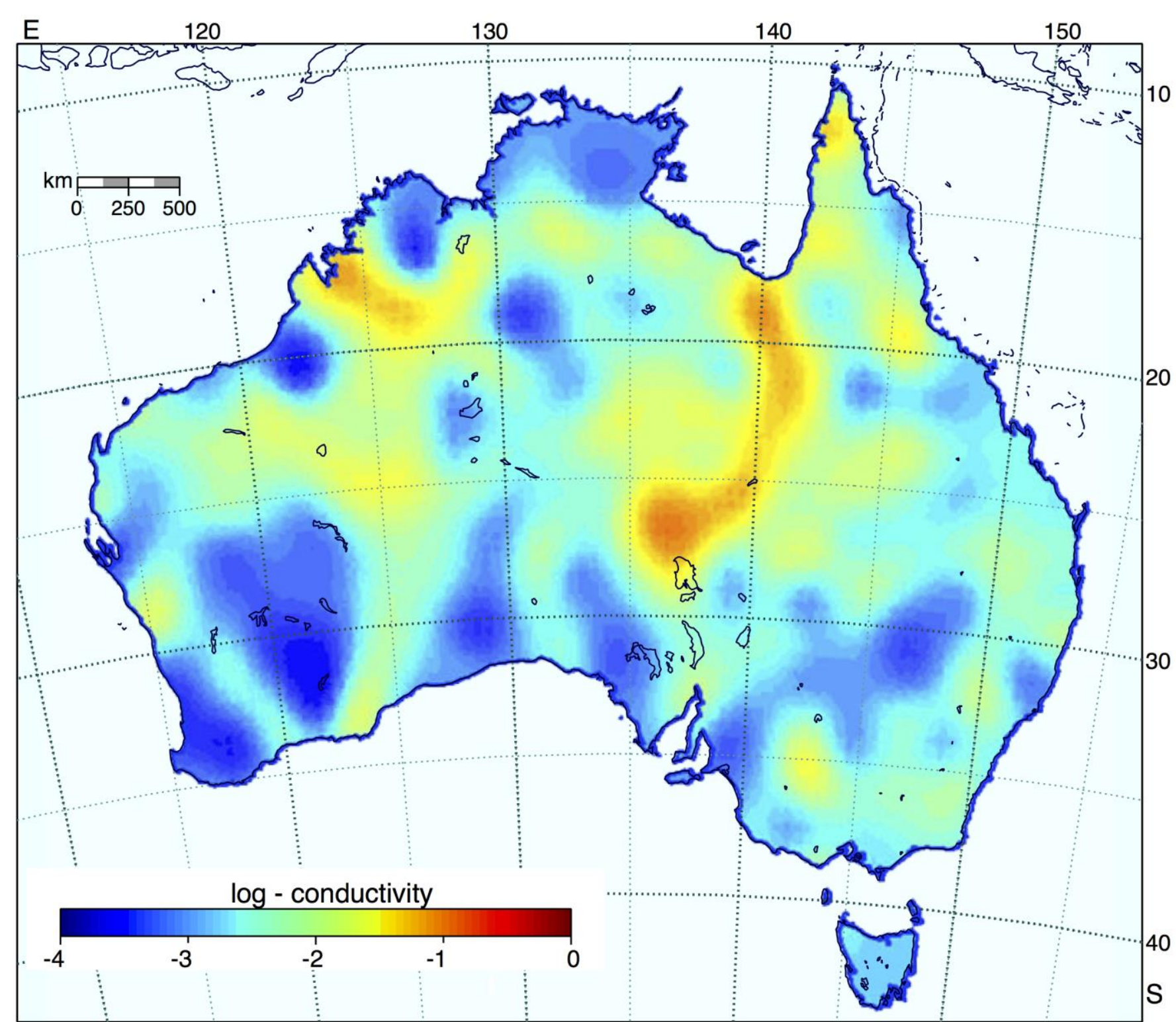

Figure 10.3: Logarithm of electrical conductivity $[\mathrm{S} / \mathrm{m}]$ at a depth of $52 \mathrm{~km}$.

In the 3-D conductivity model, the zone of high conductivity surrounds the Kimberley Block, in both the King Leopold and Halls Creek orogens. The Halls Creek anomaly fades by $92 \mathrm{~km}$ depth (Figure 10.4), but high conductivity in the King Leopold Orogen persists to great depth linking into a north-south trend of increased conductivity that traverses the continent down to at least $200 \mathrm{~km}$ (Figure 10.5).

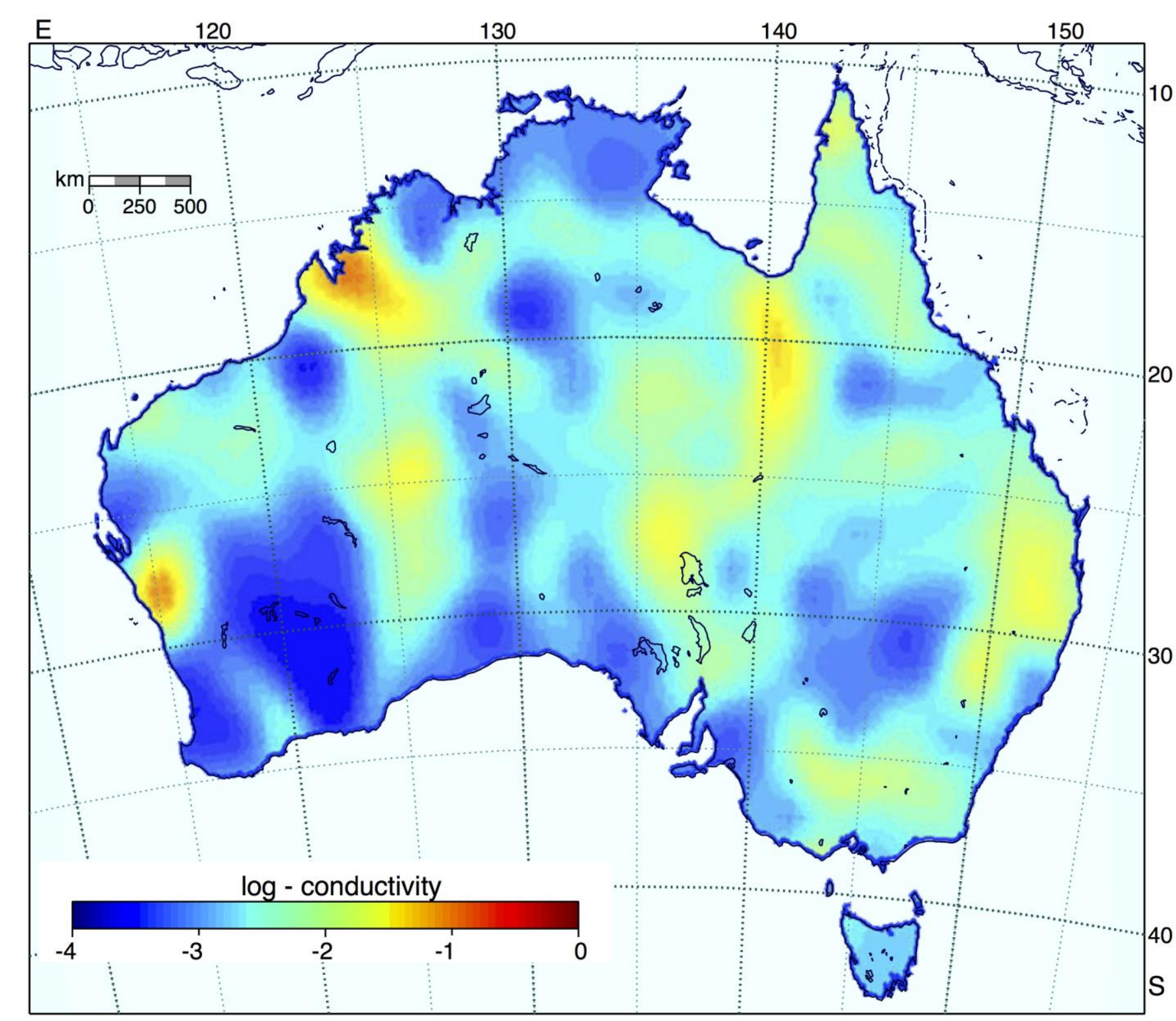

Figure 10.4: Logarithm of electrical conductivity $[\mathrm{S} / \mathrm{m}]$ at a depth of $92 \mathrm{~km}$.

By $52 \mathrm{~km}$ depth, the Rudall anomaly has subsided and now we see a zone of higher conductivity roughly parallel to the King Leopold Orogen to the southwest of the Canning Basin. At this depth a very prominent feature is the high conductivity extending from the Mt Isa Province to the south into the Eromanga Basin and then to the west to the north of Lake Eyre. The southern limb is stronger at shallower depths, but the entire feature persists to at least $100 \mathrm{~km}$ (Figure 10.4). 
A rather localised high-conductivity zone emerges at depth in the neighbourhood of Geraldton (station GER), and can be tracked to $172 \mathrm{~km}$ depth (Figure 10.5). The spatial sampling with the AWAGS stations does not place tight constraints on position and it is possible that the feature is actually confined to the Pinjarra Orogen to the west of the Yilgarn Craton.

As the depth increases, the New England region switches from rather resistive at $17 \mathrm{~km}$ depth (Figure 10.1) to a noticeable high-conductivity feature at $92 \mathrm{~km}$ and $172 \mathrm{~km}$ depth (Figures 10.4-10.5). It is likely that this change is an expression of the electrical asthenosphere with much higher conductivity than the rather thin lithosphere above. The depth of transition fits reasonably well with seismic estimates of lithosphere thickness for the eastern seaboard of Australia, and indeed a weaker version of the transition appears all along the eastern continental margin.

A deep-seated east-west oriented higher-conductivity zone also emerges in Victoria. The conductivity anomaly lies slightly further north than comparable seismic wavespeed reductions that have been linked to elevated temperatures associated with the Newer Volcanics Province. Xenolith information suggests the conductivity feature is related to metasomatised mantle.

Within the Yilgarn Craton there is a persistent contrast between the southwestern corner and the rest of the craton. In the crust this area is more resistive, but gradually its conductivity increases whilst the rest of the craton becomes steadily less conductive. Indeed, at $172 \mathrm{~km}$ depth (Figure 10.5), the eastern part of the craton has the lowest conductivity anywhere in the continent. There is a distinct contrast between the character of the Archean Yilgarn and Pilbara cratons, with much higher conductivity beneath the Pilbara.

The outlines of the other cratons are less marked in the conductivity images. The northern part of the North Australian Craton is less conductive than the south at all depths. A distinct resistive patch is found beneath the Wiso Basin (around $\left.19^{\circ} \mathrm{S}, 132^{\circ} \mathrm{E}\right)$ that persists through the full depth range illustrated. At $172 \mathrm{~km}$ depth (Figure 10.5), the lower conductivity links to a similar feature along the Musgrave Province that abruptly terminates against higher conductivity to the west, in the neighbourhood of magnetic and gravity lineations that suggest a continent-wide shear zone (Braun et al., 1991).

The South Australian Craton has a somewhat heterogeneous conductivity structure at all depths, probably related to the complex history where major volcanic events have modified the character of the core of the Gawler Craton.

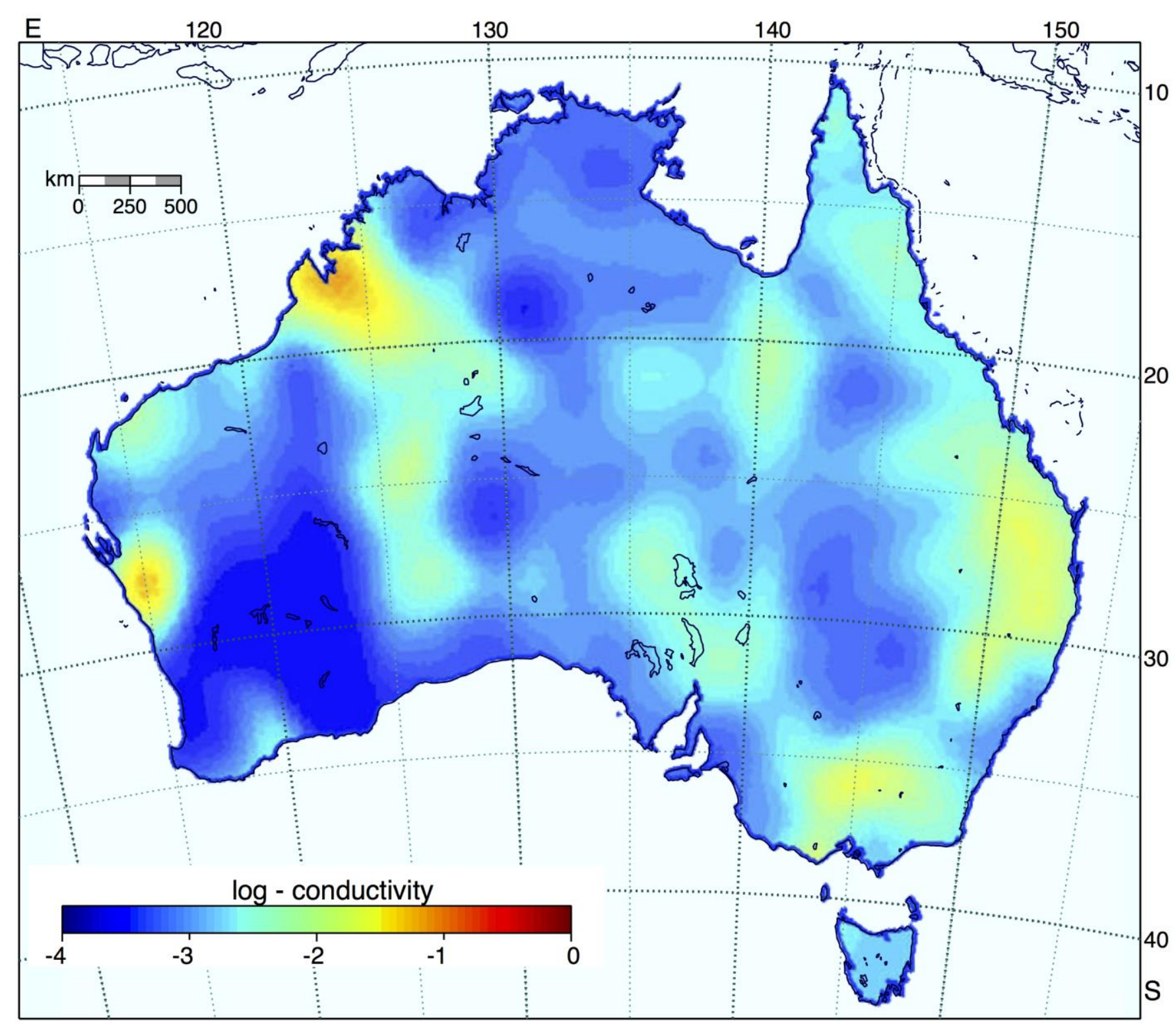

Figure 10.5: Logarithm of electrical conductivity [S/m] at a depth of $172 \mathrm{~km}$.

There is a similar subdued expression of the South Australian Craton in seismic wavespeed (Section 8.1), with lower shear wavespeeds in the mantle lithosphere than in the other cratons.

The use of the continent-wide magnetic data from the AWAGS stations has enabled the construction of a 3-D model for conductivity through the full thickness of the lithosphere, with resolution limited by the spacing between stations. Improved models of the electrical conductivity structure, with better depth control, require the joint use of magnetic and electrical information with magnetotelluric recording exploiting the full vector character of the fields induced by external sources. 
Major efforts have been made in recent years to make closely spaced magnetotelluric measurements across the entire continent. Many stations have deployed in association with major seismic reflection lines.

AUSLAMP - the Australian Lithospheric Architecture Magnetotelluric Projecthas set the goal of $55 \mathrm{~km}$ station spacing, and already significant progress has been achieved. Most of South Australia has been covered, together with Victoria and Tasmania. Substantial progress has also been made in coverage of New South Wales. The distribution of stations to the end of 2016 is shown in Figure 10.6, and subsequent deployments have covered much of New South Wales and have made significant inroads into coverage of northern Australia. Even though stations do not need to be occupied for more than a couple of months, logistical and access issues in remote areas pose considerable problems.

Once the magnetotelluric data has been acquired, substantial effort is needed to extract the appropriate complex frequency responses of the appropriate transfer functions for subsequent inversion. Full 3-D inversion of data at the AUSLAMP spatial sampling is computationally very demanding, and major challenges remain for a fully integrated model at the continental scale.

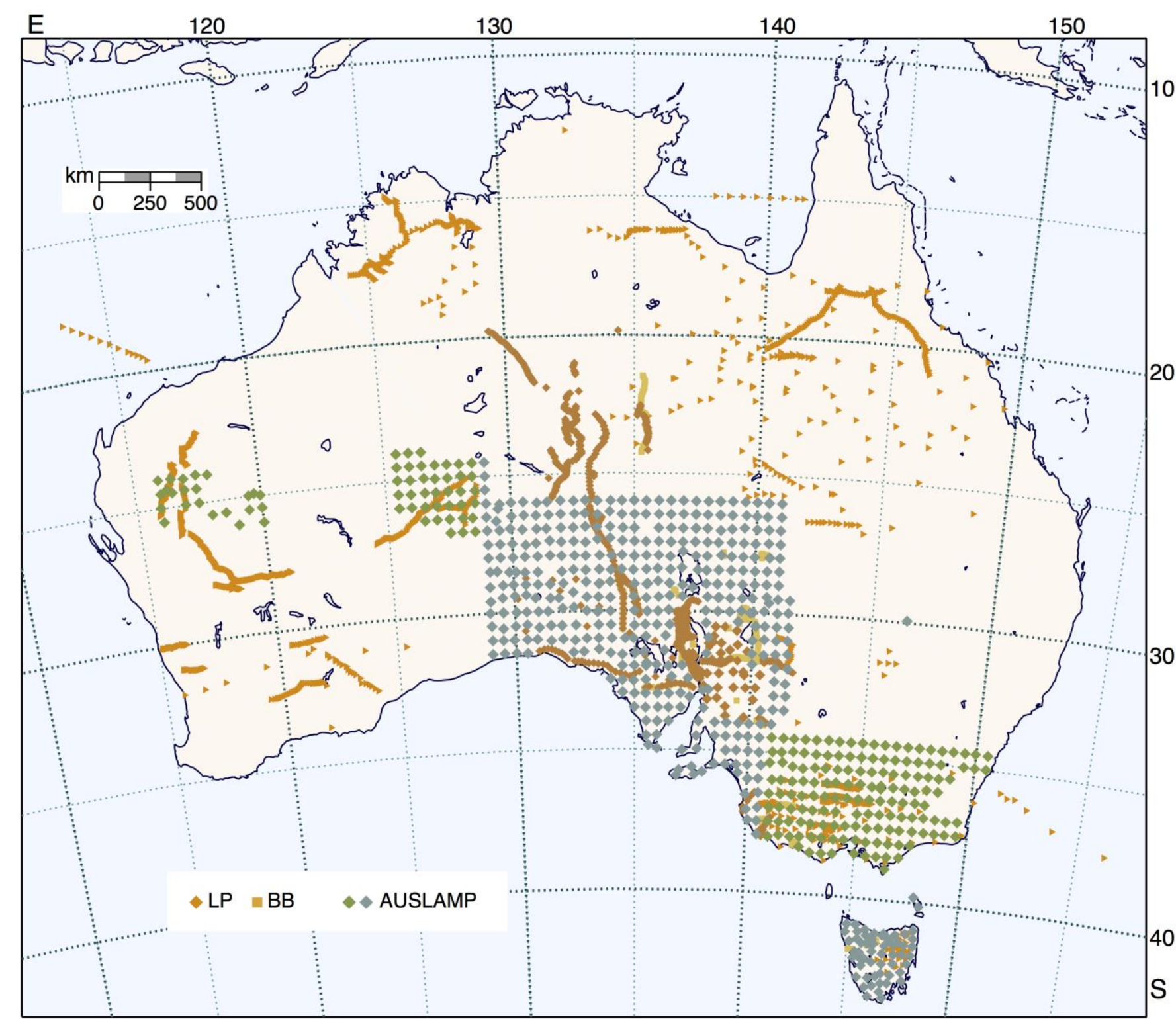

Figure 10.6: Distribution of magnetotelluric sounding stations to the end of 2016. 


\section{Heat Flow and Temperature}

Heat flow data across Australia are sparse, with around 200 publicly available data points. The heat flow data are unevenly distributed and mainly come from studies undertaken in the 1960s and 1970s by the Bureau of Mineral Resources (BMR) and the Research School of Earth Sciences at The Australian National University. Thus continent-wide studies of heat flow, such as that by Cull (1982), are strongly dependent on the limited data sampling. Nevertheless, three major zones can be identified (see, e.g. McLaren et al., 2003), which are indicated in Figure 11.1.

The dominantly Archean Western Province (W) has an average heat flow of $39 \pm 8 \mathrm{mWm}^{-2}$, consistent with global averages for this age. In the dominantly Paleozoic Eastern Province (E), the average heat flow is $72 \pm 27 \mathrm{mWm}^{-2}$, a bit higher than global averages for Phanerozoic terranes. The Central Province (C) has a surface heat flow average of $82 \pm 25 \mathrm{mWm}^{-2}$ significantly higher than $49-54 \mathrm{mWm}^{-2}$, the average expected for similar aged terranes around the globe. McLaren et al. (2003) suggest that the additional contribution comes from crustal radiogenic sources.

\subsection{Temperature Distribution}

Temperature observations are now available from a large number of sites across the continent (Figure 11.1), principally petroleum exploration and production wells, but few have the associated thermal conductivity studies needed to extract heat flow. The distribution of sampling is highly heterogeneous, with strong concentrations in hydrocarbon provinces, both onshore and offshore.

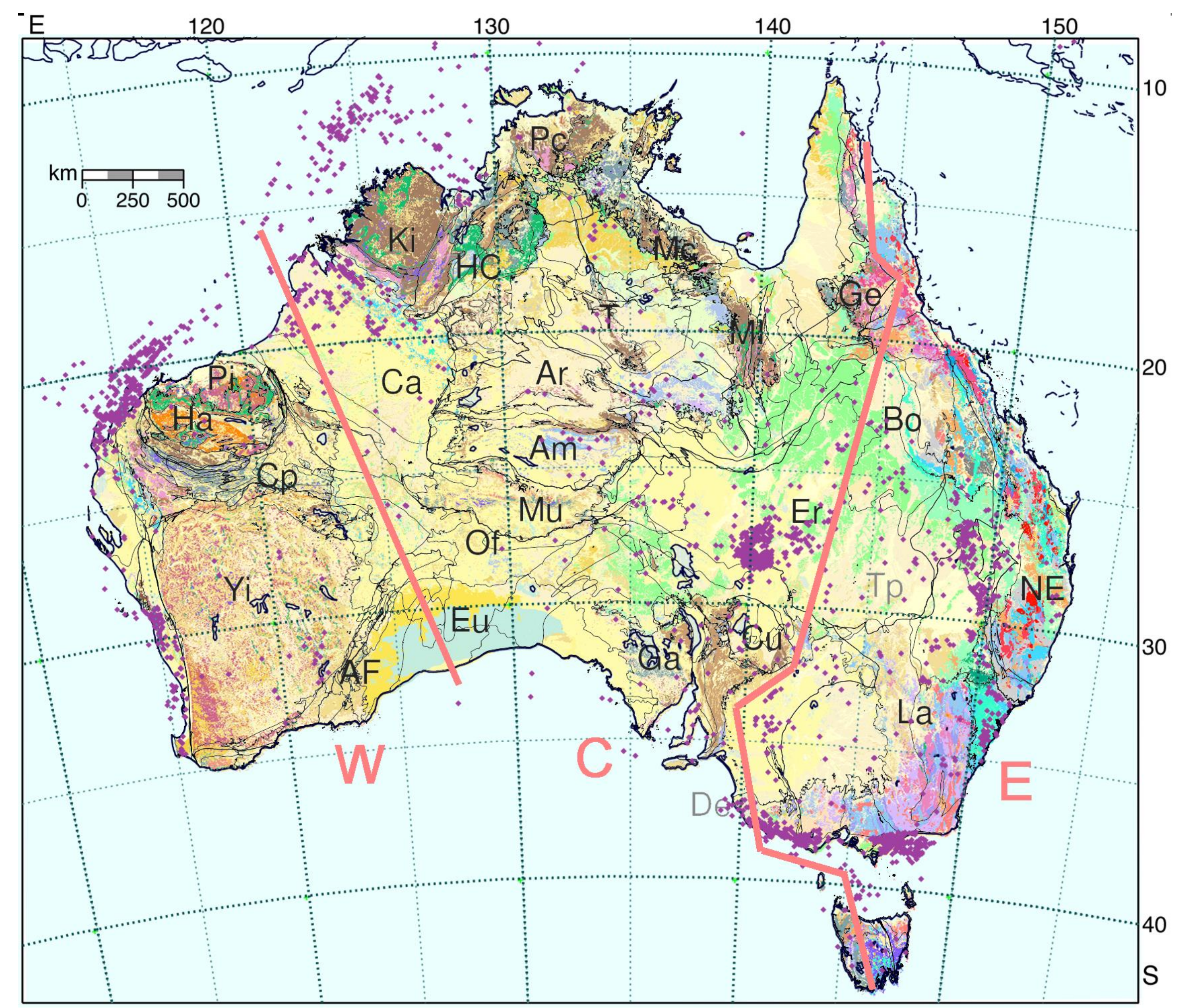

Figure 11.1: Distribution of well data (purple points) used in constructing the OZTemp distribution (Figures 11.2-11.3) superimposed on the surface geology and geological provinces. The main heat flow provinces (W, C, E) are also indicated. 


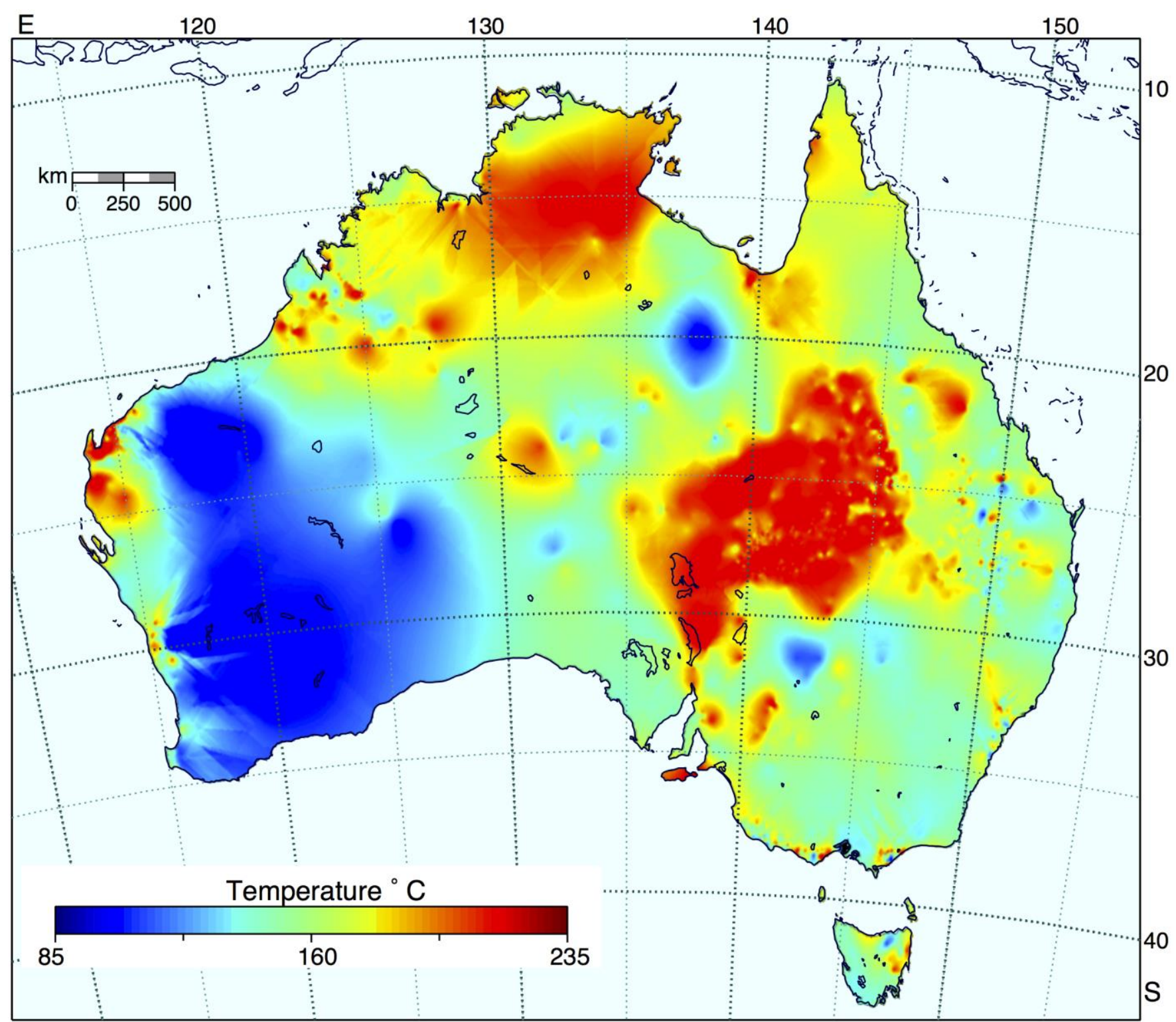

Figure 11.2: OZtemp estimate of the temperature distribution at $5 \mathrm{~km}$ depth across the Australian continent.

Estimates of the temperature distribution at $5 \mathrm{~km}$ depth have been constructed using a simple two-layer model of thermal conduction with a sediment layer over basement with a fixed thermal gradient of $25^{\circ} \mathrm{C} / \mathrm{km}$. The difference between the mean annual surface temperature and the temperature at the depth of the base of the well provides an estimate of the near-surface gradient. Extrapolation to $5 \mathrm{~km}$ is made with the fixed gradient in the basement.

The heterogeneous distribution of temperature estimates across the well sites at $5 \mathrm{~km}$ depth is then interpolated to produce a continent-wide distribution employing a kriging procedure following Chopra and Holgate (2005).

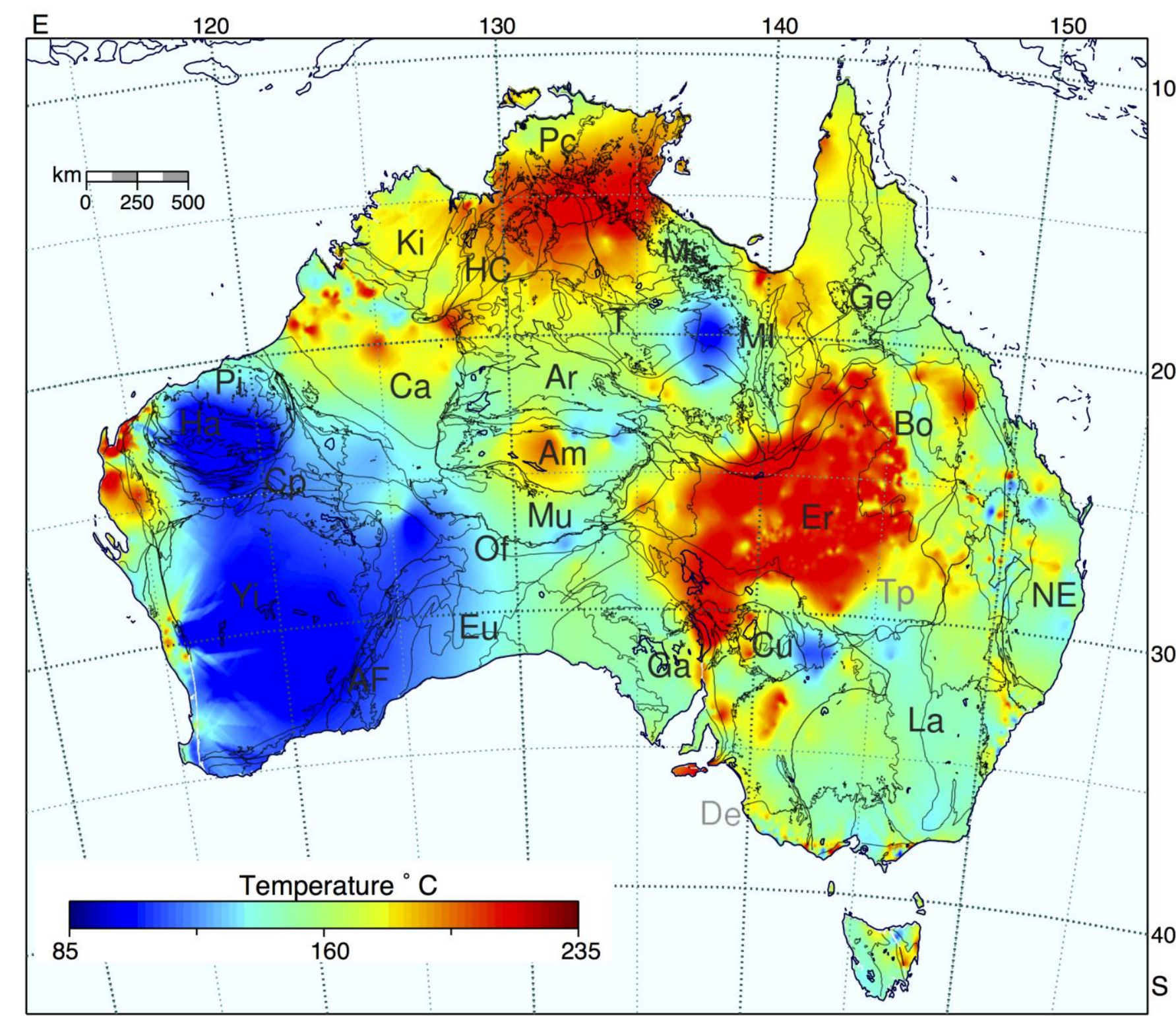

Figure 11.3: OZtemp temperature distribution at $5 \mathrm{~km}$ depth with superimposed geological provinces.

The current OZTemp estimate at $5 \mathrm{~km}$ depth (Gerner and Holgate, 2010) is illustrated in Figure 11.2, and in Figure 11.3 with the superimposition of geological provinces.

The lowest estimated temperatures are associated with regions where basement outcrops, as in the Yilgarn Craton, the Mt Isa Province, the Gawler Craton and parts of the Lachlan Orogen. Although this not unreasonable, these temperatures depend quite strongly on the assumed fixed temperature gradient. Limited deep sampling in such basement areas precludes use of more specific estimates for temperature gradients. 
Regions of high temperature are commonly associated with relatively thick sedimentary cover (cf. Figure 2.9) as, e.g. the Canning Basin in Western Australia and the Cooper-Eromanga Basin extending from South Australia into Queensland.

Interpolation artefacts associated with the limitations of data coverage are clearly present in Figures 11.2 and 11.3. A clear example is streaking from observations in the Perth Basin into the Yilgarn Craton. Such features can be quelled if ancillary assumptions are made, such as a direct correlation of the temperature distribution with tectonic units (Chopra and Holgate, 2005). Another region where limited sampling produces complex structure is the North Australian Craton, where a widespread high-temperature anomaly is apparent. Here points with similar temperature are linked without control on whether there is continuity of structure in between.

The large area of high temperature in the Eromanga Basin is generally well constrained with many wells, but the southern extension past Lake Eyre and Lake Torrens depends on far fewer observations. Although the OZTemp results indicate major geothermal potential for energy production, much of the potential resource lies rather far from major population centres.

\subsection{Use of Geological and Geophysical Information}

The rather uneven distribution of temperature observations is unlikely to be significantly modified in the near future. This means that cratonic areas, in particular, will be poorly sampled with little direct control on the temperature distribution. On the other hand, there is substantial geological and geophysical information that can be used to build estimates of the likely temperature distribution in regions without direct observations. This is the approach taken by Haynes et al. (2015), using 3-D modelling with a thermal conduction model (TherMAP) to examine the likely temperature field and its uncertainties.

Thermal conductivity estimates have been made for the major sedimentary basins based on knowledge of the stratigraphy and sediment thickness. Values range from $1.63-3.18 \mathrm{~W} / \mathrm{mK}$; a variation of $\pm 0.15 \mathrm{~mW} / \mathrm{K}$ is allowed $\square \square$ A default value of $3.0 \mathrm{~W} / \mathrm{mK}$ is used where current information is insufficient with an allowed variation of $0.3 \mathrm{~W} / \mathrm{mK}$. For granites the thermal conductivity is taken as $2.79 \pm 0.38 \mathrm{~W} / \mathrm{mK}$, and for metasedimentary basement $3.54 \pm 0.89 \mathrm{~W} / \mathrm{mK}$. An allowance is made for the temperature dependence of the thermal conductivity.

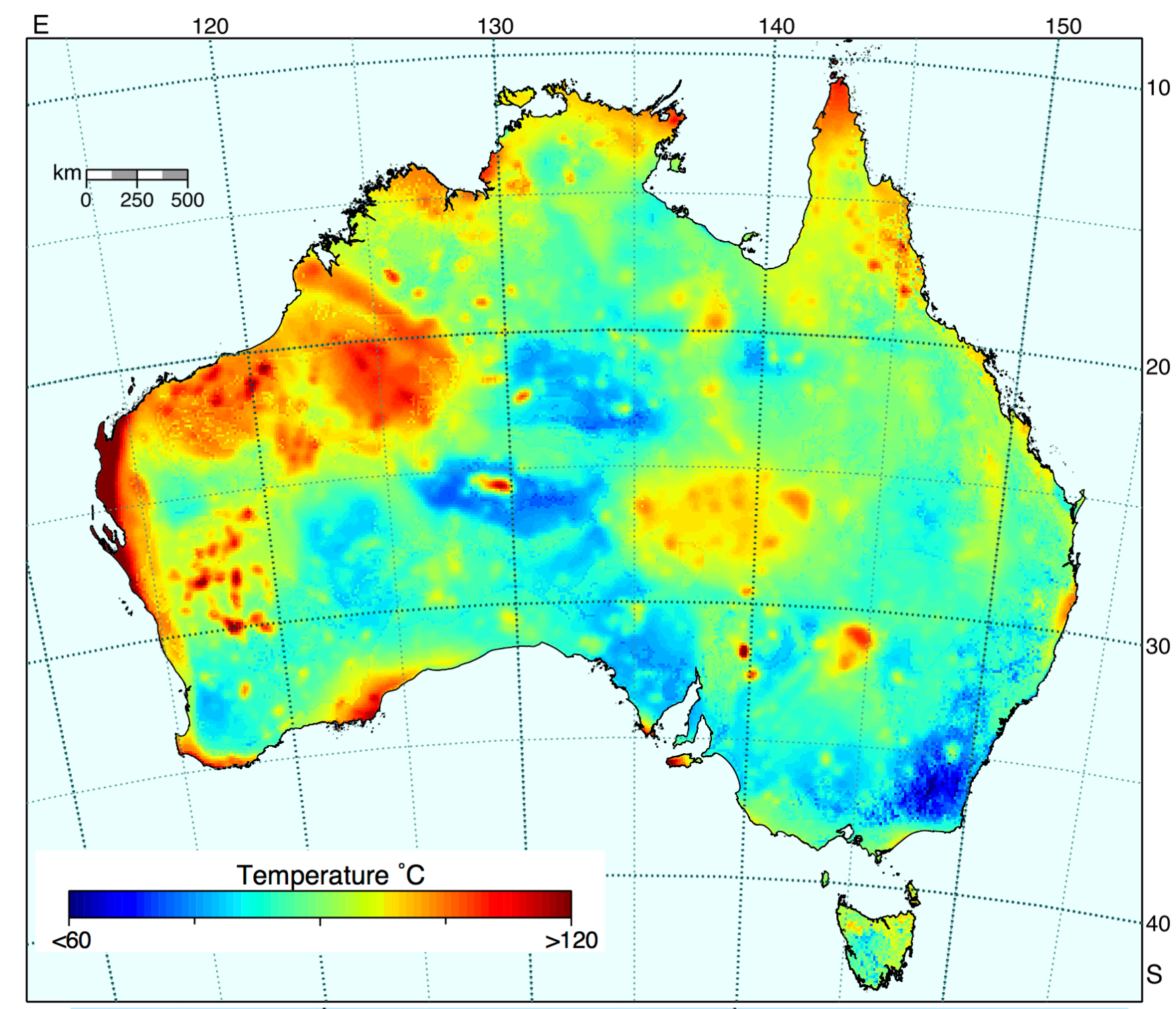

Figure 11.4: TherMAP model at $4 \mathrm{~km}$ depth, derived from an ensemble of 401 realisations.

The distribution of granite bodies has been identified from the Bouguer gravity distribution (Figure 5.7) with 3-D footprint models. Province-specific heat production rates have then been derived from the OZCHEM geochemical dataset (Champion et al., 2007). A $10 \mathrm{~km}$ thickness of basement with elevated heat production rate was included, based on the results for the Central Province of McLaren et al. (2003); the heat production was set at $4 \pm 1 \square \mathrm{W} / \mathrm{m}^{3}$. For sediments, the default heat production rate was set as $1 \square \mathrm{W} / \mathrm{m}^{3}$.

A fixed base temperature in the range $700 \pm 100^{\circ} \mathrm{C}$ was applied at the Moho. A distribution of Moho depths was allowed, drawing on the probabilistic model of Bodin et al. (2012), based on the earlier analysis of Kennett et al. (2011). 


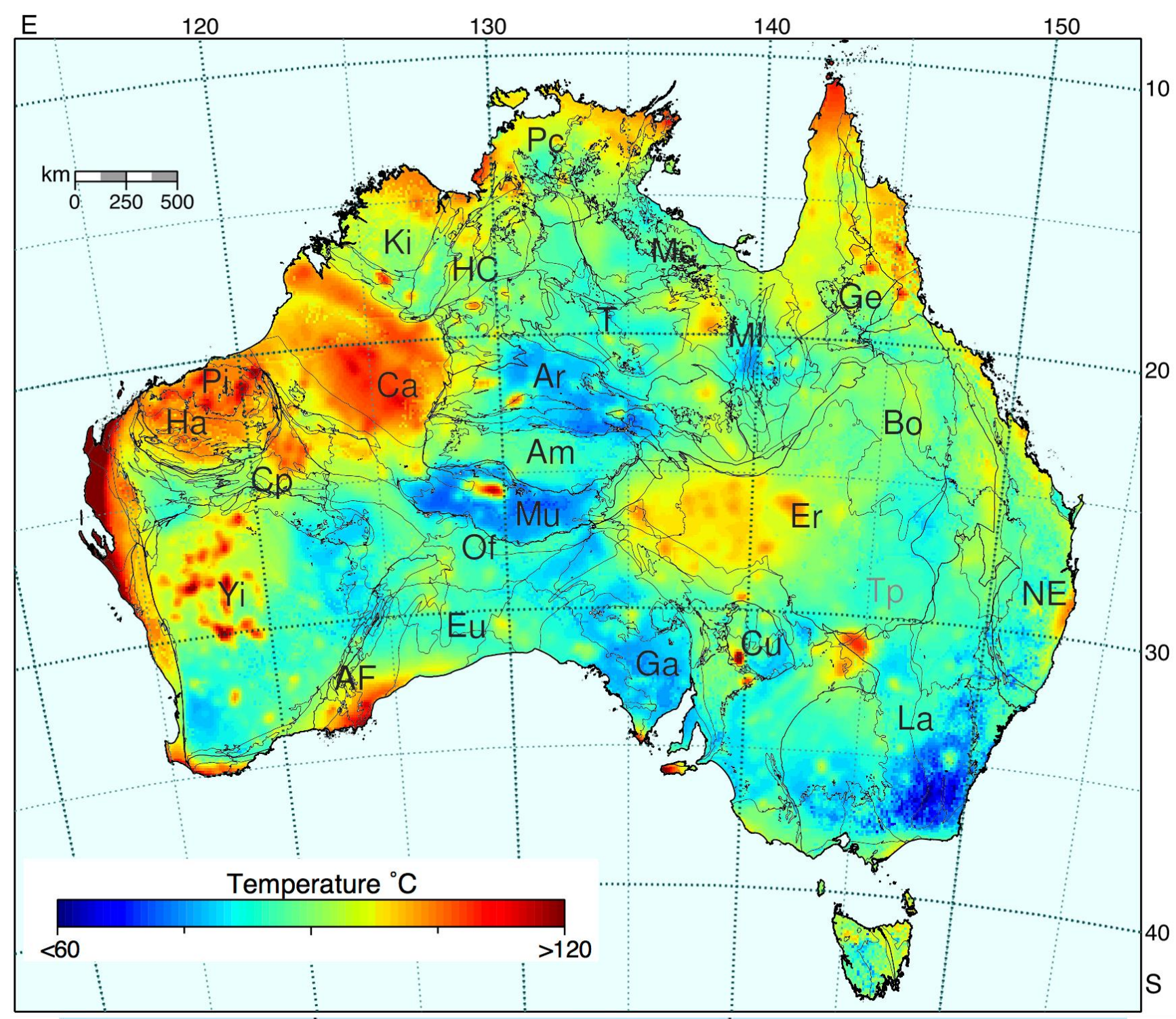

Figure 11.5: TherMAP model at $4 \mathrm{~km}$ depth with geological provinces superimposed.

The 3-D model spans the range from $4 \mathrm{~km}$ above sea level to $59.8 \mathrm{~km}$ below, using voxels with $10 \mathrm{~km} \times 10 \mathrm{~km}$ horizontal dimension and $200 \mathrm{~m}$ in depth, i.e. approximately 51 million voxels. A constant temperature condition was applied at the top surface and the properties of the atmospheric cells were adjusted to give a good rendering of the mean annual surface temperature distribution at the appropriate elevation.

An ensemble of models were created, with 401 realisations using variations of the input variables within the allowed ranges and a full 3-D solution of the heat equation. The mean of the ensemble values at $4 \mathrm{~km}$ depth is displayed in Figures 11.4-11.5, and the standard deviation across the ensemble in Figure 11.6.

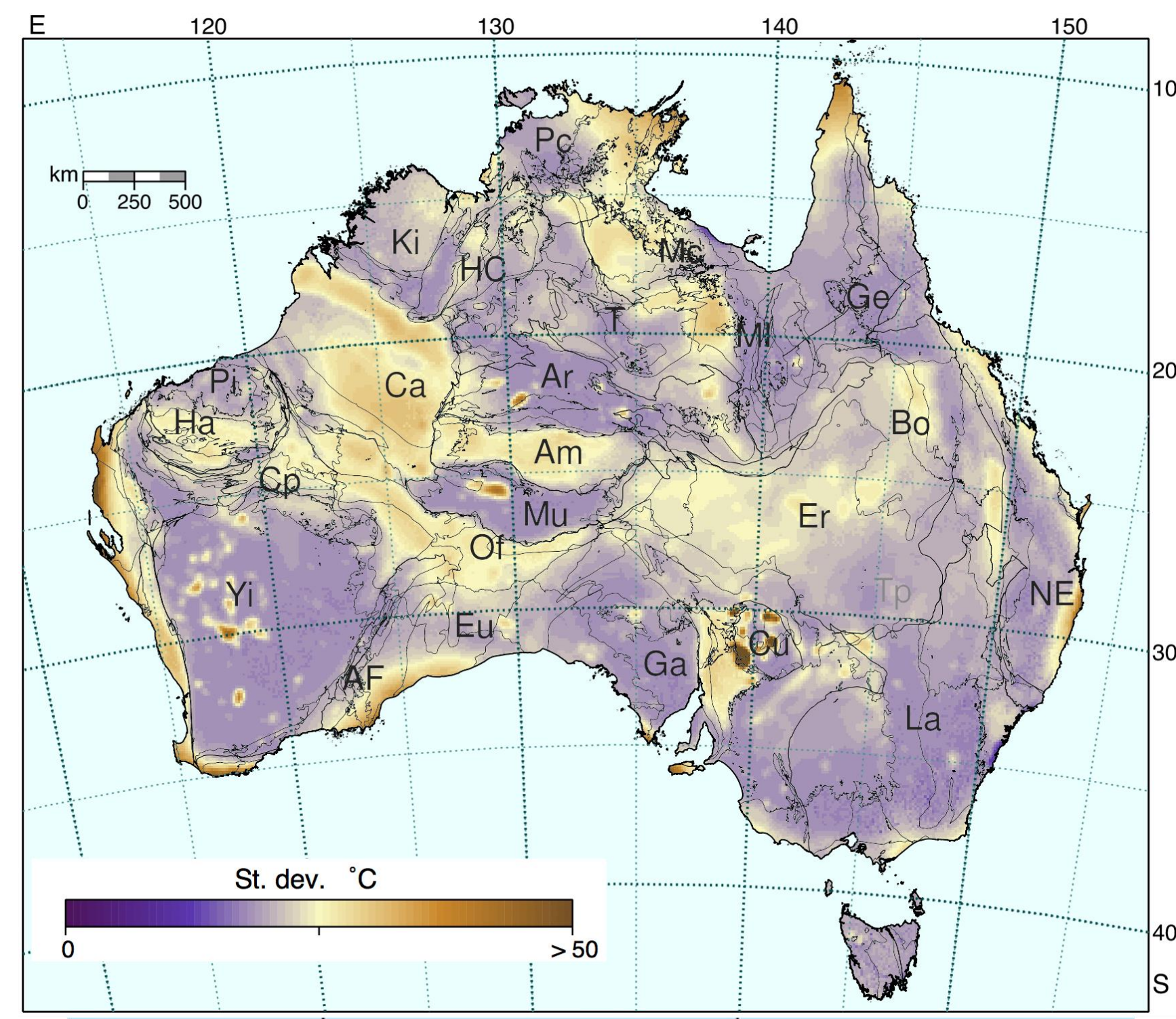

Figure 11.6: Standard deviation of TherMAP model ensemble with geological provinces superimposed.

The TherMAP results show a large thermal anomaly in Western Australia, with elevated temperature extending from the Pilbara into the Canning Basin. The area of the Pinjarra Orogen shows rather high temperatures. The northwestern Yigarn Craton is also characterised by higher temperatures than the remainder of the craton. Low temperatures are predicted at $4 \mathrm{~km}$ in the Mt Isa Province, and the Arunta and Musgrave provinces in central Australia. A band of lower temperatures extends along the Eastern Highlands from the New England Orogen into the Lachlan Orogen, with the coolest conditions in the south.

The variations across the ensemble of models tend to be larger for the hotter zones, though not in the Pilbara Craton. Relatively large variability is seen for the Amadeus and Officer basins where inferred temperatures at $4 \mathrm{~km}$ are moderate. 
Localised strong variability is found in the Curnamona Province around localised hot spots.

The general pattern of temperature in the TherMAP study links quite well with the OZTemp results in Figures 11.2-11.3, even though these values were not used in the analysis. Nevertheless, there are significant differences in the cratonic areas. Detailed comparison with the OZTemp well database suggests that there is a tendency to underestimate the temperatures in the centre and west of the continent, particularly in the offshore zone. Errors are typically around $50^{\circ} \mathrm{C}$ in the sedimentary basins, but can reach $100^{\circ} \mathrm{C}$ on the North West Shelf.

Limitations of the current TherMAP modelling include the assumption of a fixed temperature at the Moho. The results for the base of magnetisation (Figure 4.14) require this depth to penetrate the Moho (Figure 7.17), as discussed further in
Section 12.3. Thus if the cessation of magnetisation is controlled by Curie temperature, there must be substantial variability in temperature at Moho depth. Further, the variability in the character of the Moho (Kennett and Saygin, 2015), with many gradient zones at the base of the crust, suggests that a single temperature is an oversimplification. At the elevated temperatures at the base of the crust it is also likely that radiative effects may make a contribution to the apparent thermal conductivity.

Nevertheless, the TherMAP approach provides a useful integration of continentalscale datasets to provide an alternative perspective on the distribution of temperature and heat flow. In particular, the model has predictive power in regions that are otherwise undersampled. 


\section{Relations between Fields}

So far we have concentrated on aspects of individual geophysical fields rather than their interrelations. One of the benefits of working with uniform representations of the fields is that we have common registration and sampling. This means that we can readily superpose different aspects of the information, and also undertake quantitative comparisons in the spectral domain.

One of the ways in which we can introduce the aspects of different fields is by the use of ternary colour. We have seen in Chapter 3 the application of such three-colour images for the rendering of the results of radiometry, with potassium on the red channel, thorium on the green channel and uranium on the blue channel (Figure 3.1). In a similar way, we can place appropriate fields on the three colour channels and so gain a rather different appreciation of their interrelations than a simple visual comparison.

In Figure 12.1 we display a ternary image for magnetics, gravity and topography. We have placed the total magnetic intensity on the red channel, the Bouguer gravity on the blue channel and topography on the green channel. The elevated topography of the Eastern Highlands is prominent as a green band, with extension into Tasmania. Topographic influence is also strong in the centre of Australia and in the Hamersley Basin. Elsewhere we see interesting interactions between the magnetic and gravity signals. Where these are balanced, as in the Mt Isa region and the South Australian Craton, we get a bright lilac colour. When the magnetic and gravity features are displaced we see a colour dipole, e.g. in the AlbanyFraser Orogen, and the Musgrave and Arunta provinces.

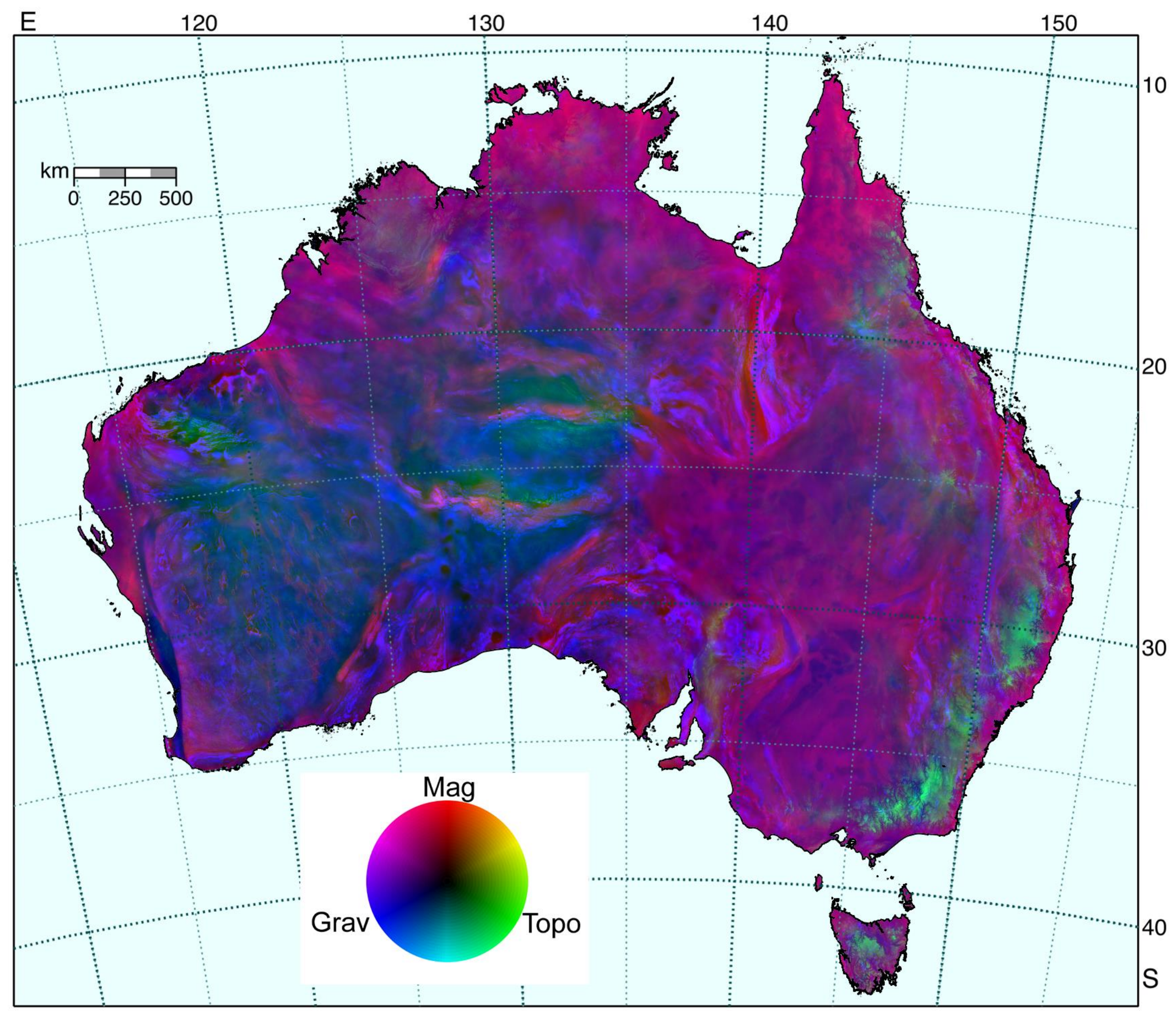

Figure 12.1: Three-colour rendering of the relation between the total magnetic intensity, Bouguer gravity and topography. 
In Figure 12.1 we have presented the ternary image without annotation, but it is also helpful to superimpose the geological provinces as in Figure 12.2. We immediately notice the strong correspondence of the differences in the correlations of these three major fields with the geological boundaries.

The subtle interrelations between the fields manifest in a variety of ways. For example, there is distinct banding in the Yilgarn Craton that corresponds to the major crustal divisions of Korsch and Doublier (2016)—cf. Figure 2.7. Likewise, the subdivisions of the Madura and Coompana provinces beneath the Eucla Basin, manifested in the full crustal seismic reflection profile (Figure 7.4), have perceptible expression in the ternary image, mostly from the interaction of gravity and magnetics.

The ternary image also draws attention to the continuity of structures extending from the Musgrave Province to the Rudall-Paterson Province at the eastern edge of the Capricorn Orogen. Even in the areas of cover we see faint but distinctive signatures as in the Canning, Eromanga and Murray basins.

When we want to look at the relation between just two fields we can gain maximum contrast by working with complementary colours, such as yellow-blue or redcyan. We use such representations below to highlight aspects of the connections between structures contributing to the gravity and magnetic anomaly fields, and the relation between gravity and topography.

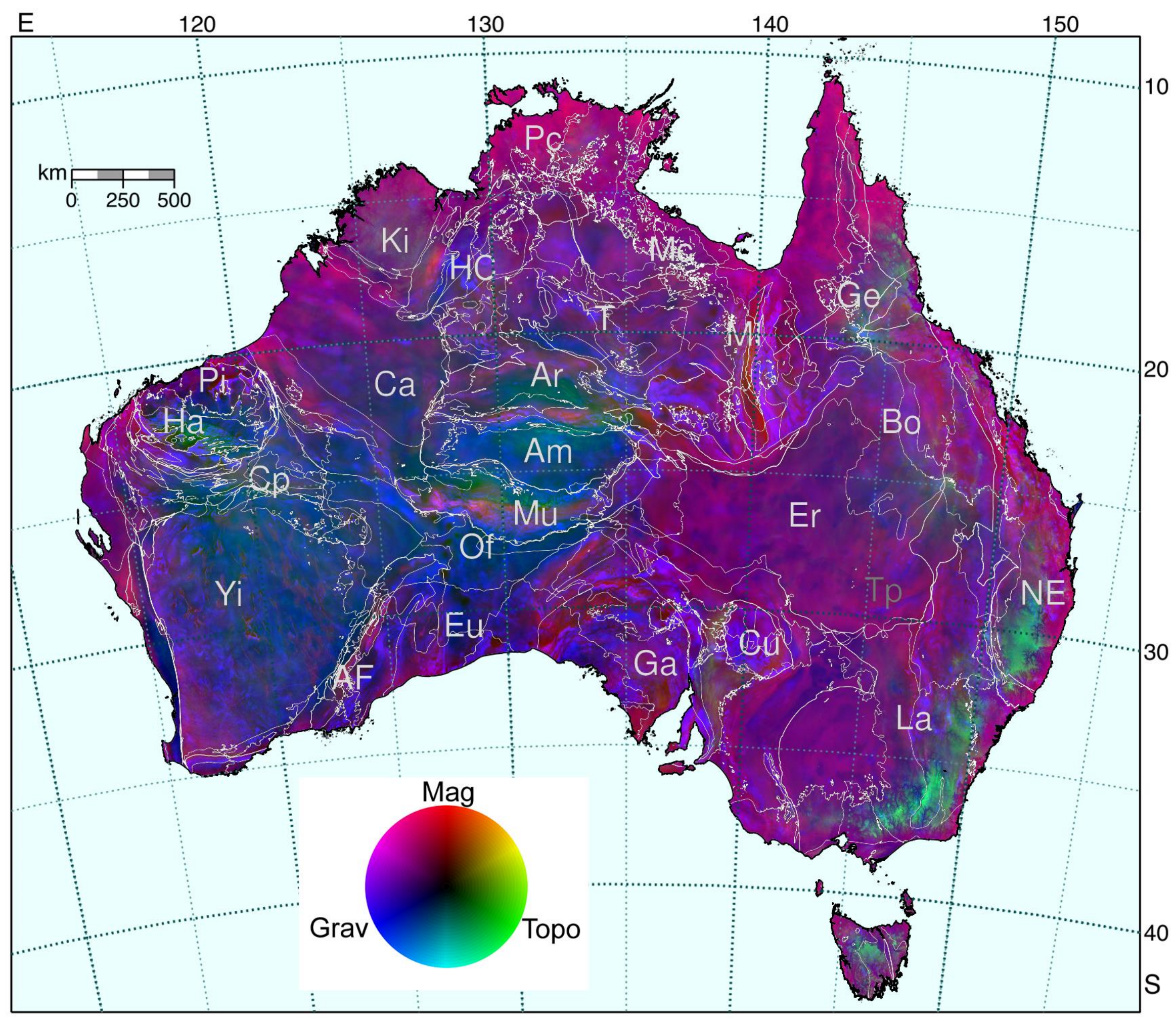

Figure 12.2: Three colour rendering of the relation between the total magnetic intensity, Bouguer gravity and topography with superimposed geological provinces. 


\subsection{Gravity and Magnetics}

Inherently, the gravity and magnetic fields sense different aspects of the same Earth. Gravity variations are induced by mass (density) changes beneath the observer, and its sensitivity to such contrasts falls off with the square of depth. Magnetic methods are sensitive to changes in the induced and intrinsic magnetic fields of rocks, controlled by their susceptibility to magnetisation, with sensitivity that falls off with the cube of depth. The magnetic field, therefore, senses shallower variations in structure. Magnetic properties are dominantly controlled by the iron content of rocks, and vary over a much wider range than densities, which link to the balance of the different minerals within a rock.

In Figure 12.3 we present the Bouguer gravity and magnetic field on the same scale and at the same resolution. When we compare the magnetic map to the gravity map, it can readily be observed that the gravity data show a much broader-scale pattern, such as the low gravity response of the Pilbara and Yilgarn cratons, and the major changes in crustal thickness in central Australia. The magnetic data, however, are more sensitive to the structures that bound individual provinces and structures and rock packages within these provinces. Thus the distinct belts of the Mt Isa Province are much more apparent in the magnetic data, including their continuation to the south underneath the Eromanga Basin.

In Chapter 4 we introduced the spatial integral of the magnetic field. This magnetic integral has depth dependence much closer to that of gravity, so it is more sensitive to deeper structures than the raw magnetic data. The integral is also more reflective of bulk mineralogy, as it represents the horizontal spatial sum of magnetic responses. As can be seen from Figure 12.3, the magnetic integral has a closer match to the character of the gravity results. This correspondence is particularly notable for the provinces that lie beneath the Eucla Basin. The eastern margins of the Yilgarn Craton are also apparent as magnetic integral highs, and these high responses match the lower gravity response due to crustal thickening at the boundary of the craton.
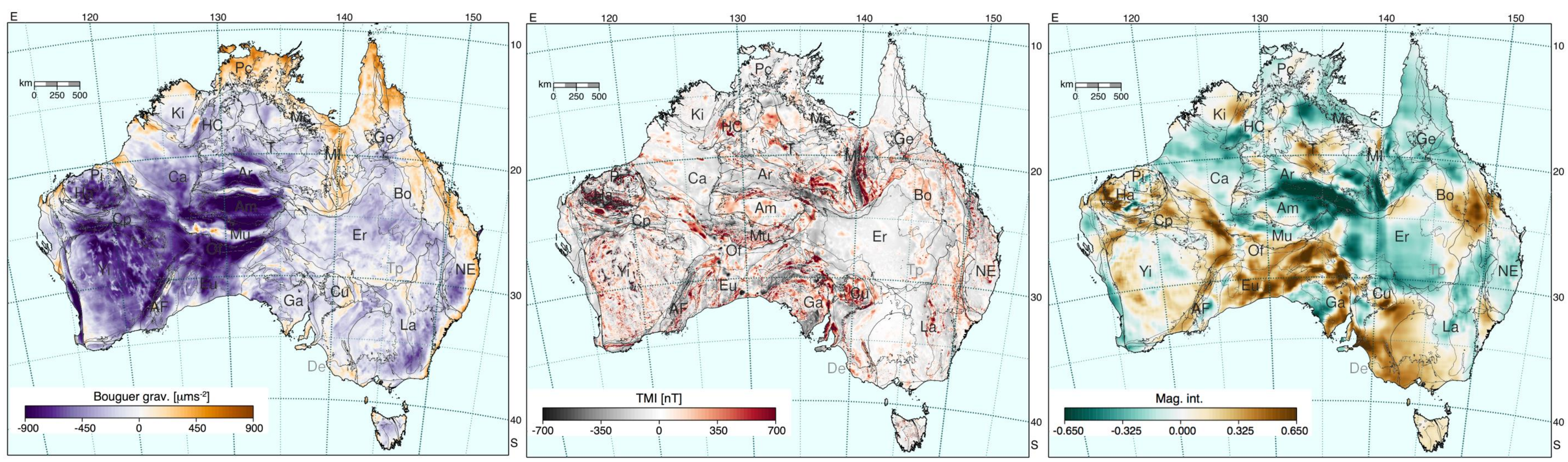

Figure 12.3: Gravity, magnetic and magnetic integral maps with geological provinces. 

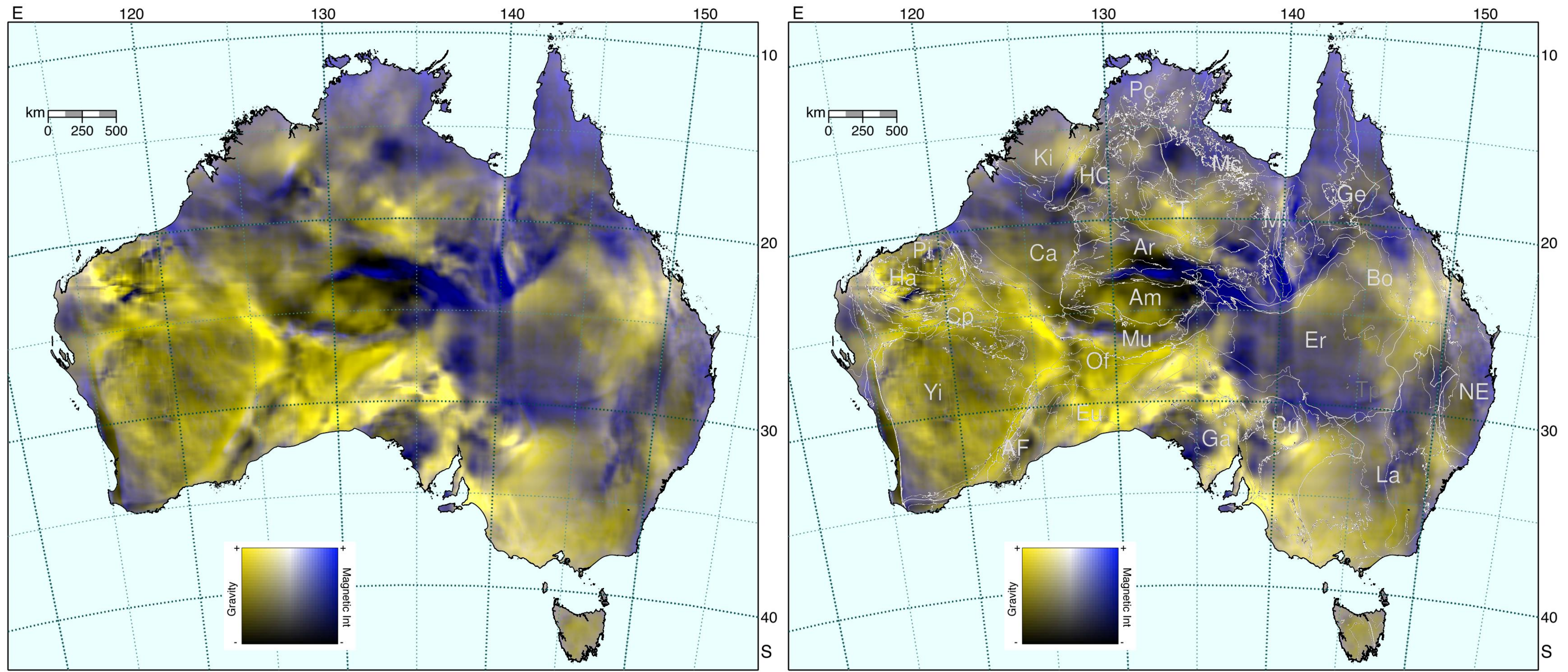

Figure 12.4: Binary colour representation of the relation between Bouguer gravity and the spatial integral of the magnetic anomaly field, with geological province boundaries shown on the right hand panel.

In Figure 12.4 we illustrate the relation between the magnetic integral and gravity data, which are relatively consistent in their depth sampling. The similarities between the two fields are now apparent when plotted with complementary colours (yellow tones for gravity, blue tones for the magnetic integral).

The low magnetic response corresponding to the Amadeus Basin and the underlying province are very clear, with the much higher magnetic integral response associated with the fault to the south of the Arunta Province clearly defined. The magnetic integral tends to emphasise features under cover, and in the combined response we see clear subdivisions within the Eromanga Basin.
Mt Isa shows contrasting banding of strong gravity and magnetic integral features. The termination of these strong signatures of the Mt Isa Province against the Cork Fault under the cover sequence is striking, because of its contrasts in gravity and magnetic behaviour.

The West Australian Craton is outlined by a gravity and magnetic doublet. In contrast, the edges of the North Australian Craton show a dominantly magnetic signature. Although the South Australian Craton is rather clearly delineated in the ternary image in Figure 12.1, it is less evident when we employ the binary image of magnetic integral with gravity in Figure 12.4. 
In Figures 12.3-12.4 we have presented the full spatial integral of the magnetic data, calculated in the spectral domain. With the spectral representations of the fields we can also take fractional spatial derivatives and integrals of the gravity and magnetic data. The concept is similar to the half-vertical derivative shown in Chapter 4 , and it produces striking results.

We illustrate in Figure 12.5 the half-derivative of the gravity field and the half-integral of the magnetic field, compared with original gravity and magnetic images. As in the comparison of gravity and spatial integral of the magnetic field, the combination of the half-derivative of gravity and the half-integral of magnetics has a similar dependence on the depth of anomalies. This depth sensitivity is focused shallower than raw gravity data, and deeper than raw magnetic data.

Whilst the full fields produce maps which are sensitive to the bulk nature of the rocks, the fractional horizontal derivatives and integrals produce maps that are significantly more sensitive to subtle features of the orientation of features. In consequence, we can perceive the grain of structural features across Australia in a way that is not often recognised at the continental scale, especially for the magnetic data.

Of particular note is the structural grain of the eastern goldfields of the Yilgarn Craton, which is quite different in the gravity half-derivative to other parts of the Yilgarn. The structures of the eastern undercover extension of the Arunta Province are also much more apparent, including those structures which then serve to truncate the undercover extension of the Mt Isa Province.
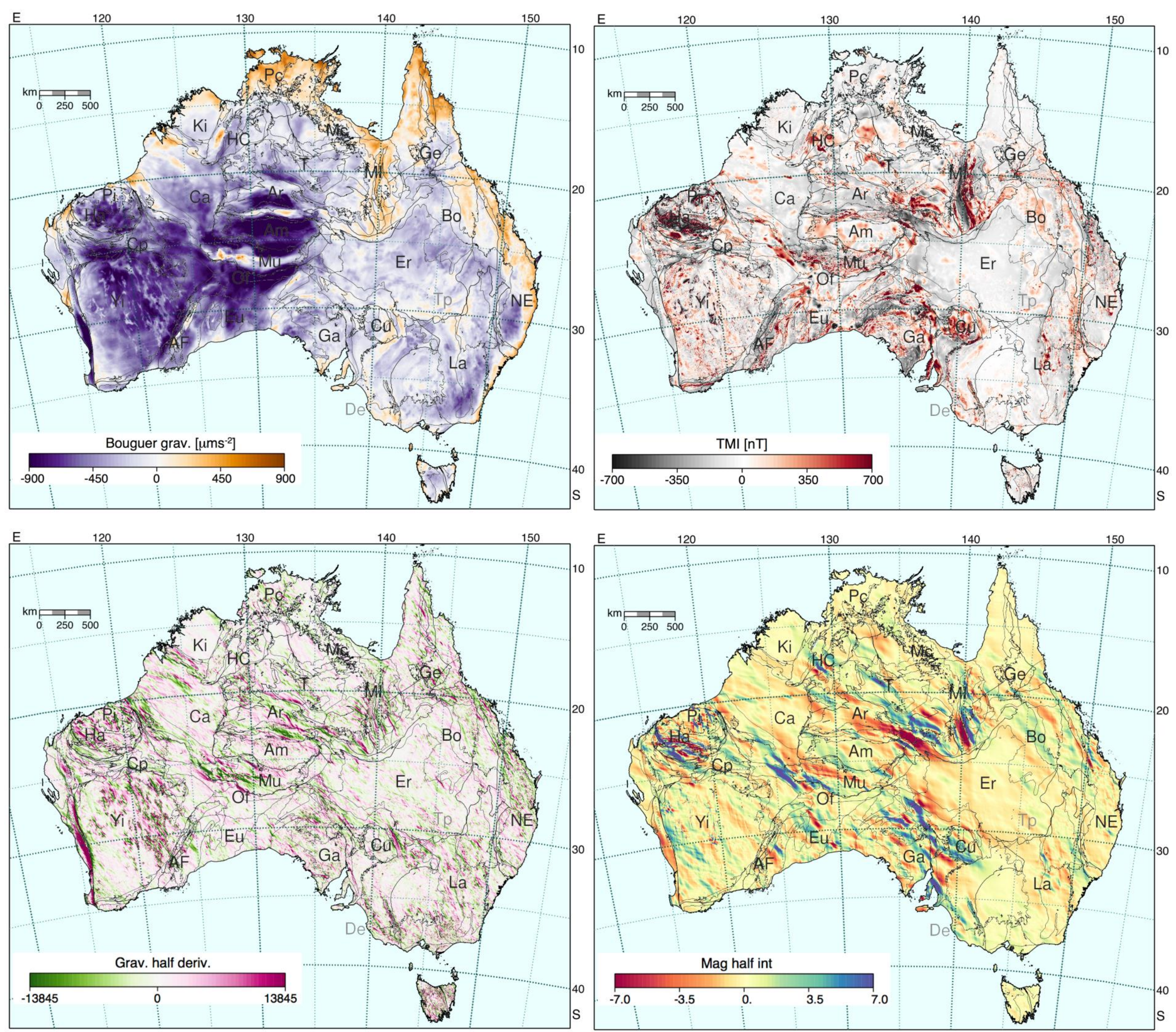

Figure 12.5: Gravity, magnetic, gravity half-derivative and magnetic half-integral maps with geological provinces. 
Figure 12.6: Comparison of the half-derivative of gravity and the half-spatial integral of the magnetic anomaly field.

In Figure 12.6 we make a direct comparison of these auxiliary gravity and magnetic fields, including a binary image to emphasise the balance of the different trends. We use a red channel for the gravity features and cyan for the magnetic, so that we would get white where strong features in both fields coincide.

The broad sweep of northwest-southeast oriented features through the centre of the continent contrasts with the swirls through the Pilbara and the north-south orientation of lineations at the western boundary of the Yilgarn Craton with the Pinjarra Orogen and in the gravity features of the Eastern Goldfields.

The Mt Isa Province shows a distinct contrast in structural lineation to the southern part of the North Australian Craton. A somewhat similar grain is apparent in the binary image under the McArthur Basin and north of the Tennant Creek Inlier.

Magnetically, the half-integral map matches very well with the subtle approximately east-west features of the Curnamona Province that are the result of later deformation during the Delamerian Orogeny. Slightly further west, we see the confluence of more northerly grain and the main central Australian trends. These cross in the neighbourhood of the supergiant Olympic Dam ore deposit.
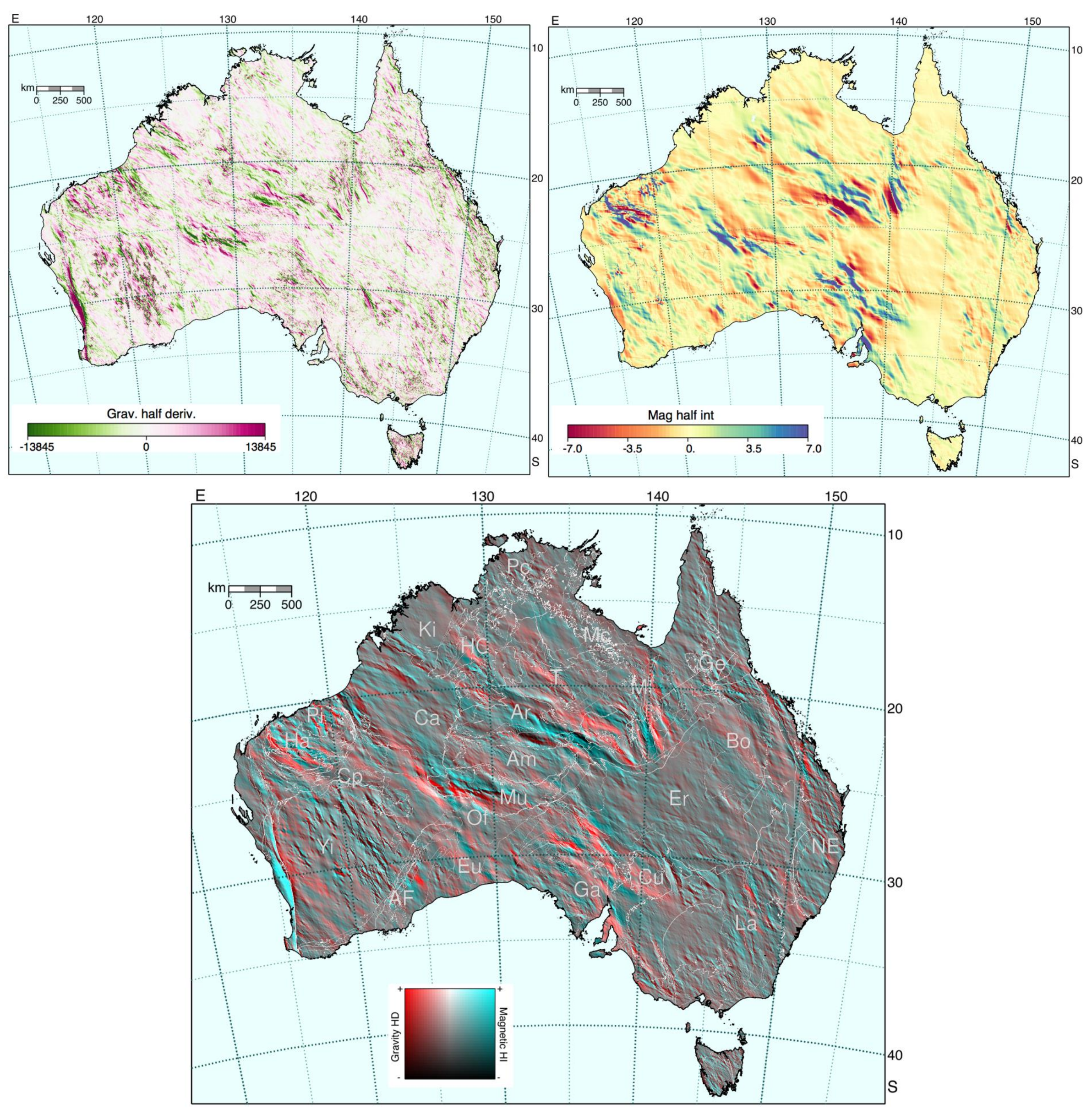


\subsection{Gravity and Topography}

In the Bouguer gravity field, corrections are introduced to remove the immediate effects of surface topography and the gravitational effects of the rocks above sea level. Nevertheless, as can be readily seen in Figure 12.7, there are clear broad correspondences between gravity anomalies and topography. The fields are shown individually and also in a binary colour combination that helps to emphasise the relation between the two fields.

In both the Eastern Highlands and much of West Australia, there is a relatively direct link between the gravity and topography. This is also found in the more subdued variations in the northern part of the North Australian Craton. In contrast, there are notable variations of both gravity and topography in central Australia that have subtle offsets in position.

As noted in Chapter 9, the density and pressure fields inferred from the surface gravity field suggest that a significant amount of isostatic compensation is achieved in the top $25 \mathrm{~km}$ of the crust. The remainder of the gravity signal is more deeply seated. Zones of thick crust upset the isostatic balance achieved at shallower levels. The presence of higher density mantle compensates for these crustal effects. Across much of the continent by $125 \mathrm{~km}$ depth, the pressure is close to background values.

Figure 12.7: Bouguer gravity, topography and binary colour representation of the relation between Bouguer gravity and topography.
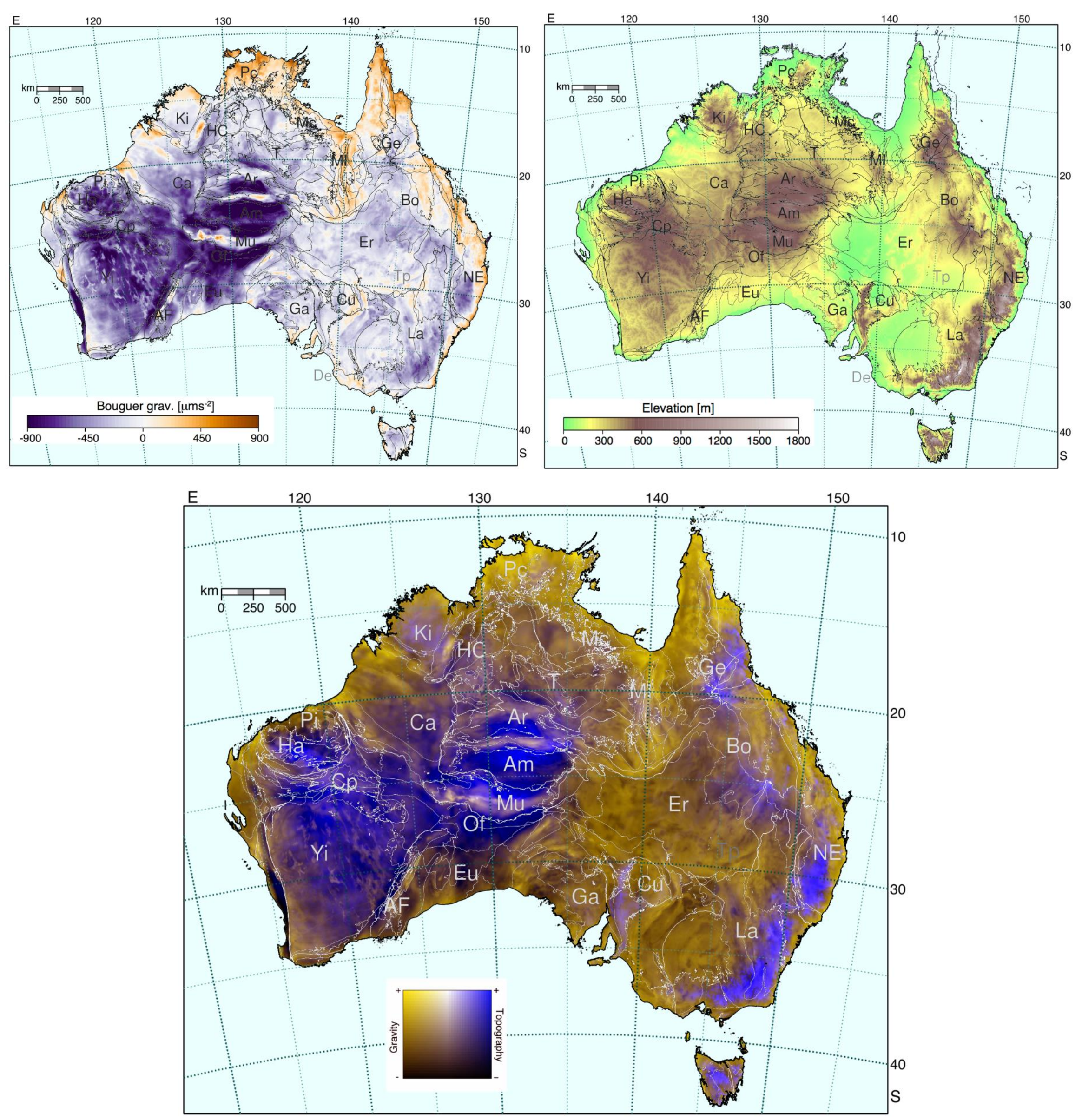
So far we have presented the relation between gravity and topography in visual terms directly in the spatial domain. Since we have the major fields represented on a common $4096 \times 4096$ pixel domain, we can also exploit their spectral characteristics. This allows us to look at field interrelations in a variety of ways.

The most direct approach is to look at the transfer function between fields. This complex admittance can be constructed as the spectral ratio of the fields. The amplitude and phase can then be transformed back to the spatial domain. Unfortunately such images are complex, and do not have the desired spatial specificity because they start from information at the full continental scale.

The apparent solution is to use specific data windows, but then the representation of the important components at long wavelength tends to be limited. This difficulty can be overcome by using a similar approach to that used by Chopping and Kennett (2015) in their study of the depth of magnetisation (see Section 4.3). With a hierarchical approach, using multifold sampling to stabilise the results, it is possible to construct stable representations of the longest wavelength features at variable window scales.

As in the magnetisation study, we here employ $400 \mathrm{~km} \times 400 \mathrm{~km}$ spatial tiles, with the centre moved by $60 \mathrm{~km}$ for successive tiles. This approach yields 3600 tiles across the continent for which we are able to undertake spectral analysis.

We can examine the correlation coefficient between gravity and topography in the wavenumber domain, using a normalised coherence measure derived from averaging the 2-D wavenumber field to extract a 1-D result in terms of a single wavenumber $k$ (e.g. Simons et al., 2000). The coherence will be unity when the gravity and topography are completely correlated and drops to zero when there is no correlation.

An alternative approach is to work with the local admittance constructed from the local spectral estimates, with again averaging to produce a 1-D result. We illustrate the amplitude of the 1-D admittance for two tiles in Figure 12.8. There is a distinctive pattern with a peak at long wavelength, then a significant drop followed by a second peak at higher wavenumber. The full 2-D admittance field contains additional information on the local directional relations of the fields that indicate anisotropy in properties.

As well as the hydrostatic compensation of topography by heterogeneities in density, the classic style of isostasy, compensation can be achieved by flexure of the lithosphere with consequent stresses. Such flexure produces regional relations between the gravity and topography fields, which can be modelled via the deformation of a lithospheric plate overlying a viscous mantle. With the assumption of an elastic plate, a spectral relation between the gravity and topography fields under load is predicted that depends on the flexural rigidity of the plate with a single spectral peak as a function of wavenumber $k$. This flexural rigidity is commonly parameterised in terms of an elastic thickness $T_{e}$ proportional to the cube root of the rigidity. More complex models with lamination can also include the possibility of internal loading. The quantity $T_{e}$ is an artificial construct and has no direct physical meaning, but can provide a useful comparator between regions.

Even without invoking any particular model of compensation, we can associate peaks or troughs in the admittance relation with an appropriate depth using the $T_{e}$ relation. We use this correspondence in Figure 12.9 to look at the nature of the relation between gravity and topography at the continental scale.

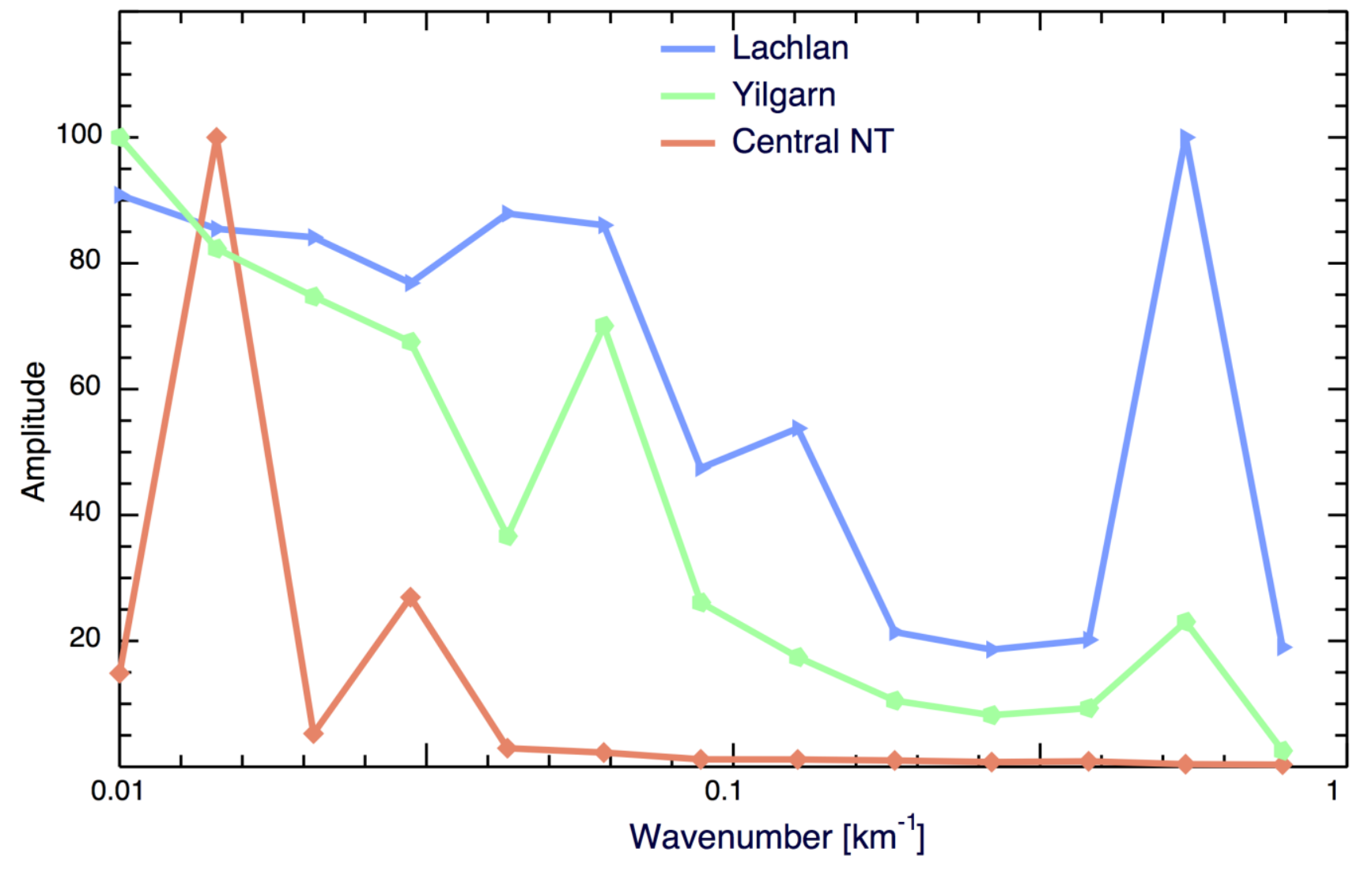

Figure 12.8: 1-D admittance between gravity and topography as a function of wavenumber for tiles in different locations: (a) Lachlan Orogen, (b) Yilgarn Craton, Western Australia and (c) central Australia. 

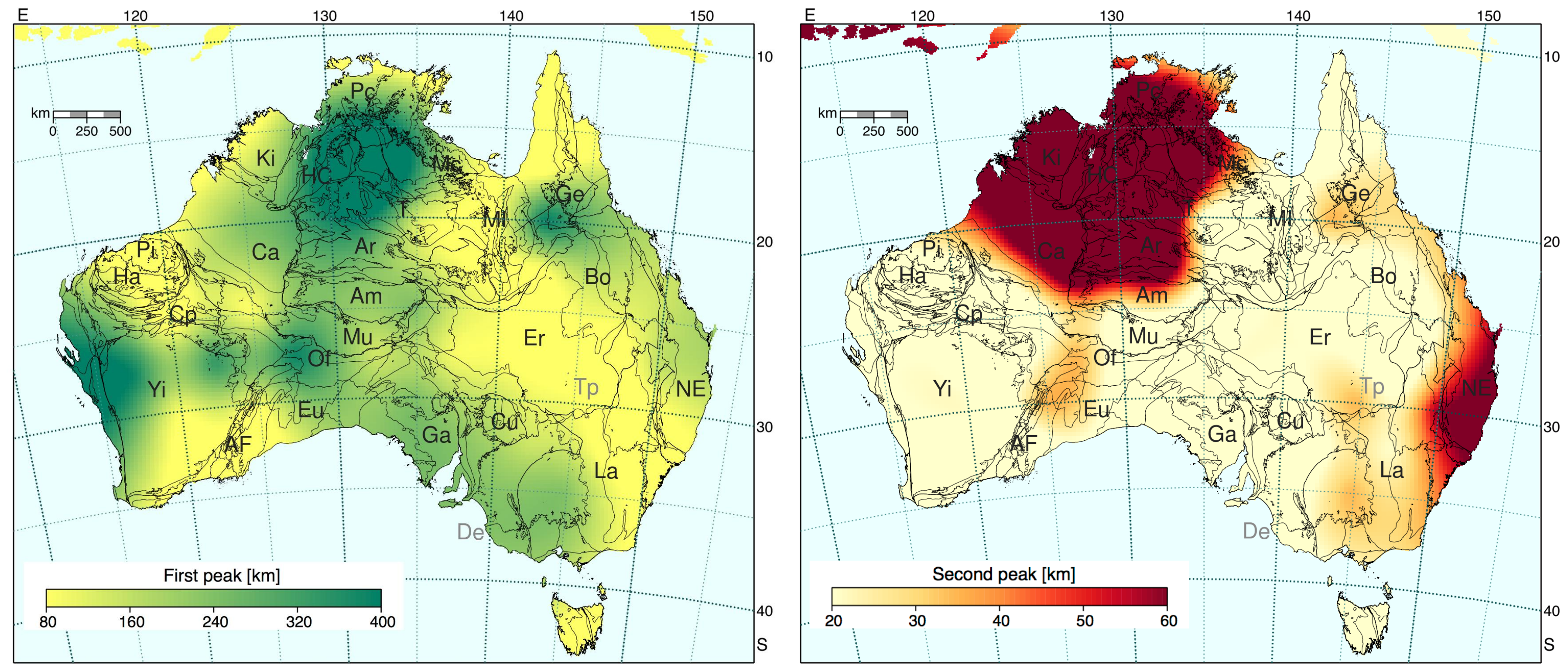

Figure 12.9: Representation of the relation between gravity and topography through the variation in behaviour of the local admittance, with the spectral features converted from wavenumber to equivalent depth.

In Figure 12.9 we display the variation in behaviour of the gravity-topography admittance function in terms of equivalent depths for the wavenumbers associated with the first, low wavenumber, peak in the spectrum, and the second, high wavenumber, peak.

For much of the continent, the second peak in the admittance spectrum occurs at wavenumbers corresponding to $T_{e}$ values less than $30 \mathrm{~km}$, as is common in continental environments. This reflects the pressure field results in the density inversion of Aitken et al. (2015) discussed in Chapter 9. The exceptions are in the New England area, and the western part of northern Australia. New England does not have a full complement of surrounding tiles, so there is a likelihood of some distortion in the wavenumber spectrum. The broad area of northern Australia with relatively deep compensation, extending below the Moho, has been identified previously in $T_{e}$ studies, e.g. Simons et al. (2000).

The first, low wavenumber, peak in the admittance spectrum shows considerable variation across Australia. The equivalent depth of this peak provides an indication of the level at which broad-scale support of topography occurs. The absolute values displayed in Figure 12.9 need be treated with caution, since they are derived from a thin plate model for the mechanical lithosphere that is an 
major oversimplification at these scales. These equivalent depths are likely to be overestimated. Nevertheless, the relative depth behaviour provides an indication of the major divisions within the mechanical lithosphere.

In the east we note a rather deep first peak around the Georgetown Inlier, when the second peak is also a little deeper than its surroundings. Beneath New England the separation between the two peaks closes towards the south. Moderate depth support, at about the depth of the base of the lithosphere, is present beneath the Murray Basin and the South Australian Craton.

Beneath much of the northern part of the North Australian Craton, the depth corresponding to the first peak is rather high, but this is also where the second peak also occurs at lower wavenumbers, i.e. greater equivalent depth. Clear contrasts are seen with the Kimberley Block and the Mt Isa Province with extensions beneath the McArthur Basin.

The distinction between the shallower equivalent depth beneath the Pilbara Craton and greater depth beneath the northern Yilgarn Craton reflects trends also seen in the seismic wavespeeds in the mantle. The east-west contrasts also have some counterparts in the seismic results, notably with a distinct feature near the Musgrave Province.

We can also map out the wavelength at which the gravity and topography fields become uncorrelated, i.e. where local effects have no broader support. This length scale is displayed in Figure 12.10. Not surprisingly, there is a fair correlation with the behaviour of the spectral peaks, notably in the larger scale in the Halls Creek area of the North Australian Craton.

Weak contrasts with the surroundings are evident in the largely covered Thomson Orogen, and in the centre of the Yilgarn Craton. The moderate length scale for the broad area around Cape York indicates a rather rapid fall off from the second peak.

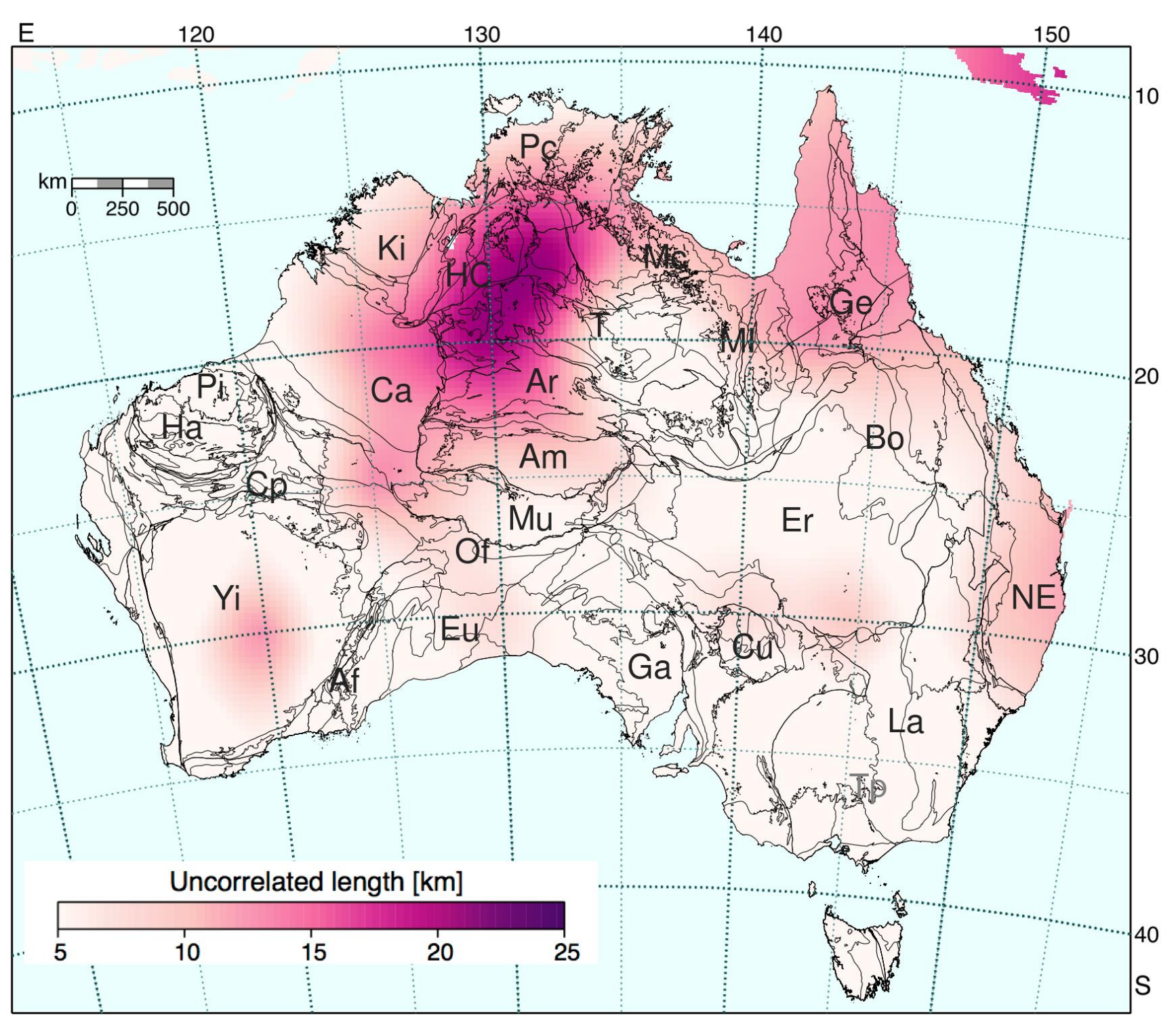

Figure 12.10: Wavelength at which correlation between gravity and topography ceases. 


\subsection{Depth of Magnetisation}

We described in Section 4.3 the construction of estimates of the depth of magnetisation by fitting a fractal model of magnetic behaviour across a suite of tiles covering the continent. An ensemble approach allows an estimate of uncertainty in the depth of magnetisation. The spatial resolution of these results is $60 \mathrm{~km}$.

This depth of magnetisation is commonly equated to the Curie depth, where thermal effects erase magnetisation. The Curie temperature is $580^{\circ} \mathrm{C}$ for magnetite. In Figure 12.11 we compare the results for the depth to magnetisation with thermal estimates for the continent, and the properties of the Moho. These depth of magnetisation results suggest that the control for Australia is not entirely thermal.

In Figure 12.11 we display both the OZTemp estimates at $5 \mathrm{~km}$ depth obtained by interpolation of information from well data (Figures 11.2-11.3), and the geologically based TherMAP results for $4 \mathrm{~km}$ depth (Figures 11.4-11.5). We can therefore examine where the estimates of the depth to the base of magnetisation match expectations of Curie depth, and where they differ. Such differences may indicate areas where our understanding of the thermal regime is incomplete, or could arise from differences in geology resulting from processes such as major tectonic events changing magnetic mineralogy.

Some of the shallowest depths to the base of magnetisation are beneath the Canning Basin and Cooper Basin within the Eromanga Basin, where high temperatures are encountered at shallow depth. Even so, there is not a direct correspondence with the temperature estimates. In particular, we see the influence of broad thermal anomalies away from any drilling control that are captured to some extent in the TherMAP estimates.

A relatively large depth to the base of magnetisation extends to the east from the Arunta Province beneath the Eromanga Basin. These deep results for the depth to base of magnetisation could imply a relatively cold region, highlighting the spatial extents of the Arunta and Warumpi provinces beneath the basin. The lower temperatures from the extension of the Arunta and Warumpi provinces is not sampled through drilling, so this colder region is not depicted in the OZTemp model.
The OZTemp model also displays a broad elevated temperature anomaly in northern Australia that is not present in the TherMAP model. The relatively deep base to magnetisation in this area suggests that the OZTemp anomaly is an interpolation artefact produced by a limited number of concordant data with high temperatures with no intervening constraints. The base of magnetisation is also quite deep beneath the Kimberley Block, even though the temperature estimates are relatively warm.

Some authors suggest that the Moho should represent a lower boundary on magnetisation in continents, due to changes in the mineralogy across the crustmantle interface. In Figure 12.11 we therefore also compare the depth of magnetisation to the Moho surface for Australia, shown in Figures 7.16-7.17.

For much of the continent, the differences between our results for the base of magnetisation and Moho are within the uncertainty of our results. However, in the case of the Yilgarn Craton of Western Australia, the base of magnetisation is significantly deeper than the Moho.

The Moho is also significantly shallower than the base of magnetisation for both the Curnamona Craton and the eastern side of Australia, in areas such as the New England Orogen, though resolution of the depth of magnetisation is relatively weak in this zone.

Another area where the base of magnetisation is shallower than the Moho estimate is beneath the western Eucla Basin, where the depth of magnetisation is much shallower than for both the Yilgarn Craton to the west and the Gawler Craton to the east. In many different datasets, e.g. Pn wavespeed (Figure 9.9), and the reflection seismic transect (Figure 7.4), this zone shows distinctive behaviour, indicating the presence of a distinct lithospheric block.

Isolated spots in Central Australia where the depth of magnetisation appears to be fairly shallow are likely to arise from the combination of rapid variations in crustal thickness, including some rather thick crust, and the limited horizontal resolution of the map of the base of magnetisation. 

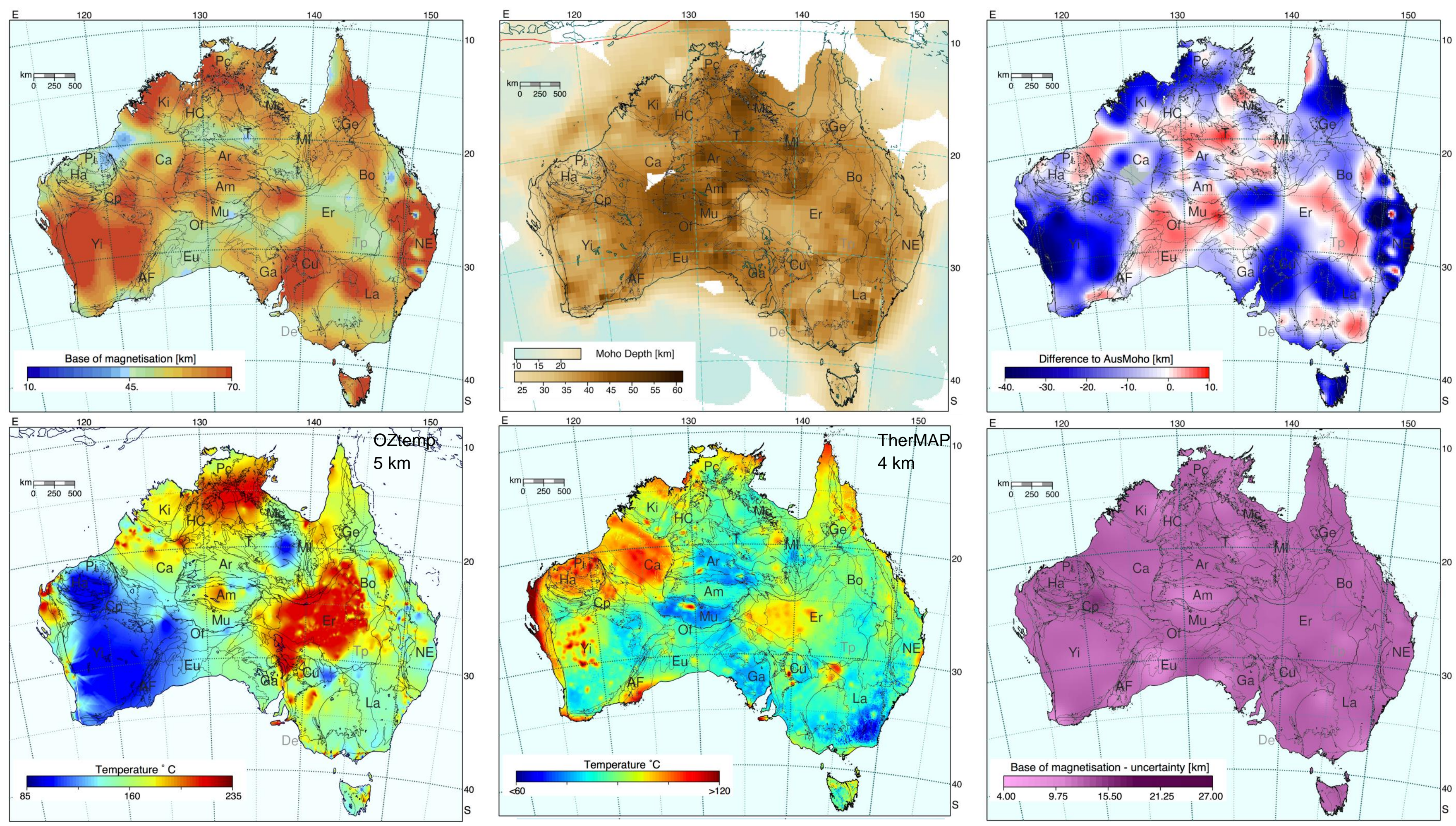

Figure 12.11: Depth of magnetisation compared with Moho depth and estimates of temperature, OZTemp at $5 \mathrm{~km}$ depth, TherMap at $4 \mathrm{~km}$ depth. 


\subsection{Temperature and Compositional Variation in the Lithospheric Mantle}

By jointly interpreting the results from seismic tomography and gravity constraints, it is possible to estimate the temperatures and compositional state in the mantle (Tesauro et al., 2017). The effect of the crust is removed from the observed gravity and topography using the AuSREM crustal model, initially assuming a homogeneous mantle. The residual gravity field that displays the heterogeneity of the mantle and the residual topography are then inverted to obtain a 3-D density model of the upper mantle. The use of both fields gives the possibility of improving vertical resolution since they are induced by the same density heterogeneity, but with different dependence on scale and depth. The residual gravity and topography fields are displayed in Figures 12.12 and 12.13.

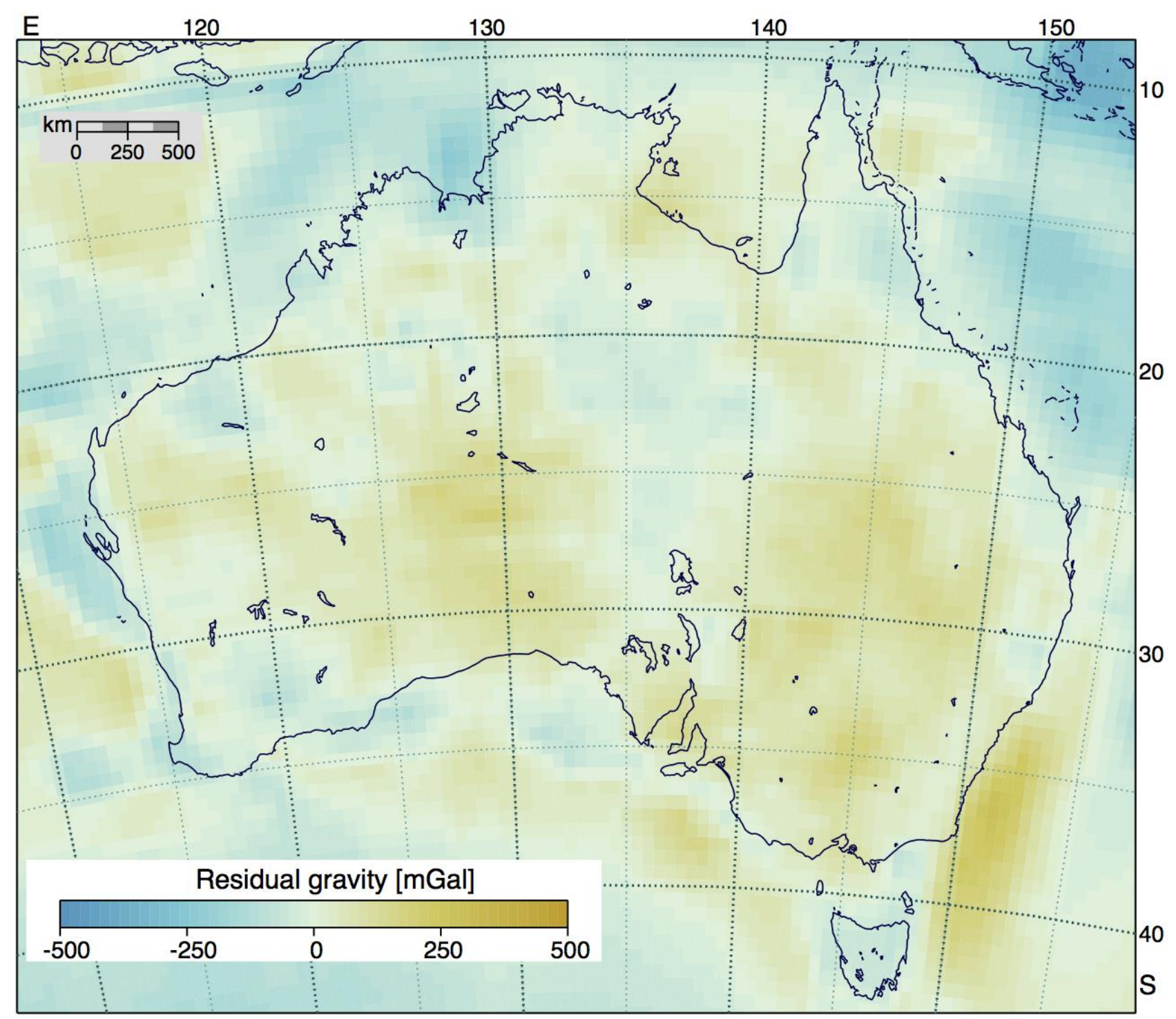

Figure 12.12: Residual gravity field after removal of crustal effects using the AuSREM crustal model.
In the next stage, the thermal contribution to the density structure is estimated by inverting the shear wavespeed distribution in the mantle from AusREM to estimate temperature. In this way, the thermal and compositional models are iteratively improved, following the approach developed by Kaban et al. (2014), Tesauro et al. (2014).

Initially, a uniform composition is assumed to extract an estimate of the main features of the temperature field. The difference between the thermal component of the density and the total mantle density then provides a measure of compositional variability.

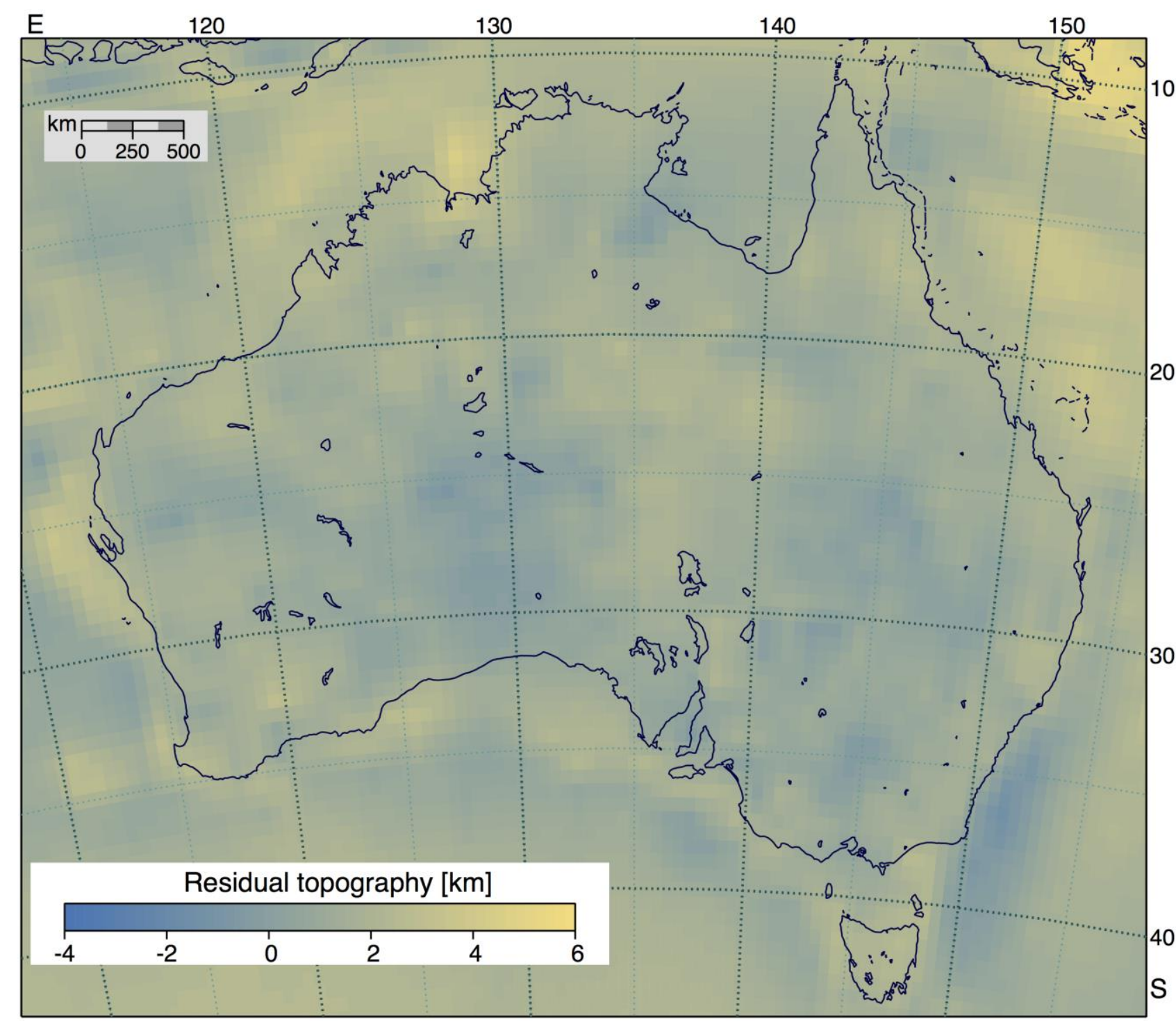

Figure 12.13: Residual topography after removal of crustal effects using the AuSREM crustal model. 
Negative density differences are then compensated by modifying the model to introduce a composition more depleted in heavier constituents, such as iron ( $\mathrm{Fe}$ ) and the minerals clinopyroxene and garnet.

The composite thermal and compositional model is then tested against the 3-D density and wavespeed fields, and iteratively improved until a self-consistent result is obtained. With the inclusion of compositional variation, the estimates of temperature beneath the cratonic zones increase by about $100-150^{\circ} \mathrm{C}$, compared to a uniform composition.

The resultant estimates of the temperature field (Figure 12.14) show distinct differences between the warm eastern margin of the continent and the cooler zones beneath the Archean and Proterozoic domains. A measure of the thickness of the thermal lithosphere can be obtained by mapping the $1300^{\circ} \mathrm{C}$ isotherm; this depth reaches up to $250 \mathrm{~km}$ beneath the coolest parts of the Yilgarn Craton.

The pattern of steps in lithosphere thickness indicates a strong relationship with age, consistent with that suggested by Fishwick et al. (2005). The South Australian Craton, with Archean to Proterozoic surface exposures, has a much thinner and warmer lithosphere than the other cratons. This modified state could be a result of extensive metasomatism associated with a major thermal event that is manifest as the Gawler Large Igneous Province ( 1600 Ma).
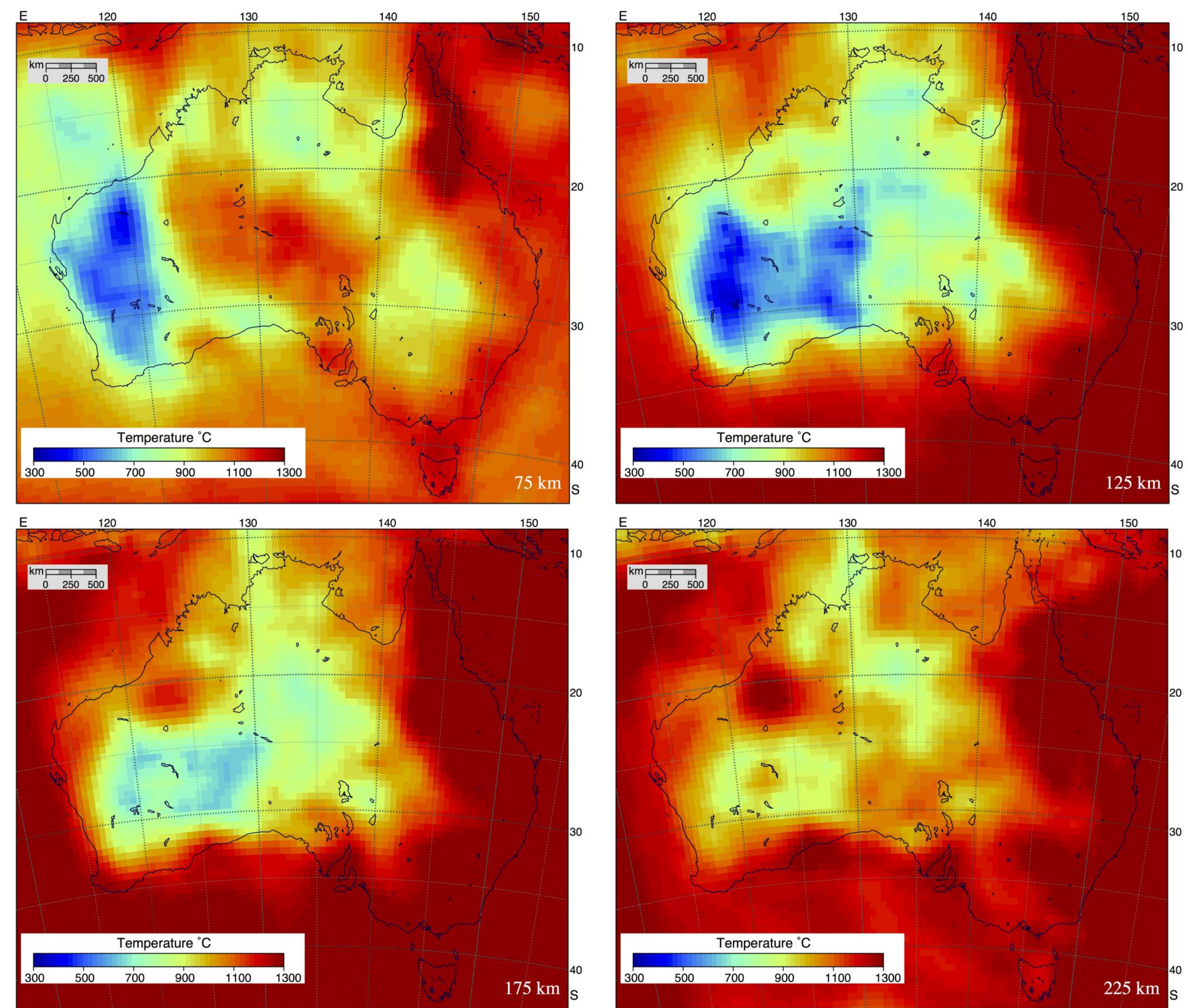

Figure 12.14: Estimates of temperature distribution in the lithospheric mantle at $75 \mathrm{~km}, 125 \mathrm{~km}, 175 \mathrm{~km}$ and $225 \mathrm{~km}$ depth. 
The 3-D distribution of compositional variability is extracted from the compositional density variations illustrated in Figure 12.15, which represents the difference between the residual gravity field and the contribution from thermal effects. Although these density variations are modest in amplitude, they require significant variations in composition.

Strong depletion is needed beneath the Northern and Western Australian cratons with thick and cool lithosphere, likely of mostly Archean provenance with only localised disturbance in the Proterozoic (Figure 12.17). In central Australia, the thick low-temperature lithosphere is somewhat more fertile. The slower shear velocities in the uppermost mantle are not accompanied by any significant seismic attenuation, and so a thermal origin is unlikely. This suggests the need for compositional change, e.g. the presence of a low temperature phase such as amphibole (cf. Fishwick and Reading, 2008).

The compositional results shown in Figures 12.15-12.17 suggest the presence of distinct domains in the Australian lithosphere, e.g. between Archean and Proterozoic regions. We display the Magnesium Number $(\mathrm{Mg} \#=100 \times \mathrm{Mg} /[\mathrm{Mg}+\mathrm{Fe}])$ as a function of depth. Stronger iron depletion is required in Western Australia than elsewhere. Indeed, this depletion appears to extend to depths that lie beneath the lithosphere. The extended depletion suggests that there may be some component of lithospheric erosion due to the rapid northward motion of the Australian Plate.
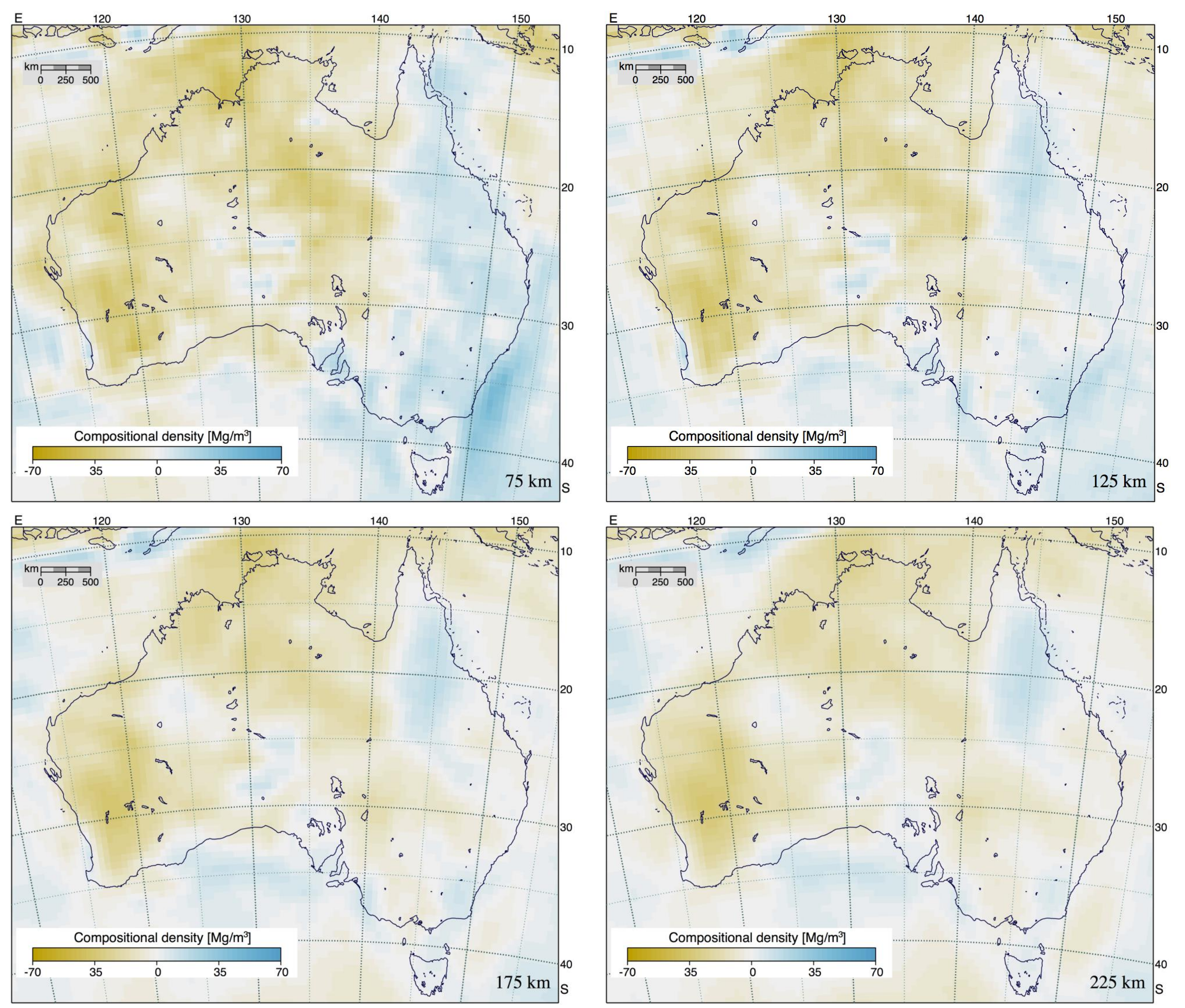

Figure 12.15: Compositional density variations remaining after extraction of the thermal signal from the residual gravity field at $75 \mathrm{~km}, 125 \mathrm{~km}, 175 \mathrm{~km}$ and $225 \mathrm{~km}$ depth. 
Beneath the Proterozoic terranes, depletion is much reduced below $150 \mathrm{~km}$ depth. The Paleozoic domains display a generally more fertile regime.

The details of the temperature and compositional fields displayed in Figures 12.15-12.17 depend on assumptions about the material properties as a function of temperature and composition. Nevertheless, the general features of the patterns are robust, and support significant segmentation of structure through the full lithosphere.
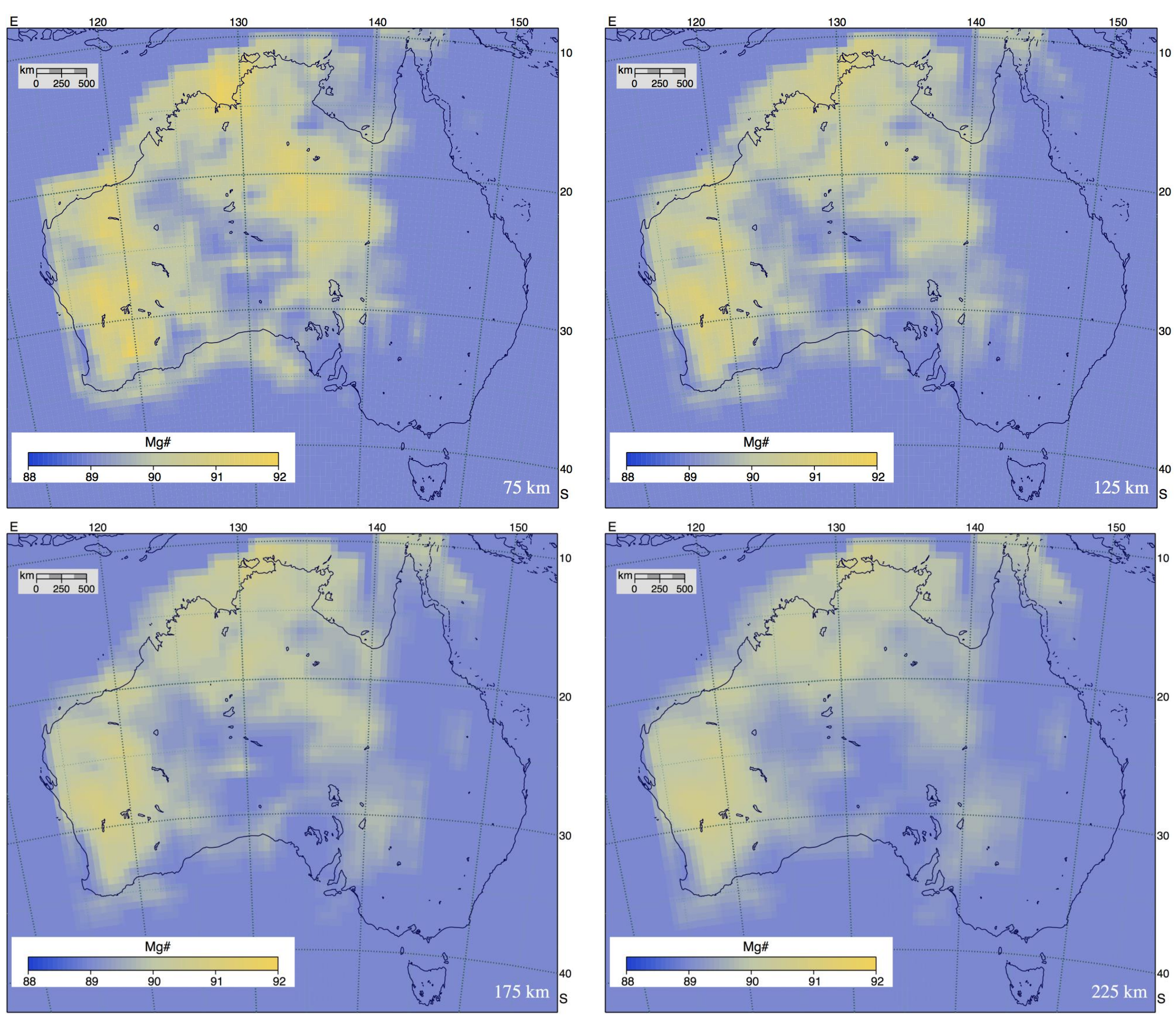

Figure 12.16: Estimates of compositional variation in the lithospheric mantle at $75 \mathrm{~km}, 125 \mathrm{~km}, 175 \mathrm{~km}$ and $225 \mathrm{~km}$ depth through Magnesium Number (Mg\#). 


\section{Resources and Geophysical Fields}

The Australian continent is well endowed with many different classes of resources. The main concentrations of minerals occur in the cratons and the eastern Paleozoic fold belts (Figure 13.1). Whereas mineral sand deposits are to be found along current or former coastlines, such as in the Murray Basin.

In Figure 13.1 we superimpose the geological province boundaries on the resource locations. However, in many instances there is a more direct relation with the major crustal boundaries of Korsch and Doublier (2016). We therefore display more specific groups of resources in Figure 13.2 with these boundaries superimposed. In Figure 13.2 we also include the areas of hydrocarbon production, major black and brown coal deposits as well as oil shales. Most onshore hydrocarbon production is gas, with only a small amount of oil. Substantial quantities of oil have been produced from Bass Strait. On the North West Shelf, gas discoveries are now more significant than petroleum. Significant coal seam gas production is being made in the coalfields of eastern Australia. There is considerable further potential for the development of such unconventional energy sources in this area and across the vast Proterozoic basins of Australia.

Key to commodities:

Al203-Alumina, Brt-Barites, Fl-Fluorite, MgOMagnesia, Phos-Phosphates, REE-Rare Earth Elements, IIm-IImenite, Rt-Rutile, Zrn-Zirconia, Dmd—Diamond, Graph—Graphite.

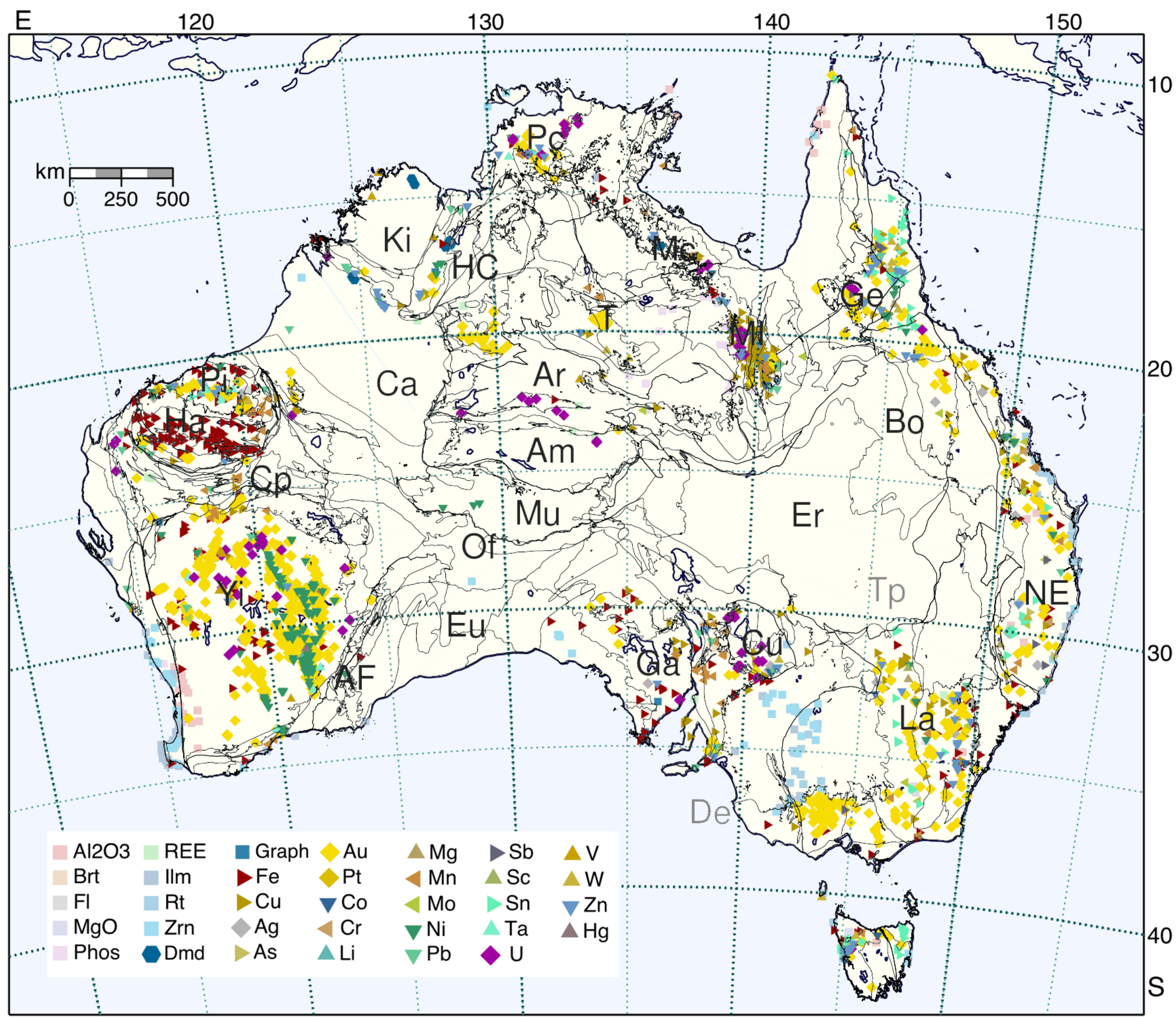

Figure 13.1: Distribution of major minerals and commodities across the Australian continent. Ores are indicated with the element symbol for the major economic constituent. 
We have seen in Chapter 3 that uranium is widely distributed about the continent, but only moderate number of places reach viable concentrations for exploitation. Approximately one-third of the known world uranium reserves are in Australia, but only a limited number of mines are operational.

Gold deposits are widespread across the continent, with a number of major current and historical gold provinces. The prosperity of the state of Victoria was established with the 1851 gold rush in the Ballarat area. The largest current mine is the 'Super pit' in Kalgoorlie, Western Australia, which has been producing gold for more than a century.

There are extensive iron ore deposits in Australia, particularly in the Hamersley Basin of the Pilbara Craton. Iron ore is a major export commodity for the Australian economy with Port Hedland as the main port.

Much of the nickel deposits lie in the greenstone belts of the eastern Yilgarn Craton, which also hosts considerable gold. These belts have a clear expression in the gravity field, notably in the half-derivative (Figures 12.5-12.6).

Major base metal ore concentrations have been found in the Mt. Isa Province, in the Curnamona Province at Broken Hill and in western Tasmania.

Diamond pipes are concentrated around and within the Kimberley Block, with a very largescale exploitation at the Argyle field. Minor finds of diamonds have also been made in the Capricorn Orogen, the New England Orogen and the Gawler Craton.
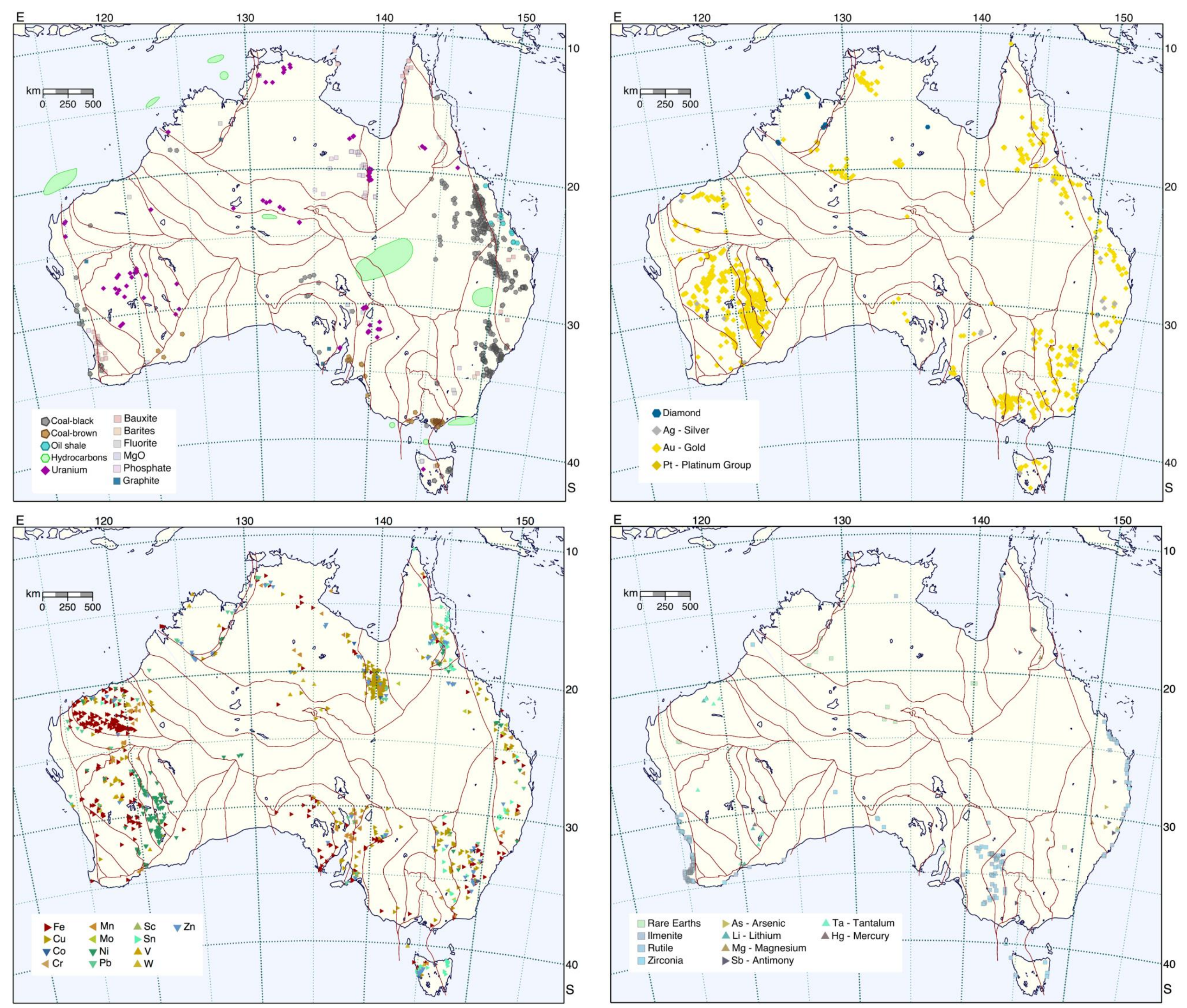

Figure 13.2: Different aspects of resources with the Korsch and Doublier (2016) major crustal boundaries. 
Many of these diamond pipe locations occur close to strong gradients in seismic wavespeeds in the mantle, linking to structural edges or suture zones (Figure 13.3).

Graphite is produced mainly in the Eyre Peninsula, where its presence undoubtedly contributes to the significant electrical conductivity anomaly in this region (Figure 10.1). Graphite is also present in the Halls Creek Belt, which also shows a strong conductivity anomaly (Figure 10.2).

In Figures 13.3-13.7 we present different aspects of the geophysical fields with superimposed locations of major mineral resources. In each case we display the major crustal boundaries from Korsch and Doublier (2016) as a reference.

We start with the seismic wavespeed in the crust and mantle. In Figure 13.3, we display in the upper row the $\mathrm{P}$ wavespeed in the crust at $15 \mathrm{~km}$ depth, and in the lower row the $S$ wavespeed in the mantle at $125 \mathrm{~km}$. Both distributions are taken from the AuSREM model and use the primary wavespeed for each component of the lithosphere.

Many crustal materials have similar seismic wavespeeds. In the middle crust the seismic contrasts are moderate, and there is little direct correspondence with surface geological provinces. No consistent pattern emerges with resource location, though there is a tendency for known deposits to lie over areas with lower mid-crustal wavespeeds.
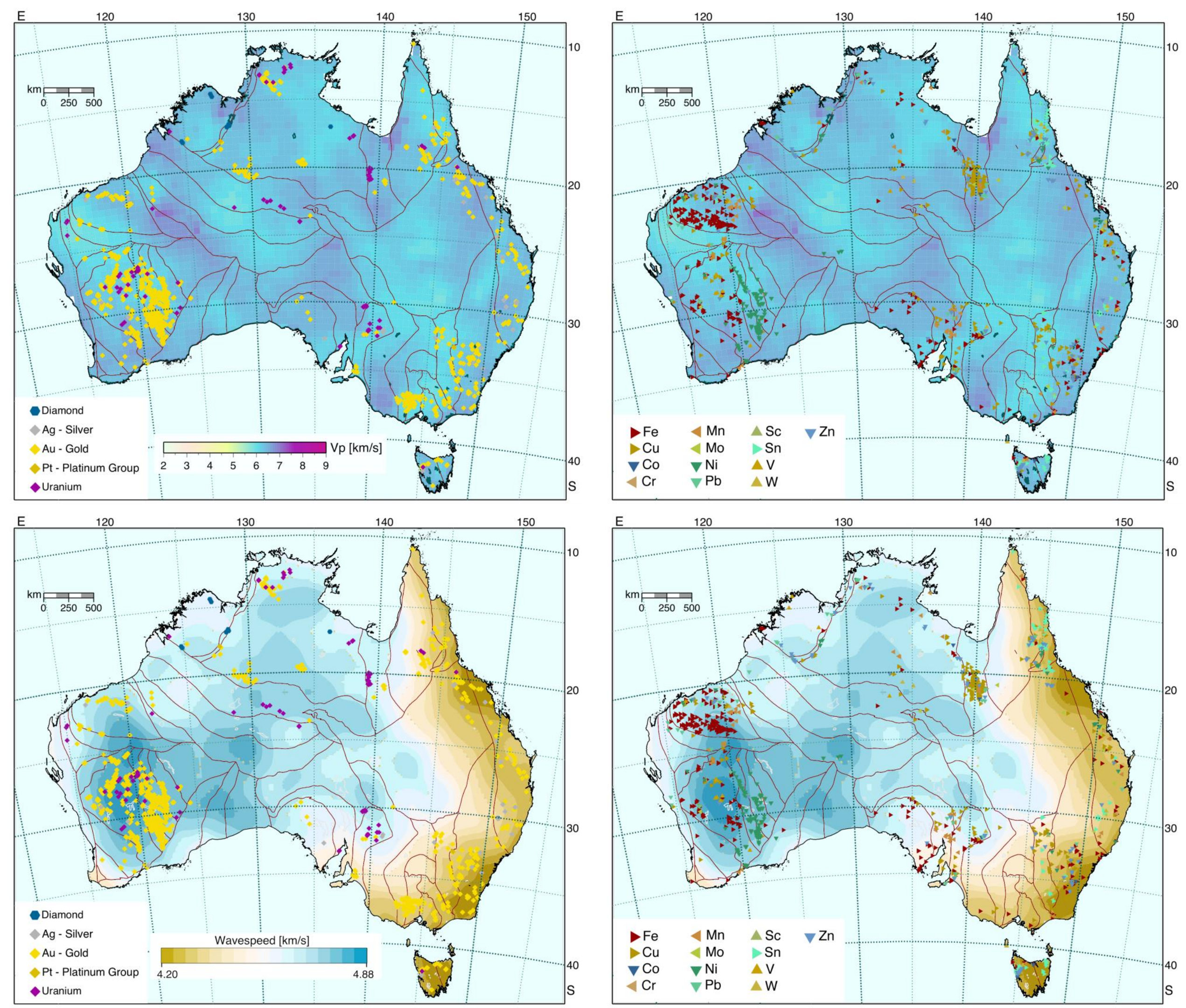

Figure 13.3: Mineral distribution relative to seismic wavespeed: upper row $P$ wavespeed at $15 \mathrm{~km}$, lower row $S$ wavespeed at $125 \mathrm{~km}$. 
In the mantle, the fast $S$ wavespeeds associated with the cratons are evident in Figure 13.3. Substructure in the mantle lithosphere tends to link to the major crustal units, particularly in the Yilgarn Craton. The locations of ore deposits seem to have their strongest association with gradients in the wavespeed structure.

In Figure 13.4 we compare the absolute gravity field and the Bouguer gravity anomaly, with the resource distributions.

As we would expect, the associations are more distinct with the Bouguer results, where fine-scale features are more readily perceived. Nevertheless, subtle variations in absolute gravity, such as the band of slightly lower values across the south of Arnhem Land, do seem to link quite well to a number of different classes of deposits.

The arcuate Bouguer gravity features around the Gawler Craton and to the north of the Murray Basin tie into a variety of styles of metallic ores. There are hints of similar gravity features under cover, particularly in the Thomson Orogen.

The greenstone belts of the eastern Yilgarn Craton, which host both major gold and nickel deposits, display significant gravity contrasts with a near north-south orientation.
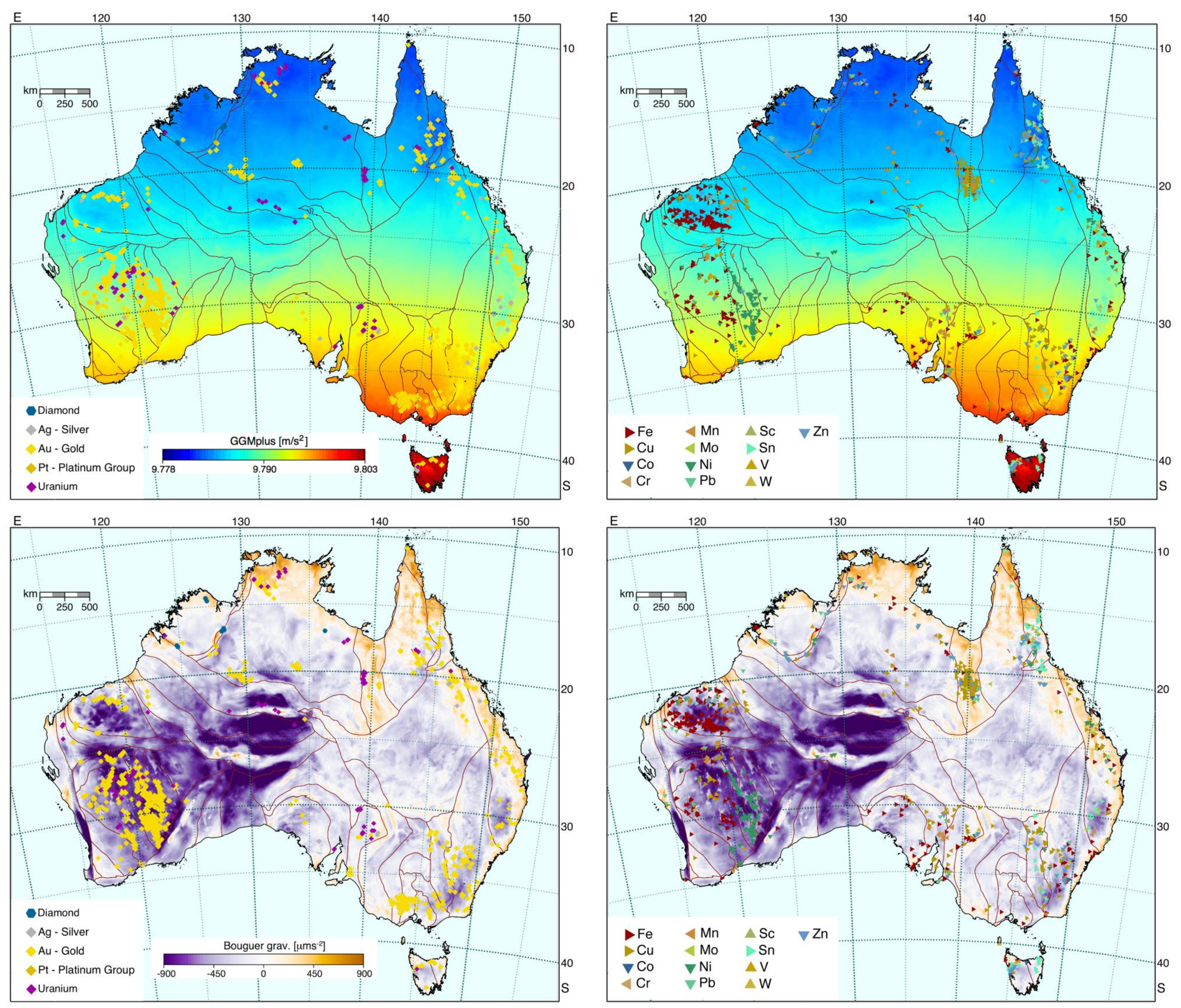

Figure 13.4: Mineral distribution relative to the gravity distribution: upper row absolute gravity, lower row Bouguer gravity anomaly. 
Figure 13.5 shows the resource distributions in relation to magnetic anomalies. In the upper row we use the total magnetic intensity, and in the lower row the spatial integral of the magnetic field.

Although there is the expected link between iron ores and areas of high magnetisation, many of the other commodities link well to the contrasts in the magnetic integral.

The magnetic integral senses deeper into the Earth than the magnetic field itself, and may therefore reveal magnetic relics of more deeply seated processes that control the surface location of deposits. It is also less sensitive to the details of patches of very high magnetisation.

As a result, some features become much more distinct with the magnetic integral. Thus the core of the Gawler Craton is very apparent, with deposits at or beyond its rim.

The truncation of the Mt Isa Province under cover by the Cork Fault appears to link into the eastern Arunta-Warumpi domain, again under cover. Both zones hint at potential for deposits in the continuation of outcrop structures.
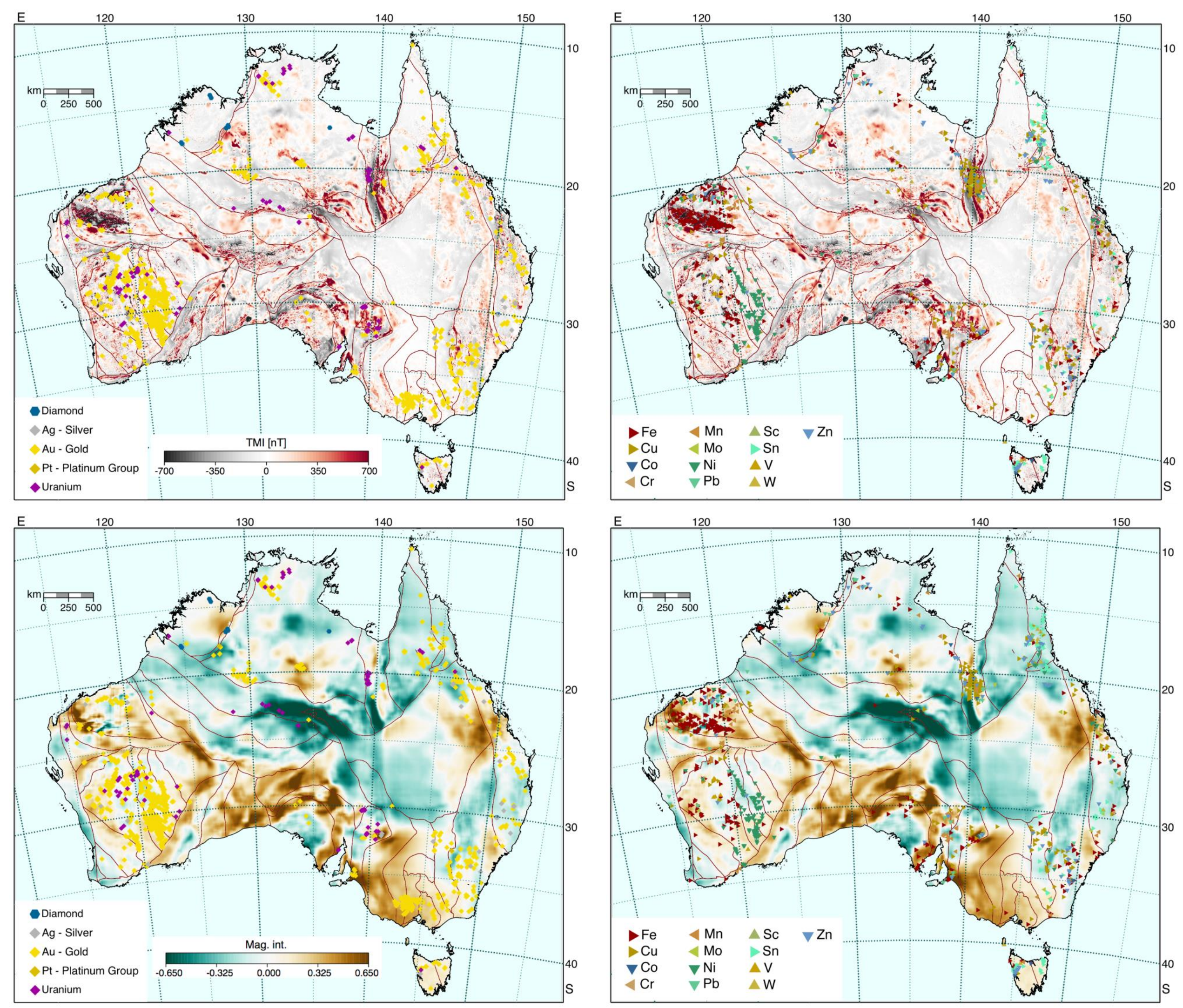

Figure 13.5: Mineral distribution relative to the magnetic field: upper row total magnetic intensity, lower row spatial integral of magnetic anomaly. 
In Figure 13.6, we use the ancillary fields introduced in Chapter 12 to discuss comparisons between gravity and magnetic behaviour. The upper row uses the spatial half-derivative of the gravity field, and the lower row the spatial half-integral of the magnetic field. These two fields have a more similar response to the depth of anomalies than the normal gravity and magnetic fields.

There are many similarities in the association of deposits with the two ancillary fields. But the orientation of the trends is not exactly the same and often deposits can be linked to zones where the trends cross (see Figure 12.7).

Alignments of deposit patterns with features of the gravity and magnetic fields are evident, as, for instance, in the Mt Isa Province and its extension under cover. Distinctive banding is also clear at the eastern edge of the Arunta Province with a likely undercover extension beneath the Eromanga Basin.

The abrupt truncation of magnetic trends against the Halls Creek Orogen resembles the southern edge of the Mt Isa Province, but in this case gravity signatures are muted.
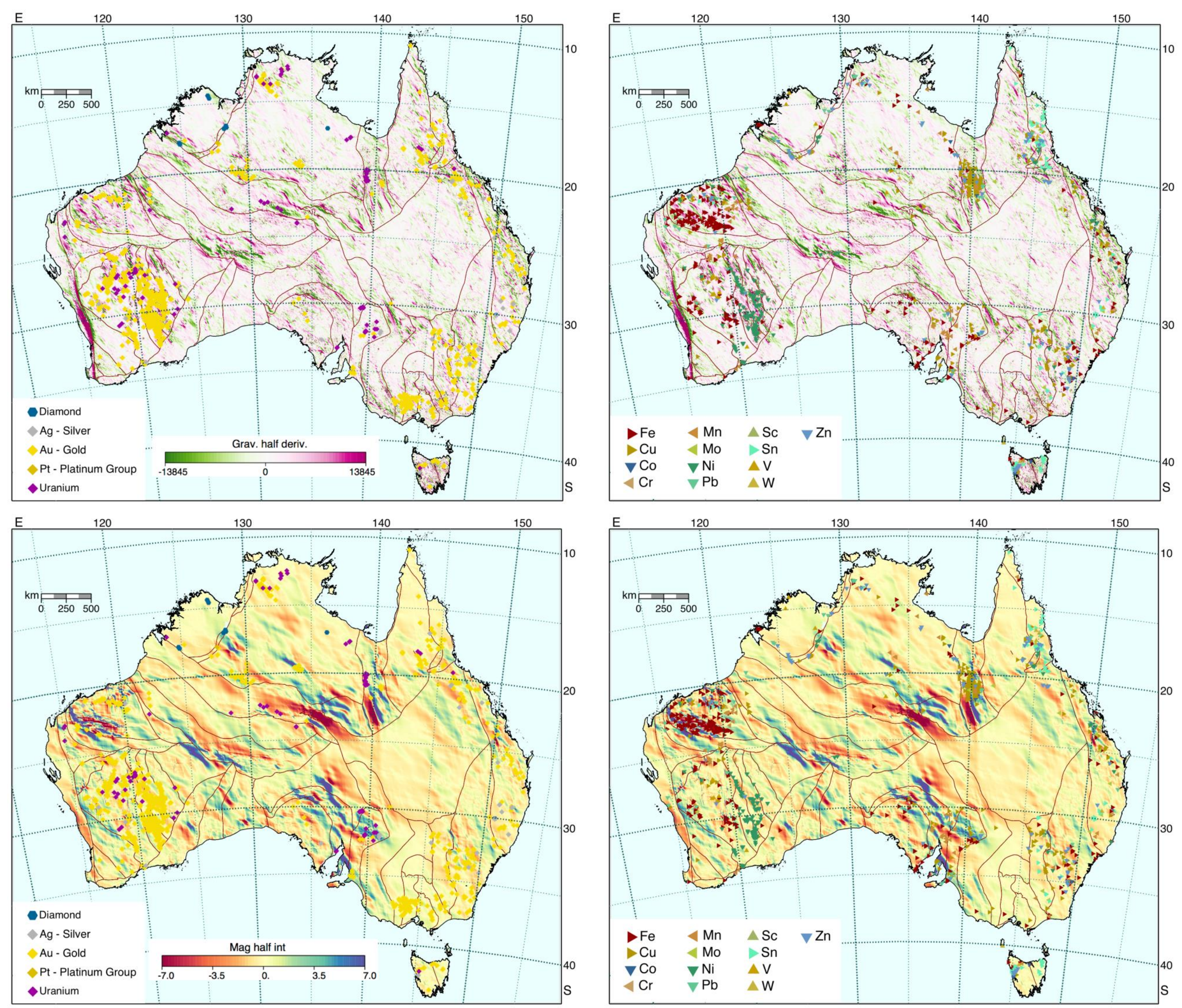

Figure 13.6: Mineral distribution relative to ancillary fields: upper row half-spatial derivative of gravity, lower row half-spatial integral of magnetic anomaly. 
In the final figure, Figure 13.7, we display the relationship of the resource distribution to the binary composite results introduced in Chapter 2. In the upper row we display the superposition of the half-derivative of gravity in red on the half-integral of the magnetic field in cyan. In the lower row we use the gravity field itself on the yellow channel, and the spatial integral of the magnetic field on a blue channel.

These displays bring to prominence textural features of the combined gravity and magnetic behaviour that are not easy to judge from individual field maps.

Areas of rapid change in the orientation of the fields or where trends in the different fields cross frequently link to the location of deposits. An example is in South Australia around the location of the massive Olympic Dam copper/gold/uranium (Cu/Au/U) deposit. A similar behaviour is seen at the western edge of the Musgrave Province, where exploration has, so far, been limited.
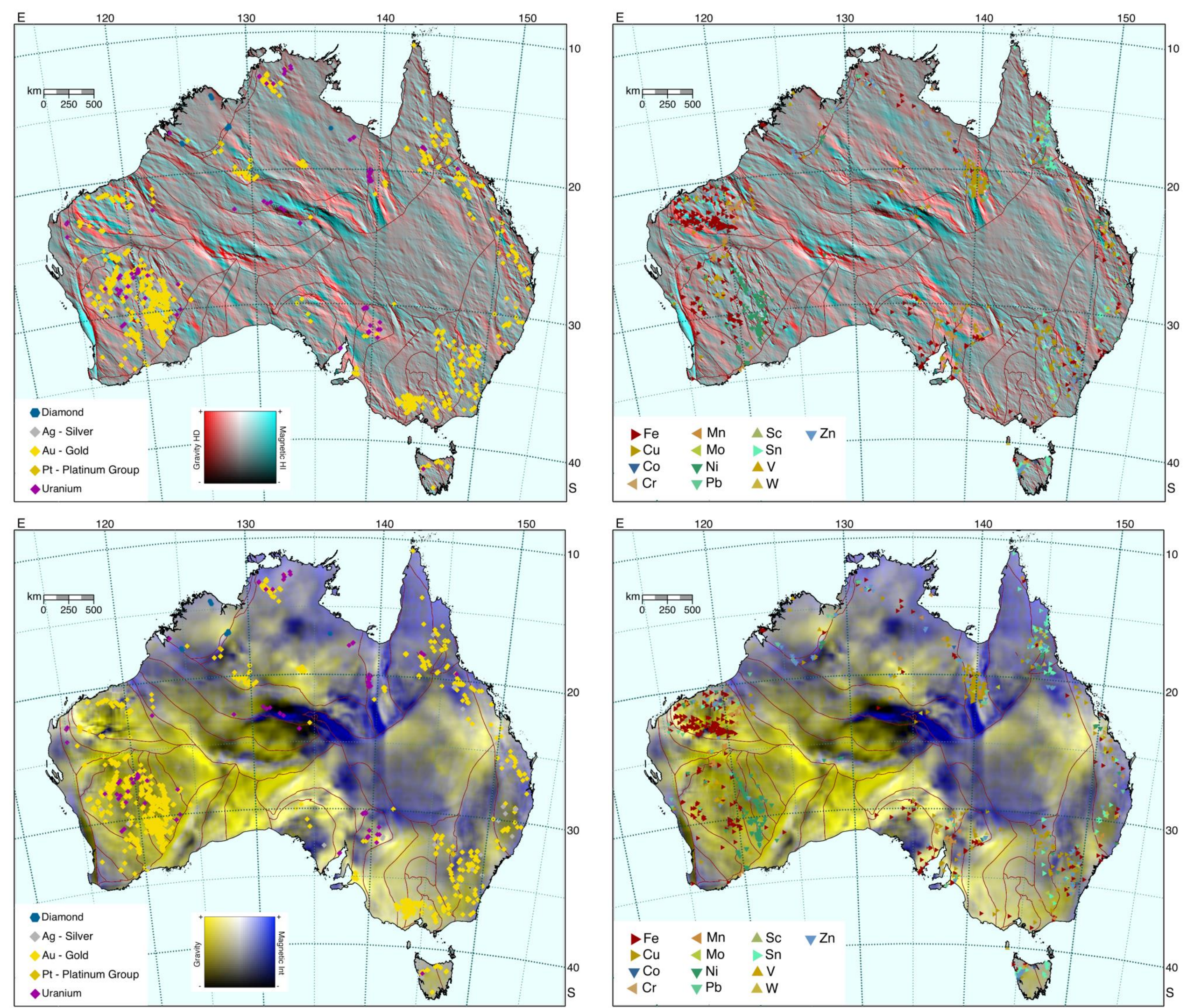

Figure 13.7: Mineral distribution relative to composite fields: upper row gravity half-derivative and magnetic half-integral, lower row gravity and magnetic integral. 


\section{Weathering and Regolith}

The regolith consists of the zone at the Earth's surface between fresh rock and the interface with the air. In Australia, regolith profiles can be up to several hundred metres thick as a result of a very long history of weathering on ancient landscapes that may have been exposed for hundreds of millions of years (Pillans, 2008). Since unweathered and slightly weathered rocky exposures cover less than 15 per cent of the 7.7 million $\mathrm{km}^{2}$ of the Australian landmass, the nature of the regolith in areas of cover is of major importance.

Regolith materials range from thin soils over slightly weathered bedrock to situations where weathering has reached more than $100 \mathrm{~m}$ beneath the surface. A range of important geological and biochemical cycles operate with the regolith zone: these include the passage of groundwater and nutrient cycles involving carbon, nitrogen, oxygen, phosphorus and sulphur. Bioturbation can mix materials in the near-surface, and geochemical processes can also transport traces of deep-seated mineral systems into the surface zone.

In the upper part of the regolith-the pedolith—the original bedrock structure has been destroyed by the weathering of the original minerals and the redistribution of secondary materials such as clays and oxides. Often the pedolith develops in situ but can also constitute transported materials. In the saprolith beneath the pedolith, the bedrock fabric is weathered but the original bedrock structures can be still recognised. Within the pedolith and saprolith there can also be secondary induration with, e.g. cementing by silica, iron, aluminium and carbonate. Such layers, such as calcrete, can play an important role in shaping the landscape and the properties of the regolith across Australia.

Intensely weathered regolith is likely to arise from the interaction of a number of factors:

- landscapes where the rate of erosion is low compared with rates of accumulation and with a long time span for weathering;

- bedrock that contains highly weatherable materials; and

- environmental conditions that promote rapid weathering through the action of water, temperature and biological action.

Provided there is sufficient time to weather the bedrock, and denudation rates are low, high weathering rates are not required to produce deep weathering. Thus ancient landscapes with low relief and low slope angles can be highly weathered, and can also be affected by more recent processes.

\subsection{Weathering Intensity Index}

The extent to which the regolith is weathered is linked to the factors that lead to the formation of soils, including the nature of the substrate, topography, climate, biological activity and time. As the weathering intensity increases, there are progressive changes in the physical and geochemical characteristics of regolith materials. With weak weathering, there is little change from the parent materials. But with intense weathering and leaching of the regolith, almost all traits of the original unweathered rock are overprinted or completely lost.

Weathering intensity has a strong influence on the extent to which the mineralogy of the original bedrock is converted into secondary minerals such as clays and oxides. With similar parent materials and climatic conditions, increasing weathering intensity leads to a change in the nature and proportions of the secondary minerals, so that more stable clays are produced and the regolith has more distinct zones.

With increased weathering, soluble elements such as potassium, sodium and calcium are lost into solution, while the more stable oxides and minerals such as quartz and zircon are retained in the regolith. This enables a measure of weathering intensity to be derived from geochemical indices based on the relative proportions of the stable elements compared with their more mobile counterparts. Measurements need to be taken from sample points through a weathering profile, and cannot be easily extrapolated across the landscape from the specific sample points.

With calibration at a broad range of sample points with different classes of regolith, a weathering intensity index can be developed exploiting radiometric information and terrain attributes from a digital elevation model (Wilford, 2012). The field sites were assessed using a six-level classification scheme. Level 1 describes largely unweathered landscapes with a high proportion of fresh bedrock exposed at the surface. Level 6 is assigned to areas where bedrock is completely weathered to secondary materials such as clays and oxides. The intermediate levels are based on the level of preservation of bedrock structures and fabrics, the relative proportion of clay and the degree of mottling and iron staining. 
As discussed in Chapter 3, airborne gamma-ray spectroscopy provides a measure of the flux emitted from the major radioelements in soils and bedrock to a depth of about $40 \mathrm{~cm}$. For a $100 \mathrm{~m}$ flying height, about 80 per cent of the recorded gamma rays will originate from about $600 \mathrm{~m}$ radius around the flight position. Hence estimates of element concentration and total flux (dose) provide averages over a significant footprint. The full continental coverage of radiometric results across Australia means that these results can be exploited to provide proxies for weathering intensity in conjunction with information on relief.

The concentration of potassium (K) generally decreases with increase in weathering because its compounds are soluble, and given sufficient time leach from the weathering profile. In contrast, thorium (Th) is less soluble, and by association with clays, oxides and weathering resistant minerals is retained in preference to the more soluble $\mathrm{K}$. Very highly weathered materials such as iron-rich duricrust and bauxitic soils typically exhibit high-Th responses.

Some rock types contain few or no gamma-emitting radioactive elements, e.g. highly siliceous sandstones or ultramafic rock. Where the gamma-ray dose is very low, it is necessary to exploit the relief derived from digital elevation models on the assumption that landscapes with high relief are likely to maintain thin soil and slightly weathered bedrock.

Where the total dose is high (about 90 per cent of the continent) a broader range of environmental variables are brought into consideration for a weathering intensity model, exploiting, in order of importance, $\mathrm{K}$ concentration, relief, the $\mathrm{Th} / \mathrm{K}$ ratio and the total dose.

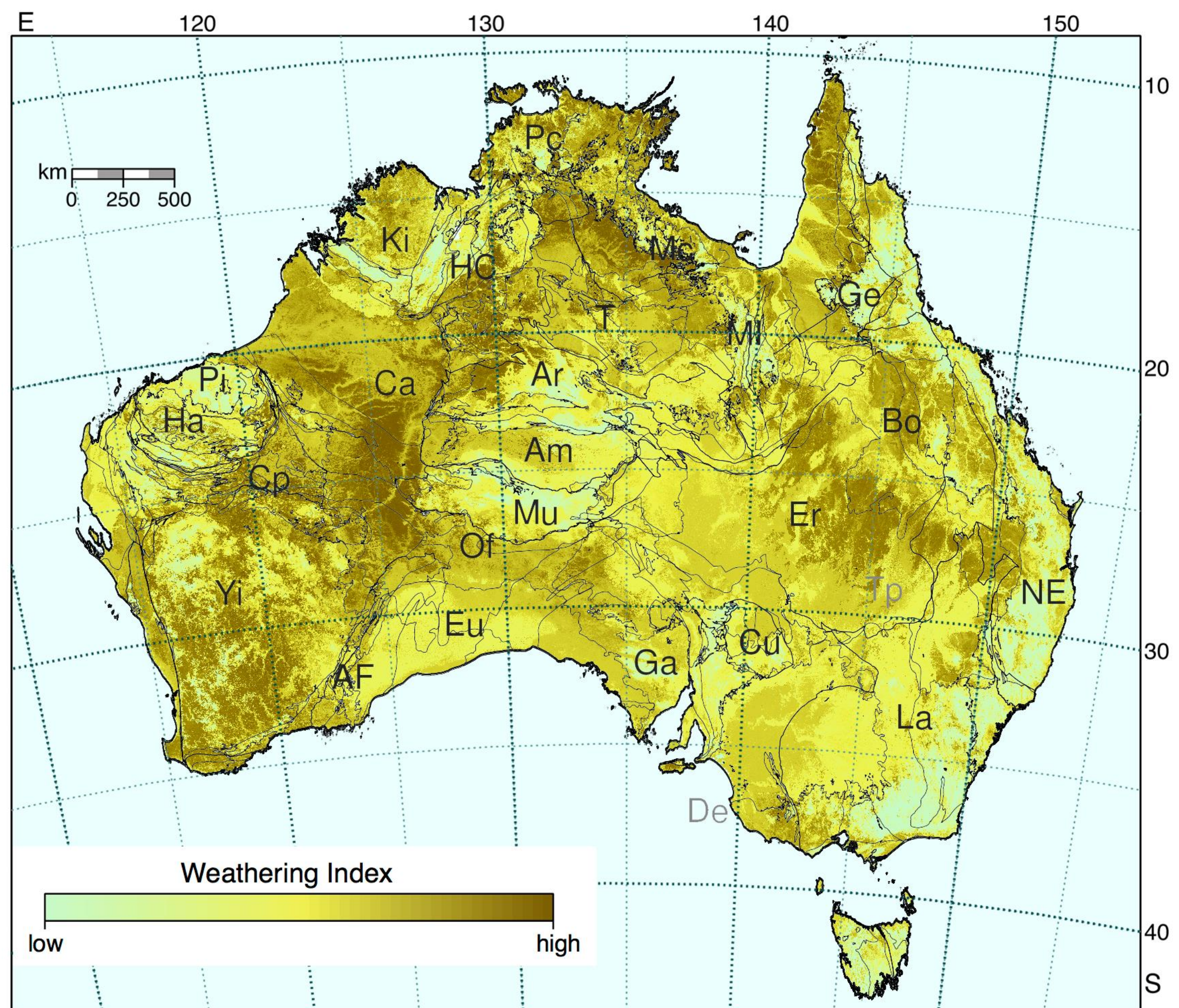

Figure 14.1: Weathering intensity index with superposition of geological provinces. 
These two classes of model for relating weathering intensity to aspects of the surface and sub-surface have been trained by comparison with weathering results from around 300 sites in southeastern Australia to develop regression models for the weathering intensity index (Wilford, 2012). For intermediate gamma-ray dose, a linear combination of the two models is employed to remove any abrupt boundary effects on the final grid. This composite model has then been further refined using machine learning techniques.

By this means, the combination of the radiometric results from Chapter 3 and digital elevation data for the whole continent can be brought together to provide a continent-wide measure of a relative weathering intensity index (Figure 14.1). As might be expected, this index shows a strong correlation with geological province boundaries, but also notable variation within provinces. Strong weathering is commonly associated with major areas of sedimentary basins, but there are many instances of strong weathering without sedimentary cover, e.g. in the North Australian Craton and the southeastern Yilgarn Craton.

When examined in detail, the weathering index has a good correlation with prior regolith-landform maps, with sharp boundaries in index behaviour often corresponding to erosional scarps (Wilford, 2012). There is also reasonable correlation with geochemical indices for weathering based on ratios of mobile and immobile elements.

Weathering intensity reflects changes in the geochemical, physical and hydrological aspects of the regolith as the bedrock breakdown under weathering and leaching. Understanding the nature of weathering through the weathering intensity index can help with understanding the pattern of pathfinder signals used in geochemical exploration for mineral signatures, and potentially mapping of paleo-landscape features.

Many upland areas of Australia show the impact of recent erosional processes superimposed on much older features as a result of tectonic processes, e.g. tilt and regional scale warping (Sandiford, 2007), changes in the base level of basins and climate. The weathering intensity index allows assessment of the interplay of such changes across a wide range of spatial scales.

\subsection{Regolith Thickness}

In addition to the radiometric estimates of the $\mathrm{K}$, Th and $\mathrm{U}$ concentrations in the near-surface, a number of other geophysical fields contain a signature from shallow contrasts. Thus the Bouguer gravity anomaly (Figure 5.7) is sensitive to the density contrast between the lower density regolith and the bedrock. Gradients of the gravity field can also highlight contrasts in density. The local magnetic anomaly (Figure 4.9) also provides information on bedrock structure. Estimates of the depth to magnetic source based on the gradient properties of the magnetic anomalies help to discriminate between magnetic and nonmagnetic components of the regolith and bedrock.

Wilford et al. (2016) have used the full range of such geophysical and geological constraints in conjunction with multi-scale attributes from digital topography to develop a model for regolith thickness across the whole continent. They use a database of depth to bedrock derived from drillhole data as the training dataset.

The drillhole information has been extracted from the National Groundwater Information System database. There is a broad spread of sites across the continent, but uneven coverage and notable gaps, e.g. in arid areas. Automated procedures were used to extract an estimate of the depth to fresh bedrock, from the descriptions of the logging parameters. This was a complex procedure because there had been no standard protocol for recording the drillhole information. The datasets were winnowed to remove records that were inconsistent with neighbouring drillhole estimates and landscape setting. The weathering intensity index was also used to define areas with relatively fresh bedrock.

This procedure yielded around 128,000 sites across the continent for which there was an estimate of the depth to the base of the regolith. The statistical distribution of these depth estimates is strongly skewed with a very long tail. to limit the impact of possible spurious values, Wilford et al. (2016) restricted the maximum depth to $200 \mathrm{~m}$. This means that that regolith thickness will be underestimated in regions of thick cover such as depositional basins.

The suite of drillhole estimates was then used to develop a multivariate model for regolith thickness that could be used across the whole continent. The model fitting was carried out using the logarithm of the drillhole depths, which ensures that regolith thickness estimates remain positive. 
The fitting procedure employing a large suite of continental-scale datasets is based on a complex decision tree approach, employing multiple linear regression models at the terminal nodes of the tree. Uncertainty estimates based on the difference between the 5th and 95th percentiles were generated using a bootstrap procedure and stabilised after 100 iterations.

The resulting model (Figure 14.2) has reasonable predictive power in matching the drillhole information, and extends coverage to the whole continent in a consistent framework. There is a tendency for some bias towards shallower depth for the base of the regolith, arising from the processes that were used to reduce the variability of the drillhole dataset. For example, where regolith thickness is greater than $200 \mathrm{~m}$, bedrock may well not be reached in sedimentary basins, particularly those with unconsolidated sediments of Cenozoic origin.

The most useful covariates for the regolith prediction include the nature of the local geology, the distance from outcrop, the depth to magnetic source, the characteristics of the terrain, radiometrics and the weathering intensity index, and soil clay characteristics. Many of the factors considered depend strongly on surface and near-surface character and processes, so that the principal controls at depth come from the geophysical information.

The uncertainty in the model estimates increases steadily with regolith thickness, but the relative uncertainty remains roughly constant and of the order of the thickness estimate itself. Thus the model provides a useful framework for assessing regolith thickness that can now be supplemented by area specific information.

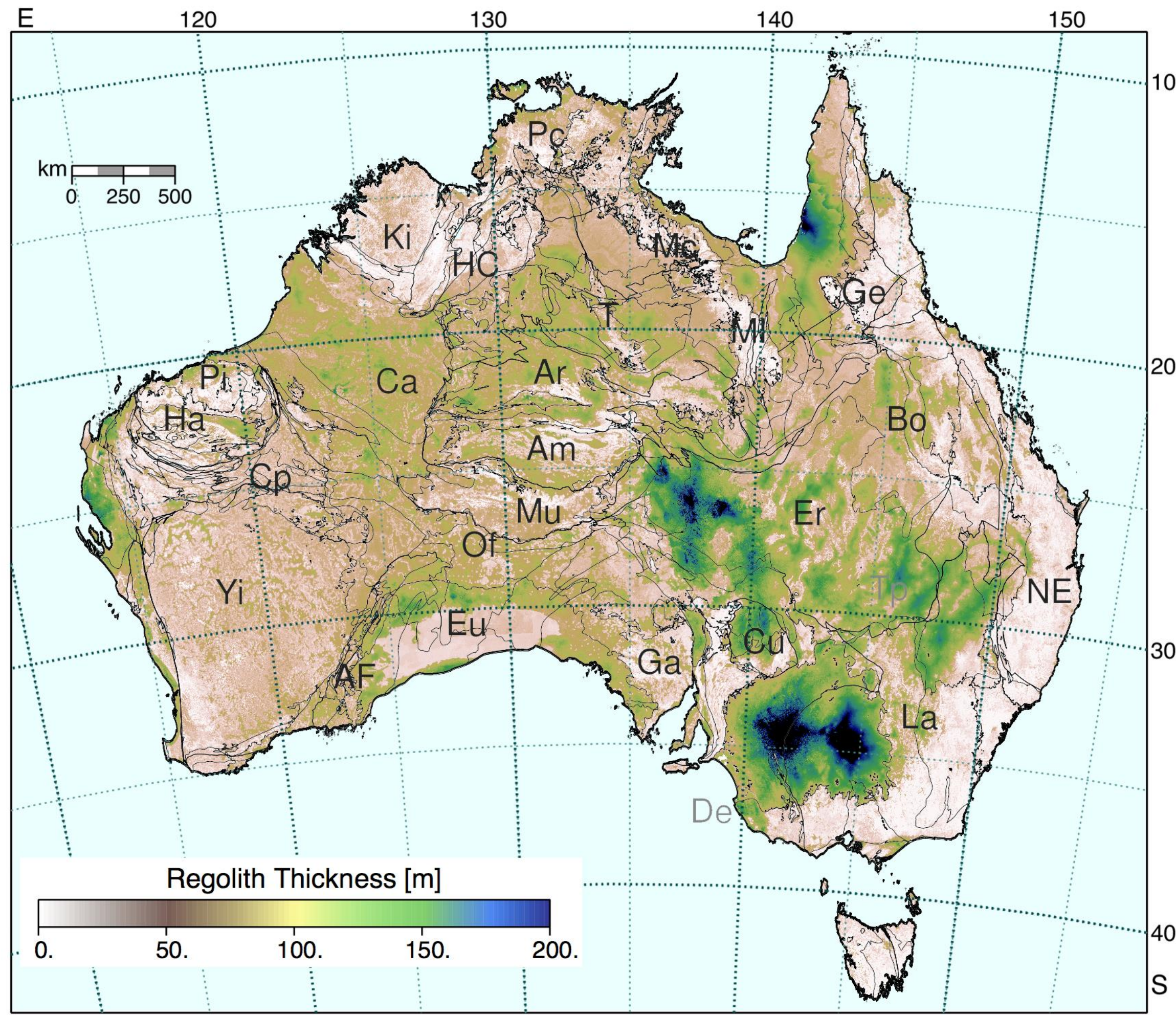

Figure 14.2: Estimate for the thickness of the regolith based on geophysical information, with geological provinces superimposed. 


\section{Bibliography}

\section{General background}

Artemieva I., 2011. The lithosphere: An interdisciplinary approach, Cambridge University Press, Cambridge. doi:10.1017/CBO9780511975417.

Blewett R.S. (ed.), 2012. Shaping a nation: A geology of Australia. ANU Press and Geoscience Australia, Canberra, Australia. press.anu.edu.au/ node/409/download.

Braun J., Dooley J., Goleby B., Van der Hilst R., Klootwijk (eds), 1998, Structure and evolution of the Australian continent, American Geophysical Union Geodynamics Series 26.

Drummond B.J. (ed.), 1991. The Australian lithosphere, Geological Society of Australia Special publication 17.

Hillis R.R., Müller R.D., (eds), 2003. Evolution and dynamics of the Australian plate, Geological Society of Australia Special Publication 22 and Geological Society of America Special Paper 372. doi: 10.1130/SPE372.

Huston D.L., Blewett R.S., Champion, D.C., 2012. The evolution of the Australian continent, Episodes, 35, 23-43.

Kennett B.L.N., Blewett R.S., 2012. Lithospheric framework of Australia, Episodes, 35, 9-22.

\section{References}

Aitken A.R.A., Altinay C., Gross L., 2015. Australia's lithospheric density field, and its isostatic equilibrium, Geophys. J. Int., 203, 1961-1976. doi:10.193/gji/ggv396.

Aitken A., Salmon M. Kennett B., 2013. Australia's Moho: a test of the usefulness of gravity modelling for the determination of Moho depth, Tectonophysics, 609, 468-479. doi:10.1016/j.tecto.2012.06.049

Bacchin M., Milligan P.R., Wynne P., Tracey R., 2008, Gravity anomaly map of the Australian region, 3rd edn, 1:5,000,000, Geoscience Australia, www.ga.gov.au, ecat Id: 65682.

Barton C., 2002. Survey tracks current position of South Magnetic Pole, EOS Transactions AGU, 83, 291. doi: 10.1029/2002EO000210.

Bendat J.S., Piersol A.G., 2010. Data analysis, in Random data analysis and measurement procedures, 4th edn, Wiley, Hoboken NJ, USA. doi: 10.1002/9781118032428.ch11.

Bodin T., Salmon M., Kennett B.L.N., Sambridge M., 2012. Probabilistic surface reconstruction from multiple data sets: An example for the Australian Moho, J. Geophys. Res., 117, B10307. doi:10.1029/2012JB009547.

Bowman J.R., Kennett B.L.N., 1991. Propagation of Lg waves in the North Australian craton: influence of crustal velocity gradients, Bull. Seism. Soc. Am., 81, 592-610.

Bowman J.R., 1992. The 1988 Tennant Creek, Northern Territory, earthquakes: A synthesis, Austral. J. Earth. Sci., 39, 651-669. doi:10.1080/08120099208728056.

Braun J., McQueen H., Etheridge M., 1991. A fresh look at the late Paleozoic tectonic history of western-central Australia, Explor. Geophys., 22, 49-54. doi:10.1071/EG991049.
Champion D.C., Budd A.R., Hazell M.S., Sedgmen, A., 2007. OZCHEM National Whole Rock Geochemistry dataset. Geoscience Australia, www.ga.gov.au, ecat Id: 65464.

Champion, D.C., 2013. Neodymium depleted mantle model age map of Australia: explanatory notes and user guide, Geoscience Australia Record 2013/44. doi:10.11636/Record.2013.044.

Chopping R., Kennett B.L.N., 2015. The depth of magnetisation in Australia and its uncertainty, GeoResJ, 7, 70-77. doi:10.1016/j.grj.2015.06.003.

Chopra P., Holgate F.L. 2005. A GIS Analysis of Temperature in the Australian Crust. Proceedings of the World Geothermal Congress 2005, 24-29 April, Antalya, Turkey.

Clark D., McPherson A., Collins C.D.N., 2011. Australia's seismogenic neotectonic record: a case for heterogeneous intraplate deformation, Geoscience Australia Record 2011/11,

Collins W.J., Vernon R.H., 1992. Palaeozoic arc growth, deformation and migration across the Lachlan Fold Belt, southeastern Australia, Tectonophysics, 214, 381-400.

Cooper G.R.J., Cowan D.R., 2005. Differential reduction to the pole, Comput. Geosci., 31, 989-999. doi:10.1016/j.cageo.2005.02.005.

Cull J., 1982. An appraisal of Australian heat flow data, BMR Journal of Australasian Geology \& Geophysics, 7, 11-21

Davies D.R., Rawlinson N., laffaldano G., Campbell I.H., 2015. Lithospheric controls on magma composition along Earth's longest continental hotspot track, Nature, 525, 511514. doi:10.1038/nature14903.

Debayle E., Kennett B., Priestley K., 2005, Global azimuthal seismic anisotropy: the unique plate-motion deformation of Australia, Nature, 433, 509-512. doi:10.1038/nature03247.

DeMets C., Gordon R.F., Argus D.F., 2010. Geologically current plate motions, Geophys. J. Int., 181, 1-80. Doi:10.1111/j.1365-246X.2009.04491.x.

Dutch R.A., Pawley M.J., Wise T.W. (eds), 2015. What lies beneath the western Gawler Craton? 13GA-EG1E Seismic and Magnetotelluric Workshop 2015. Department of State Development, South Australia, Adelaide. Report Book 2015/00029.

Farrington R., Stegman D., Moresi L.N., Sandiford M., May D., 2010. Interactions of 3D mantle flow and continental lithosphere near passive margins, Tectonophysics, 483, 20-28. doi:10.1016/j.tecto.2009.10.008.

Faul U.H., Jackson I., 2005, The seismological signature of temperature and grain size variation in the upper mantle, Earth Planet. Sci. Lett., 234, 119-134. doi:10.1016/j.epsl.2005.02.008.

Fichtner A., Fishwick S., Yoshizawa K., Kennett B.L.N., 2012. Optimal spherical spline filters for the analysis and comparison of regional-scale tomographic models, Phys. Earth Planet. Inter., 190, 44-50. doi: 10.1016/j.pepi.2011.11.001.

Fishwick S., Kennett B.L.N., Reading A.M., 2005. Contrasts in lithospheric structure within the Australian Craton, Earth Planet. Sci. Lett., 231, 163-176. doi:10.1016/j.epsl.2005.01.009. 
Fishwick S., Heintz M., Kennett B.L.N., Reading A.M., Yoshizawa K., 2008. Steps in lithospheric thickness within eastern Australia, evidence from surface wave tomography, Tectonics, 27, TC4009. doi:10.1029/2007TC002116.

Fishwick S., Reading A.M., 2008. Anomalous lithosphere beneath the Proterozoic of western and central Australia: A record of continental collision and intraplate deformation? Precambrian Research, 166, 111-121. doi: 10.1016/j.precamres.2007.04.026.

Ford H.A., Fischer K.M., Abt D.L., Rychert C.A., Elkins-Tanton L.T., 2010. The lithosphereasthenosphere boundary and cratonic lithospheric layering beneath Australia from $\mathrm{Sp}$ wave imaging. Earth Planet. Sci. Lett., 300, 299-310. doi:10.1016/j.epsl.2010.10.007.

Frogtech, 2005. OZ SEEBASE ${ }^{\mathrm{TM}}$ Study, 2005. Public domain report to Shell Development Australia by FrOG Tech Pty Ltd.

Gerner E.R., Holgate F.R., 2010. OZTemp - Interpreted Temperature at $5 \mathrm{~km}$ Depth Image, Geoscience Australia, www.ga.gov.au, ecat Id: 102801.

Goleby B.R., Shaw R.S., Wright C., Kennett B.L.N., Lambeck K. 1989. Geophysical evidence for 'thick-skinned' crustal deformation in central Australia, Nature, 337, 325-330. doi:10.1038/337325a0.

Gorbatov A., Kennett B.L.N., Saygin E., 2013. Crustal properties from seismic station autocorrelograms, Geophys. J. Int., 192, 861-870. doi:10.1093/gji/ggs064.

Gudmundsson O., Kennett B.L.N., Goody A., 1994. Broadband observations of upper mantle seismic phases in northern Australia and the attenuation structure in the upper mantle, Phys. Earth Planet. Inter., 84, 207-236. doi:10.1016/0031-9201(94)90042-6.

Haynes M., Budd A.R., Gerner E.J., Harris-Pascal C., Kirkby A.J., 2015. TherMAP - assessing subsurface temperatures in Australia from a geothermal system perspective, Proceedings of the World Geothermal Congress 2015, 19-25 April, Melbourne, Australia.

Heidbach, O. Rajabi M., Reiter K., Ziegler M., WSM Team, 2016. World Stress Map Database Release, 2016, GFZ Data Services. doi:10.5880/WSM.2016.001.

Hillis R.R., Reynolds S.D., 2003. In-situ stress field of Australia, Geological Society of Australia Special Publication 22, 43-52. doi:10.1130/0-8137-2372-8.49.

Hirt C., Claessens S.J., Fecher T., Kuhn M., Pail R., Rexer M. 2013. New ultrahigh-resolution picture of Earth's gravity field, Geophys. Res. Lett., 40. doi:10.1002/grl.50838.

Jackson I., Faul U.H., 2010. Grainsize-sensitive viscoelastic relaxation in olivine: Towards a robust laboratory-based model for seismological application, Phys. Earth Planet. Inter., 183, 151-163. doi:10.1016/j.pepi.2010.09.005.

James D.E., Fouch M.F., VanDecar J.C., van der Lee S., Kaapvaal Seismic Group, 2001. Tectospheric structure beneath southern Africa, Geophys. Res. Lett., 28, 2485-2488. doi:10.1029/2000GL012578.

Kaban M.K., Tesauro M., Mooney W.D., Cloetingh S.A.P.L., 2014. Density, temperature and composition of the North American lithosphere: New insights from a joint analysis of seismic, gravity and mineral physics data. Part 1: Density structure of the crust and upper mantle. Geochem., Geophys., Geosyst., 15, 4781-4807. doi:10.1002/2014GC005483.
Kaiho Y., Kennett B.L.N., 2000. Three-dimensional seismic structure beneath the Australasian region from refracted wave observations, Geophys. J. Int., 142, 651-668. doi:10.1046/j.1365-246x.2000.00087.x.

Kennett B.L.N., 2001. Representations of seismicity, Geochem. Geophys. Geosystems, 2, 2000 GC00140.

Kennett B.L.N., Furumura T., 2008. Stochastic waveguide in the Lithosphere: Indonesian subduction zone to Australian Craton, Geophys. J. Int., 172, 363-382. doi:10.1111/j.1365246X.2007.03647.x.

Kennett B.L.N., Abdulah A., 2011. Seismic wave attenuation beneath the Australasian region, Austral. J. Earth. Sci., 58, 285-295. doi: 10.1080/08120099.2011.550318.

Kennett B.L.N., Salmon M., Saygin E., AusMoho Working Group, 2011. AusMoho: the variation of Moho depth in Australia, Geophys. J. Int., 187, 946-958. Doi:10.1111/j.1365246X.2011.05194.X.

Kennett B.L.N., Salmon M., 2012. AuSREM: Australian seismological reference model, Austral. J. Earth Sci., 59, 1091-1103. doi:10.1080/08120099.2012.736406.

Kennett B.L.N., Fichtner A., Fishwick S., Yoshizawa K., 2013. Australian seismologica reference model (AuSREM): Mantle component, Geophys. J. Int., 192, 871-887. doi:10.1093/gji/ggs065.

Kennett B.L.N., 2015. Lithosphere-asthenosphere P-wave reflectivity across Australia, Earth Planet. Science Lett., 431, 225-235. doi: 10.1016/j.epsl.2015.09.039.

Kennett B.L.N., Saygin E., 2015. The nature of the Moho in Australia from reflection profiling: A review, GeoResJ, 5, 74-91. Doi: 10.1016/j.grj.2015.02.001.

Kennett B.L.N., Saygin E., Salmon M., 2015. Stacking autocorrelograms to map Moho depth with high spatial resolution in southeastern Australia, Geophys. Res. Lett., 42, 38393846, doi:10.1002/2015GL065345.

Kennett B.L.N., Saygin E., Fomin T. and Blewett R.S., 2016. Deep Crustal Seismic Reflection Profiling: Australia 1978-2015. ANU Press, Canberra, Australia. press.anu.edu.au/ node/163/download.

Kennett B.L.N., Yoshizawa K., Furumura T. 2017. Interactions of multi-scale heterogeneity in the lithosphere: Australia, Tectonophysics, 717, 193-213. doi:10.1016/j.tecto.2017.07.009.

Kennett B.L.N., Sippl C., 2018. Lithospheric discontinuities in central Australia, Tectonophysics, 744, 10-22. doi:10.1016/j.tecto.2018.06.008.

Korsch R.J., Goleby B.R., Leven J.H., Drummond B.J., 1998. Crustal architecture of central Australia based on deep seismic reflection profiling, Tectonophysics, 288, 57-69. Doi: 10.1016/j.tecto.2012.02.022.

Korsch R.J., Kositcin N. (eds), 2010. South Australian seismic and MT workshop 2010 Geoscience Australia Record 2010/10. 
Korsch R.J., Huston D.L., Henderson R.A., Blewett R.S., Withnall I.W., Fergusson C.L., Collins W.J., Saygin E., Kositcin N., Meixner A.J., Chopping R., Henson P.A., Champion D.C., Hutton L.J., Wormald R., Holzschuh J., Costelloe R.D., 2012. Crustal architecture and geodynamics of North Queensland, Australia: Insights from deep seismic reflection profiling, Tectonophysics, 572-573, 76-99. doi:10.1016/j.tecto.2012.02.022.

Korsch R.J., Spaggiari C.V., Occhipinti S.A., Doublier M.P., Clark D.J., Dentith M.C., Doyle M.G., Kennett B.L.N., Gessner K., Neumann N.L., Belousova E.A., Tyler I.M., Costelloe R.D., Fomin T., Holzschuh J., 2014. Geodynamic implications of the 2012 Albany-Fraser deep seismic reflection survey: A transect from the Yilgarn Craton across the AlbanyFraser Orogen to the Madura Province. In C.V. Spaggiari and I.M. Tyler (compilers) 2014, Albany-Fraser Orogen seismic and magnetotelluric (MT) workshop 2014: Extended abstracts: Geological Survey of Western Australia, Record 2014/6, 130-156-129.

Korsch R.J., Doublier M.P., 2016. Major crustal boundaries of Australia, and their significance in mineral systems targeting, Ore Geology Reviews, 76, 211-218. doi:10.1016/S0040-1951(97)00283-7.

Laske G., Masters G. Ma. Z., Pasyanos M. 2013. Update on CRUST1.0 - a 1 degree model of Earth's crust, Geophys. Res. Abstracts, 15, Abstract EGU2013-2658.

Leonard M., Ripper I.D., Yue L., 2002. Australian earthquake fault plane solutions, Geoscience Australia Record 2002/19.

McLaren S., Sandiford M., Hand M., Neumann N., Wyborn L., Bastrakova L., 2003. The hot southern continent: heat flow and heat production in Australian Proterozoic terranes. Geological Society of Australia Special Publication 22, 151-161. doi:10.1130/0-81372372-8.157

Minty B.R.S., 1997. Fundamentals of airborne gamma-ray spectrometry, AGSO Journal of Australian Geology and Geophysics, 17(2), 39-50.

Minty B., Franklin R., Milligan P., Richardson M., Wilford J., 2009. The Radiometric Map of Australia, Exploration Geophysics, 40, 325-333. doi:10.1071/EG09025.

Müller R.D., Sdrolias M., Gaina C., Roest W.R., 2008. Age, spreading rates, and spreading asymmetry of the world's ocean crust, Geochem. Geophys. Geosyst., 9, Q04006. doi:10.1029/2007GC001743.

Nakamura A, Milligan P.R., 2015. Magnetic anomaly map of Australia (Sixth Edition), Geoscience Australia. www.ga.gov.au, ecat Id: 89595.

Pilia S., Rawlinson N., Direen N.G., Reading A.M., Cayley R., Prior L., Arroucau P., Duffet M., 2015. Linking mainland Australia and Tasmania using ambient seismic noise tomography: Implications for the tectonic evolution of the east Gondwana margin, Gondwana Research, 28, 1212-1227. doi:10.1016/j.gr.2014.09.014.

Pillans B., 2008, Regolith through time. In Regolith Science, K.M. Scott and C.F. Pain (eds), 730, CSIRO Publishing, Australia.

Quigley M.C., Clark D., Sandiford M., 2010. Tectonic geomorphology of Australia, Geological Society of London Special Publication 346, 243-265. doi:10.1144/SP346.13.
Rawlinson N., Salmon M., Kennett B.L.N. 2014. Transportable seismic array tomography in southeast Australia: Illuminating the transition from Proterozoic to Phanerozoic lithosphere, Lithos, 189, 65-76. doi:10.1016/j.lithos.2013.06.001

Rawlinson N., Pilia S., Young M., Salmon M., Yang Y., 2016. Crust and upper mantle structure beneath southeast Australia from ambient noise and teleseismic tomography, Tectonophysics, 689, 143-156. doi:10.1016/j.tecto.2015.11.034.

Rawlinson N., Davies D.R., Pilia S., 2017. The mechanisms underpinning Cenozoic intraplate volcanism in eastern Australia: Insights from seismic tomography and geodynamic modelling. Geophys. Res. Lett., 44, 9681-9690. doi:10.1002/2017GL074911.

Reading A.M., Kennett B.L.N., Goleby B.R., 2007. New constraints on the seismic structure of West Australia: Evidence for terrane stabilization prior to the assembly of an ancient continent? Geology, 35, 379-382. doi:10.1130/G23341A.1.

Reynolds S.D., Coblentz D.D., Hills R.R., 2003. Influences of plate-boundary forces on the regional intraplate stress field of continental Australia, Geological Society of Australia Special Publication 22, 53-64. doi:10.1130/0-8137-2372-8.59.

Rosenbaum, G., 2018. The Tasmanides: Phanerozoic tectonic evolution of eastern Australia: Ann. Rev. Earth Planet. Sci., 46, 291-325. doi:10.1146/annurev-earth-082517-010146.

Salmon M, Kennett B.L.N., Saygin E., 2013a. Australian seismological reference model (AuSREM): Crustal component, Geophys. J. Int., 192, 190-206. doi: 10.1093/gji/ggs004.

Salmon M., Kennett B.L.N., Stern T., Aitken A.R.A., 2013b. The Moho in Australia and New Zealand, Tectonophysics, 609, 288-298. doi:10.1016/j.tecto.2012.07.009.

Sandiford M., 2007. The tilting continent: A new constraint on the dynamic topographic field from Australia, Earth Planet. Sci. Lett., 261, 152-163. doi:10.1016/j.epsl.2007.06.023.

Saygin E., Kennett B.L.N., 2010. Ambient noise tomography for the Australian Continent: Tectonophysics, 481, 116-125. doi:10.106/j.tecto.2008.11.013.

Saygin E., Kennett B.L.N., 2012. Crustal structure of Australia from ambient seismic noise tomography, J. Geophys. Res. Solid Earth, 117, B01304. doi:10.1029/2011JB008403.

Simons F.J., Zuber M.T., Korenaga J., 2000. Isostatic response of the Australian lithosphere: Estimation of effective elastic thickness and anisotropy using multi-taper spectral analysis J. Geophys. Res., 105, 19,163-19,184. doi:10.1029/2011JB008403.

Sippl C., Kennett B.L.N., Tkalčić H., Spaggiari C.V., Gessner K., 2015. New constraints on the current stress field and seismic velocity structure of the eastern Yilgarn craton from mechanisms of local earthquakes, Austral. J. Earth Sci., 62, 921-931. doi:10.1080/08120099.2015.1130173.

Sippl C., Brisbout L., Spaggiari C.V., Gessner K., Tkalčić H., Kennett B.L.N., Murdie R., 2017. Crustal structure of a Proterozoic craton boundary: East Albany-Fraser Orogen, Western Australia, imaged with passive seismic and gravity data, Precambrian Research, 296, 79-82. doi:10.1016/j.precamres.2017.04.041.

Smith W.H.F., Wessel, P., 1990. Gridding with continuous curvature splines in tension, Geophysics, 55, 293-305. doi:10.1190/1.1442837. 
Snyder R.P., 1987. Map projections: A working manual, United States Geological Survey Professional Paper 1395, U.S. Government Printing Office, Washington, D.C., pubs.er.usgs.gov/publication/pp1395.

Sun W., Kennett B.L.N., 2016. Uppermost mantle structure of the Australian continent from Pn traveltime tomography, J. Geophys. Res., Solid Earth, 121, 2004-2019. doi:10.1002/2015JB012597.

Sun W., Fu L.-Y., Saygin E., Zhao L., 2018. Insights into layering in the cratonic lithosphere beneath Western Australia, J. Geophys. Res., Solid Earth, 123, 1405-1418. doi:10.1002/2017JB014904.

Tesauro M., Kaban M.K., Mooney W.D., Cloetingh S.A.P.L., 2014. Density, temperature and composition of the North American lithosphere: New insights from a joint analysis of seismic, gravity and mineral physics data. Part 2: Thermal and compositional model of the lithosphere. Geochem., Geophys., Geosyst., 15, 4808-4830. doi:10.1002/2014GC005484.

Tesauro M., Kaban M.K., Aitken A.. 2017. Thermo-compositional and strength variability of the Australian plate: clues of intraplate deformation, Abstract T51A-0441 presented at 2017 Fall Meeting, American Geophysical Union, 11-15 December, New Orleans, USA.

Thybo H., 2008. The heterogeneous upper mantle low velocity zone, Tectonophysics, 416, 5379. doi:10.1016/j.tecto.2005.11.021.

Tregoning P., 2003. Is the Australian Plate deforming? A space geodetic perspective, Geological Society of Australia Special Publication 22, 41-48. doi:10.1130/0-8137-23728.41 .

Tregoning P., Burgette R., McClusky S.C., Lejeune S., Watson C S., McQueen H., 2013. A decade of horizontal deformation from great earthquakes, J. Geophys. Res. Solid Earth, 118, 2371-2381. doi:10.1002/jgrb.50154.

van der Hilst R., Kennett B.L.N., Christie D., Grant J., 1994, Project SKIPPY explores the lithosphere and mantle beneath Australia, EOS Transactions Am. Geophys. Union, 75, 177. doi:10.1029/94EO00857. van Ufford A.Q, Cloos M, 2005. Cenozoic tectonics of New Guinea, AAPG Bulletin, 89, 119140. doi:10.1306/08300403073.

Wang L., Hitchman A.P., Ogawa Y., Siripunvaraporn W., Ichiki M., Fuiji-ta K., 2014. A 3-D conductivity model of the Australian continent using observatory and magnetometer array data, Geophys. J. Int., 198, 1143-1158. doi:10.1093/gji/ggu188.

Wei Z., Kennett B.L.N., Zhao L.F., 2017. Lg-wave attenuation in the Australian crust, Tectonophysics, 717, 413-424. doi:10.1016/j.tecto.2017.08.022.

Wessel P., Smith W.H.F., 1998. New, improved version of generic mapping tools released, EOS, Trans. Am. Geophys. Union, 79, 579. doi:10.1029/98EO00426.

Wilford J.R., 2012. A weathering intensity index for the Australian continent using airborne gamma-ray spectrometry and digital terrain analysis, Geoderma, 183-184, 124-142. doi:10.1016/j.geoderma.2010.12.022.

Wilford J.R., Searle R., Thomas M., Pagendam D., Gundy M.J., 2016. A regolith depth map of the Australian continent, Geoderma, 266, 1-13. doi:10.1016/j.geoderma.2015.11.033.

Yoshizawa, K., 2014. Radially anisotropic 3-D shear wave structure of the Australian lithosphere and asthenosphere from multi-mode surface waves. Phys. Earth Planet. Inter 235, 33-48. doi: 10.1016/j.pepi.2014.07.008.

Yoshizawa, K., Kennett, B.L.N., 2015. The lithosphere-asthenosphere transition and radia anisotropy beneath the Australian continent. Geophys. Res. Lett. 42, 3839-3846. http://dx.doi.org/10.1002/2015GL063845.

Young M.K., Rawlinson N., Arroucau P., Reading A.M., Tkalčić H., 2011. High-frequency ambient noise tomography of southeast Australia: New constraints on Tasmania's tectonic past, Geophys. Res. Lett., 38. doi:10.1029/2011GL047971.

Young M.K., Tkalčić H., Rawlinson N., Reading A.M., 2012. Exploiting seismic signal and noise in an intracratonic environment to constrain crustal structure and source parameters of infrequent earthquakes, Geophys. J. Int., 188, 1302-1321. doi:10.1111/j.1365246X.2011.05326.x. 


\section{National Geophysical Datasets}

Available through Geoscience Australia: www.ga.gov.au

Digital Elevation Model (DEM) Shuttle Radar Topography Mission (SRTM)

1 Second over Australian Bathymetry Topography WCS

eCat Id: 100320

Ternary Radiometric Image of Australia 2015

eCat Id: 82851

Total Magnetic Intensity (TMI) Grid of Australia 2015 - sixth edition eCat Id: 89595

Gravity Anomaly Map of the Australian Region, 3rd edition, 2008 eCat Id: 65682

OZTemp Well Temperature Data Extract WMS

eCat ld: 102903

OZCHEM National Whole Rock Geochemistry Dataset

eCat Id: 65464

The Australia-Wide Array of Geomagnetic Stations (AWAGS)

eCat Id : 116283
Available from the Research School of Earth Sciences, The Australian National University: rses. anu.edu. au/AuSREM

Grids at $0.5 \mathrm{deg}$ resolution

Moho depth (2013 version)

Crustal Seismic velocities (10 km intervals)

Mantle seismic velocities (25 km intervals) 


\section{Appendix: Spectral Stabilisation}

When we wish to examine the relation between different geophysical fields it is desirable to have each of them in a common representation. We can achieve this by using a down-sampling approach implemented in the spectral domain, which has the additional merit of suppressing noise and thereby increasing the reliability of the longest wavelength components of the field. Such long wavelength components play an important role in many comparisons between fields

For studies at the continental scale, most available datasets are oversampled relative to the information content required by the particular methodology. For Australian datasets available, the applicable resolutions are:

Gravity each pixel: 800 x 800 m (Bacchin et al., 2008)

Magnetic intensity each pixel: $80 \times 80 \mathrm{~m}$ (Milligan et al., 2010)

Onshore topography each pixel: 30 × 30 m (internal Geoscience Australia data)

Combined on and offshore topography each pixel: $250 \times 250 \mathrm{~m}$ (internal

Geoscience Australia data)

Our approach has been to work with a $4096 \times 4096$ pixel representation of each field using a resolution with pixels $1.28 \mathrm{~km}$ square. This is sufficient to retain much detail, but also is a very manageable size for further spectral domain processing, such as extraction of derivatives or upward continuation.

Rather than simply reduce the data density in each direction by the appropriate factor, we employ an ensemble of multiple realisations for a dataset produced by sub-sampling. By selecting existing pixels from the dataset for larger 'master pixels', we can achieve multiple realisations for the random processes that yielded the original data (Bendat and Piersol, 2010). This approach provides stable long wavelength components at the expense of some spatial resolution and the highest frequency components.

Consider a two-dimensional dataset with $n X \times n Y$ original pixels, with a target number of pixels of $X \times Y$. We thus wish to subsample by a factor of $n$ in each dimension. The first stage is to pad the dataset with additional zeroes so that number of pixels in each dimension is an integer multiple of $n$. As a simple example, consider a $7 \times 6$ pixel image that we wish to subsample by a factor of 4 in each dimension. We begin by padding this to $8 \times 8$ pixels.
In the general case, we now define master pixels where the number of master pixels in each dimension is the number of zero-padded pixels divided by $n$. For the simple example, we have 2 master pixels in each dimension. We now select, from our data, each possible value from each sub-pixel that relates to each master pixel. This provides $\mathrm{n}^{2}$ realisations of the original data. For our trivial example, we have $4 \times 4=16$ realisations in the spatial domain. From these $n^{2}$ realisations in the spatial domain, we take the 2-dimensional Fourier transform (FFT) of each of these realisations, to compile 16 Fourier representations of the sub-sampled data. Each of these realisations is an equally valid representation of the original data in the frequency domain. From these multiple realisations of the subsampling, we can average to produce a stabilised representation of the data in the spectral domain. This averaging is performed for each Fourier component in the final set to produce a single value with reduced noise compared with the individual subsamples. In addition to the average, we can collect other statistics on the various wavelength components.

As an example, consider the 5th edition of the magnetic map of Australia, with variable reduction to the pole to the pole using the algorithm of Cooper and Cowan (2005). The preliminary step is to project the data to an area-preserving projection (Albers Equal-Area projection: Snyder, 1987, European Petroleum Survey Group coordinate reference 3577). The dataset is then padded with zeroes and centred in a space of $64000 \times 64000$ pixels. The pixels in the original dataset pixels are $80 \mathrm{~m}$ × $80 \mathrm{~m}$; by applying a $16 \times 16$ sub-sampling procedure there are 256 separate realisations of the magnetic data that can be averaged to provide a spatial resolution of $1280 \mathrm{~m} \times 1280 \mathrm{~m}$ pixels. After sub-sampling and averaging these 256 frequency-domain realisations, we can obtain statistics about the distribution of Fourier components. The level of detail recovered after inverse Fourier transforming the data to the spatial domain is higher (but also smoother) than the resolution achieved by spatial down-sampling (Figure A.1).

This example shows a portion of the magnetic anomaly dataset in Western Australia, with a rich collection of features at many spatial scales and orientation. Figure A.1(A) displays the original dataset employing $80 \mathrm{~m} \times 80 \mathrm{~m}$ pixels. The other two images show the effect of down-sampling to $1280 \mathrm{~m} \times 1280 \mathrm{~m}$, i.e. a reduction in sampling density of 16 in both latitude and longitude. Figure $A .1(B)$ illustrates the result with spectral stabilisation (using 256 spectral sub-samples) and Figure A.1(C) uses simple 16-fold data resampling. 
Figure A.1: A) Magnetic data in Western Australia extracted from the magnetic anomaly map of Australia, using the original $80 \times 80 \mathrm{~m}$ pixels. B) Same data extent as A) but $1280 \times 1280 \mathrm{~m}$ pixels, derived from spectral domain averaging of 256 realisations. C) Same data extent as A) but $1280 \times 1280 \mathrm{~m}$ pixels, spatially resampled only.

From Figure A.1 we see that with the spectral stabilisation approach it is possible to preserve the strong contrasts in the original image more effectively and retain detail at a level approaching the pixelation employed. The procedure requires significantly more computational effort than simple spatially resampling, but has the added benefit of providing statistics for the spectral components.

The representation of data in this fashion has an additional benefit beyond stabilising the longest wavelength components: by down-sampling both gravity and magnetic data in the same fashion but to varying degrees, we can maintain comparable frequency content between the two datasets. This assists in comparison of these two datasets, since most geophysical filtering techniques work in the spectral domain.

The process of spectral stabilisation can also be employed in a hierarchical fashion to provide a representation of the variation in spectral content across the continent. Thus we can successively halve windows across the continental dataset, and use 64-fold, then 16-fold and finally 4-fold averaging for the spatial spectra at each step. In this way a stable calculation of the longest wavelength features that can be represented at each window scale is achieved, along with a measure of the uncertainty in the 1-D power spectra. This process has been employed by Chopping and Kennett (2015) in a study of the variation of Curie depth across the continent (see Chapter 4), and also provides the foundation for comparisons of the gravity and topography fields (Chapter 12).
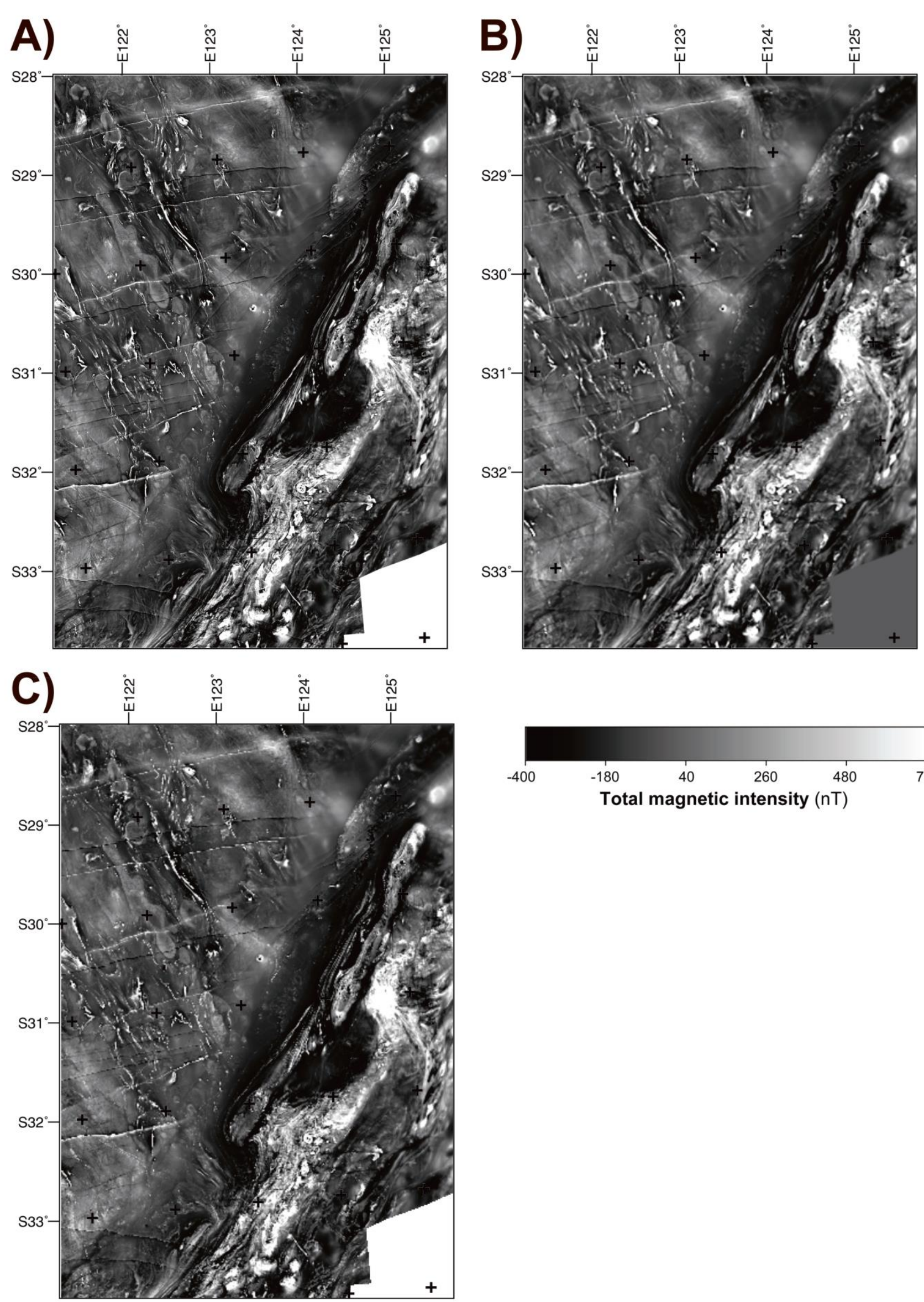

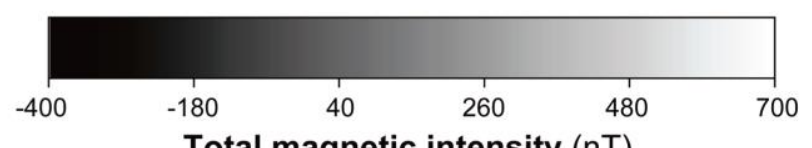

Total magnetic intensity (nT) 